\title{
Towards an Australian social housing best practice asset management framework
}

Authored by

Andrea Sharam, RMIT University

Sean McNelis, Swinburne University of Technology

Hyunbum Cho, University of South Australia

Callum Logan, RMIT University

Terry Burke, Swinburne University of Technology

Peter Rossini, University of South Australia
Publication Date October 2021

DOI 10.18408/ahuri5324001 
Title

Towards an Australian social housing best practice asset management framework

\section{Authors}

Andrea Sharam, RMIT University

Sean McNelis, Swinburne University of Technology

Hyunbum Cho, University of South Australia

Callum Logan, RMIT University

Terry Burke, Swinburne University of Technology

Peter Rossini, University of South Australia

\section{ISBN}

978-1-922498-34-2

\section{Key words}

Asset management; best practice asset management; best practice asset management framework; social housing; community housing; public housing.

\section{Series}

AHURI Final Report

\section{Number}

$367 a$

\section{ISSN}

1834-7223

\section{Publisher}

Australian Housing and Urban Research Institute Limited Melbourne, Australia

DOI

10.18408/ahuri5324001

\section{Format}

PDF, online only

\section{URL}

https://www.ahuri.edu.au/research/final-reports/367

\section{Recommended citation}

Sharam, A., McNelis, S., Cho, H., Logan, C., Burke, T. and Rossini, P. (2021) Towards an Australian social housing best practice asset management framework, AHURI Final Report No. 367a, Australian Housing and Urban Research Institute Limited, Melbourne, https://www.ahuri.edu.au/ research/final-reports/367, doi: 10.18408/ahuri5324001.

\section{Related reports and documents}

Logan, C., Sharam, A. and McNelis, S. (2021) An Australian social housing best practice asset management framework, AHURI Final Report No. 367b, Australian Housing and Urban Research Institute Limited, Melbourne, https://www.ahuri.edu.au/research/ final-reports/367, doi: 10.18408/ahuri5324001

\section{AHURI}

AHURI is a national independent research network with an expert not-for-profit research management company, AHURI Limited, at its centre.

AHURI's mission is to deliver high quality research that influences policy development and practice change to improve the housing and urban environments of all Australians.

Using high quality, independent evidence and through active, managed engagement, AHURI works to inform the policies and practices of governments and the housing and urban development industries, and stimulate debate in the broader Australian community.

AHURI undertakes evidence-based policy development on a range of priority policy topics that are of interest to our audience groups, including housing and labour markets, urban growth and renewal, planning and infrastructure development, housing supply and affordability, homelessness, economic productivity, and social cohesion and wellbeing.

\section{Acknowledgements}

This material was produced with funding from the Australian Government and state and territory governments. AHURI Limited gratefully acknowledges the financial and other support it has received from these governments, without which this work would not have been possible.

AHURI Limited also gratefully acknowledges the contributions, both financial and in-kind, of its university research partners who have helped make the completion of this material possible.

\section{Disclaimer}

The opinions in this report reflect the views of the authors and do not necessarily reflect those of AHURI Limited, its Board, its funding organisations or Inquiry Panel members. No responsibility is accepted by AHURI Limited, its Board or funders for the accuracy or omission of any statement, opinion, advice or information in this publication.

\section{AHURI journal}

AHURI Final Report journal series is a refereed series presenting the results of original research to a diverse readership of policy-makers, researchers and practitioners.

\section{Peer review statement}

An objective assessment of reports published in the AHURI journal series by carefully selected experts in the field ensures that material published is of the highest quality. The AHURI journal series employs a double-blind peer review of the full report, where anonymity is strictly observed between authors and referees.

\section{Copyright}

(C) Australian Housing and Urban Research Institute Limited 2021

This work is licensed under a Creative Commons Attribution-NonCommercial 4.0 International License, see http://creativecommons.org/licenses/by-nc/4.0/. 


\section{Contents}

$\begin{array}{ll}\text { List of tables } & \text { iii }\end{array}$

List of figures $\quad$ iii

Acronyms and abbreviations used in this report

$\begin{array}{ll}\text { Executive summary } & 1\end{array}$

1. Introduction $\quad 7$

1.1 Policy context $\quad 8$

1.2 Indigenous housing $\quad 11$

1.3 Existing research on social housing assets in Australia $\quad 13$

1.3.1 Social housing stock and organisations

1.3.2 Type, size, age, condition, quality and amenity of social housing stock

1.3.3 Energy efficiency

1.3.4 Utilisation of housing stock and assets

1.3.5 Concentration of social housing 16

$\begin{array}{ll}\text { 1.3.6 Transferred housing stock } & 17\end{array}$

$\begin{array}{ll}\text { 1.3.7 Value of social housing stock } & 17\end{array}$

$\begin{array}{ll}1.4 \text { Research questions } & 17\end{array}$

$\begin{array}{lr}1.5 \text { Research methods } & 18\end{array}$

$\begin{array}{ll}\text { 1.5.1 Literature review } & 18\end{array}$

1.5.2 Workshops 18

1.5.3 Survey

$\begin{array}{ll}\text { 1.5.4 Interviews } & 20\end{array}$

2. What is asset management?

2.1 Introduction $\quad 22$

2.2 Definitions $\quad 22$

$\begin{array}{ll}2.2 .1 \text { Assets } & 22\end{array}$

2.2.2 Asset management $\ldots$

2.2.3 Strategic asset management

2.2.4 Property asset management 24

2.2 .5 Public sector asset management

2.2.6 Best practice asset management $\quad 25$

2.3 Social housing asset management $\quad 27$

2.4 Conclusion $\quad 28$

3. Unique features of social housing in Australia $\quad 29$

3.1 The business of social housing $\quad 30$

3.2 The unique characteristics of Australian social housing 31

3.2.1 Portfolio size $\quad 31$

3.2.2 Mission

3.2.3 Attributes of dwellings 31 
3.2.4 Location of dwellings

3.2.5 Choice of tenants

3.2.6 Rental revenue

3.2.7 Capital funding for acquisition of new stock

3.2.8 Short-term turnover

3.2.9 Split incentive

3.2.10 Eviction

3.2.11 Regulation and oversight

3.2.12 Population densities and distance $\quad 36$

3.2.13 Federal political system 36

$\begin{array}{ll}3.3 \text { Summary } & 37\end{array}$

4. Social housing asset management $\quad 38$

4.1 Emergence of social housing asset management as an issue overseas 39

4.1 .1 Europe

4.1.2 United Kingdom

4.1.3 USA 42

4.1.4 Canada

$\begin{array}{ll}4.2 \text { Summary } & 44\end{array}$

4.3 Australian social housing asset management

4.3.1 Public housing

4.3.2 Community housing $\quad 46$

4.3.3 Indigenous housing

$\begin{array}{ll}4.4 \text { Concluding comments } & 47\end{array}$

5. Social housing asset management planning practices and issues $\quad 49$

5.1 Introduction $\quad 50$

5.2 Asset management frameworks $\quad 50$

5.3 Asset management plans $\quad 51$

5.4 Terminology, standards and measures for asset management $\quad 52$

5.4.1 Terminology

5.4.2 Standards and measures

5.5 Levels of service $\quad 54$

5.6 Human and technological capacity 57

5.6.1 Specialist skills are required $\quad 57$

5.6.2 Governing bodies lack skills $\quad 59$

$\begin{array}{ll}5.6 .3 \text { Software } & 59\end{array}$

$\begin{array}{ll}\text { 5.6.4 Data collection } & 60\end{array}$

5.7 Regulation

5.7 .1 Who is subject to regulation? 
5.7 .2 Reporting requirements

5.7 .3 Housing registrars

5.7.4 Regulation through management contracts

5.7 .5 Other regulatory requirements

5.7.6 Regulation and private financing

5.8 Planning for demand $\quad 65$

5.9 Policy development implications $\quad 66$

5.9.1 A common Australian asset management framework $\quad 66$

5.9.2 Capacity building $\quad 67$

5.9 .3 Indigenous housing

5.9.4 Uniform standards and measures $\quad 68$

$\begin{array}{lr}5.9 .5 \text { Habitation standard } & 69\end{array}$

5.9 .6 Regulation

5.9.7 AM software

5.9.8 Planning system-level supply $\quad 69$

6. Social housing asset-creation practices and issues

$\begin{array}{ll}6.1 \text { Introduction } & 70\end{array}$

6.2 Taking account of long-term maintenance costs $\quad 71$

6.3 Development versus asset management

6.4 Growth rather than maintaining current stock $\quad 72$

6.5 Opportunistic asset creation $\quad 72$

6.6 Policy development implications $\quad 73$

7. Social housing asset management practices and issues $\quad 74$

7.1 Introduction $\quad 74$

7.2 Reactive and planned maintenance $\quad 74$

$\begin{array}{ll}7.3 \text { Management transfer } & 78\end{array}$

7.3.1 Condition assessment rating $\quad 81$

7.4 Policy development implications $\quad 82$

7.4.1 Maintenance backlog

7.4.2 Shift to planned maintenance $\quad 82$

7.4.3 Purchasing components $\quad 82$

8. Social housing asset-disposal practices and issues

8.1 Introduction $\quad 84$

8.2 Sale of assets $\quad 85$

8.3 Stock transfer $\quad 85$

8.4 Policy development implications $\quad 87$

9. Financing social housing asset management $\quad 88$

9.1 Introduction $\quad 89$ 
9.2 Capital funds

9.3 Provision for upgrades, renewal and redevelopment

9.4 Revenue does not cover the costs of provision

9.5 Policy development options

10. Conclusion

10.1 An Australian social housing best practice asset management framework

10.2 Principles and processes

10.3 Unique features of Australian social housing provision

10.4 Unique features of social housing providers

10.5 Major barriers to implementation

10.6 Summary

References 100

Appendix 1: The Australian social housing best practice asset management Framework 109

Appendix 2: Ethics approval

Appendix 3: Survey instrument

Appendix 4: Interview guide (CHPs and IHOs)

Appendix 5: Workshop guide 


\section{List of tables}

Table 1: Characteristics of strategic asset management

Table 2: Indicators of asset management performance 41

Table 3: Levels of service examples

Table A1: Categorisation of data

Table A2: Example of level of service alignment to corporate plan $\quad 121$

Table A3: Example of simple cashflow of an individual housing asset

Table A4: Housing assets performance requirements under the National Regulatory System for

$\begin{array}{ll}\text { Community Housing } & 144\end{array}$

Table A5: Asset management standards in the National Community Housing Standards 145

\section{List of figures}

Figure 1: Sustainable asset management over the life cycle of social housing

Figure 2: Type of social housing dwellings at June 2019

Figure 3: Size of social housing dwellings at June 2019

Figure 4: Age profile of public housing stock and total maintenance liability 15

Figure 5: Types of assets

Figure 6: Fields of asset management and built environment asset management $\quad 25$

Figure 7: Sustainable asset management over the life cycle of social housing $\quad 27$

Figure 8: Typical stages in the life cycle of an asset: Canada

Figure 9: Human resources to effectively manage assets

Figure 10: How do staff access professional development? $\quad 59$

Figure 11: Example portfolio renewal profile

Figure A1: Sustainable asset management over the life cycle of social housing

Figure A2: Asset management plan roadmap

Figure A3: Sustainability dashboard wheel $\quad 119$

Figure A4: Connectivity mapping 119

Figure A5: Example of portfolio renewal profile 


\section{Acronyms and abbreviations used in this report}

ACNC

AGDSA

AGT

AGV

AGWA

$\mathrm{AHO}$

AHURI

AHV

AlHW

AM

AMC

AMF

AMP

ANAO

AONSW

APCC

BPAM

BPAMP

CA

CHIA

CHIA NSW

CHP

CRA

CREM

CSHA

DETR

DHS

DTF

DELWP

FACS

FaHCSIA

GFC

GIS

HUD

IAM

IFMA

IHO

IPA
Australian Charities and Not-for-profits Commission

Auditor-General's Department, South Australia

Auditor-General of Tasmania

Auditor-General Victoria

Auditor-General for Western Australia

Aboriginal Housing Office (NSW)

Australian Housing and Urban Research Institute

Aboriginal Housing Victoria

Australian Institute of Health and Welfare

asset management

Asset Management Centre (Canada)

asset management framework

asset management plan

Australian National Audit Office

Audit Office of NSW

Australian Procurement and Construction Council

best practice asset management

best practice asset management plan

condition assessment

Community Housing Industry Association

Community Housing Industry Association NSW

community housing provider

Commonwealth Rent Assistance

corporate real estate management

Commonwealth-State Housing Agreement

Department of Environment, Transport and Regions (UK)

Decent Homes Standard

Department of Treasury and Finance (Victoria)

Department of Environment, Land, Water and Planning (Victoria)

Family and Community Services (NSW)

Department of Families, Housing, Community Services and Indigenous Affairs (Australia) global financial crisis

Geographical Information System

Housing and Urban Development (USA)

Institute for Asset Management

International Facilities Management Association

Indigenous housing organisation

Infrastructure Partnerships Australia 
IPWEA Institute of Public Works Engineering Australasia

ISO

KPI

LALCs

LOS

NAMS

NHFIC

NPV

$\mathrm{NRSCH}$

NSHS

NSWALC

ODM

PARS

PCA

PHADA

PPP

QDHPW

QHWRA

REAM

RSLs

SAMP

SCRGSP

SHA

SHAPE

$\mathrm{SHO}$

SOMIH

UK DCLG

UK

USA

VAGO

WALA.SCULIA Western Australia Legislative Assembly, Standing Committee on Uniform Legislation and Intergovernmental Agreements

WWII

International Organization for Standardization

key performance indicator

Local Aboriginal Land Councils

levels of service

National Asset Management Support

National Housing Finance and Investment Corporation

net present value

National Regulatory System for Community Housing

National Social Housing Survey

NSW Aboriginal Land Council

optimised decision-making

Provider Assessment and Registration System

Property Council of Australia

Public Housing Authorities Directors Association (USA)

public-private partnerships

Queensland Department of Housing and Public Works

Quality Housing and Work Responsibility Act (USA)

Real Estate Asset Management

Registered Social Landlords

strategic asset management plan

Steering Committee for the Review of Government Service Provision

state housing authority

Social Housing Approval and Provider Evaluation

social housing organisation (includes both SHA and CHP)

state-owned and managed Indigenous housing

Department for Communities and Local Government, United Kingdom

United Kingdom

United States of America

Victorian Auditor-General's Office

World War II 


\section{Executive summary}

Key points

- Social housing is a distinct asset subclass with unique asset management challenges that necessitate placing the tenant at the centre of provision.

- Greatly varying asset management planning, practice and performance are driven by differences in ownership, regulation and financing. Too often the result is substandard housing.

- The social housing sector is seriously constrained in its ability to maintain, renew and configure stock to meet current and future demand.

- An inadequate and failing social housing finance system is at the heart of the asset management challenges the sector faces.

- Aside from the need for adequate revenues, a coordinated approach to building (i) a common asset management framework and standard terminology and measures; and (ii) human and technological asset management capacity, including skills development, training and education, is needed to address current and future asset management needs.

\section{Key findings}

Social housing is a distinct asset subclass with unique asset management (AM) challenges. Best practice asset management (BPAM) reflects a life-cycle approach to managing assets, which puts the 'customer'-or in the case of social housing, the tenant-at the centre of provision. BPAM requires a whole-of-organisation commitment embedded through data collection and analysis, integration of systems and continuous improvement.

A life-cycle approach to social housing AM encompasses asset creation, asset management and asset disposal. The process of developing an asset management plan (AMP) and roadmap will be informed by the current and future demand for social housing, and by an assessment of the housing needs for current and future tenants, the service standards to be achieved, the mission and objectives of the social housing organisation (SHO), and the environmental, social, economic, political and cultural costs and benefits (see Figure 1). 
Figure 1: Sustainable asset management over the life cycle of social housing

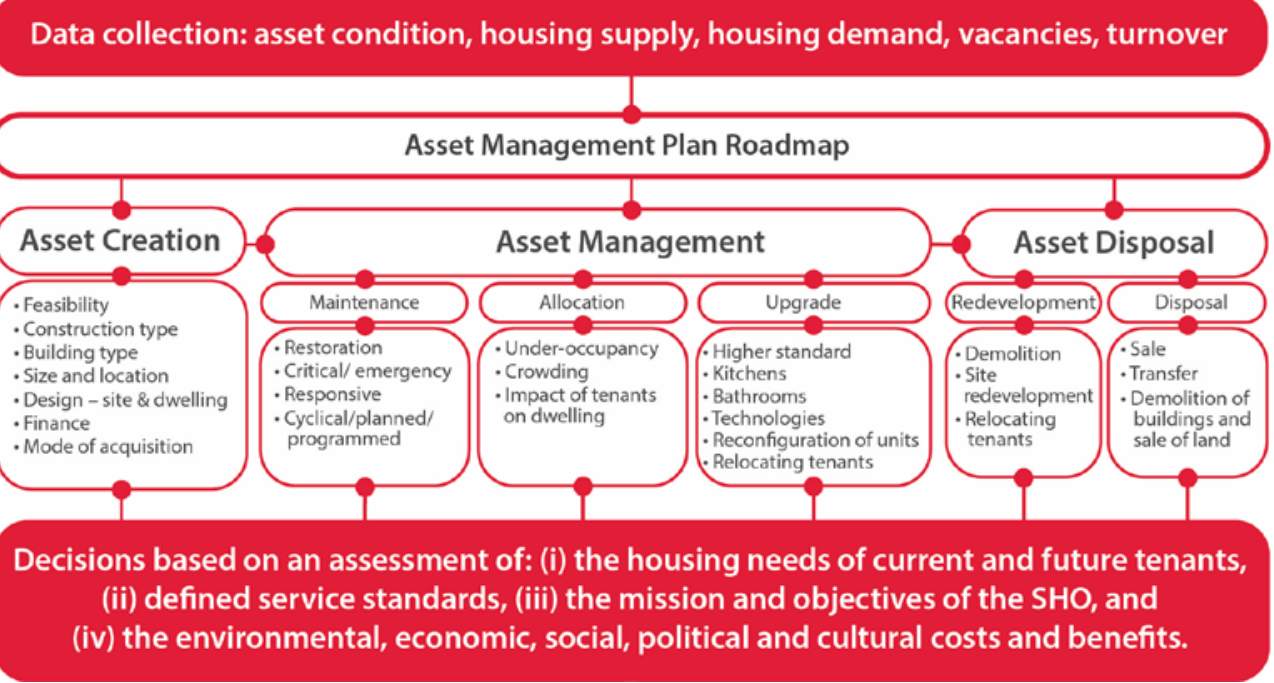

Source: McNelis 2020.

\section{Asset management planning}

SHOs are unable to maintain, renew and configure stock to meet current and future demand. Our research revealed that the varying understandings and practices in the public housing sector identified by Kenley, Chiazor et al. (2010) remain, and are now also recognisable in the community sector. Many SHOs do not develop AM strategies or, if they do, do not implement them. The community sector is on two trajectories. Larger community housing providers (CHPs), largely driven by regulation and private capital finance, are on track to achieve BPAM. Smaller CHPs do not have the same drivers, and there are worrying practices.

To date, little social housing-specific AM guidance has been available to SHOs. Private sector AM has some relevance, but large differences necessitate a specific framework. Multiple AM tools and systems are in use and standardisation would be beneficial.

\section{Maintenance backlog}

Across both public and community sectors, maintenance backlogs are producing unacceptable conditions for many tenants. Some of the backlog is so serious that it results in the premature disposal of assets, financial losses and a reduction in provision at times of growing demand. In the community sector, lack of stringent reporting requirements means Housing Registrars in most states are unlikely to detect problems until a crisis emerges.

The provision of substandard social housing reflects inadequate consumer protection, with habitation standards only recently included in tenancy legislation in some states. In the absence of new funding, habitation standards may precipitate disposal of properties to fund repairs.

\section{Renewal of existing housing stock}

The current value of social housing is estimated at $\$ 100$ billion. Much of this stock was constructed between 1950 and 1970 and is substantially depreciated. While much of the value is in the underlying land, the cost to replace the housing are in the order of tens of billions of dollars. In the state sector, renewal is largely premised on selling stock to finance existing operations), stock transfer, public-private partnerships (PPPs) and land sales, but this is insufficient to prevent contraction. The larger CHPs are making provision for renewal-for example, through active recycling programs aimed at intensifying sites and allowing them to simultaneously renew and grow. Worryingly, many smaller CHPs make inadequate financial provision for capital works. Many simply do not have renewal plans. 


\section{Inadequate revenue flows}

The fundamental reason why SHOs are unable to maintain, renew and configure stock to meet current and future demand is inadequate revenue flow.

Australia has a unique social housing finance system. It operates a dual rental system:

- a property rental system that determines the maximum rent for each dwelling

- a household rental system that determines the rent for each household, based predominantly upon household income, which is usually 25-30 per cent of household income with adjustments for those tenants eligible for Commonwealth Rent Assistance (CRA).

SHOs are required to meet all their costs from rental revenue and are not compensated for housing very low-income and low-income tenants.

SHO revenue flow is highly constrained by their tenant profile and target groups - that is, households in receipt of very low incomes from social security (Centrelink) payments. While revenue from Centrelink payments for pensioners is generally sufficient to meet the costs of maintenance, rates, insurance and administration, it is not sufficient to meet the costs of upgrading, renewal and redevelopment of housing stock. However, revenue from recipients of JobSeeker and Youth Allowance is even less sufficient to meet maintenance, rates, insurance and administration costs.

SHOs' reliance on household rents deprives them of the funds required to undertake investment in upgrading, renewal and redevelopment of their housing stock. The revenue-cost gap has been worsened by restricting eligibility criteria as a means of moderating demand.

From an AM perspective, inadequate and unstable revenue flow works against long-term planning, maximisation of asset life and equity of service provision.

\section{Asset management capacity, skills and training}

Reflecting much of what is unique about social housing, AM skills are often obtained on the job. External training opportunities are few and typically do not directly relate to social housing. Professionally credentialed asset managers often cycle in and out of social housing, reflecting cultural and remuneration differences between for-profit and not-for-profit sectors. AM knowledge requirements extend beyond those responsible for AM on a day-to-day basis, to senior managers, governance boards, regulators and policy makers.

\section{Regulation}

Despite providing the vast majority of social housing in Australia, state housing authorities (SHAs) are not regulated. SHA performance, including asset performance, is subject only to ministerial oversight and occasional inquiries. The vastly smaller community sector is held to greater account-although this varies according to size and risk profile of the CHP and by state or territory. CHP AM is undermined by inadequate Housing Registrar resourcing and differential treatment of providers according to tier, which enables unsatisfactory performance among smaller providers.

\section{Indigenous housing}

The growth of Aboriginal-controlled housing organisations heralds a changing Indigenous housing landscape. These include:

- Aboriginal Housing Victoria (AHV)

- NSW Aboriginal Land Council (NSWALC) Housing Ltd

- Aboriginal Housing-associated with Community Housing Limited.

These organisations show that self-determination and capacity building are critical for improving AM in Indigenous communities. 


\section{Policy development options}

Social housing AM is in need of thoroughgoing reform. However, the issues that need to be addressed are not simply confined to AM. If SHOs are to take responsibility for acquiring, maintaining, upgrading, renewing and redeveloping housing stock and establishing themselves as sound asset managers, then the social housing sector needs a new operating framework. It cannot happen through a piecemeal approach focussed exclusively on AM. It will only happen through a consolidated approach that includes all of the following policy development options.

\section{SHOs adopt a uniform asset management framework}

Ultimately, all SHOs would adopt an BPAM framework based on ISO 55000 from the International Organization for Standardization (ISO). BPAM is the only way by which critical risks can be addressed.

A range of specific policy development options would contribute to the adoption of a BPAM within the social housing sector.

\section{Financing asset management}

The Australian social housing finance system needs radical reform if it is to achieve the twin goals of providing affordable housing for tenants and financial viability for SHOs.

Commonwealth and state government grants provide an essential base for the expansion of social housing, and governments need to undertake greater and substantial investment. The current level of investment will not allow SHOs to meet the current and future demand for social housing. SHOs need access to capital funds for the acquisition of housing stock beyond this very limited source.

Currently, SHAs cannot borrow funds and their borrowing restrictions could be relaxed. CHPs and Indigenous housing organisations (IHOs) can borrow funds, primarily through the recently established National Housing Finance and Investment Corporation (NHFIC) but, despite high levels of equity, their borrowing capacity is severely restrained by their revenue flows.

SHOs need sufficient rental revenue to meet all the ongoing costs of housing provision, including reactive and planned maintenance, rates, insurance and administration, as well as the costs of upgrading, renewal and redevelopment of housing stock.

A recalibration of Commonwealth payments would ensure that the gap between rental revenue and the ongoing costs of providing social housing can be closed. On one hand, all Centrelink payments-both pensions and allowances - could be adjusted so that recipients have sufficient income to pay rents that can meet the costs of reactive and planned maintenance, rates, insurance and administration. These costs are common across all tenures. On the other hand, rent-assistance payments need to meet the depreciation or asset-utilisation costthat is, the cost of upgrading, renewal and redevelopment of housing stock-as these costs are particular to the rental sector.

A recalibration of Commonwealth Centrelink payments would also facilitate a transition to a property rent system based on the costs of providing social housing. This would ensure the financial viability of SHOs while providing housing affordability for tenants and vertical and horizontal equity among social housing tenants.

With the introduction of a property rent system, SHOs would have the cashflow to service borrowings and could embark on a sustained program of major capital projects to renew and reconfigure their portfolios. If this was accompanied by relaxation of borrowing restrictions imposed on SHAs, it would permit the best utilisation of the government equity tied up in public housing. 


\section{Capacity building}

A forum to showcase best-practice asset management, such as a biennial AM conference, would serve to raise the profile of AM and promote knowledge transfer across the social housing sector. This could be accompanied by an online forum and resource repository for exchange of ideas, initiatives, issues and problems.

Community housing

Peak and industry bodies have important roles to play in facilitating the community housing sector moving towards BPAM. These bodies could:

- lead cooperative efforts to obtain specialist AM software solutions to ensure all CHPs have the most effective systems possible

- engage with training organisations to ensure CHPs can obtain high quality and affordable training to support on-the-job learning (such as through unaccredited short courses) and promote entry into AM Bachelor and Masters degree courses

- establish new AM communities of practice where they do not currently exist

- undertake regular reviews and updates of AM guidance in the Community Housing Standards Manual

- initiate secondment and pro bono schemes in which AM professionals in private and government sectors spend time with a CHP, either on staff or with the board. The number of professionals with AM expertise on $\mathrm{CHP}$ boards needs to be increased. These need to be AM professionals rather than property development professionals.

Governments could support these efforts through special-purpose grants.

Indigenous housing

State-owned Indigenous housing AMPs could be developed as part of a co-design process with Indigenous communities. An outcome of the co-design process would be the development of IHO AM and governance capacity. This, in turn, could have the aim of putting IHOs on a growth trajectory, initially though assuming management responsibility and later through stock transfer.

Capacity-building initiatives could include government funding of Indigenous scholarships for AM training and education; financial support for an Indigenous asset managers network; and secondment or placement of Indigenous AM staff within non-Indigenous housing organisations, and within IHOs overseas.

\section{Regulation}

The ambitions for a National Regulatory Scheme for Community Housing (NRSCH) have only been partially realised.

- A genuinely national uniform scheme would remove or reduce many transaction costs relating to AM.

- The performance of Tier 2, 3 and 4 providers who own assets needs to improve. Greater scrutiny of governance, management and AM systems are needed to ensure maintenance is not unduly deferred and provision is made for renewal. Governments could consider facilitating greater consolidation of the sector.

- Consideration could be given to the role external AM accreditation schemes-for example, ISO 55000-could play in driving continual improvement and reducing regulatory burden.

- Governments need to develop a protocol for stock transfer agreements to include data requirements to address the market power of the SHA, and the costs and benefits of competitive tendering, etc.

- Housing Registrars require greater resourcing to maintain adequate oversight of the risks associated with AM.

- Public housing needs to be included in a uniform national social housing regulation scheme to ensure greater accountability and transparency, and to provide horizontal and vertical equity between tenants and across states and territories. 
- Registration of CHPs should be mandatory.

- A habitation standard for social housing could be developed. In the absence of regulation, it could take the form of a voluntary code.

- A process could be established to develop national AM measurement and performance standards, which could take account of the specific building regulation variances between states and territories, as well as variables such as climatic variations or location-specific conditions.

- SHOs need to benchmark their performance against peer organisations to promote continual improvement.

\section{Planning system-level supply}

A multi-provider service system requires a coordination mechanism to deliver rational planning, including:

- an assessment of current and future social housing demand by household type, household preferences and needs, household size and location across each state

- an analysis of vacancies and turnover within social housing

- an assessment of the housing market in view of different modes of acquiring housing stock.

The objective is to coordinate the acquisition of housing stock of specific types and sizes in specific locations across multiple SHOs.

\section{The study}

The aim of this study was to add to our knowledge about social housing AM in Australia and address the emerging issues by developing an BPAM framework that: (i) outlines AM processes and criteria for making decisions; (ii) is suitable to the specific and unique aspects of social housing; (iii) is flexible enough to be used by different types of social housing providers; (iv) provides metrics to drive organisational excellence; and (v) provides the basis for national regulation and policymaking.

The primary question guiding this research was:

\section{What is a suitable BPAM framework for social housing in Australia?}

The research was guided by the following sub-questions:

- What BPAM principles and processes should guide an Australian social housing best practice asset management framework?

- What are the specific and unique attributes of social housing provision that need to be incorporated into an BPAM framework?

- What are the specific and unique features of social housing providers that need to be recognised in the development of an BPAM framework?

The research also investigated the current AM practices of SHOs.

The research utilised three methods: workshops, a survey and interviews. Workshops were conducted with SHO staff, consultants and advocates to identify the unique attributes of social housing provision, and with providers to inform the development of a national survey. Interviews with SHOs, consultants, advocates, financiers and Housing Registrars enabled reflection on the learnings from the workshops and survey. The fieldwork was conducted throughout the last quarter of 2020. 


\section{Introduction}

The key features of the policy context for social housing AM are:

- households with complex needs tend to make a higher demand on housing agencies

- the growth of the social housing sector is stymied by the lack of a long-term national plan

- maintenance backlogs frequently manifest as housing unfit for occupation, as tenant protections are weak

- Indigenous peoples' housing needs are unique, arising from cultural and spiritual identity that is distinct from other Australians, and which includes surviving invasion, marginalisation and dispossession of traditional lands

- IHOs work within particularly complex institutional arrangements, reflecting the unique status of Indigenous peoples within the Australian system of federation. Indigenous housing policy is often at odds with Indigenous Australians' desire for self-determination.

Social housing stock has the following characteristics:

- approximately 438,000 dwellings are managed by eight large SHAs, 518 CHPs and 226 IHOs -53 per cent of CHPs and 40 per cent of IHOs manage fewer than 20 dwellings

- a significant proportion of social housing stock has issues of age, condition, quality and amenity, and does not adequately meet tenants' needs 
- over the past five years, upwards of 10,000 dwellings valued at over $\$ 5.4$ billion have been transferred from state or territory housing authority ownership to CHPs

- the value of social housing stock is not aggregated and reported-it is estimated at $\mathbf{\$ 1 0 0}$ billion-and reporting of replacement cost is needed to further understanding of renewal liabilities.

\section{The research adopted a mixed-methods approach involving a literature review, workshops, a national survey and interviews.}

\subsection{Policy context}

Understanding the policy context for social housing AM partly depends on how AM is defined; narrower or broader interpretations will have different policy implications. As outlined in Chapter 2, this research was driven by a broad definition that sees AM as a whole-of-life process underpinned by a strategic plan with clearly defined objectives and performance measures.

This means that the AM process includes:

- asset creation-acquisition, including design, construction and purchase of property

- asset management-reactive and planned maintenance, upgrade and renewal

- asset disposal-redevelopment, sale and transfer.

These parts of the AM process sound rather dry, and the term 'asset' conjures up notions of property, but we have to remember that AM is also about people; about the occupants of social housing, those wanting to access social housing, the residents in those communities that host social housing and all the employees that manage and administer the assets. This means many of the policy issues around AM are also about tenancy management, stakeholder engagement and building communities.

And then there is the context of finance. The forms and amounts of social housing finance are fundamental to achieving effective and efficient outcomes in all stages of the AM process. Put simply, the contemporary financial environment of social housing is not adequate for the sector to grow or even to bring the existing stock to an adequate standard or to meet housing needs. This is an historical issue compounded by more recent funding decisions (Hall and Berry 2004; 2006; 2007a; 2007b; 2009).

The original 1945 Commonwealth-State Housing Agreement (CSHA) and its variations for the next three decades provided capital funding for new growth with all ongoing costs met by an historic cost rent-that is, a property rent that covered recurrent costs and loan repayments, and a household rent based on the income of tenants.

The weakness in this financial arrangement only become clearer as decades went by; the historic cost rent was not adequately adjusted to account for increasing operating costs, and so was not sufficient to cover maintenance, upgrades and renewal as properties deteriorated over time. From the 1980s onwards, as public housing became more targeted and average tenant income decreased, it was evident that public housing agencies - as the community sector was minimal at that stage - had a large maintenance backlog and deteriorating assets without the finances to deal with them. 
Subsequent housing agreements have never reached a formula to address this revenue-cost issue: recent agreements really only cover recurrent costs and not the upgrade and renewal of housing stock. In some cases, housing jurisdictions have sold housing stock to finance existing operations, even at times of great housing need.

Community housing, being the newish player to the social housing domain, has had a slightly different funding environment. Growth has mainly come from transfers from the public housing sector, supplemented by the limited growth enabled by irregular grants from state governments and whatever surplus (very little) can be extracted from rental income. But, relative to need, this funding model is also flawed. In very recent times, ad hoc state capital grants and access to debt-especially the National Housing and Finance and Investment Corporation's (NHFIC) provision of long-tenor debt-have provided limited opportunity for community housing agencies to acquire new stock. Grant programs are on a competitive tender basis with demanding conditions, and NHFIC has a high threshold for creditworthiness. Both competitive tenders and NHFIC lending require reaching demonstrable organisational performance benchmarks; the latter to establish capabilities and a sound financial model, and the former to take advantage of relatively rare opportunities for growth without assuming excessive risk.

Accentuating the revenue-costs issue has been the policy redirection since the early 1980 s to ever-greater targeting of applicants. All housing agencies have a priority allocation system that now focusses on those with the greatest housing and support needs. For AM this policy redirection has a number of issues.

\section{Households with complex needs}

Households with complex needs tend to be smaller, and disproportionately singles. This means that three-bedroom stock once built for families is not necessarily appropriate for current needs. This highlights the requirement for an AM strategy to be driven by a long-term strategic plan: should current need as reflected in waiting lists determine the attributes of new stock, given needs might change in 20+ years' time?

Nearly all households with complex needs are on very low Centrelink incomes and in the bottom income quintile. Few, if any, pay a property rent and revenue from household rents decreases as the proportion of tenants on very low incomes increases. As a result, rents no longer bear any relationship to the attributes of the dwelling - such as location, housing quality and amenity - and lower rental revenue worsens an already problematic revenue-cost situation.

Households with complex needs tend to make a higher demand on housing agencies in terms of property damage and turnover; churning is a major issue among certain tenant groups.

As the diversity and needs complexity of applicants for social housing have increased in recent decades, new social housing models have emerged including crisis accommodation-for example, boarding houses and transitional housing, both of which are managed by community housing agencies. Such accommodation has very different AM issues to long-term social housing. This is starkly revealed by the issues associated with the particular design elements of some of this housing - for example, the safety and associated sanitation issues of boarding houses during COVID-19 lockdown.

\section{Growth of the community sector}

The growth of the community sector over recent decades is another important policy change, as there was virtually no community housing prior to the mid-1980s. While the policy context has been broadly one of encouraging community housing, there has not been a great degree of thought put into a transparent, long-term plan for public housing and community housing - although there will be degrees of variation by jurisdiction. For instance:

- Are public housing and community housing competitors? Or do they complement each other?

- How big should community agencies be to achieve the best asset and tenancy outcomes?

- What are the most appropriate organisational and regulatory structures to facilitate the best outcomes? 
Then there is the asset issue of transfers, which has been an important part of the growth of the community sector, although its scale has varied from state to state: Victoria is at the lower end of transfers; Tasmania is at the higher end. Unlike in the UK, where transfers were often accompanied by funding for maintenance and upgrade, this has not been the case in Australia and there are risks for community agencies as to what maintenance and repair obligations they are taking on.

PPPs have emerged in most jurisdictions - partly because of the difficult environment outlined earlier, but partly because it fits the policy thinking of state treasury and finance departments. The idea is that partnerships between governments who have poorly yielding social housing property, private developers who can provide development and financing capacity, and community agencies who have management skills can increase the level of social housing stock at relatively little public expense. Whether this is the best way to achieve desired stock outcomes is contestable. Only time will tell what the asset implications are.

\section{Contracting-out property maintenance}

Another historical policy shift with continuing implications is the move to contract-out property maintenance. Until the mid-1980s, state and territory housing agencies had their own in-house maintenance staff. With the shift in that period to greater market orientation in public sector management, a policy of contracting-out was adopted, which is now the general practice for social housing maintenance.

This creates new sets of AM issues as agencies work out:

- how to design and monitor performance contracts that are efficient, timely and improve the tenant experience

- how to train or educate maintenance contractors in their dealings with tenants and confront issues that they would not necessarily face in the private sector.

The absence of policy is as much an AM issue as the existence of policies. At the moment, the Commonwealth (the major funder) has no long-term national plan for the growth of the social housing sector. This creates major challenges in developing strategic plans that should be setting the framework for AM, including capital replacement and asset regeneration. Some states are planning growth in the social housing sector. Victoria has announced a major capital funding program (Victorian Government 2021a), and in February 2021 set up a consultation on the future infrastructure for social housing (Victorian Government 2021b). However, without a Commonwealth plan, such plans operate in a policy vacuum.

The outcome of this lack of focus on strategic AM is a contracting social housing system and an increasing proportion of social housing in poor condition. The public housing maintenance backlog is well known. Maintenance backlogs frequently manifest as housing unfit to be occupied. This is especially an issue for remote Indigenous housing. ${ }^{1}$ This state of affairs occurs because there are inadequate tenant protections. Residential tenancy laws have provided little in the way of habitation standards. Australia has no equivalent to the UK Decent Homes Standard (UK DCLG 2006) or the more recent New Zealand Healthy Homes Standards (New Zealand Tenancy Services 2021).

Maintenance liabilities are being transferred to $\mathrm{CHPs}$ via stock and management transfers. The assumption is that CHPs can increase their rental revenue by setting rents that capture CRA, and thus fund maintenance programs. However, CHPs are finding that even this increased rental revenue is inadequate. Lack of adequate data on transferred dwellings undermines due diligence and state agencies can exercise market power in the setting of conditions. Again, these point to a lack of policy clarity about community housing.

Compared to the private rental sector, the social housing sector operates in a much more complex and demanding policy and regulatory environment, with important implications for all stages of the life-cycle AM process. Understanding this policy environment and developing the skills to work within it is a challenge for the social housing sector.

1 Following Memmott, Birdsall-Jones et al. (2012), the term 'Indigenous' is used in this report because our study included Torres Strait Islander people. When we discuss matters that apply to Aboriginal people and not to Torres Strait Islander people, we use the term 'Aboriginal'. 


\section{Building capacity}

Whether it is the development of a whole-of-life, long-term AM strategy, the preparation of submissions for capital finance, the development and management of maintenance contracts, or the financing, purchase, construction or disposal of property, social housing AM requires high-level conceptual and technical skills of an order very different to the private sector. Building and sustaining the human capacity in this area is a substantial challenge.

\subsection{Indigenous housing}

Indigenous housing needs are the outcome of an unresolved national historical legacy. Indigenous housing accordingly exists within a complex set of institutional arrangements reflecting intergovernmental processes in which the Australian Government retains special powers and in which Indigenous people have no formal voice. The unmet need for Indigenous housing is substantial.

In Australia, Indigenous peoples have suffered immensely under Government policies of dispossession, marginalisation and assimilation through forcible removal from our lands and territories, without any proper access to reparation mechanisms (NSW Aboriginal Land Council 2019: 4)

Dispossession of traditional lands and the struggle for restitution have resulted in complex land title and tenures that have bearing on the provision of Indigenous housing and AM.

Like non-Indigenous Australians, Indigenous peoples are highly urbanised-although less so. About four in five Indigenous people (80\%) live in major cities, inner regional or outer regional areas, compared to 98 per cent of non-Indigenous people. About 148,700 Indigenous people live in remote and very remote areas. In remote areas the Indigenous population is 18 per cent, increasing to 47 per cent in very remote areas (Australian Institute of Health and Welfare [AIHW] 2019c).

Indigenous peoples are overrepresented among those experiencing homelessness and disadvantage and they are less likely than other Australians to have home ownership (AIHW 2019c). Accordingly, social housing is a key source of housing for Indigenous peoples. According to the AlHW (2019c), at 30 June 2018 there were 55,859 Indigenous households in social housing, with most $(35,619)$ in public housing, 13,817 in state-owned and managed Indigenous housing (SOMIH) and 6,423 in community housing. Only 17,477 Indigenous households were living in housing provided by an IHO.

The prevalence of primary and secondary homelessness among Indigenous people reflects complexities associated with the impact of dispossession and ongoing discrimination and a general shortage of housing in Indigenous communities. These factors also drive overcrowding (Memmott, Birdsall-Jones et al. 2012).

Each state or territory has a unique history, but state governments remain the dominant provider of Indigenous housing though $\mathrm{SOMIH}$. However, there are a large number of very small IHOs. The revenue-cost gap for Indigenous social housing is larger than mainstream social housing as Indigenous tenants tend to be poorer, arrears higher and the cost of provision higher in remote areas. The adequacy and quality of Indigenous social housing is much poorer than mainstream social housing (AlHW 2019a).

Intergovernmental agreements have delivered funding for remote and very remote Indigenous housing in recent decades. Governance of IHOs has been a key government concern. However, constant reform has been detrimental to the establishment of efficient systems of $\mathrm{SOMIH}$ and $\mathrm{IHO}$ housing construction and maintenance-and is, as a consequence, a key reason for the inadequacy and poor quality of remote housing (Commonwealth of Australia 2017). The backlog of housing maintenance in remote Indigenous housing is more significant for NT than for other jurisdictions (Commonwealth of Australia 2017), reflecting the refusal of the NT Government to fund Indigenous housing while the federal government retained legislative responsibility for Indigenous Affairs. 
Restitution of traditional lands as a consequence of Land Rights legislation, the granting of lands of former missions, and Native Title have provided property titles to Indigenous owners. Title is typically vested in a Trust. In the NT, 'Community Living Areas' have been excised from pastoral leases (Central Land Council n.d.) to provide for small Aboriginal communities that work in the pastoral industry. Special-Purpose Leases have also been granted by the Northern Territory Government to Aboriginal 'Town Camp' communities (informal settlements of Indigenous peoples on the edge of existing municipal boundaries).

Community-titled land presents a challenge in obtaining home ownership (AlHW 2019c), increasing the reliance on social housing. Hence, reforms have aimed to enable freehold title to be excised from community title in Aboriginal towns (Australian Government c. 2013). Community title also presents difficulties for IHOs seeking private financing. These challenges are magnified for remote and very remote communities.

Most Indigenous people in Australia, as noted earlier, live in major urban centres. The greatest number live in the state of NSW.

Reflecting the aspirations of Indigenous peoples for self-determination, some state governments have been transferring management and freehold title of SOMIH stock to Aboriginal-controlled organisations. Victoria and NSW provide contrasting case studies in transfer of title.

\section{Victoria}

In 2016, the Victorian Government transferred ownership of $\$ 500$ million of housing stock to Aboriginal Housing Victoria (AHV), which made AHV the largest single Indigenous housing provider in the country. AHV had previously managed this state-owned housing. The transfer took place as part of a collaborative long-term plan to develop AHV (Brackertz, Davison et al. 2017). However, the poor condition of some of this housing at transfer meant AHV accepted significant liabilities. The May 2020 decision by the Victorian Government to fund social housing maintenance backlogs, including those of AHV (Victorian Government 2020), belatedly addresses this problem.

\section{NSW}

The situation in Australia's most populous state, NSW—which has the largest Aboriginal community housing sector-is more complicated.

In NSW, a two-tiered system of membership-based, democratically operated and non-government Aboriginal Lands Councils was established by the Aboriginal Land Rights Act 1983 (NSW). One hundred and twenty Local Aboriginal Land Councils (LALCS) have responsibility to protect and foster the best interests of Aboriginal people in their respective geographical areas, with a peak body for LALCs - the NSW Aboriginal Lands Council (NSWALC) — having the responsibility to protect and foster the best interests of all LALC members and Indigenous communities in NSW (NSW Aboriginal Land Council 2019).

Around 2,000 houses previously held by the Aboriginal Lands Trust were transferred to LALCs in 1983. Much of this housing was in a poor state. As much of it is in regional and remote areas there remains limited opportunity for development on these titles (Aboriginal Affairs New South Wales 2013). Today the NSW Aboriginal housing sector comprises the LALCs and Aboriginal Community Housing Providers (NSW Aboriginal Land Council 2019) who, in the main, manage state-owned housing. Recently the NSW Aboriginal Land Council established a new entity, NSWALC Housing Ltd, which has the objective of becoming a Tier ${ }^{2} 1$ provider in NSW.

2 The National Regulatory Code (NRSCH 2014) assesses performance against tiers of registration. The Code provides for three tiers reflecting graduations of risk associated with scale of operations and ongoing development activities. Tier 1 are the largest providers who engage in development activities whilst Tier 3 are the smallest with no development activities. Tier 2 is at intermediate scale. Victoria has adopted a framework reflecting two tiers; Housing Associations or Housing Providers. Associations have 'an increased level of risk due to the scale and scope of their operations and generally larger, more complex' registered agencies' (Housing Registrar Victoria 2020). Housing associations reflect Tier 1 agencies in the Code. 
IHOs are subject to the Social Housing Approval and Provider Evaluation (SHAPE) scheme administered by the NSWALC and, more recently, to the Provider Assessment and Registration System (PARS) scheme administered by the Registrar of Community Housing on behalf of the Aboriginal Housing Office (AHO). IHOs with substantial maintenance backlogs have found it difficult to obtain SHAPE registration. However, while maintenance funding has flowed at times - such as when the Commonwealth provided monies as part of the National Partnership Agreement on Remote Indigenous Housing and with the NSW Government's 'Build and Grow' Strategy-access to funding has required registration through either SHAPE or PARS. Thus, some IHOs are caught in a catch-22 situation requiring law reform, increased funding and capacity building (Aboriginal Affairs New South Wales 2013; NSW Aboriginal Land Council 2019).

The AHO is a statutory office, established in 1998 by the NSW Government and led by an all-Aboriginal board, with most senior executive positions held by Indigenous persons. The AHO itself owns about 4,500 properties, which are managed by the NSW Department of Family and Community Services (FACS) in much the same way as other public housing. The AHO is also responsible for developing and regulating approximately 4,400 dwellings owned by LALCs and other NSW IHOs (Martin 2016).

AHO strategies to strengthen and grow the LALC and IHO sector revolve around a registration process similar to that required by the CHPs, a rent-setting policy that combines income-based rent-setting and market rents, organisational capacity building, transfer of housing and AM (AHO 2019; NSW Government and AHO c. 2018). LALCs that are unable to obtain registration can only access 'Build and Grow' maintenance funds if they agree to headlease their properties to the $\mathrm{AHO}$, which subleases to a registered provider. The headlease provides the $\mathrm{AHO}$ with a statutory interest in the land, which may be registered on title (Aboriginal Affairs New South Wales 2013). As the Law Society of New South Wales (2019) notes, such policy has promoted conflict within Aboriginal communities, and has resulted in further deterioration of housing in communities where registration cannot be obtained (directly or via headleases).

\subsection{Existing research on social housing assets in Australia}

This research was conducted against the background of SHOs, their assets and the current status of these assets as outlined in the existing research. The key characteristics of $\mathrm{SHO}$ and their assets, as outlined in this section, are relevant to AM.

\subsubsection{Social housing stock and organisations}

In its report Housing assistance in Australia 2020, the AIHW (2020) presents some key data on the status of social housing in Australia.

As at 30 June 2019, the 437,718 social housing dwellings in Australia were made up of 305,191 public housing dwellings, 100,205 community housing dwellings, 17,660 Indigenous community housing dwellings, and 14,666 SOMIH dwellings (AlHW 2020). These dwellings have accrued over a period of 75 years, with significant acquisitions 1945-1975 and 1983-1989.

A single agency in each of the eight states and territories owns and manages public housing. These eight state housing authorities (SHAs) still provide most social housing. However, over the past 10 years the public housing sector has declined; in 2010, it managed 81.4 per cent of all social housing; now it manages 69.7 per cent. This decrease has mostly occurred through the transfer of stock to the community housing sector.

Community housing consists of 518 organisations, the majority of whom (53\%) manage fewer than 20 dwellings. Only 15 per cent of CHPs manage portfolios of 200 or more properties (AIHW 2020). Indigenous community housing is similar. It consists of $226 \mathrm{IHOs}, 40$ per cent of which manage fewer than 20 dwellings and only 7 per cent that manage portfolios of 200 or more dwellings. This data refers to community-based organisations that lease properties from government, and which receive government capital grants or recurrent subsidies (AlHW 2020). Although this accounts for the vast majority of organisations, it does not cover all. 
The legal status of $\mathrm{SHO}$ and their relationship to overarching organisations such as state and territory governments, faith-based organisations, larger welfare agencies or Indigenous Land Councils is important for AM. SHAs are subject to state borrowing requirements and are thus constrained in raising loan funds for the acquisition and renewal of housing stock. CHPs and IHOs may hold a complex array of titles that have significant implications for capital-raising. For example, CHPs may 'own' dwellings located on Crown land or church land, or lease land or dwellings from government under a variety of terms. CHPs may receive donations or bequests that limit future decisions on dwellings, necessitating cy-près applications to the Supreme Court or Special Acts of Parliament to remove restrictions.

\subsubsection{Type, size, age, condition, quality and amenity of social housing stock}

While data on the number of social housing dwellings, the extent to which they are unoccupied and even the number of dwellings undergoing refurbishment are readily available, current data on the type and size of dwellings are limited, and current data on their age, condition, quality and amenity are not readily available in the publicly available literature.

The AlHW (2020) does provide some overall data on the type and size of social housing dwellings, as depicted in Figure 2 and Figure 3.

Figure 2: Type of social housing dwellings at June 2019

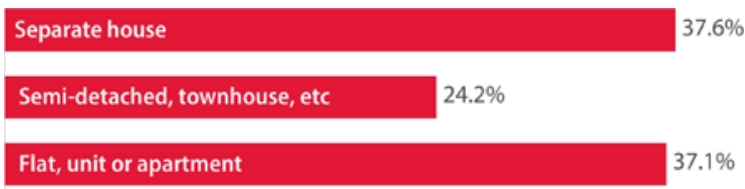

Other $1.0 \%$

Source: AlHW (2020), Supplementary data tables, Social housing dwellings, Dwellings 7.

Figure 3: Size of social housing dwellings at June 2019

\begin{tabular}{|l|l|}
\hline $\mathbf{1}$ bedroom or bedsit & $26.1 \%$ \\
\hline $\mathbf{2}$ bedrooms & $31.4 \%$ \\
\hline $\mathbf{3}$ bedrooms & $35.1 \%$ \\
\hline $\mathbf{4}$ bedrooms $6.5 \%$ \\
\hline $\begin{array}{l}5 \text { or more } 0.9 \% \\
\text { bedrooms }\end{array}$ \\
\hline
\end{tabular}

Source: AIHW (2020), Supplementary data tables, Social housing dwellings, Dwellings 8.

Also, some indications of the condition, quality and amenity of social housing stock can be obtained from the 2018 National Social Housing Survey ([NSHS]; AlHW 2019a; AIHW 2019b). The NSHS asked tenants:

- if their dwelling had any structural problems - rising damp; wood rot or termite damage; major cracks in walls or floors; major electrical problems, sinking or moving foundations; major plumbing problems; sagging floors; major roof defect; walls or windows not square (out of alignment); other structural problems

- whether they had access to seven working facilities - cooking facilities, refrigerator, bath or shower, toilet, washing machine, kitchen sink and laundry tub

- what amenities they rated as important - size of dwelling, number of bedrooms, modifications for special needs, ease of access and entry, car parking, yard space and fencing, privacy of home, safety/security of home, safety/security within neighbourhood, energy efficiency, water efficiency and thermal comfort

- what proximity they had to services and facilities they rated as important-shops and banking, public transport, parks and recreational facilities, emergency services, medical services and hospitals, childcare facilities, education or training facilities, employment or place of work, community and support services, family and friends. 
The overall results indicated that:

- 19 per cent of households had one structural problem, 10 per cent had two problems, and 14 per cent had three or more problems; only 57 per cent of tenants indicated no structural problems (Table S1.5)

- 26 per cent of households did not have access to all seven of the working facilities (Table S1.7)

- in public housing, amenities rated as important and met the needs of households ranged from 61.7 per cent for thermal comfort to 89.6 per cent for ease of access and entry (Table S3.4)

- in public housing, proximity to services and facilities rated as important and met the needs of households ranged from 87.3 per cent for proximity to employment or place of work to 93.4 per cent for proximity to emergency services, medical services and hospitals (Table S4.2).

The overall results varied by state or territory, by form of social housing, by age and disability within households, and by whether households had children. Much Indigenous housing, whether in the public, community or Indigenous sectors, is in notably poor condition.

In summary, a significant proportion of social housing stock has issues of age, condition, quality and amenity, and does not adequately meet the needs of tenants.

One indication of the age of social housing dwellings is the Victorian Auditor-General's Office (VAGO) 2017 report Managing Victoria's Public Housing (VAGO 2017), depicted in Figure 4, which indicates that over 50 per cent of dwellings are more than 30 years old. The rate of acquisition of new stock has not replaced stock that has been demolished or sold, and the number of social housing dwellings as a proportion of all dwellings has decreased from 4.7 per cent in 2010 to 4.3 per cent in 2019. The lack of acquisition or renewal has contributed to an aged asset profile with significant liabilities.

Figure 4: Age profile of public housing stock and total maintenance liability

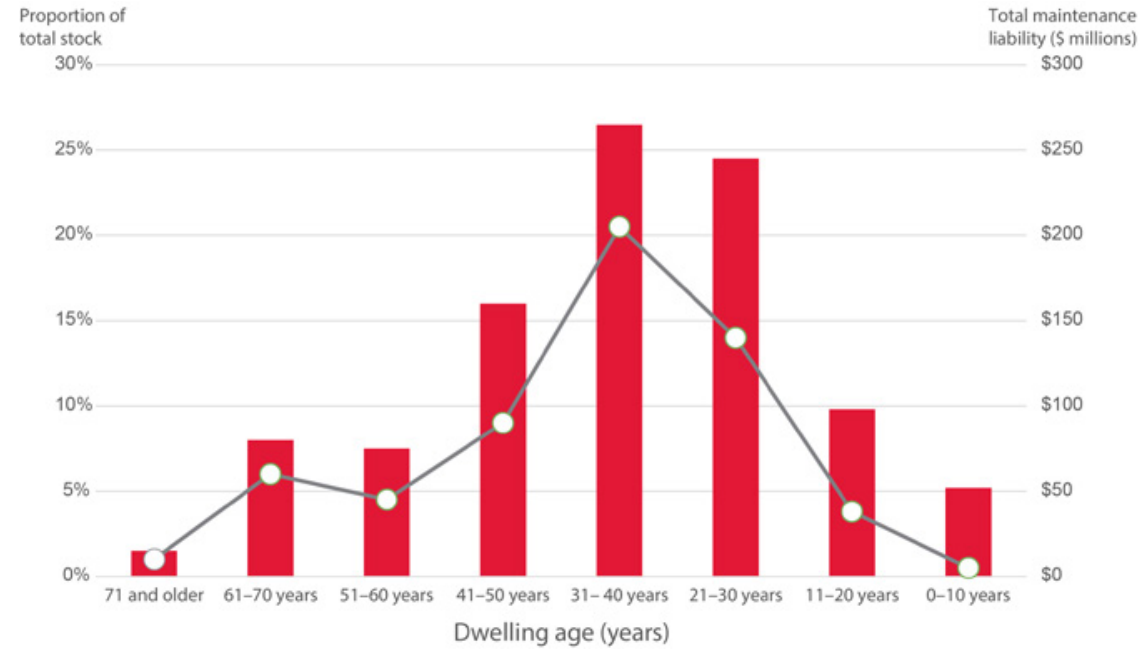

Source: VAGO (2017:14).

Additional information on the data collected by public housing organisations on their housing stock can be found in Section 4.3.1. 


\subsubsection{Energy efficiency}

Mitigating the impact of climate change has become a key challenge for all sectors of the economy. The building sector, through both construction and the operation of buildings, accounts for nearly 40 per cent of global energyrelated greenhouse gas emissions (International Energy Agency 2018). Social housing is a sector of interest, not only because of climate change but also because of fuel poverty (Daly, Tibbs et al. 2019). SHOs constructing new dwellings have had to adapt to new sustainability standards. However, most social housing dwellings are older, and funds for retrofitting are scarce. While CHPs aspire to improving the energy and environmental performance of their stock, to reduce both their own energy costs and that of their tenants (Milligan, Hulse et al. 2015), Liu and Daly (2019) found energy efficiency improvements were limited. The Victorian Department of Families, Fairness and Housing (FFH 2021) have released a joint climate change adaptation plan for the next five years that includes specific objectives for social housing, but no budget appears to exist at this stage to translate the plan into action.

\subsubsection{Utilisation of housing stock and assets}

The fit between housing stock and the size of households continues to be an ongoing issue. As at June 2019, the majority of households (80\%) occupied dwellings according to the size of their household. However, 16 per cent of dwellings were officially underutilised and 5 per cent were overcrowded. The proportion of underutilised and overcrowded dwellings varied according to the type of social housing, with the largest proportion (26\%) of underutilised dwellings in SOMIH social housing and the largest proportion (25\%) of overcrowding also in SOMIH social housing, particularly those in very remote areas (AIHW 2020).

Underutilisation, particularly lone persons occupying three- or four-bedroom homes, deprives SHOs of rental revenue. Given higher security of tenure provisions than private rental housing and expectations of quality tenant service, it is difficult for social housing agencies to forcibly require relocation to more appropriate stock. Conversely, overcrowding increases the likelihood of property damage, thus increasing maintenance costs.

Unlike most western countries, Australia developed its social housing in the post-WWII era by building in a form that broadly emulated that of the private sector: low-density estates of detached and semi-detached housing (Troy 2012). Other countries - for reasons of land constraints, the desire to be modernist, or to build a distinctly different product to the private sector-largely provided social housing in the form of high-rise and walk-up apartments (Harloe 1995). While there are many public housing high-rise towers in Australia, the bulk of post-WWII public housing comprises low-density estates. The relative absence of high-rise towers in Australia meant that SHAs avoided most of the many AM issues associated with them-but low-density estates created a different problem.

As cities and towns have expanded, SHOs-mainly public ones-have found themselves with an enormously valuable land asset that is greatly underutilised in terms of number of dwelling units offered. One of the big AM strategy issues for social housing is how best to capitalise on this land availability. Over the last 20 years, the various jurisdictions have grappled with this asset problem, raising issues of PPPs, social mix, tenure mix, deconcentration and appropriate design. It remains a key issue for social housing agencies, whether as the owners of the land or providers seeking to make the best use of it.

\subsubsection{Concentration of social housing}

In their AHURI Report Wellbeing outcomes of lower-income renters: a multilevel analysis of area effects, Parkinson, Ong et al. (2014) reported that 27 per cent of Small Local Areas had high or very high concentrations of social housing (more than 5.4\% of households were social housing households). These tend to be 'poorer' areas and also have high unemployment. Deconcentration of social housing is a widely accepted social policy objective (Hulse, Pawson et al. 2014). In examining a sample of areas with concentrations of disadvantage, Pawson and Herath (2015) found public housing tenants generally rated the external condition of their property, their garden or landscape and their street as good, very good or excellent. 


\subsubsection{Transferred housing stock}

Over the past five years, upwards of 10,000 dwellings valued at over $\$ 5.4$ billion have been transferred from state or territory housing authority ownership to CHPs (Steering Committee for the Review of Government Service Provision [SCRGSP] 2021: Table 18A.2). Little is understood of the condition of this stock. Anecdotally, some CHPs have accepted housing in poor condition for which they were required to make unexpected maintenance expenditures to remediate critical dwelling deficiencies.

\subsubsection{Value of social housing stock}

Currently, the value of social housing stock is not aggregated and reported by either the Productivity Commission or the AlHW. This is an odd omission, given the data exists for other related performance measures such as asset condition, revenue and expenditure. One estimate ${ }^{3}$ (unsupported) is that the value of social housing stock in Australia is approximately $\$ 100$ billion. Victorian public housing was valued in 2016 at \$21 billion (VAGO 2017). In 2015 the NSW Land and Housing Corporation (LAHC) reported a book value of circa \$38.4 billion, although Infrastructure Partnerships Australia (IPA) regards this as very conservative figure (IPA 2016). South Australian public housing was valued at \$7.98 billion in 2017 (Auditor-General's Department, South Australia [AGDSA] 2017). The value of dwellings is an indication of the liability for renewal.

\subsection{Research questions}

Against this background of social housing assets in Australia, this study sought to fill a gap in knowledge about social housing AM. The timing is important, as AM issues are intensifying in the social housing system. Previous research on AM such as Gruis et al. (Gruis and Nieboer 2004a; 2004b; 2004c; 2007; Gruis, Nieboer et al. 2003; Gruis, Nieboer et al. 2004) and Kenley, Chiazor et al. (2009; 2010) did not provide guidance to SHOs beyond principles. Further, SHA unwillingness (or incapacity) to provide data hampered investigation by Kenley, Chiazor et al., (2010) and the community housing sector is almost entirely absent, reflecting the nascent status of the sector at the time. Our study also benefits from the continuing development of AM as a field.

The research aims to develop an Australian social housing best practice asset management framework that:

1. outlines AM processes and criteria for making decisions

2. is suitable to the specific and unique aspects of social housing

3. is flexible enough to be used by different types of social housing providers

4. provides metrics to drive organisational excellence

5. provides the basis for national regulation and policymaking.

The primary research question guiding this research, then, is:

- What is a suitable framework for social housing in Australia?

This is further informed by three research sub-questions:

- What BPAM principles and processes should guide the Framework?

- What are the specific and unique attributes of social housing provision that need to be incorporated into the BPAM Framework?

- What are the specific and unique features of social housing providers that need to be recognised in the development of the Framework?

3 This estimate is a back-of-the-envelope calculation based on SCRGSP (2021) data, Table 18A.43. The average annual depreciation on 302,789 public housing dwellings was $\$ 3,474$ per annum per dwelling. Assuming a depreciation rate on dwellings of 2 per cent per annum and that the dwelling is approximately 50 per cent of property value, the value of social housing stock is in the order of $\$ 105$ billion at June $2020-$ i.e. $(302,789 \times \$ 3,474) /(2 \% \times 50 \%)$. 


\subsection{Research methods}

The research adopted a mixed-methods approach involving a literature review, workshops, a national survey and interviews. The workshop findings informed both the national survey and the interviews. The literature review, workshops and survey informed the interviews.

Confidentiality of respondents is preserved by strict non-identification of each person, their organisation, sector and state, as AM is a small community of practice and even low-level detail may result in identification by some readers. Confidentiality enabled respondents to be very candid. Many respondents were also speaking to their experience across organisations, sectors and states, so singular attributions would not be appropriate.

\subsubsection{Literature review}

The literature review focussed on AM in the context of social housing, both in Australia and overseas-the UK, Europe, USA and Canada. It aimed to:

- develop a definition of best practice social housing AM within the broader context of the differing understandings of AM

- develop an understanding of the origins and history of social housing AM

- review the experience of organisations with AM, including their processes, frameworks, methods, tools and standards

- develop a framework that would underpin the workshops, the survey and the interviews.

\subsubsection{Workshops}

A purposive sample of $\mathrm{SHO}$ stakeholders was recruited, permitting four workshops with asset managers, general managers, finance managers and CEOs of SHOs, peak community housing and homelessness bodies and AM consultants. The aim of the workshops was to:

- ascertain aspects of AM of social housing in Australia that may be unique to Australia

- ascertain aspects of AM that may be unique to social housing

- obtain an understanding of social housing AM in Australia.

The last bullet informed the national survey that formed the second stage of the research.

Recruitment involved development of a database of SHAs, CHPs, SOMIH and IHOs, with AM personnel the focus of targeted invitations. The database entries were sourced from public listings of CHPs, the Australian Charities and Not-for-profits Commission (ACNC) website, Linkedln searches and the networks of the researchers. Over 700 possible social housing providers were identified. Housing assistance in Australia 2020 identified there are 518 CHPs in Australia that lease properties from government and receive government capital grants or recurrent subsidies (AlHW 2020). While this accounts for the vast majority of organisations, it does not cover all. Listings of community providers do not specifically identify whether the organisation owns assets. As already noted, the majority of CHPs (53\%) manage fewer than 20 dwellings and only 15 per cent manage portfolios of 200 or more properties (AlHW 2020). However, aggregated data on asset ownership is not available. There is no clear picture of the population of organisations.

Identified organisations - and in many cases, specific people within the organisations-were emailed an invitation to provide an Expression of Interest for the workshops. The workshops were also advertised through the researchers' Linkedln accounts and by CHP peak bodies. This process was run between March and August 2020 and garnered 65 responses. 
Four workshops were held; two online and two face-to-face (in Adelaide and Brisbane, respectively) during August 2020. The online workshops were developed in response to COVID-19 restrictions, with planned whole-day events reduced to half-days. An on-demand video presentation was prepared for participants to watch before the workshops. Online workshops permitted participation from around Australia. In total there were 38 participants from SHOs, peak bodies and consultancies. The SHOs ranged from SHAs and large CHPs through to organisations that own only a single dwelling. This sample reflects the profile of SHOs. The sample was sufficient to obtain saturation, permitting the development of a robust and valid understanding of the phenomena (Hennink and Kaiser 2019). Guided discussion focussed on the unique aspects of providing social housing in Australia; current AM practices; and barriers and constraints to improving AM practices. Participants were asked to rank the importance of the factors they identified. The workshop guide is provided in Appendix 5.

The workshops were audio-recorded or audiovisually recorded and transcribed. In addition, participants worked on documents in the workshops. All the resulting documents were thematically analysed, guided initially by Gruis and Nieboer's strategic business framework (2004c). The workshop material was reviewed again after the interview analysis. The workshop results informed the survey instrument and interview guide. Findings of all methods have been combined, reflecting the themes that emerged most strongly from the workshops and interviews.

\subsubsection{Survey}

The survey was conducted online using the Qualtrics system. The recruitment strategy utilised the database discussed in Section 1.5.2, and involved directly emailing specific persons within organisations or the organisation itself, or contacting people via Linkedln. CHP peak bodies also promoted the survey to their members.

The survey aimed to gather information about the organisations, as well as the AM staffing. The survey asked respondents to answer questions about:

- their experience and role

- the organisational type, length of time in operation and the number and breakdown of dwellings

- aspects of the planning and provision of AM such as documentation, use of standards, guidelines and regulations

- how the organisation deals with data collection, internal and external communication, tools and systems, reporting, assessment of assets, financial decision-making, training, maintenance standards and the ability to meet demand and waiting lists.

The survey questions are in Appendix 3.

Five pilot surveys were completed prior to the survey being released. The survey was open for a period of three weeks in September 2020. In total, 108 surveys were completed, including the pilot surveys, test attempts, aborted and incomplete attempts. Cleaning of this data resulted in 61 surveys of unique organisations. This represents approximately 10 per cent of CHPs. Just over a third of SHAs responded. There was only one SOMIH response, which has been combined with the other SHAs to ensure confidentiality. Similarly, the small number of $\mathrm{IHO}$ responses have been merged with CHPs in the presentation of results.

As the number of respondents was low, analysis of the survey involved descriptive analysis, particularly case summaries, frequencies, cross-tabulations, summary tables and summary descriptive statistics. The low number of responses imposed limitations on obtaining statistically significant results for cross-tabulations. Accordingly, the key cross-tabulation utilised was organisational size. Given the limitation on generalising the results, the survey findings are mainly used in the report to support the workshop and interview findings, and only when statistical robustness was possible. 


\subsubsection{Interviews}

A purposive sample of SHOs resulted in 23 semi-structured individual or group interviews conducted with 28 senior managers in CHPs, IHOs, SHAs and other parties with an interest in social housing AM, such as AM consultants or software providers, financiers, Housing Registrars and community housing peak bodies. Interviewees were approached as people with a depth and breadth of experience in social housing, often across organisations and sectors, or-as with the Housing Registrars-occupying highly specific roles. The focus of the interviews was on their experience and industry insights rather than being concerned with their current organisations.

Strategic AM is highly complex, involving every part of an organisation. For example, the Institute of Public Works Engineering Australasia's International Infrastructure Manual ([IPWEA] IPWEA 2020a) is around 300 pages. In order to gain an overview of AM across SHOs, we distilled seven key elements from the literature as the organising principle for the questions:

1. Philosophy and approaches to AM

2. Scope of AM

3. Process used to develop a strategic asset management plan (SAMP)

4. Tools and systems

5. Content of SAMPs

6. Performance indicators and measurement

7. Decision-making processes.

Two or three questions were asked within each of these elements. The semi-structured interviews permitted the respondents to engage with each of these elements, or to focus on some parts, or to introduce a different angle. It also provided the opportunity for the interviewer to seek clarifications, follow up on answers and change the order to facilitate the dialogue. As a single interview guide was not suitable for all organisations, a number of modified versions of the guide developed for the SHOs were used. The guides for CHPs and IHOs are included in Appendix 4.

CHPs from six of the eight states and territories were represented, with one CHP a multi-state provider. Eight interviews were conducted with CHPs, three each with IHOs and SHAs, two with financiers, four with Housing Registrars, two with peak bodies and two with consultants. The interviews were conducted between 9 November and 9 December 2020.

Microsoft Teams online meeting software was used for all but two interviews - with these being telephone interviews - because of COVID-19 restrictions and geographical limitations. Most interviews took an hour, although some extended to an hour and a half. Microsoft Teams allowed audiovisual recording. The telephone interviews were audio-recorded, then transcribed. Participants are identified throughout the report by their designed code numbers. At times the numbers are followed by ' $a$ ' or ' $b$ ' to denote different workshop sessions. However, because of the online technology used for workshops, it was not always possible to identify speakers in the larger groups. These speakers are identified simply as 'Workshop'.

NVivo software was used to code the data for inductive thematic analysis (Braun and Clarke 2006). The thematic analysis was both structured, reflecting the seven elements listed (with additional sub-components of those elements), and unstructured, allowing additional themes to emerge from the data. A separate summary note of each interview was created. 


\section{What is asset management?}

The goal of AM is to meet a required level of service, in the most effective manner, through the management of assets for present and future customers.

Asset management refers to the systematic management of any physical asset (or portfolio of assets).

Best practice AM (BPAM) is the gold standard, and is defined as follows:

- the AM strategy is clearly derived from a corporate strategic plan

- there are long-term, whole-life plans and cost/risk/performance optimisation

- objectives and performance measures are aligned and complementary

- systems are integrated, used and understood

- competencies and training are aligned to roles, responsibilities and collaborative requirements

- strategies are risk-based, with appropriate use of predictive methods and optimised decision-making (ODM) techniques to identify the optimum long-term AMP to deliver a particular level of service

- there is iterative continuous improvement.

In the public sector, good AM also ensures greater governmental effectiveness and accountability, and provides for higher regulatory quality. 


\subsection{Introduction}

Asset management (AM) is a broad term used to describe the management of both physical and intangible assets. For this reason, its definition means different things to different people.

As noted by Kenley, Chiazor et al. (2010) and the Institute for Asset Management ([IAM] IAM 2015), AM involves inconsistent usage of terminology with property management, facility management, portfolio management, service delivery management and strategic AM-all terms that are often interpreted differently. The inconsistent use of terminology and varying definitions were a concern raised by the respondents in this research, which reinforced the need for a common understanding of terms. This section discusses the different definitions before outlining a definition of BPAM.

\subsection{Definitions}

\subsubsection{Assets}

'Asset' is a broad term used to describe a diversity of physical and non-physical property. According to the International Organization for Standardization (ISO) an asset is an 'item, thing or entity that has potential or actual value to an organization' (clause 3.2.1) and asset management is 'the coordinated activity of an organization to realise value from assets' (clause 3.3.1) (cited in IAM 2015).

For example, wealth management is a specialist AM area involving the management of intangible assets such as cash, equities, bonds and real estate (Kenley, Chiazor et al. 2010). Kenley, Chiazor et al. (2010) note that physical assets involve many diverse asset types - for example, furniture, vehicles, the built environment, infrastructure and real estate assets.

The natural environment is also a type of asset. However, not all physical things are regarded as assets for the purposes of AM. Assets are distinguishable from consumables as they have a life expectancy of greater than one year (NAMS 2014).

Asset types are defined as either current or non-current assets:

- Current assets include cash and assets readily convertible to cash.

- Non-current assets include physical (or tangible) assets such as real estate, and intangible assets such as intellectual property (Koskelo 2005; Leong 2004).

Figure 5 illustrates the diversity of asset types that fit within this definition.

Figure 5: Types of assets

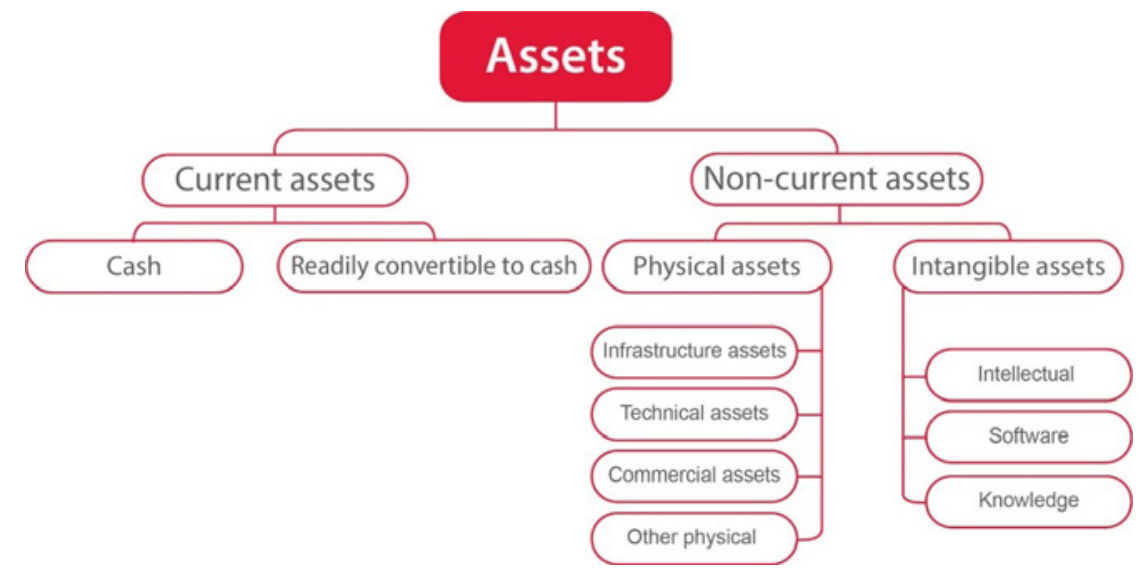

Source: Leong (2004); Koskelo (2005). 
Real estate is clearly a non-current physical asset. However, a portfolio of real estate may also involve cash and elements of intellectual property, software and knowledge. For example, property fund managers regularly review market risk and may adjust their cash positions to reduce portfolio risk, and many will have intellectual property as well as software assets. SHOs will also manage a portfolio of real estate and have cash, software and, in some cases, elements of intellectual property.

\subsubsection{Asset management}

Kenley, Chiazor et al. (2010) found that the same AM terms can be interpreted differently, even by practitioners, depending on the practice area. They summarise these many terms that cover the AM spectrum as: estate management, property management, facility management, portfolio management, service delivery management, and strategic AM.

Estate management is a historic UK term described by Deakin (1999) as emphasising the landlord's ownership of land and their legal and social relationship with the tenants. This definition assumes static real estate and a reactive maintenance approach to ensuring the physical integrity of the assets to meet the landlord's legal and social obligations.

Property management is a more dynamic approach to real estate management and now includes appreciation for tenant or occupier interests (Deakin 1999; Varcoe 2000). However, the inclusion of profit interests shifts the balance back to the interests of the owners or holders of tenure (Rondeau, Brown et al. 2012). Jones Lang Laselle (JLL) Advisory describes the activities of property management as maintenance, tenant relations, security, income and cost administration, reporting and leasing (JLL Advisory 1995). This definition of property management has more emphasis on day-to-day operations than a more strategic management approach.

Facility management is the practice of design, documentation, construction and coordination of assets or resources to support the delivery of the organisation's objectives (Alexander 1993, as cited in Kenley, Chiazor et al. 2010). Facility management encompasses the management of the built environment through integrating people, place, process and technology (Alexander, Atkin et al. 2004; and Chotipanich 2004, as cited in Kenley, Chiazor et al. 2010; International Facilities Management Association [IFMA] 2020).

Portfolio management is defined as the management of a group of properties with the aim of increasing value and benefit over and above that derived from management of individual assets (Varcoe 2000). The emphasis here is on maximising returns while minimising risk through appropriate diversification strategies.

Service delivery management is the management and administration of resources for delivery of specified services (Varcoe 2000). While this definition is specifically intended for property services provided by real estate professionals, the term also includes managing services housed in an asset or facility—for instance, library services in a library asset. The separation of service and asset management functions as recommended by the Productivity Commission (Industry Commission 1993) clearly reflects this distinction. This view could be extended to include the provision of social housing as a service-that is, accommodation services for public sector housing.

\subsubsection{Strategic asset management}

Strategic AM, according to Gruis and Nieboer (2004a), combines the principles of commercial AM and strategic planning. Strategic planning is defined as 'the process of developing and maintaining a viable fit between the organisation's objectives and its resources' (Hannagan 1992, quoted in Gruis, Nieboer et al. 2004: 1230). The components of strategic AM outlined in Table 1 are market-oriented, systematic, comprehensive and proactive. 
Table 1: Characteristics of strategic asset management

\begin{tabular}{ll}
\hline Characteristics of strategic asset management & 'Indicator' of occurrence \\
\hline Market-oriented & $\begin{array}{l}\text { Rents, allocations, sales maintenance and renewal are related } \\
\text { to tenants' preferences, market demand and financial return or } \\
\text { opportunities }\end{array}$ \\
\hline Systematic & $\begin{array}{l}\text { Frameworks for decision-making and structured planning processes } \\
\text { are applied }\end{array}$ \\
\hline Comprehensive & $\begin{array}{l}\text { Goals are formulated for the development of the entire housing stock } \\
\text { and individual estates are analysed in relation to each other }\end{array}$ \\
\hline Proactive & Investments and other activities anticipate threats and opportunities \\
\hline
\end{tabular}

Source: Gruis, Nieboer et al. (2004: 1234); see also Gruis, Nieboer et al. (2003).

\subsubsection{Property asset management}

The Property Council of Australia (PCA) defines asset management as a 'systematic approach to the procurement, maintenance, operation, rehabilitation and disposal of one or more assets which integrates the utilisation of assets and their performance with the business requirements of asset owners or user' (PCA 2019). This definition has a clear emphasis on life-cycle management, asset utilisation, asset performance and alignment of these with owner or user requirements.

This alignment is also well defined in corporate real estate management (CREM) or corporate real estate asset management as complete alignment of asset strategies with organisational objectives (Haynes, Nunnington et al. 2017). This includes budgeting and performance measurement to ensure asset strategies are contributing to organisation objectives in a tangible way. CREM practice also requires significant consideration of future trends as well as assessment of business and asset risk. CREM differs from pure property investment in that the property (leased or owned) is seen as a vehicle for maximising business potential by providing property assets in the right place at the right time and designed in a way to maximise productivity. Similarly, social housing has many multifaceted objectives that also tie the success of the organisation with the success in management of the assets. Kenley, Chiazor et al. (2010: 18) state that 'while asset management is extremely useful to investment real estate, it is just as useful for CREM and Property Real Estate Management (PREM) organisations. Where the real estate assets are managed for operational purposes, such as is the case with public housing, then the CREM field, potentially, has useful insights to be applied, especially as recent thinking in the field has emphasised both strategic and business outcomes.'

Property, or real estate asset management (REAM), is defined as comprising a number of fields within built environment asset management (Kenley, Chiazor et al. 2010). This is depicted in Figure 6. 
Figure 6: Fields of asset management and built environment asset management

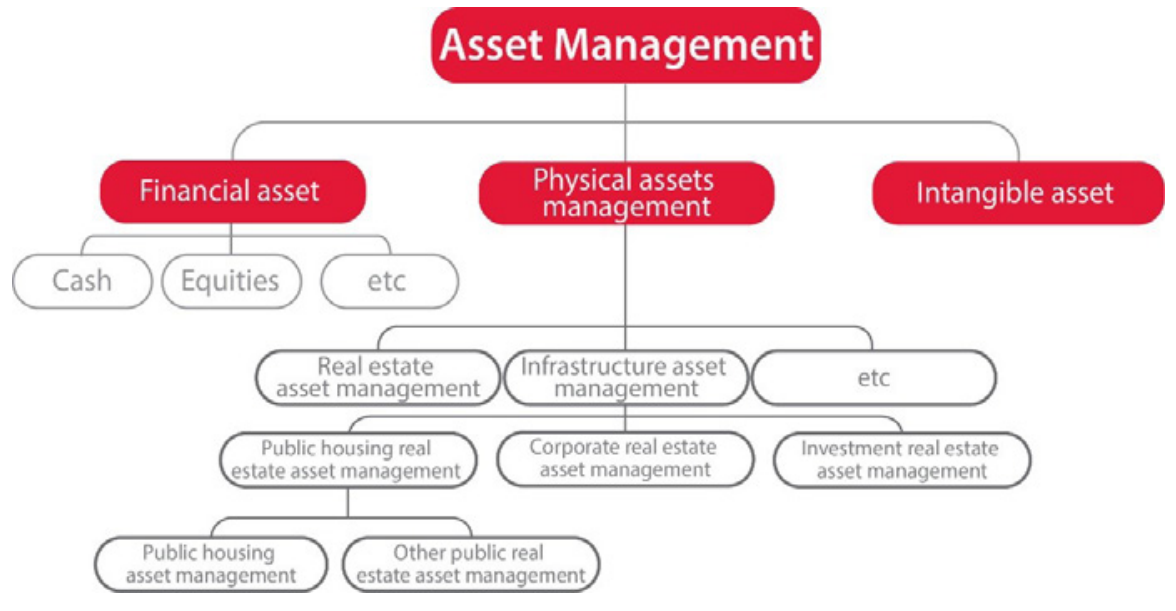

Source: Kenley, Chiazor et al. (2010: 19).

While these definitions of AM, REAM and corporate real estate provide a good overview, a closer examination of current social housing $A M$ is required.

\subsubsection{Public sector asset management}

Kasperskaya (2018: 319) identifies ‘sound' AM in the public sector as being concerned with:

- controlling corruption

- ensuring greater governmental effectiveness and accountability

- providing higher regulatory quality.

She argues that 'the main building blocks of effective AM are (1) faithful asset measurement and reporting, (2) a comprehensive asset register, (3) a supportive institutional and regulatory framework, and (4) the employment of best practices of AM by government entities'. Three of these elements are common to most conceptions of AM. Her nomination of a supportive institutional and regulatory framework as integral to good AM is particularly relevant in the context of social housing provision in Australia.

\subsubsection{Best practice asset management}

Defining AM is subject to an ongoing effort by industry peaks, such as IAM and ISO, to ensure appropriate standards. IAM (2015: 9) highlights the shift in the ISO 55000:

- from tactical to strategic

- from isolated life phases and functional disciplines to a full life-cycle view

- from individual assets to asset systems and systems of systems

- from management of discrete activity types to an integrated management system.

The Institute of Public Works Engineering Australasia (IPWEA), a key international actor in promoting AM best practice, argues that the goal of AM is to manage assets in the most efficient and effective manner, with infrastructure assets going beyond traditional infrastructure to community assets essential to communities' health and socialconnectedness. (IPWEA 2020a). 
The ISO defines the AM system as 'the set of inter-acting elements of an organisation to establish AM policies and objectives, and processes to achieve those objectives' (quoted in IPWEA 2020). IPWEA (2006) describes those elements as:

- an AM strategy clearly derived from a corporate strategic plan

- long-term, whole-life plans and cost/risk/performance optimisation

- objectives and performance measures which are aligned and complementary

- systems are integrated, used and understood

- competencies and training are aligned to roles, responsibilities and collaborative requirements

- strategies are risk-based, with appropriate use of predictive methods and optimised decision-making (ODM) techniques to identify the optimum long-term AMP to deliver a particular level of service

- there is iterative continuous improvement.

In short, the aim of is to deliver the mission of the organisation.

IPWEA produces AM manuals and practice notes for practitioners on various types of assets (IPWEA 2020c).

IPWEA's key publication is the International Infrastructure Management Manual (IIMM), which is now in its sixth edition. IIMM now includes a supplement, Meeting ISO 55001 requirements for asset management 2015 (IPWEA 2020a). ISO is a worldwide federation of national standards bodies that has developed international standards on AM and AM systems:

- ISO 55000 provides an overview of AM and AM systems and a context for ISO 55001 and ISO 55002 (ISO 2014b)

- ISO 55001 sets out the requirements of an AM system (ISO 2014a)

- $\quad$ ISO 55002 provides additional useful guidance for applying ISO 55001 (ISO 2018).

While the ISO Standards outline 'what to do', the IIMM provides the 'how to do it'. Thus, the IPWEA Manual and its supplement are based on ISO 55000, ISO 55001 and ISO 55002 and are: 'primarily intended for use by:

- those involved in the establishment, implementation, maintenance and improvement of an AM system

- those involved in delivering asset management activities and service providers

- internal and external parties to assess the organization's ability to meet legal, regulatory and contractual requirements and the organization's own requirements' (ISO 2014a).

The New Zealand National Asset Management Support group (NAMS) produces a Property Manual, a comprehensive guide to the management of property assets for the 'strategic to tactical long-term planning for property assets' (NAMS 2014: 2), as well as another manual on ODM guidelines that consider a sustainable approach to managing infrastructure (IPWEA 2020b). Some useful practice guides under the IPWEA umbrella include:

- Practice note 3: Building condition and performance assessment guidelines

- Practice note 6: Long-term financial planning

- Practice note 8: Levels of service and community engagement (IPWEA 2020c).

IPWEA also offers training and events.

The IPWEA framework and definitions are appropriate for social housing, but it is also important to include the unique aspects and challenges that managing Australian social housing presents. These are discussed in Chapter 3. 


\subsection{Social housing asset management}

Social housing AM has been defined as 'the range of activities undertaken to ensure that the housing stock meets the needs and standards now and in the future in the most efficient way' (Larkin 2000). Larkin's definition seems to capture the long-term or life-cycle focus on the needs of current and future tenants, the standards to be achieved and the sustainability of services provided through asset activities undertaken in the most efficient way. This implies that decisions undertaken today must account for their future impact on long-term sustainability of services. This is the principle behind ODM (IPWEA 2020c).

As depicted in Figure 7, this long-term life-cycle focus on the sustainability of services in social housing AM covers three broad areas (Wiewiora, Brown et al. 2012):

- asset creation - the processes involved in the acquisition of stock through building and purchasing dwellings and land

- asset management - the processes involved in reactive maintenance (repairs and critical/emergency repairs), cyclical/planned or programmed maintenance, the allocation of dwellings and the upgrade of current stock requirements

- asset disposal - the processes involved in the demolition and redevelopment of sites so that they meet current or future demand, and the sale or transfer of land or dwellings that no longer meet current or future demand. Demand forecasting and management must involve current and prospective tenant consultation to ascertain location, dwelling type and dwelling amenity expectations. This is to achieve alignment of assets to user requirements (Wiewiora, Brown et al. 2012).

The process of developing a strategic asset management plan (SAMP) — the AMP roadmap — requires SHOs to collect data on the condition of their assets, the supply of social housing, the current and future demand for social housing and their vacancies and turnover, particularly as it relates to specific areas and specific housing types.

For SHOs, this is the starting point for developing an AMP and working through the implications of this data in each of the three areas of asset creation, asset management and asset disposal, and making optimal decisions about their stock based on an assessment of:

- the housing needs of current and future tenants

- the service standards to be achieved

- their mission and objectives

- the environmental, economic, social, political and cultural costs and benefits.

Figure 7: Sustainable asset management over the life cycle of social housing

Data collection: asset condition, housing supply, housing demand, vacancies, turnover

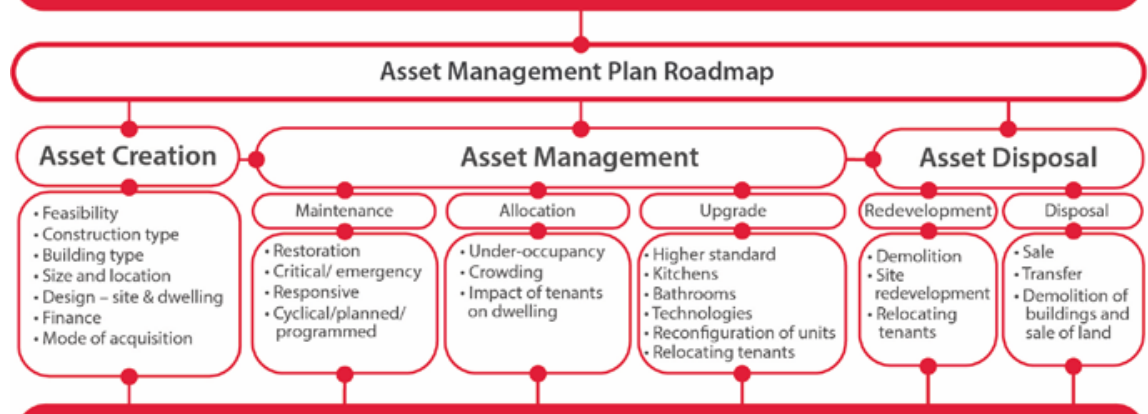

Decisions based on an assessment of: (i) the housing needs of current and future tenants, (ii) defined service standards, (iii) the mission and objectives of the SHO, and

(iv) the environmental, economic, social, political and cultural costs and benefits. 


\subsection{Conclusion}

Significant work has been undertaken by industry bodies concerned with AM to regularise definitions and terminology, and to conceptualise what asset management is and what it involves. In addition, organisations such as IPWEA have produced excellent resources to support organisations in preparing their AM strategies and plans. However, these are generic guides, reflecting a diversity of physical asset types. The NAMS Property Manual provides a specific guide for property, but it encompasses many types of built assets. It references Housing New Zealand Corporation and the Auckland City Council's Affordable Housing Partnership as examples of social housing property. The Australian social housing best practice asset management Framework being developed as part of this research provides the next level of AM specificity required for Australian SHOs. The Framework is included in Appendix 1. 


\section{Unique features of social housing in Australia}

Social housing AM presents challenges that are different to those faced by private landlords.

Social housing AM operates at the intersection of:

- the internal demands of financial management and the housing needs of a diverse, complex and shifting population group

- the external demands of diverse interests seeking to use social housing for social and economic purposes.

Social housing AM operates predominantly within private markets that determine land prices, the supply of construction services, house prices and rents.

SHOs are required to be accountable to government and the community for performance.

Australian social housing has unique features when compared to other social housing systems, as:

- Australia's system of federation creates issues for housing policy and funding

- income-based rents are the means by which affordability is achieved for tenants, but the financial gap in the cost of provision is not fully addressed through other funding mechanisms.

Social housing AM has many commonalities with AM more broadly. However, each class of asset has specific issues and challenges. Social housing is a special form of property asset which, while sharing features with private rental housing, still has significant differences-particularly in Australia. These have implications for AM. So, it is useful to compare social rental housing with the private rental sector in order to understand some of the unique challenges faced by social housing asset managers. 


\subsection{The business of social housing}

Social housing is a complex business with aims that distinguish it from corporate real estate. The main objective of social housing is to provide affordable and sustainable housing options to the most vulnerable people. In achieving this objective, SHOs have to integrate, on a long-term sustainable basis, a complex set of processes or recurring schemes (McNelis 2006a):

- an eligibility/allocations scheme that relates specific characteristics of applicants with the processes for determining who is eligible for social housing, the processes for determining their priority and the processes by which dwellings are chosen by or allocated to applicants

- a housing acquisition scheme that relates a standard of housing with the processes for raising of capital funds, the processes for determining these standards and the processes by which land and dwellings are acquired

- an AM scheme that relates a standard of housing with the processes for maintaining that standard, the process for bringing dwellings up to that standard and the processes for deciding whether and when to upgrade, demolish or sell dwellings

- a property management scheme that relates an ongoing standard of maintenance and repair of properties with the processes whereby they are maintained

- a tenancy management scheme that relates management of tenancies with processes whereby tenants and staff can interact and whereby tenants' rights are ensured

- a finance scheme that relates different transactions - capital and operating-with processes for determining ongoing costs, with processes for determining rents and with processes for allocating subsidies.

The management of assets is one process, but its integration within social housing needs to occur within the larger context of a SHO achieving its objectives and the differing roles that these different complex processes play. Thus, the unique and specific characteristics of social housing are relevant to AM.

If $\mathrm{SHO}$ s are to meet the diverse and complex needs of their target groups-as reflected in their eligibility/ allocation processes - they need to acquire and configure their housing portfolios with housing stock of certain attributes-type, size, location, amenities.

If $\mathrm{SHOs}$ are to fund acquisition, upgrades and maintenance, then they require access to funds for these purposes.

If $\mathrm{SHO}$ are to support the wellbeing of tenants, then they need to provide housing in ways that promote local communities and neighbourhoods, education, employment, industry, regionalisation, etc.

Part of the complexity of social housing AM is that is operates at the intersection of:

- the internal demands of financial management (capital expenditure, operating expenditure, rental revenue) and tenancy management (eligibility, allocations, antisocial behaviour, rent arrears, termination of tenancies, etc.)

- the housing needs of a diverse, complex and shifting population group

- the external demands of diverse interests seeking to use social housing for particular purposes (such as regionalisation, providing a workforce, economic stimulus, piloting new technologies, growing cities, etc.).

Social housing AM involves all this, while also predominantly operating within private markets that determine land prices, the supply of construction services (reflecting property cycles), house prices and rents-and while also accountable to government and the community for their performance. 


\subsection{The unique characteristics of Australian social housing}

\subsubsection{Portfolio size}

In Australia, private rental housing is dominated by small-scale landlords with only a nascent build-to-rent sector. Accordingly, around 90 per cent of private landlords have holdings consisting of one or two houses (Hulse, Martin et al. 2018; Reserve Bank of Australia 2017) and, as such, do not have housing portfolios.

In contrast, as outlined in Section 1.3, while a significant proportion of CHPs have relatively small portfolios, these are larger than small-scale landlords' portfolios, and many SHOs hold housing portfolios in excess of 100 dwellings, with some holding stock in the thousands or tens of thousands.

\subsubsection{Mission}

Private landlords are typically exclusively concerned with financial returns, whereas the mission of social landlords is social return on investment. This means social landlords must take at least a double bottom-line business approach. Whereas financial return from private residential property may be rental yield or capital gains, social landlords build to hold, and the portfolio rental yield must balance housing affordability and the need for revenue to cover costs and growth. At the same time, Australia's private 'Mum and Dad' investors are encouraged by public policy to seek capital gains rather than yield. These differing priorities result in divergent strategic AM and often different approaches to AM.

The primary objective of social housing is increasingly to provide affordable housing to the most vulnerable. Vulnerabilities arising from disability, family violence, mental health, autism, asylum seeker/refugee status, chronic illness, sole parenting and unemployment or under-employment, to name a few, are commonly associated with barriers to obtaining employment that can enable such households to sustain market housing.

\subsubsection{Attributes of dwellings}

In allocating tenants to particular dwellings, SHOs take into account the size of a household, the age of applicants, whether they have a disability and, to a very limited extent, the preferences of households for a particular location and type of dwelling. However, other considerations such as culture are also important, and it is very difficult to imagine how social housing providers could provide social housing services for Indigenous people, for example, without understanding their cultural and spiritual needs. Similar approaches are also needed for people experiencing disability, family violence, mental illness, autism, refugee status, chronic illness, new immigrant status, etc. Many of these people need social housing but their requirements for housing types, options and services might be significantly different. This also helps social housing providers to understand and manage their costs for maintenance, turnover, selecting location and developing new housing that is better aligned with tenants' needs.

\subsubsection{Location of dwellings}

SHOs seek to provide good quality housing that is affordable. Non-traditional landlord activities enhance the efficiency of the main traditional social housing objectives (Czischke 2009). Through the location of housing they can contribute to the education and employment of tenants, ultimately helping people to live independently in the future without the support of the social housing sector, which eventually allows other people in need to be housed (Prentice and Scutella 2020).

\subsubsection{Choice of tenants}

Landlord choice of tenants in the private rental sector reflects the rent the private landlord seeks in order to obtain the desired return on investment. Market rents therefore are very often out of the financial reach of households in the lowest two income quintiles (Hulse, Reynolds et al. 2019), which are the main targets of social housing. 
In addition to seeking rents that will adequately compensate them, private landlords are concerned with creditworthiness as a surety that rental payments will be made. To this end, private landlords are able to seek extensive information from prospective tenants regarding their income and income sources in order to potentially deny them a tenancy. Social landlords seek the same information-but in order to ensure inclusion. Private landlords tend to prefer higher-income households, which are perceived as being readily able to afford the rent. Prospective tenants with low income or in receipt of statutory payments can be legitimately refused a property.

Private landlords protect their investment by choosing tenants they perceive as creditworthy, and will use eviction when necessary to prevent loss of income. The social purpose of SHOs means eviction is only ever a last resort. Private landlords' choice of tenants provides the opportunity to select tenants who are also perceived to be unlikely to damage properties. Lower wear and tear and minimal damage reduce expenditure on maintenance, and thus improve the rate of return. The social housing mission to accommodate the most disadvantaged overrides this concern.

My experience has been that the [social] assets tend to get ... a more stern working out, if you like, and so base life of components particularly shouldn't, isn't as what would be expected in the private market. So as an example of carpet in the private world, life expectancy 10 years? That's not usually the case, particularly where there's some difficult clientele. (34)

Children are sometimes perceived as likely to damage properties and so families can sometimes find it difficult to obtain a private rental property (Hulse and Sharam 2013). Single parent families can find it particularly difficult, despite parenting status being a protected status under Equal Opportunity laws. Aboriginal and Torres Strait Islander peoples experience extensive discrimination in the private rental sector.

Social landlords serve tenants the private market fails - those unable to afford quality housing in the private sector, or who have characteristics that make private rental housing unsuitable or mean they face discrimination.

Social landlords often see it as undesirable to charge tenants for damage they incur, although tenants are liable for damage. Not only do social tenants typically have little financial capacity to pay for damage, but pursuit of debt can also be counterproductive in terms of alleviating financial hardship and promoting wellbeing.

Social housing asset managers will consider the wellbeing of the tenant to a greater extent than a private landlord typically would. For example, some tenants have issues that mean they are highly reluctant to permit people into their homes-especially strangers. Social housing asset managers commonly have protocols to address this, which can extend to not undertaking maintenance at all:

[We are] mindful and check that the residents are comfortable and aware of who is going into the unit. (Workshop 1)

A private landlord who is frustrated in attempts to access properties has the ultimate option of evicting the tenant. Private landlords may also use the potential for eviction as a method to deter maintenance requests. However, a request for repairs will not expose a social tenant to the threat of eviction (Workshop 4).

Maintenance is sometimes used by social landlords as a tool to obtain tenant behavioural change. For example, in exchange for moderating behaviours that impact on neighbours, a tenant may have a backlog of repairs addressed. However, a private landlord - particularly one who does not own surrounding properties-is unlikely to take any responsibility for tenant behaviour that does not involve damage to their own property or income.

The need to be sensitive to tenant concerns shapes $\mathrm{SHO}$ businesses in other ways that are different to private rental. SHOs need trade contractors who can work well with tenants. In order to build partnerships that will contribute to tenant satisfaction, many SHOs provide their contractors with short payment periods, delivering the contractor a positive cashflow benefit even though this negatively affects the SHO's own cashflow position and increases administrative pressures. 
Tenant attributes have implications for property management. Some tenants are more likely to damage property or have their homes damaged by third parties - for example, perpetrators of family violence. Overcrowding exacerbates wear and tear. As social housing systems residualise with 'a rising share of single-person (lowerincome) households in the tenant population' (Pawson and Herath 2015: 10), the tenant profile increasingly reflects those cohorts more likely to be more costly to house, both from property damage and tenancy management perspectives. This is a growing marker of difference between social and private provision.

\subsubsection{Rental revenue}

Private landlords in Australia invest in rental housing for potential capital appreciation. However, an investment decision will also reflect potential rental revenue, operating costs and the price of the asset. Rental revenue is based on market rents. Rents of sitting tenants may be increased annually or every six months depending on the jurisdiction, although increases cannot be above the prevailing market rents. Rents and asset prices will reflect market conditions, including the location, type, age, size and quality of the housing, as well as the supply and demand of rental housing.

In contrast, the only role capital gain has for social housing is as equity or as collateral when borrowings are used to finance acquisition or renewal. SHO rental revenue is predominantly in the form of household rents based on a proportion of income (usually 25-30\% of household income) regardless of the location, type, age, size or quality of the housing. SHOs must fund all operational expenses out of rental revenues. ${ }^{4}$

Australia has a unique social housing finance system (McNelis 2006b; McNelis and Burke 2004). In contrast to most European $\mathrm{SHOs}$ that operate a single property rental system, Australia operates a dual rental system:

- a property rental system that determines the maximum rent for each dwelling

- a household rental system that determines the rent for each household based predominantly upon household income (usually $25-30 \%$ of household income with adjustments for those tenants eligible for CRA).

In European countries, housing affordability is achieved through some form of housing subsidy from central government paid directly to tenants. This permits property-based rents. In Australia, reduced household rent is the main mechanism through which affordability is achieved. Moreover, of those countries that charge a household rent such as New Zealand, Canada and the USA, Australia is the only country that does not compensate social housing landlords for housing very low and low-income tenants. This deprives SHOs of the funds required to undertake capital investment in the upgrade, renewal and redevelopment of their housing stock. ${ }^{5}$ With the increasing residualisation of social housing over the past 40 years, rental revenue has progressively decreased and the financial viability of SHOs has been undermined (Pawson, Martin et al. 2016). Social housing is now in a parlous financial state (Hall and Berry 2004; 2007a; 2007b; 2009).

Further, household rents bear no relationship to the size, quality and location of the dwelling. Thus there is a disjuncture between tenancy management objectives and AM objectives. For instance, one issue is underutilisation, where a small household occupies a largish dwelling but pays a low household rent. Another issue is stock matching, where decisions need to be made about new stock in relation to the current and future needs of tenants. Building only one-bedroom and two-bedroom dwellings is an indirect way of addressing underutilisation. However, an overprovision of smaller dwellings now may reduce flexibility in dealing with changing future housing needs.

4 CHPs and IHOs generally have no other source of operating funds, although some have established social enterprises such as private real estate agencies to generate income.

5 Some CHPs and IHOs may also provide affordable housing that provides higher levels of rental revenue. If they are registered as charities, CHPs and IHOs may charge up 75 per cent of market rent for their affordable housing and retain their GST-free status. This provides the opportunity to charge rents that reflect housing type, quality and location. Affordable housing rents may cross-subsidise the social housing tenants. 


\subsubsection{Capital funding for acquisition of new stock}

Private landlords raise capital for the acquisition of properties as they discern opportunities for good returns on their investment. Some landlords may use equity, and thus the investment is positively geared. However, many borrow for acquisition. If rents do not cover costs, the landlord may claim the difference as an income tax deduction under negative gearing provisions that allow individuals to write off costs against other income. Any capital appreciation at disposal is lightly taxed. Private landlords are therefore significant recipients of public funds.

In contrast, social landlords are constrained, indeed prevented, from accessing capital for the acquisition of properties:

- by their revenue flows from household rents

- by the lack of compensatory subsidies for housing very low-income tenants

- by government borrowing requirements (SHAs)

- by very low levels of government investment in social housing.

The main mechanism through which SHOs can access capital funding is through bilateral agreements between the Commonwealth and the states and territories. These funds are in the form of capital grants. These grants were originally intended for the acquisition of new stock, but have increasingly been used as a supplement to rental revenue to meet the costs of a maintenance backlog, upgrading, renewal and redevelopment.

Government capital grants are provided to CHPs and IHOs on an irregular basis. The largest recent allocations -during the global financial crisis (GFC) and the COVID-19 pandemic-were emergency stimulus economic measures. The pool of grants provided through philanthropy is very limited (Sharam, Moran et al. 2018), although philanthropy is a key source of grants in the USA. Therefore capital grants are the exception, rather than the rule. This results in a lumpy asset profile. Moreover, grants are typically for 'growth' of social housing stock rather than renewal, although the historic $\$ 5.2$ billion social housing fund announced by the Victorian Government as part of its 2020 Budget specifically allocated funds to repairs and upgrades.

CHPs and IHOs also have access to private finance to acquire, develop and redevelop housing, although long-tenor debt was generally unavailable (Sharam, Moran et al. 2018) until the NHFIC was established by the Australian Government to raise bonds (NHFIC 2020).

\subsubsection{Short-term turnover}

Private landlords, who are overwhelmingly higher-income households, can offset operating losses against income from other sources for tax purposes-called negative gearing-and this mitigates investment risk to some extent. In the Australian context, the potential for asset appreciation is arguably more important than rental yield. Generous capital gains tax-concession provisions over the past 20 years have dramatically increased the attractiveness of rental housing as a speculative investment. This has contributed to significant housing price inflation.

Speculation means that properties are 'flipped' after relatively short periods. Weak tenancy laws mean investors may choose to avoid maintenance while they hold the property. Alternatively, if they renovate prior to resale, upgrade costs will be capitalised into the sale price. Sitting tenants can be evicted if there is no timely vacancy.

Whether or not a private landlord is pursuing rental yield or asset appreciation, they have the flexibility to dispose of the asset at any time.

In contrast, social housing landlords hold properties over very long periods. 


\subsubsection{Split incentive}

All tenants in Australia are responsible for their energy and water consumption. As landlords do not pay for this consumption, the choice of fixed appliances in the private and social housing sectors has been driven by the cost borne by the landlord, rather than the operating costs of the appliance.

However, high, uncontrollable utility consumption is a source of credit risk to landlords, as tenants experiencing the resulting financial stress will at times prioritise paying a utility services bill rather than rent (Sharam 2007). $\mathrm{SHOs}$ are increasingly aware of fuel poverty, and an increased focus on sustainability and revenue protection is resulting in new housing designs incorporate energy efficiency measures and renewable energy systems, as well as retrofit programs.

If you've got good passive cooling, you don't need to run mechanical electrical products and if you got a tenant in there that is responsible for paying the electricity bill, it's a positive impact on their life ... We need to understand what our property portfolio's doing relative to the cost of living for tenants. (30)

Unless a private landlord is concerned about the environment, there is little to incentivise them to pay the higher cost of better housing and fixed appliances.

\subsubsection{Eviction}

Australian tenancy laws provide landlords with the right to evict without reason, subject to a Notice to Vacate order providing the stipulated notice period. Certain reasons, such as arrears, are grounds for eviction with short notice periods. Thus tenancy laws provide considerable flexibility to investors, allowing them to take advantage of, for example, the price premium attached to vacant possession when selling a property.

A social housing landlord's decision to evict will be tempered by considerations such as whether the tenant will become homeless, the prospect of further serious damage to properties if this is the issue, or behavioural issues that impact on neighbours. Eviction is typically a last resort.

\subsubsection{Regulation and oversight}

All residential tenancies are subject to state-based tenancy laws. These are regularly criticised for failing to provide adequate protections for private tenants. The Productivity Commission (2019: 91) notes that vulnerable tenants tend to live in poorer quality housing that is 'in greater need of repair or have major structural problems', which they suggest may reflect the power landlords have over poorer tenants. Residential tenancies legislation varies around the country. There are currently no minimum habitation standards in the ACT, WA, QLD or NT. Habitation standards in the other states vary. Victoria's recently introduced habitation standards include considerable detail-not just what a dwelling must include, but the performance that must be achieved. (See Appendix 7 for current provisions.)

Social housing is subject to the same state-based tenancy laws. As outlined in Section 5.7, community and Indigenous housing are also subject to sector-specific regulation. This regulation does not mandate minimum habitation standards, although providers must lodge AMPs - which in theory could detail the level of service the $\mathrm{CHP}$ intends to provide - and detail planned and reactive maintenance regimes. Surveys of tenant satisfaction are also a key means by which property maintenance is understood by regulators. Where transfers have occurred or capital grants have been made, SHAs and government may dictate maintenance standards to be achieved.

There are significant differences in the provision of private versus social rental housing. In many respects, private rental housing has more in common with other types of assets than with social housing. This reflects the focus on the asset as an investment vehicle compared to the social landlord's focus on the provision of social outcomes. 
Both sectors are subject to the same residential tenancies laws, but CHPs and IHOs are subject to further regulation intended to protect public investment in these non-government organisations and ensure good tenant outcomes. As public monies support social housing, it experiences a higher degree of scrutiny and accountability than private landlords, despite the tax breaks afforded to many private landlords.

\subsubsection{Population densities and distance}

Australia is a vast continent with a relatively small population. This population is mainly concentrated into five major cities on its coasts. When compared to Europe, distances between regional cities and towns are great while the populations of the hinterlands are low. Much of Australia is very sparsely populated. Remoteness brings many complexities to delivering and managing social housing, including additional costs. On the other hand, Australian cities are dominated by extensive, very low-density suburbia. This sprawl can impose AM costs that would not exist for most European or many North American SHOs.

SHAs have large geographical catchments, reflecting state-level provision. An increasing number of CHPs also provide housing across the nation. Dispersed housing across large geographical areas presents AM logistical challenges and can add costs.

It's certainly a challenge ... In terms of the tyranny of distance.

We do have some regional properties and we find those quite challenging to manage. (37)

As a consequence, maintenance is often contracted out on a regional basis. There may nevertheless be few service options and little competition to drive quality and price-setting.

Australia's main cities also reflect strong bid-rent price curves for housing, with land near city centres very expensive and that at the fringe relatively low-cost. The relative affordability of land on the fringe is drawing social housing provision to localities that tend to be poorly served by physical and social infrastructure, and which provides fewer employment opportunities.

\subsubsection{Federal political system}

Australia is a federation of states in which a vertical fiscal imbalance exists between the national government, which has the most significant revenue-raising powers, and the states and territories that fund community services. Ministerial Councils have been established on many broad and specific issues and are 'the principal means of facilitating intergovernmental cooperation in Australia' (WALA.SCULIA 1997: 2). Between 1992 and 2020 the Council of Australian Governments (COAG) was the primary intergovernmental forum for intergovernmental collaboration and decision-making. An intergovernmental policy framework for housing provision (the CSHA) was established after WWII to 'co-ordinate housing-related activities at national, state, territory and local government levels' (Owen, Winter et al. 2002) and reflected a shared vision of the role of government in overcoming the country's acute housing shortage. Such political consensus has long since broken down and coherent policymaking is especially difficult to achieve. The process of cooperation itself has faltered with the abandonment of the CSHA and establishment of successor agreements; the currently agreement is the National Housing and Homelessness Agreement (NHHA). The NHHA does not exist within a broader national housing plan, and state and federal housing policy are frequently at odds with each other.

We haven't got a national housing plan. That's not very helpful. Most first-world countries do, for both the social housing sector and the private sector. But we still have this difficult relationship between the Commonwealth and state jurisdictions with the way that social housing is funded... the complex overarching funding arrangements between the Commonwealth and the states and then individual providers still provides a level of complexity and the potential for some inherent dysfunction. And I don't mean dysfunction in the way they operate but dysfunction or a handbrake on better asset planning and asset delivery and asset activity funding, because there's debates about who pays for what. (14) 
As a consequence, housing policies are often short-term. For social housing providers with physical assets that are long-lived, the short-term nature of housing policy makes planning for assets very challenging.

Community housing regulation reflects this system of federation. Western Australia and Victoria established their own regulatory regimes, while the other states and territories adopted the nominally national system. Moreover each state and territory exercises other controls over its CHPs via transfer and grant agreements-and this creates a layered patchwork of regulation for CHPs operating in multiple states.

The Australian system of federation fosters incoherent housing policy, and leaves funding of housing assistance at the mercy of often fractious intergovernmental processes. Long-term consistency in policy approaches is absent. Constant reform engenders policy uncertainty. The most pressing issue for the social housing financial system is the gap between rental income and the cost of provision.

\subsection{Summary}

In summary, compared with the private rental sector, the AM challenges for SHOs are unique in 11 ways:

1. Housing portfolios among SHOs are larger.

2. The mission of $\mathrm{SHOs}$ is more complex.

3. The target group for SHOs is those on very low incomes, often with complex needs, and those whom the private rental market fails or excludes.

4. Rental revenue is severely constrained and barely covers operating costs, let alone the long-term costs of upgrade, renewal and redevelopment of housing stock.

5. Capital funding for acquisition is dependent upon grant allocations from Commonwealth and state or territory governments, which have been 'lumpy' and largely overtaken by the demands to meet backlog maintenance, upgrade, renewal and redevelopment of current housing stock.

6. SHOs hold stock for very long terms.

7. SHOs are increasingly aware of fuel poverty, the importance of energy-efficient homes and appliances and the long-term sustainability of their housing stock.

8. For SHOs, eviction is a last-resort option.

9. While both private landlords and SHOs are subject to residential tenancies legislation, SHOs are subject to additional regulation and oversight as organisations providing social benefits.

10. Low-density population in cities and dispersed housing across large geographical areas presents logistical challenges for AM.

11. The federal political system, with its entrenched vertical fiscal imbalance, makes consistent capital funding for acquisition difficult and creates a patchwork of regulation. 


\section{Social housing asset management}

- Social housing AM is still in its infancy-it emerged in the early 1990s as SHOs sought to deal with ageing stock and a policy environment that was increasingly applying market discipline.

- SHOs are still learning how to develop and implement AM plans.

- Social housing AM overseas has been variously driven by the external demands of regulators (particularly in the UK and USA) and by the internal demands of organisations (particularly in Europe and Canada).

- Social housing AM frameworks have shifted focus over time from the technical elements of dwellings and financial performance to aligning assets with a SHO's mission, its clients and local area development.

- The literature on AM in Australian social housing is very limited.

- AM in the public housing sector in Australia is 'inconsistently understood and diversely applied' across jurisdictions (Kenley, Chiazor et al. 2010).

- Little is known of AM in the community housing sector.

- Australia has no common AM framework.

- Terminology, standards and measures and tools vary considerably.

\footnotetext{
Interest in AM within SHOs is relatively new. It emerged in the early 1980s as AM emerged across the private and public sectors generally, as SHOs confronted a large maintenance backlog and renewal challenges that developed as housing built during the post-WWII boom period required major upgrading works, and as the European context for social housing provision changed.

This section is divided into two subsections. The first explores the emergence and context of social housing AM in Europe, the UK, the USA and Canada. The second explores the literature on social housing AM in Australia in public housing, community housing and Indigenous housing. This section seeks to develop an understanding of the origins and history of social housing AM and to draw on the experience of organisations with AM, including their processes, frameworks, methods, tools and standards.
} 


\subsection{Emergence of social housing asset management as an issue overseas}

In the 1980s and 1990s, as SHOs were facing a large maintenance backlog-with the large number of social housing dwellings acquired in the post-WWII boom period reaching an age where they required major upgrading works and their condition was deteriorating-social housing was undergoing some major changes in Europe. Priemus, Dieleman et al. (1999) summarise these changes:

- the increasing market orientation of property management (see also Gruis and Nieboer 2004b)

- a shift from public responsibility to privatisation, and an increasing independence from public authorities

- a generally decreasing market share for social housing

- increasing concentration of lower-income groups in social housing

- increasing differentiation in housing services.

Gruis and Nieboer (2004b) point to the following examples:

- In the Netherlands, prescriptive government control of landlords' activities was replaced by the principle of retrospective accountability on the basis of generally described performance criteria.

- In Germany, the distinction between commercial and social landlords disappeared with the repeal of the 'public housing interest' law in 1990.

- In Britain, local authorities and housing associations are encouraged to develop AM skills in support of strategic business planning and option appraisal.

- The changes in policy have enlarged the need for sound financial planning, risk management and market orientation in social housing management.

The initial AM issues faced by the SHOs in this new environment were twofold:

- maintenance and upgrade of dwellings

- disposal of dwellings.

In one of the early journal articles about what is now known as asset management, Bowles, Dagpunar et al. (1997) discuss the use of sinking funds as a way of financing building AM in housing associations in the UK. Drawing on experience in the UK, Murie (1999) discusses the acquisition and disposal of housing stock, noting the different contexts within which they occur and that decisions are not simply based on housing needs but on a range of political and ideological considerations. Boelhouwer, van der Heijden et al. (1997: 526) describe 'the increase in the opportunities to sell non-profit rental houses ... as a form of asset management'.

\subsubsection{Europe}

As $\mathrm{SHO}$ began to adopt more market-oriented approaches and AM became a feature of private organisations, government agencies and government departments, SHOs began to adopt their AM frameworks. In the early 2000s, AM as a focus of social housing practice received a major boost when a European Network of Housing Researchers Working Group on Housing Management began an international comparative research project. It sought to describe and compare the social housing AM practices in Europe and Australia, focussing particularly on the strategic aspects of AM — strategies, objects, means, methods, instruments and criteria - within their political, institutional and economic context (Gruis, Nieboer et al. 2003). Gruis and Nieboer (2004a) present the results of this project for eight European countries-Austria, Belgium (Flanders), Denmark, England, France, Germany, Latvia and the Netherlands - as well as Australia. 
Gruis and Nieboer advocated strategic AM, which views housing stock as dynamically changing and thus requiring a systematic, comprehensive and proactive approach to its management (Gruis and Nieboer 2004a; 2004b; 2004c; Gruis, Nieboer et al. 2003; Gruis, Nieboer et al. 2004) Gruis and Nieboer put forward a model of AM based on a private-sector strategic business planning process. Referring to commercial real estate management (Miles, Haney et al. 1996), they distinguish between three levels of management:

- property management

- asset management

- portfolio management.

Gruis and Nieboer (2004b) argue that strategic AM also includes aspects of portfolio management, such as working out the mix of housing types and guidelines for acquisition and disposal (see also Nieboer 2007). Distinguishing between property management (day-to-day operational management) and strategic AM, they identify five stages in developing a strategic AMP:

- determining the mission

- analysis (internal and external)

- formulating goals

- formulating strategy

- strategy appraisal.

This private-sector process has limitations. Nevertheless, with qualifications, it has some potential benefits:

- increased effectiveness in meeting tenants' needs

- increased market efficiency

- prevention of the stigmatisation and spatial segregation of social housing tenants (Gruis and Nieboer 2007; Gruis, Nieboer et al. 2004).

Gruis and Nieboer also proposed that SHOs in different countries approach strategic AM differently, depending upon the context within social housing operates: legislation, policies, regulations, financial support, other institutional arrangements, its historical development and the local housing market (Gruis and Nieboer 2007; Gruis, Nieboer et al. 2003).

Early discussion of AM set out ways in which SHOs could develop strategic AMPs. However, there was a gap between what was proposed and what was actually done, and it took some time for SHOs to learn from the implementation of these proposed processes and how the unique aspects of social housing impacted on their plans. Whereas housing is a capital-intensive asset fixed in a particular location; social housing operates in a complex environment with many interested players (van Overmeeren and Gruis 2011).

Traditional approaches to AM focus on the technical aspects of the dwellings and how dwellings can be improved through maintenance and upgrading. In the mid-2000s, the weaknesses of this rational-analytic model of AM began to be recognised and some Dutch housing associations began to focus more on area-based AM, the liveability of local areas and the creation of value at the neighbourhood level by not only improving their housing stock but also through urban regeneration, local safety measures, and building other social infrastructure such as schools and care centres (van Overmeeren and Gruis 2011).

In a study of 12 housing associations in the Netherlands, Saridayi (2019: 9) concludes that 'asset management is still in its infancy'. Recognising the importance of both social returns and financial efficiency as indicators of the performance of assets, Saridayi (2019: 7) set out 'to develop a model that can be used by housing associations for the measurement of financial efficiency and social return of their assets in an integrated manner in order to stimulate uniformity regarding AM in the social rented sector and therewith increase the learning capacity within the sector'. Saridayi recommends a set of nine AM indicators in these two categories - financial efficiency and social return - with three subcategories within social return, as outlined in Table 2. 
Table 2: Indicators of asset management performance

\begin{tabular}{llll}
\hline Financial efficiency & Social return & \\
\hline Return & Contribution to portfolio strategy & Quality and sustainability & Customer value \\
\hline Direct return & Rent price category & Energy performance & Customer satisfaction score \\
The gross-net ratio & Type of real estate & Technical condition NEN 2767 & Liveability score \\
Internal rate of return (IRR) & Location & Application rate \\
& Floor space & Acceptance rate \\
& Actual rent/desired rent & \\
\end{tabular}

Source: Saridayi (2019: 10), Table 0.1.

\subsubsection{United Kingdom}

In the 1980s, the United Kingdom saw the:

- sale of public housing to tenants under the Right to Buy program

- transfer of housing stock from local councils to housing associations

- reduction in financial support from central government.

Pawson (2006: 769) suggests that 'in the failure to develop an asset management culture, the seeds of council housing's demise were already taking root well before 1970'. With the transfer of stock and decreasing financial support, local councils and housing associations had to focus on their assets. Larkin (2000) undertook one of the earliest reviews of AM strategies in England and Australia.

One of the key stimuli for a renewed focus on AM was the Labour government's Housing Green Paper, Quality and choice: a decent home for all (UK Department of Environment, Transport and Regions [DETR] 2000). One policy outcome of this paper was a mandatory 10-year Decent Homes Standard (DHS) for social housing (Morrison 2013). Along with a specific rent framework, this requirement placed great strains on housing associations. It promoted the development of strategic AMPs, which led to the sale of existing housing stock to fund repairs and upgrades of other stock, among other unintended consequences. However, by 2012, housing associations were no longer required to comply with the DHS. 'Yet despite this, the principle as well as processes have been set in motion with regard to HAs continually monitoring and maintaining their stock to a decent condition thereafter' (Morrison 2013: 2584; also see UK House of Commons 2010).

Yet, even as late as the most recent decade, Styles (2013) and Irwin and Medley (2015) found a lack of structured guidelines for AM practice in the UK. A key change in the operating context of Registered Social Landlords (RSLs) came in 2013 when the social housing regulator Homes and Communities Agency required them to demonstrate value for money. These were among the reasons that the Chartered Institute of Housing launched its 'Working together to redefine asset management' project. This project is seeking to extend the horizon of AM planning beyond traditional stock condition and regulatory-driven approaches by working towards planning future strategies (Irwin and Medley 2015).

However, in Scotland, the Scottish Housing Regulator (2012: 4) published a practice guide to assist RSLs in the development of their strategic AMPs. It proposes that 'good asset management is a creative process'. So, rather than outlining a prescriptive way of developing strategic AMPs for all RSLs, it recommends that they develop their own definition-one that suits their specific context, their organisational objective and focusses on their specific issues. It then goes on to outline 10 strands of any strategic AMP:

1. a whole organisation approach

2. understanding their customers

3. risk-based and proportionate 

4. based on good information
5. joined-up planning
6. looking after core stock
7. compliance with standards
8. dealing with 'cause for concern' stock
9. new development
10. value for money.

Currently this practice guide is under review (Scottish Housing Regulator 2020).

\subsubsection{USA}

AM as a formal practice first began to emerge in the USA in the 1990s as federal capital grants and operating subsidies decreased and, along with a decrease in federal regulations, encouraged public housing authorities to rethink the ways they provided housing to low-income households (US Department of Housing and Urban Development [US HUD ] 1996). In a 1996 study, US HUD sought to understand how public housing would fare in a competitive private housing market by examining the operations of a Baltimore housing authority. It proposed that six elements should be considered in a comprehensive analysis and future planning of a housing authority's portfolio (US HUD 1996):

1. a property profile

2. comparable rents

3. operation costs

4. a market dynamics analysis

5. a property needs assessment

6. knowledge and application of real estate business benchmarks.

The 1998 Quality Housing and Work Responsibility Act (QHWRA) required public housing authorities to bring their stock up to specified standards and mandated that each authority managed their dwellings as real estate assets and present to US HUD five-year and annual plans which included an AMP: 'A statement of how the agency will carry out its asset management functions with respect to the public housing inventory of the agency, including how the agency will plan for the long-term operating, capital investment, rehabilitation, modernization, disposition, and other needs for such inventory' (USA Government 1998: QHWRA Section 511 (d) (17)).

'Implementing QHWRA's mandates for AM, site-based maintenance and site-based waiting lists forced SHAs - many for the first time - to consider their long-term operations in light of data on each of their units and how it would fair in the market for affordable housing' (Kleit and Page 2015: 629). The QHWRA created tension within SHAs between their mission of providing low-income housing and having to operate on market principles and make a profit. While SHAs were willing to adopt the new framework, its implementation by US HUD underpinned by the Harvard Cost Study created ongoing issues for public housing (Public Housing Authorities Directors Association [PHADA] 2002; 2006).

In a policy brief, Bavan and Shamsuddin (2007: 185-186) viewed AM as a way of improving 'public housing as a whole by holding SHAs accountable for the success of each separate property they own. Asset management is also meant to facilitate future private investment in public housing.' They also noted that 'asset management poses excessive administrative burdens, results in funding imbalances, and requires major operational changes' (2007: 186). Rather than process driven by state housing authorities, AM has been driven by US HUD. 


\subsubsection{Canada}

In 2009, the Asset Management Centre (AMC) produced The Asset Management Resource Kit for SHOs in Ontario. Figure 8 outlines the framework adopted in this kit. At its centre are the typical stages in the life cycle of an asset, with capital-replacement decisions supported by capital planning and maintenance decisions supported by operational planning. Each of these two supporting functions is divided into two parts: work tools and financial tools. In this way, the framework links different organisational functions. Within this framework, it also distinguishes between (AMC 2009):

- demand maintenance that responds to tenant requests

- planned maintenance based on a schedule of activities to maintain building components

- preventative maintenance intended to be proactive in preventing system failures

- capital replacement whereby major building components are replaced at the end of their useful life

- asset regeneration whereby properties are revitalised, repurposed or redeveloped.

Figure 8: Typical stages in the life cycle of an asset: Canada

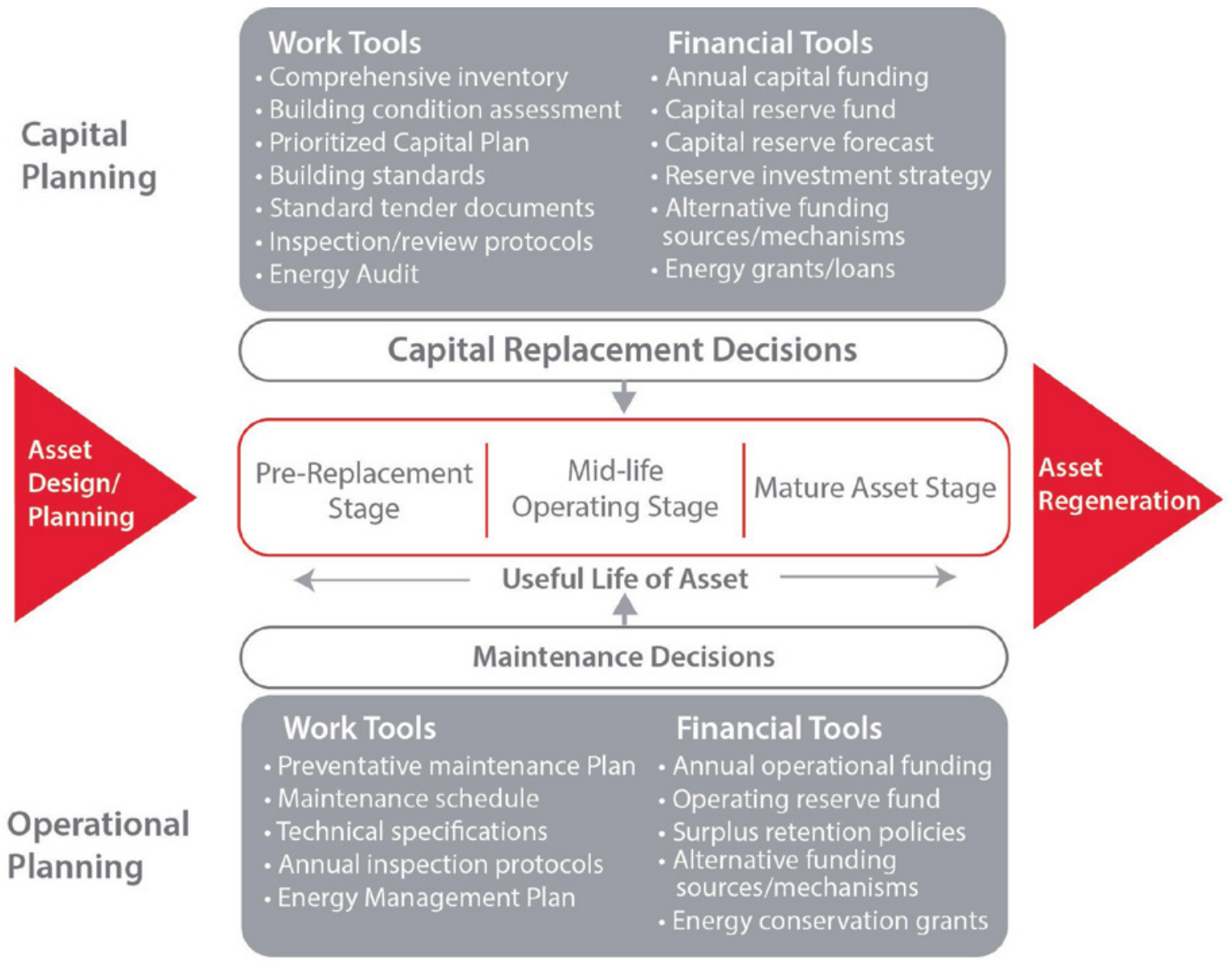

Source: AMC (2009: 9). 


\subsection{Summary}

The contexts within which social housing AM emerged in the 1980s and 1990s in Europe, the UK, the USA and Canada were very different. Thus, the parameters within which AM emerged and the issues each sought to address differed. In Europe and the UK, the social housing sector as a proportion of all dwellings is far larger than in the USA and Canada.

The form of SHOs also varied: government agencies were predominant in the USA and Canada; independent organisations, particularly cooperatives, were more prominent in some European countries; in the UK, the organisational form was transitioning from predominantly government agencies to independent organisations.

Each had a different social housing finance system with different rent-setting practices and varying types of government subsidies supporting the provision of housing. SHOs in Britain, the USA and Canada were heavily regulated, and it is notable that their AM is centrally driven by the regulator. In contrast, AM in less-regulated European countries tended to be driven internally as SHOs sought to deal with ageing stock and a marketoriented environment.

\subsection{Australian social housing asset management}

The literature on AM in Australian social housing is very limited. Apart from the AHURI study by Kenley, Chiazor et al. (2009; 2010), the only other material we have found is: some work undertaken by CSIRO in the 1990s on public housing maintenance, life-cycle costing of housing assets and a housing stock condition index (Tucker, Bromilow et al. c. 1989; Tucker, McFallan et al. 1996; Tucker and Rahilly 1990; 1991); a book chapter by Flood (2004); and an article on the Queensland Property Standards Index tool, a tool that builds on the work of the CSIRO (Johnston, McFallan et al. 2002). Even strategic AMPs of SHOs are not readily available publicly; very few organisations have their plan on their website.

AM approaches in Australian social housing vary according to the form of social housing. They range from the most sophisticated strategies and technologies of the large state and territory organisations through to the minimal approaches of the small CHPs.

According to Flood (2004: 30), SHAs have increased their level of sophistication in AM. All states have AM mechanisms, 'which may include business planning, options appraisal systems, stock condition assessment (CA), asset registers, online property management systems, planned maintenance schedules, and risk assessment'. Flood provides little comment on community housing AM, except acknowledging that community housing stock may have a younger age profile than state housing.

\subsubsection{Public housing}

Over recent decades, concerns have been raised in many quarters about the condition and maintenance of public housing dwellings, as well as the lack of or adequacy of AM strategies (AGDSA 2017; Auditor-General of Tasmania [AGT] 2005; Auditor-General Victoria [AGV] 2004; Auditor-General for Western Australia [AGWA] 2003; Audit Office of NSW [AONSW] 2013; Industry Commission 1993; Northern Territory Government 2016; NSW Parliament 2014; Supreme Court of Victoria 1999; Tasmanian Audit Office 2016; VAGO 2017).

AM as a practice is not new to SHOs. In the 1950s, 1960 s and 1970s, the focus of public housing organisations was very much on the construction of new dwellings and later on the purchase of dwellings. In the 1980s, as stock aged, the focus shifted towards the modernisation and upgrade of housing stock. It was only in the 1980s and 1990s, as governments more generally began to focus on the management of public assets (see Kenley, Chiazor et al. 2009), that SHOs began to develop AMPs that covered a range of aspects of the acquisition, maintenance and upgrade of housing stock. The 1993 report on public housing by the Industry Commission recommended the separation of tenancy management and AM as a way for public housing organisations to give more focus on AM (Industry Commission 1993, in particular Appendix H). 
In the 1990s Australian governments, following an international trend, began to focus on AM (Shah, Tan et al. 2004). In 1996, the Australian National Audit Office (ANAO) released its Asset Management Handbook (ANAO 1996). In the same year, the Australian Procurement and Construction Council (APCC), consisting of key government authorities, released their initial guide to Total Asset Management (APCC 2001) with regular updates since then (APCC 2020). As jurisdictions developed their AM policies and guides, public housing organisations began operating within the general context of their jurisdiction's AM strategy frameworks and became expected to meet the requirements of these frameworks (e.g. Victorian Department of Treasury and Finance [DTF] 2016; NSW Treasury 2019; Queensland Department of Housing and Public Works [QDHPW] 2017; WA Treasury 2020).

In a report for AHURI in 2001 in the lead-up to the 2003 Commonwealth-State Housing Agreement (CSHA), Owen Donald notes that with tighter targeting of public housing and the consequent reduction in rent revenue, SHAs had little funds for the reconfiguration and refurbishment of their stock; that in many instances even maintenance had been neglected (Donald 2001). The state of public housing has become even more pressing over the past 20 years as public housing organisations face the challenge of reduced capital funding coupled with the urgency of dealing with ageing stock. Hall and Berry (2004) noted that in the 1990s, SHAs actively developed AM strategies. As a result, they increased expenditure on maintenance and upgrading of stock, gradually selling off stock and reconfiguring their portfolios. The sale of stock allowed them to bridge, in the short-term, the gap between capital funding and the demands for maintenance and upgrading of their stock.

While the literature on current AM practice in Australian social housing is scarce, with a few notable exceptions, the AHURI report by Kenley, Chiazor et al. (2010) is the most significant review of Australia's public housing AM and provides an initial, though now dated, overview.

According to Kenley, Chiazor et al. (2010: 61), AM practices in public housing organisations 'range from elementary financial management of the assets through to strategic management and practices adopted from corporate real estate management'.

The key findings of Kenley, Chiazor et al. (2010) in relation to AM practices include the following:

- Public housing organisations use different standards to manage existing properties due to differences in geography and climate as well as use of dwellings.

- AM is 'inconsistently understood and diversely applied' (2010: 17, 95) across jurisdictions in Australia.

- Knowledge of AM terminology and practices is inconsistent and generally poor.

- AM strategies tend to be focussed on the operation of assets rather than on the role of assets in achieving the objectives of the organisation-asset managers lack a business perspective.

- Organisations have 'variable guidance and priorities in determining the application and use of software' for managing data and data collection on dwellings.

- Two polarising approaches to AM need to be bridged to build a viable AM policy and environment:

- a governance or 'bricks and mortar' approach that seeks to preserve the financial value of social housing assets and where service delivery means the maximum utilisation of dwellings

- a social policy or housing approach whose focus is on service delivery - the value of social housing assets is in their capacity to deliver services.

Kenley, Chiazor et al. (2010: 86) conclude that social housing 'would benefit from a new approach to social housing asset management with consistency in approach across all jurisdictions, and with a well-defined knowledge base' accommodating both approaches to AM. This new approach would need to identify and propagate best practices across the social housing sector and promote better education and training. 


\subsubsection{Community housing}

The literature on AM in community housing and Indigenous housing is even scarcer than that for public housing.

CHPs are in an expansionary phase and are predominantly focussed on growing their organisations through the acquisition of stock. Acquisitions are primarily in the form of transfers of public housing stock and development of stock. As they grow and their stock ages, CHPs will face more complex asset decisions-such as when to undertake upgrades, replacement and disposal of dwellings - and so their AM capabilities will also need to develop and become more sophisticated. However, as noted in Section 1.3.1, CHPs vary in size and responsibility, with various levels of responsibilities for AM.

Some CHPs have been actively developing their AM capabilities. For example, the Community Housing Industry Association NSW (CHIA NSW) operates an Asset Managers Network, which brings together a number of community housing asset managers in NSW to discuss best practice, sustainability and long-term planning (CHIA NSW 2020). Q Shelter provides a similar function in Queensland and PowerHousing Australia operates a similar national network.

Unlike SHAs, CHPs and IHOs are subject to a regulatory system that requires them to meet a broad range of performance outcomes. The NRSCH specifies a performance outcome for assets and the performance requirements, performance indicators, thresholds, evidence required to demonstrate capacity (depending upon tier) and evidence required to demonstrate compliance (depending upon tier) for each performance requirement (see Table A4 in Appendix 6). This performance outcome applies to both CHPs and IHOs.

NRSCH performance outcomes and requirements are succinct and provide little in the way of how they can be achieved. However, an alternative, the National Community Housing Standards (NCHS) manual, which is currently being revised (Community Housing Industry Association [CHIA] 2020), not only specifies five standards for AM but also outlines good practice, and has further explanation and examples to assist CHPs achieve these standards (CHIA 2020; JPX Consulting Pty Ltd 2010). Table A5 outlines the five NCHS AM standards, along with good practice for achieving them. Fuller explanations and examples are included in the NCHS manual. The Housing Registrar in Victoria also provides a good practice guide to AM (Housing Registrar Victoria 2016).

\subsubsection{Indigenous housing}

As already discussed, AM performance outcomes for IHOs are generally covered by the NRSCH. The condition of much Indigenous social housing is poorer than non-Indigenous social housing. See, for example, Hall, Memmott et al. (2020) for a recent case study of the relationship between Indigenous housing conditions and health outcomes.

However, there are some particular aspects of AM in IHOs that need to be noted.

Habibis, Phillips et al. (2016: 107-108) note that IHOs operating in remote parts of Australia face some unique AM challenges, including:

- the lack of skilled tradespeople

- the high cost of transporting tradespeople, building materials and equipment

- harsh climates with extremes of hot and cold, dry and wet

- particular geological or hydrological conditions that put significant stress on dwellings

- the higher number of people living in the dwellings. 
Long, Memmott et al. (2007: 340) in their review of Indigenous housing research also noted the ongoing issue of AM, in particular the importance of house design, particularly among remote Indigenous peoples. They quote Parnell and Seemann on the link between the life of a dwelling and social factor:

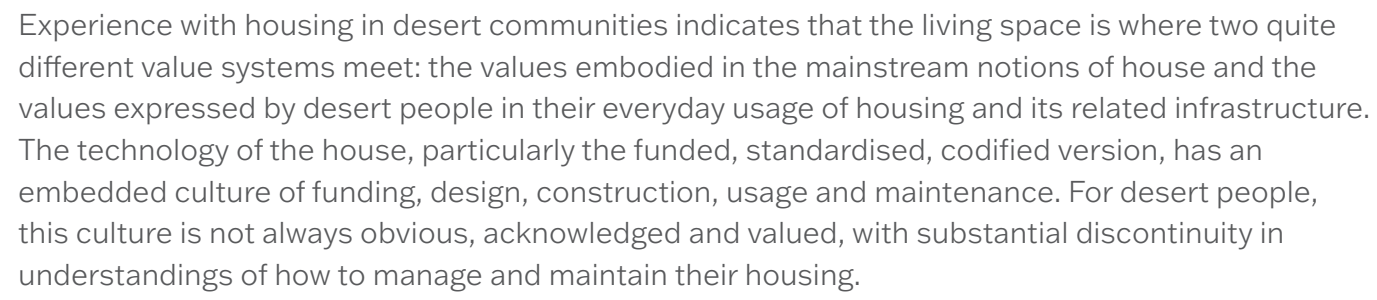

Seemann, Parnell et al. (2008: 1) recommend a 'Housing for Livelihoods' approach for desert settlements, in which life-cycle housing provision is premised on 'investment reach into the local fabric of settlement livelihoods'. They identified a range of issues affecting AM, including:

- engagement of end users to inform desert housing standards

- personalisation of dwelling technology

- insufficient synchronisation between housing production choices and subsequent housing maintenance requirements

- failure of K-9 school curriculum to provide adequate understanding of physical technologies.

The design of Indigenous housing and its links to culture and country is a particular theme of Indigenous research -one that is critical to AM (Chan, Fowler et al. 2010; Memmott 2007; Memmott and Chambers 2003; Memmott, Birdsall-Jones et al. 2012; Pholeros and Phibbs 2012). For example, Pholeros and Phibbs (2012: 1) recommend that what succeeds is: 'Designing and constructing housing based on the established standards and accumulated knowledge in the National Indigenous Housing Guide (FaHCSIA 2008). This includes a process of consultation with the local community and designing housing that meets the social and cultural needs of occupants.'

A recent review by the Nous Group (2017) found remote Indigenous housing provision involves both high costs and a significant shortfall in rental revenue. Emergency maintenance is extremely costly, reflecting the call-out costs of tradespersons and lack of competition.

Improving the AM capacity and skills of IHOs has been a long-held goal of housing ministers (Northern Territory Government 2004). The Australian Government's Indigenous Housing Management Improvement System also aimed to improve housing outcomes for Indigenous people and continuous improvement in the delivery of housing services (Eringa, Spring et al. 2008).

Over recent years, the larger IHOs such as the AHO (NSW) and the AHV have had a particular focus on developing strategic AMPs. Recently the NSW Aboriginal Land Council established a new entity, NSWALC Housing Ltd, which has the objective of becoming a Tier 1 provider in NSW.

\subsection{Concluding comments}

This review of the emergence of AM highlights a number of issues for the development of AM in Australia.

First, AM within governments and SHOs is a fairly recent practice, and one the organisations are still developing.

Second, AM is variously driven by the external demands of regulators and by the internal demands of organisations. The development of AM throughout Europe has a complex history intertwined with the changing context of social housing. In Europe, the reduction in control over the SHOs and the consequent internal demands on improving financial and social returns on social housing has driven the development of AM. In contrast, in the UK, government 
regulation has largely driven the development of AM. Similarly, in the USA, US HUD has driven the development of AM through the requirement for AMPs. However, in Canada, AM in the community sector has been driven internally by publication of a resource kit and framework, by education and training and by examples of good practice. This has also been the approach of the Scottish Housing Regulator, the Victorian Housing Regulator and CHIA as they develop and revise guidelines for social housing AM.

Third, the framework for AM has shifted focus over time from the technical elements of dwellings and financial performance to aligning assets with the mission of an organisation and its clients, within the broader context of its impact on local areas. What has been retained in this shift is a businesslike approach to AM.

Fourth, it seems that AM practices in Australia have not improved substantially since the previous AHURI report (Kenley, Chiazor et al. 2010), on public housing AM.

Finally, the unique characteristics of social housing, in particular Indigenous housing, have yet to be recognised and incorporated into viable and sustainable strategic AMPs. 


\section{Social housing asset management planning practices and issues}

- AM practices of SHOs vary considerably and this is complicated by management contracts and stock transfer agreements.

- Many SHOs do not have adequate AMPs. Of those that do, many have large gaps.

- Mandated levels of service are generally minimal, providing scope for cost-cutting.

- Tenant and asset protection varies according to whether the tenant is in the public or community sector (and then the size of the provider), the state, who holds the title, management rights and how the dwelling is funded.

- Standards and measures, as well as terminology for AM, are not consistent and uniformity would allow benchmarking and drive continuous improvement.

- Human and technological capacity building, including skills development, training and education, is required so that SHOs can develop and implement strategic AMPs.

- Regulation and, increasingly, capital finance sourced from the private sector, have driven improved asset management among larger CHPs.

- A common asset management framework would facilitate benchmarking of SHOs and promote performance improvement.

- A national uniform approach to regulation, terminology, standards and measures is broadly supported. 


\subsection{Introduction}

The role of AM planning is to ensure that SHOs make sensible and reasonable decisions about their housing stock, so that it meets the needs and standards now and in the future in the most efficient way. Planning includes a range of activities that positions $\mathrm{SHOs}$ to make these decisions.

As discussed in Section 4.2, investigation of social housing AM is relatively recent, reflecting shifts in social policy and the general problem of ageing public infrastructure. In Australia, public housing AM was investigated by Kenley, Chiazor et al. (2010), providing some insight into AM but leaving much to be explored. At the time, the community housing sector was very small and Kenley was not able to make any findings. Indigenous housing was included as a part of public housing. The community sector has grown considerably since then and IHOs have continued to evolve as a distinct sector. However, these sectors are not discrete, which has many ramifications for AM.

This chapter and the next four chapters present key findings from the empirical research regarding the AM practices of SHOs in Australia, with a key focus on key drivers and outcomes. They outline some of the issues for policymaking and regulation. A caveat is necessary, as the findings are based on self-reporting and an individual's understanding of what is occurring and why. Often, particularly in large organisations, the functions relating to AM are divided into different organisational divisions-for example, tenancy teams and AM teams. This meant that participants did not necessarily have a full view of what their organisation was doing in regard to AM. On the other hand, many participants have occupied many roles across social housing, moving between public, community, Indigenous housing, peak bodies and consultancies. This provided the opportunity for reflection on each sector as a whole in addition to insights about specific organisations.

The role of AM is to maintain and extend the life of an asset, and eventually to replace the asset if service need continues and provides a framework for strategic and operational decision-making. A SAMP guides management of assets across the life cycle. An AMP is the operational guide for maintaining and extending the life of the assets. Embedded within the AMP are the levels of service (LOS), being the standard of service the asset aims to deliver. The LOS reflect legal minimum standards as a starting point. Robust data and data analysis enable ODM to identify the optimal outcomes should circumstances change.

This chapter and the next four chapters will answer the research question: 'What are the current AM practices of SHOs in Australia?' We will do this by providing an overview, rather than cataloguing practices. What is important are the drivers of good or bad practices and the challenges for delivering an BPAM.

This chapter discusses practices and issues related to asset planning. The next four chapter also discuss practices and issues, with a particular focus:

- Chapter 6: asset creation

- Chapter 7: asset management

- Chapter 8: asset disposal

- Chapter 9: financing asset management.

\subsection{Asset management frameworks}

Regulation of community housing varies from state to state. This lack of uniformity adds costs to community housing provision. The lack of uniformity is further compounded by management contracts between SHAs and CHPs and by stock transfer agreements. SHAs and CHPs have developed their own AM frameworks, standards and measures in response to specific jurisdictional regulation and contractual arrangements, leading to a multitude of approaches. This is particularly challenging for CHPs who operate in multiple states. 
ISO 55000 provides a common framework. Many SHOs have adopted this framework or are working towards it, although others described it as a starting point and argue that NAMS is a better option (15). Victorian Housing Associations, by virtue of compliance with regulatory guidance, have adopted frameworks reflecting BPAM. However, it is likely that many CHPs are not so guided. One of the SHA participants was working on a framework, which suggests that SHAs, despite their size, may vary in the extent to which their AM is driven by an overarching framework. Despite this, it was clear that SHA participants were well aware of the principles.

NAMS (2014) provides a property-specific AM roadmap. It is a guide to world's best practice and as one participant (3) said, there is no need to reinvent the wheel. A framework provides consistency while providing the opportunity for SHOs to determine the detail. An AM framework such as NAMS is sufficiently high-level to incorporate the differences in regulation and contractual obligations.

\subsection{Asset management plans}

The largest SHOs practice good AM, with some at the level of BPAM. Many of the smallest SHOs practice negligible AM. It is common In both large and small organisations for there to be gaps in their AM. There are very small organisations managing very well, reflecting the skills of the CEO, but governance is weak. Commonly, some large organisations still have gaps relating to software systems and data. SHAs are often addressing issues arising from organisational restructuring. The key here is that AM practices largely reflect organisational size. Understanding how size matters for AM has important policy implications.

The regulatory requirement to lodge an AMP was regarded as a tick-box exercise (26b). However, this was not limited to the smaller SHOs, with Tier 1 CHPs also implicated.

Some participants said CHPs either did not have an AMP or ignored their AMP (Participants 2, 4).

But it was quite an uphill battle ever to get anybody to actually read the plan and make use of it. And I call it the third-drawer plans; you know, we need a plan, write the plan then put it in the third drawer. (4)

Having lived a life of asset management in [country], I found it quite different because there is no formal regulation from either the funder or the state or the federal government about what is required of a Community Housing Provider ... And then there's no regulation about whether the organisation has a long-term financial management plan and understands its maintenance liabilities moving forward. (Workshop 24)

Tier 1 providers had similar concerns.

The Community Housing Register requires these plans, so they were submitted and ticked off and we were compliant in having the plans. And I have to say the only reason that I was retained was really to meet the obligation of updating the plan annually to get the tick off from the registrar the next year. (4)

... becoming an association, the key component ... is asset management ... Where I think things get a little bit wobbly is people get to tick the association status and then there's no more ... So, your asset strategy, your asset plan, kind of sits in the background a little bit. And it becomes a nice tick-box exercise and requires a bit of refreshing and going back to and reminding. (12)

However, one participant (3), drew attention to a misunderstanding about AMPs, citing the focus on maintenance plans.

[A] maintenance plan [is] ... not an asset management plan. That's a focus on what do you need to do to maintain. It's not talking about levels of service policies and standards - shortfalls and different options to address those. (3) 


\subsection{Terminology, standards and measures for asset management}

SHOs are using a diversity of frameworks, data-collection systems, software programs, assessment/appraisal systems, performance benchmarks, decision-making systems and other tools.

Technological differences may not be an issue in themselves. However, differences in terminology, in the data collected, the basis on which decisions are made and in performance benchmarks make it very difficult for:

- learning new practices

- improving good practice systematically

- developing best practice

- making comparisons between organisations.

\subsubsection{Terminology}

Kenley, Chiazor et al. (2010) found that varying interpretation of AM terms among SHAs was a major issue. Both Kenley, Chiazor et al. (2010) and Proctor (2014) note that participants in a meeting can use the same terminology and agree on courses of action but understand things differently - and so their practices vary considerably. Proctor (2014: 34) gives the following examples of terminology that commonly differs:

- What is meant by maintenance backlog, what does it include and how is it calculated?

- What do the terms responsive repairs, planned maintenance, upgrading, and vacant maintenance actually include?

The inconsistent use of terminology and varying definitions were a concern raised by CHPs and consultants, reinforcing the need for a common framework. The issue affects all facets of AM practice.

... I would like clarity and almost a unification of language when it comes to asset management. So, there are asset management standards. Well, I mean there are many-are we talking about asset management standards? Are we talking about maintenance standards? Are we talking about reletting standards? Are we talking about procurement standards? And by all means we don't have all of these. (6)

You look at the fixed assets within the property and again terminology is not consistent. So if the research does anything, then a consistent terminology about what is an asset is it. Is it a property? Is it a room? Is it a tenancy? We tend to look at the property being an asset and then within that asset there are fixed assets like the air conditioner and everything else that is the property we look at that and what it needs in terms of expenditure for planned maintenance and for life-cycle costing. (Workshop 24)

I think the definitions of data and the different systems within some organisations, they're different people with different vested interests often, including contractors, tenancy management and property staff, they've all got their jobs. This is why they need to understand where their cog fits into that bigger wheel, and why they need to understand the data that another team is inputting in, and how that impacts on the data they're putting in, and how they can merge them about or talk to each other. I think some of the siloing can get in the way. (9)

This comment from Interview 9 may stem from their experience in a large organisation where specialisation of task and different vested interests create the environment for manipulation of process and definition. An example may be a contractor expanding the scope of works while out on the job, or a tenancy manager responding to a demanding tenant by making repair work appear more urgent than it is.

Participants indicated that the differences between a property inspection (which is carried out by tenancy worker) and asset inspection (which is a CA) (2) are often confusing. 


\subsubsection{Standards and measures}

Many CHPs are required to conform to multiple sets of standards. If they own stock, they will have the standards and measures of their choosing, which will enable them to meet the performance standards required by their Housing Registrar. If they also have a management contract, this will reflect the SHA's system. A CHP who operates in multiple states will contend with multiple standards. Off-the-shelf AM software systems must be adapted to accommodate such variations. Key implication standards are the inability to compare performance and the lack of efficiencies.

Standards are the ideal performance level assets are required to meet, and measures are used to identify the current state of assets in relation to the standards set. Multiple standards will be set-for example, for new build, maintenance and amenity standards. Some standards will reflect regulation, but others will be of the SHO's own devising.

One of our first questions is how do you define your standard for the houses? And the result is usually, 'We don't know' ... But there's no point writing a standard that can't be measured ... I've seen over the years many plans written with a levels of service section that have very high-level policies or levels of service statements that can only be measured by judgement as opposed to objectively and with real data. (Interview 3)

A key issue once a standard is set is ensuring it is interpreted in a consistent way $(4,11)$.

Many participants identified the differences in both measures and standards across states and between CHPs and SHAs, and differences in condition-rating systems and scoring as problematic (4). Such differences undermine the effectiveness of due diligence when stock is transferred. When management is transferred, it requires the $\mathrm{CHP}$ to use the SHA system, in addition to the system they already have.

We've had to retrain ... rather than [use] our own tool ... then we've had to buy an app that we've integrated into our system, and we've had to then link it to our ICT platform ... there have been some hiccups along the way ... but then we've had to develop our own sort of more manual kind of spreadsheet tool for the external [building standard]. (Interview 11)

The variety of condition-rating systems in use is particularly perplexing, as an international standard exists. The cost and inefficiency are recognised (8).

Everyone thinks they're too smart for the class, and they always want to invent the new ... So, we're in this bizarre situation of having all these different systems which cost every CHP working across constituencies more money, more time in training people different ways, more time for management to sort out what the different information means. Yeah, so less efficient and it makes it harder to provide the service in the end. (4)

These differences make it very difficult or impossible to benchmark individual organisation performance against broader sector performance. Benchmarking asset performance is a fundamental part of BPAM practice.

The gold standard is that you should be benchmarking, as an organisation, to understand your performance. And that's one of the reasons why we need a common framework. People can choose different routes to get to it ... There needs to be common language somewhere in that, so everyone can understand, so there's transparency sitting there. (Interview 8)

A uniform approach to standards was broadly supported $(2,3,4,6,9,15,32,37)$, although there were concerns that innovation could be stifled $(3,21)$. 
Well, it was 1 to 10, but the scoring included things like age, cost and condition, but then not all of the levels included each factor, so it was very messy. So I think that's one thing for the next round as well to make it a simpler, like good, poor, average, something that everyone understands, rather than is 1 good, or is it bad? And does 1 mean it's over ten thousand or is it a high priority? ... we've had a lot of point-in-time data, it's not live, it's been held in different areas. And the terminology as well, we've got different areas using different names for things and reporting is all over the place, so there's a few issues. (6)

A uniform approach was argued as providing certainty for the industry and ensuring the reputation of SHOs and providing assurance to funders (4). Moreover, asset-condition reporting has a direct bearing on the valuation of the assets. Therefore, it is important that third-party providers of services such as property valuers also understand how asset condition is assessed.

Obviously has a financial implication because we say our properties are maintained at a certain standard, the value of that property is this, and that therefore has an impact on the corporate statement. (35)

Tenants, as the customer and focus of AM, would benefit as a result of continuous improvement in relation to maintenance, for example, but also because it drives equity outcomes $(4,9,11)$. Currently, it is a matter of 'potluck' whether or not a tenant is allocated a property in good condition.

Lack of consistent terminology and tools were identified by participants as impeding training and retention of corporate knowledge (7). It was suggested more sophisticated national standards and greater uniformity would give staff:

... a structure to start with and [they can] move around the sector, they don't walk up [to] another $\mathrm{CHP}$ and start completely again with learning. (24b)

Most participants thought standardisation would be almost impossible, given the power of SHAs and the extent to which SHOs have already invested in systems.

\subsection{Levels of service}

A key element of an AMP are the levels of service (LOS). IPWEA (2020a: s 2.2) describes LOS as:

... the outputs a customer can expect to receive from the asset related activity (e.g., safe housing), while performance measures indicate the specific level of performance against those levels of service (e.g. number of safety incidents, response to safety incidents). The level of service framework should demonstrate how strategic organisational objectives translate into AM objectives, level of service objectives and operational objectives with aligned performance measure reported against each level.

LOS statements link the organisation's objectives and policies with asset outcomes, including asset programs of work and budgets. They also represent a set of key performance indicators (KPIs). They consist of objectives, statements, measures, targets and current performance. The statement must include strategic, tactical, operational and implementational objectives. Table 3 is an example of a LOS statement aligned to corporate objectives.

LOS incorporate legislative requirements and regulatory performance standards. Where gaps exist, the LOS will nominate the service and the standard the organisation will meet. Further, beyond mandated standards, SHOs need to consider additional or higher standards, such as universal accessibility or energy ratings in order to meet current or future needs of tenants and assets. The establishment of standards beyond mandated minimums will depend on the organisational mission and the affordability of such measures. Affordability is determined through cost-benefit analysis and scenario modelling. Adjustments to LOS statements, timeframes and program budgets is one way that programs can fit within budget constraints. 
Table 3: Levels of service examples

\begin{tabular}{|c|c|c|c|c|c|c|c|}
\hline $\begin{array}{l}\text { Corporate } \\
\text { business plan } \\
\text { objectives }\end{array}$ & $\begin{array}{l}\text { Asset } \\
\text { management } \\
\text { strategy } \\
\text { statement }\end{array}$ & $\begin{array}{l}\text { Tactical } \\
\text { statement }\end{array}$ & $\begin{array}{l}\text { Operational } \\
\text { statement }\end{array}$ & $\begin{array}{l}\text { Implementation } \\
\text { statement }\end{array}$ & Measures & Target & $\begin{array}{l}\text { Current } \\
\text { performance }\end{array}$ \\
\hline \multirow[t]{3}{*}{$\begin{array}{l}\text { Objective 1: ABC } \\
\text { Corporation } \\
\text { will provide } \\
\text { appropriate } \\
\text { housing for those } \\
\text { in greatest need }\end{array}$} & \multirow[t]{3}{*}{$\begin{array}{l}\text { All tenants will } \\
\text { have access to } \\
\text { healthy, energy- } \\
\text { efficient homes }\end{array}$} & $\begin{array}{l}\text { All dwellings } \\
\text { must be } \\
\text { insulated } \\
\text { within } 2 \text { years }\end{array}$ & $\begin{array}{l}\text { For older dwellings, } \\
\text { retrofitting ceiling } \\
\text { and wall insulation } \\
\text { only. All new } \\
\text { dwellings insulated } \\
\text { to new build } \\
\text { standards }\end{array}$ & $\begin{array}{l}\text { Tenants will be } \\
\text { inconvenienced } \\
\text { during installation. } \\
\text { Minimum 2-week } \\
\text { notice, and } \\
\text { reminder 24-hour } \\
\text { notice to be } \\
\text { provided. }\end{array}$ & $\begin{array}{l}\text { All ceilings in } \\
\text { cool-climate zones } \\
\text { are insulated to R } \\
\text { factor } 5 \text {. Warmer } \\
\text { climates to R2.5. } \\
\text { Walls to R2.5 and } \\
\text { floors to R2 unless } \\
\text { on slab }\end{array}$ & $\begin{array}{l}100 \% \text { of houses } \\
\text { to comply } \\
\text { within } 2 \text { years } \\
\text { (2023) }\end{array}$ & $50 \%$ \\
\hline & & \multirow[t]{2}{*}{$\begin{array}{l}\text { Maximise } \\
\text { renewable } \\
\text { energy } \\
\text { opportunities }\end{array}$} & \multirow[t]{2}{*}{$\begin{array}{l}\text { All homes with roof } \\
\text { aspects suitable } \\
\text { for solar have solar } \\
\text { energy systems }\end{array}$} & \multirow{2}{*}{$\begin{array}{l}\text { Tenants will be } \\
\text { inconvenienced } \\
\text { during installation. } \\
\text { Minimum 2-week } \\
\text { notice, and } \\
\text { reminder 24-hour } \\
\text { notice to be } \\
\text { provided. }\end{array}$} & \multirow[t]{2}{*}{$\begin{array}{l}\text { All solar systems } \\
\text { sized to meet } \\
100 \% \text { of household } \\
\text { demand }\end{array}$} & $\begin{array}{l}80 \% \text { of current } \\
\text { portfolio to } \\
\text { have solar } \\
\text { systems in } \\
5 \text { years }\end{array}$ & $25 \%$ \\
\hline & & & & & & $\begin{array}{l}100 \% \text { of new } \\
\text { homes }\end{array}$ & $10 \%$ \\
\hline
\end{tabular}

Source: Authors.

A key set of LOS for SHOs are property-related LOS. For example, legislation for fire safety and tenancy legislation will inform the 'minimum' standard a SHO applies in relation to property condition. It is clear from the annual report of the Steering Committee for the Review of Government Service Provision that a worrying number of social tenants are in 'substandard' housing.

\section{A dwelling is assessed as meeting minimum acceptable standards if it has at least four working facilities (for washing people, for washing clothes/bedding, for storing/preparing food, and for removing sewerage) and not more than two major structural problems. (SCRGSP 2021: Box 18.7)}

In 2018, just under 20 per cent of all social tenants lived in substandard dwellings, with this rising to 31.5 per cent for Indigenous tenants (SCRGSP 2021: Table 18A.36).

Therefore a key LOS relates to the habitation standard to be included in an AMP.

Making sure the properties are habitable and in good living condition ... that's an important element of asset management. (1)

The habitation standard will define the dwelling and each of its components, and include the minimum performance these should reach. For example, should there be a stovetop? If so, how many hobs? The condition of the dwelling and each nominated component will need to meet a nominated minimum condition rating-for example, condition level 2 if the rating is zero to six (with zero being unacceptable and six being the best). Some of the management contracts between SHAs and CHPs detail the components and condition rating they must achieve.

A standard suggests that if you don't do it there'll be a consequence. (3)

Many participants discussed properties that failed to meet explicit or implied LOS habitation standards. This was a source of considerable anxiety. A SHO may have a LOS that permits poor dwelling condition-for example, the rating may be set low at one out of six. Or the SHO may not have a LOS habitation standard at all, or simply fail to meet the standard.

The housing standard for us we go by, it's got to have running water in the bathrooms, kitchens and laundry so that they can wash themselves and food. They've got to have no sewage issues and no more than two structural issues. As long as the property meets that criteria, it makes the housing standard. It's a low base. (38) 
As noted in Section 3.2, tenancy legislation provides the minimum standards, but many states and territories do not provide for habitation standards. (See Appendix 7 for the current standards in each state, and in NZ.)

I was shocked by ... the South Australian [residential tenancies] standards. They were appalling ...

I ... found out that heating wasn't mandatory. (12)

The Residential Tenancies Act ... requires premises to be habitable ... [but] it doesn't actually state precisely the conditions, so it's ... the ... Tribunal ... says what is habitable. (5)

Tenant satisfaction is a key element of the community housing regulatory system and is intended to protect against poor AM. CHPs demonstrate tenant satisfaction through biannual surveys. One participant (3) argued the surveys are inadequate, as the questions do not elicit the correct information and are thus an inadequate expression of tenancy satisfaction. Participant 3 said a typical question is:

'Are you happy with the responsiveness of our maintenance team?' as opposed to... 'What do you need from this house that will make your life better?' or something like that. (3)

requires tenant consultation in the development of the LOS, but this comment suggests that while community tenants are commonly involved in planning, the effectiveness of such consultation can be challenged. SHAs have consultative mechanisms, but the existence of the public housing maintenance backlog suggests there is likely to be a gap between tenant aspirations and service levels delivered.

The consequence for SHOs of more onerous mandatory habitation standards would be the need to meet the cost of upgrades. The current weak tenancy rights and lack of habitation standards provides SHOs with flexibility.

We've just reduced our maintenance standard ... What we were doing before was scoping way above that, which was costing more money. (9)

Mandatory habitation standards would not need to be substantially improved to drive disposal of public housing stock, given the current maintenance backlog and funding constraints.

Lack of mandatory habitation standards contributes to the serious deficiencies that continue to be a problem for remote Indigenous housing $(9,41)$.

In theory, the setting of LOS dwelling standards would act as a brake on cutting maintenance budgets as a means to address any financial problems an organisation may experience. LOS, as one participant (9) indicates, may be amended. More commonly, as highlighted in Section 7.1, maintenance budgets are changed. This is likely to occur without reference to LOS.

Some CHPs have LOS that seek to satisfy multiple objectives. One participant (10) said they aim to make their dwellings look like private housing, firstly through the architectural design and through the maintenance regime, in order to reduce stigma and promote tenant feelings of personal safety. This has the benefit of creating more stable tenancies and reducing property damage (both of which reduce costs).

Developing LOS is challenging, as little public material can be referenced. So SHOs draw on what they can.

We've been inventing some of our own standards around - we looked at liveability standards and universal design, but again the cost considerations of having platinum or silver and what our budgets are means that we've provided our own maintenance accommodation standards. (6)

However, as Sharam, Byford et al. (2018) identify, voluntary standards for accessibility have resulted in a high level of variation, which undermines the benefits of a having a standard. 
Asset managers also highlighted that little consideration is given to the LOS in the asset planning process.

I've seen over the years many plans written with a levels of service section that [has] very high-level policies, or levels of service statements that can only be measured by judgement, as opposed to objectively and with real data. (3)

I'm not seeing too many AMPs being produced other than maybe through the requirements of the regulatory system ... There's a 10-year maintenance plan that's being produced ... but that's not an asset management plan. That's a focus on what do you need to do to maintain. It's not talking about levels of service policies and standards shortfalls and different options to address those. (3)

An insufficient revenue stream establishes a prima facie argument for concern that habitation standards embedded in LOS are likely to be weak, will be ignored or will be subject to change in the face of financial pressures. The lack of-or negligible-legally enforceable habitation standards means that property condition acts as a financial safety valve for cash-strapped SHOs.

\subsection{Human and technological capacity}

\subsubsection{Specialist skills are required}

AM capacity within SHOs varies from specialised functions broken into different teams within the SHAs to CHPs who have no specific AM personnel but rely on tenancy workers supported sometimes by contractors (24b). The survey suggests that a little under a third of $\mathrm{SHOs}$ (27.5\%) outsource some aspect of their AM. Contractors and consultants are commonly used to provide specialist knowledge, such as for the development of an AMP or to undertake work such as condition assessments. Only SHOs with less than 100 dwellings fully relied on external $\mathrm{AM}$, and this was rare (5\%).

As AM is an important component of development feasibility, consultants might be brought in for preparing tenders (25a). If an organisation has a development pipeline, it may be able to bring such skill sets in-house. Given the cost of consultants, CHPs, such as the one participant 27a worked at, only contracted out very high-value tender work.

It is very common for contractors to be used for condition assessments. Sometimes this is only for specific elements such as an electrical inspection; at other times, for a full inspection of all components. The quality of assessors was sometimes questioned, given the degree of subjectivity involved when training and the inconsistent application of standards. It is also very common for trades work to be contracted out. CHPs often agree to pay tradespeople within seven days to promote quality and consistency of work and maintain respectful relationships with tenants (41). However, SHAs contracting-out too often focusses on cost-cutting over other objectives, which often drives inefficient outcomes (1).

A significant concern revealed by the survey is whether SHOs have AM human-resource capacity to manage assets effectively. Of the respondents who were able to answer the question, 35 per cent indicated they did not have the capacity. This was felt most acutely among larger SHOs (see Figure 9). The workshops and interviews indicated that insufficient staff and funds constrain effective AM. 
Figure 9: Human resources to effectively manage assets

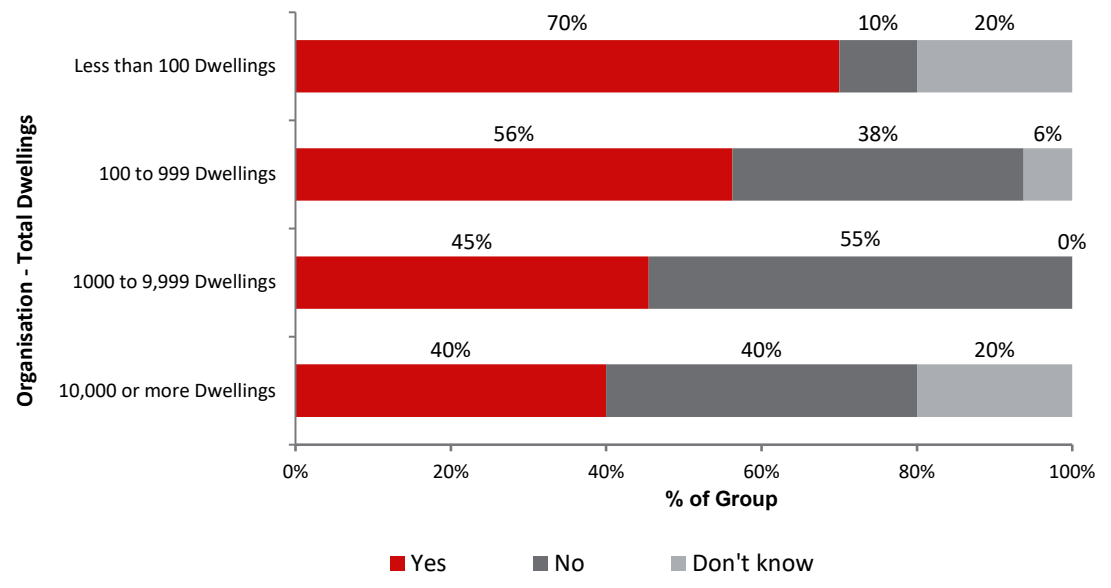

Source: Survey Analysis.

Many CHP asset managers reported being in roles that had significant non-asset management responsibilities, despite AM more than justifying a full-time load (25b, 26b, 29, 31, 32).

$\mathrm{SHO}$ can attract asset managers from the private sector but there is often a values mismatch that makes this problematic. These asset managers often cycle in and out of the sector, reflecting economic conditions (2). Salaries are lower in the community and public housing sectors, but work opportunities are more consistently available and jobs are more secure.

The most common pathway into AM within the social housing sector is via trade occupations. Tradespersons are initially engaged in maintenance, and progress into AM (4). However, this pathway presents problems, as although AM benefits from trades knowledge, it actually requires a different skill set, such as financial forecasting and analysis (2) - skills that tradespersons rarely have (32). The larger the organisation, the more specialisation that can occur. A key distinction in roles within AM is strategic AM versus operational AM. Strategic AM requires analysis and planning, consultation with stakeholders and writing. Someone with responsibility for operations will often be subsumed by reactive needs, and many will lack an aptitude for strategy (3, 4). One participant (7) argued that asset managers - both strategic and operational-need strong advocacy skills in order to convince their organisations that AM is about investment rather than cost. Too often the deficit of AM skills is such that organisations resort to 'cutting and pasting in asset strategy from another organisation' (9).

We don't have the right people, with the right skills, on the right seats. (25b)

Small CHPs are sometimes assisted by larger CHPs in the development of their AMP and integrating this into their corporate processes $(3,41)$.

The survey indicated that professional development training is predominantly in-house and informal (self-learning and on-the-job), as depicted in Figure 10. 
Figure 10: How do staff access professional development?

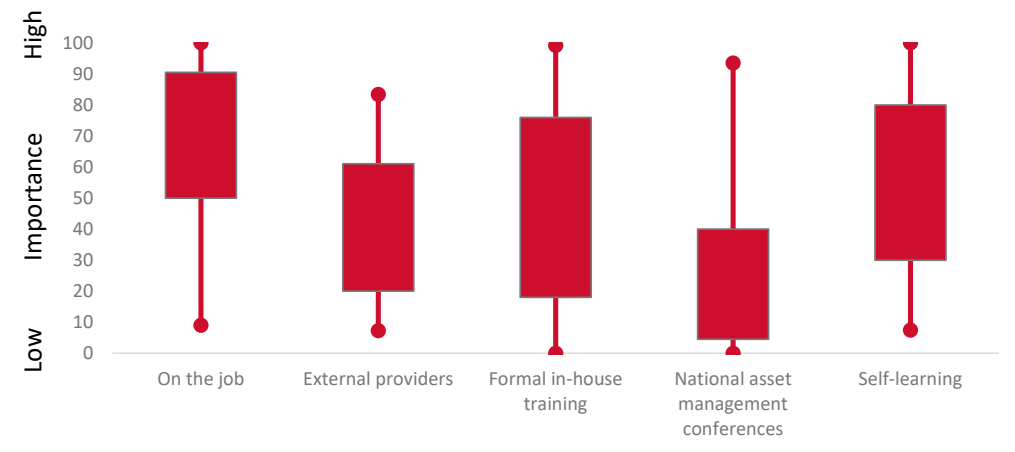

Source: Survey Analysis.

On-the-job training is important for all larger organisations, but particularly for SHAs. SHAs, IHOs and larger organisations uniformly place low importance on external providers of training. Formal in-house training is important for IHOs and of variable importance for CHPs but less so for SHAs. Accessing formal training while on the job can be difficult, as options are limited $(31,37)$. External AM training does not provide enough specificity for SHOs (37).

Few survey respondents indicated that national conferences were a source of professional development, and the need for conferences was highlighted in the workshops. Some peak bodies run communities of practice and many participants mentioned their participation. While generally regarded as important, some participants were critical, suggesting existing communities of practice provide little of worth (27b, 37). In one case, participant (15) suggested they were development-focussed rather than AM-focussed.

The AM skills deficit was cited as being partly responsible for high levels of reactive maintenance rather than planned maintenance (11).

\subsubsection{Governing bodies lack skills}

The skills and knowledge of those sitting on the governing bodies of SHOs is also critically important. Tier $1 \mathrm{CHPs}$ have skills-based boards, with many able to attract highly credentialed private-sector professionals. There was a tendency to conflate development skills and AM with the focus in recent years on attracting people with development expertise viewed-incorrectly-as satisfying the need for AM skills. The lack of skills and knowledge on smaller CHP board members was a concern $(2,3)$. Some CHP managers find board turnover and the impossibility of educating and then retaining members long enough to deliver a long-term vision very challenging (28). A primary concern about smaller CHPs was boards pursuing growth without understanding existing maintenance liabilities, the new liabilities that would be taking on and the need to fund renewal (4b, 29).

\subsubsection{Software}

All AM requires data. Data describes and explains 'exactly what your portfolio looks like. [Without it] you can't build an asset management plan' (31). Data must be collected, stored, verified, analysed and communicated. AM is derived from AM systems and other organisational systems such as finance and tenancy (7, 20). A key functionality of specialist AM is predictive capacity, which permits ODM.

The challenges of data collection and data analysis have driven the development of specialist AM software. One participant (4) described BPAM as 'a game of databases and statistics and ... sophisticated software to track your portfolio'. Data would be continually updated enabling it to be 'live' to provide for ODM. BPAM requires software interoperability with other systems. 
Various specialist AM software systems are used by SHOs. Many SHAs use Northgate Public Services-a major international social housing package (14). Many CHPs use SPM. However, it is still common for CHPs to use spreadsheets. There was little in the way of complaints about specialist AM software as such. The difficulty is the interoperability of AM software with other software packages, with various 'work-arounds' required to deliver the functionality required (7). The largest CHPs are increasingly investing in specialist AM software and interoperability. At least one SHA invested heavily into developing tools compatible with Northgate Public Services-but this is not an option for most CHPs. Currently, no off-the-shelf software package provides a full suite of systems for social housing providers $(13,28)$. Chintaro is tenancy management software that has some AM capability. It was both criticised (27b) and praised (28). Maintenance Manager, which was developed for private rental landlords, is used by some CHPs to manage workflow.

Many CHPs use spreadsheets, including at least one Tier 1 provider in the study. Spreadsheets can be very sophisticated (22, 27a). Some participants argued that spreadsheets are a reasonable choice for small CHPs (24). Others thought specialist software delivers significant benefits, including financial savings that warrant the purchase cost. However, small CHPs have difficulty determining the costs and benefits (3).

Making good use of the data requires investment in human capacities. Skill is needed to use software. The need for data analysts is increasing as portfolios grow in size and complexity.

Without specialist software, knowledge and records may be fragmented and held by individuals_for example, on laptops rather than in a centralised system $(6,30)$.

Some very small CHPs do not keep formal AM records, relying on staff familiarity with properties-although it is highly problematic to do so. Smaller CHPs have less financial and human-resource capacity and are likely to struggle to collect and adequately store data, maintain the currency of data or make good use of the data.

For all SHOs, BPAM goes well beyond the tools and the capacity of those using them.

It's one thing to provide a tool, whether it's a spreadsheet or whether it's an off-the-shelf product, software product. It's another thing to embed it within business process, training and connecting it to KPIs and position descriptions. I think unless those tools, whatever the tools and frameworks are, are driven from the top of the organisation down and those roles and business processes are aligned and it sends it as a continuous enduring business process, it's doomed to failure. (3)

Key issues emerging from the need to manage data and analyse it include the following:

- Smaller CHPs are being left behind.

- Going it alone to purchase or develop software is inefficient and costly.

- Differing software solutions are a barrier to employment mobility.

- A single, common software solution would aid benchmarking and reduce financial and skill barriers for smaller SHOs.

\subsubsection{Data collection}

A key issue is data collection. The best systems include mobile technologies and cloud-based systems-for example, to undertake CAs with data uploaded directly to databases $(4,6,15)$. This ensures data remains as live as possible and collection is cost-effective. Some CHPs (e.g. 27b) are manually updating data, which they know to be inefficient and a source of data error.

Data integrity is a major issue. Problems may occur with the consistency of data-for example, when CAs are undertaken by different staff or contractors (15). Data may be missing or incorrect. It is common for SHOs to be unaware of how many properties they have $(2,25 b)$. Key data such as CAs are sometimes decades out of date (25b). The granular level of detail required for BPAM is very often missing (2). Poor data collection or data integrity is a concern for SHOs and problematic for regulators (20). 
Once data is collected, it must be verified to make it useful for analysis. Increasingly, analysts are being employed in order to interrogate data (26a).

Collection and analysis of data - and I'm speaking about public and community housing here - is only as good as the people that are tasked with collecting first the data; the interpretation of the data that needs to be collected; why it needs to be collected. (9)

However, such roles are still relatively rare and organisations that do develop this capacity often lose the staff and any investment they have made in them. This is part of the dilemma of whether or not to contract-out (2). Contractors were regarded by one participant (2) as inadequately versed in community housing, and that data analysis, as a form of business analysis, should in any event be kept in-house. The participant suggested that CHPs develop a data analysis consortium.

AM is so data heavy that SHOs will end up with 'a massive pile of data' (15) and the challenge is to understand what data is necessary to be effective. Asset managers reiterated that AM is more than quantitative analysis. They argued that each property involves a narrative. It is not simply enough to ask, for example, what may have been spent on a property. The circumstances of the tenant are also a vital piece of the asset story (9). Good AM analysis requires not just what happened, but why it happened.

\subsection{Regulation}

Regulation has many purposes. For the community housing sector, regulation is concerned with building confidence in the system and promoting performance.

\subsubsection{Who is subject to regulation?}

SHAs are not subject to independent oversight.

The elephant in the room ... is the majority of social housing properties are still owned and operated by state government authorities, and they're not subject to the national regulatory code. (11)

CHPs, apart from in Victoria and Western Australia, are subject to a national regulatory regime (as described in Section 4.3.2. Victoria and Western Australia established their own regimes, which nevertheless align with the national regime. WA, unlike other states and territories, does not require CHPs to be registered to receive grants or transfers, and not all of them are registered. Therefore, the WA Housing Registrar does not have oversight of all community housing stock in that state. The AM standards in the NRSCH are underdeveloped, although each Housing Registrar may provide more. For example, Victoria's Office of the Housing Registrar has highly detailed AM guidelines that reflect BPAM practice (Housing Registrar Victoria 2016).

At the time of this research report (2021), Victoria is undertaking a social housing regulation review brought about by the Big Housing Build —-the largest single investment in social housing in the state's history (Victorian Government 2021c; 2021d). The objective of the review is to ensure that stock investment is done wisely and that the regulatory environment facilitates best outcomes for tenants and applicants, while ensuring appropriate financial and stock provision, and appropriate management. Two consultation papers-a background and scoping paper, and a paper on service delivery and the tenant experience-have been published (Social Housing Regulation Review 2021a; 2021b). One of the interesting ambits of the review is whether SHAs and CHOs should be brought under a common regulatory body.

\subsubsection{Reporting requirements}

The level of oversight by the Housing Registrars reflects the size of the CHP to ensure regulatory burden is commensurate with the perception of the risk posed to tenants and funders (NRSCH n.d.). 
The performance and reporting requirements of a CHP who manages a single house are accordingly very different to a CHP with a billion-dollar balance sheet. The regulatory regime is performance-based rather than prescriptive. The following description by a Housing Registrar of the role of the regulator indicates a focus on maintenance and a relatively short time horizon for life-cycle AM.

\begin{abstract}
We are a self-reporting type system ... [CHPs] develop a suite of policies and procedures ... that gives [this office] the comfort to maintain their registration ... they all have a requirement to have a policy and procedure ... [regarding] how they will receive complaints around maintenance, how they will log jobs around maintenance and the timeframes which they'll complete them ... We don't prescribe ... how they've got to do it. We just want to see that they are conscious of it and that it sort of aligns with their financial planning and modelling for the future. So, we get a 10-year forecast in terms of finances and that would include pipeline stuff around their strategic asset management processes. (Registrar)
\end{abstract}

This is a light-touch approach to regulation, which requires very little from the smaller CHPs. This was criticised, as it does not drive continuous improvement.

It's a tick-box ... there's no business analysis applied to it, as far as I know. It might be different for ... the big Tier 1s. (2)

[The regulation] is tick-box. Did you give us a 10-year forecast? (26b)

\title{
5.7.3 Housing registrars
}

There were participants who suggested that Housing Registrars lack expertise, if not basic understanding of AM.

[They] had no idea. I said, 'Do you realise [what] you're saying?' They go, 'Oh I don't know'. So even the regulators don't really know ... It's just scary. (25b)

The offices of most regulators wouldn't necessarily, if at all, have anyone who has the sufficient asset management skills to really analyse those plans ... I don't believe the regulators undertake any formal assessment of an asset management plan. I imagine they'll have a reasonable degree of experience about what's in them, but I don't think there would be any deep dives or interrogation of those plans to see whether they were entirely fit for purpose for whichever organisation was involved. (14)

One participant (25b) highlighted that the Housing Registrars' poor understanding of AM conflicts with their objective of ensuring financial viability.

It really needs to focus on how they can give us flexibility to run our businesses the way we need to, to survive. (25b)

Despite some degree of negativity towards the Housing Registrars, regulation was viewed positively.

Regulation has actually been quite positive ... I know compliance is a bit onerous and [CHPs] whinge, but ... without the whole national code ... it's actually improved the sector a lot. (2)

The performance and the requirements imposed on us by government forced us, or was the catalyst, for us to drive that improvement. (9)

[It is] legislation or the incentives provided through funding [that] really drive behaviour in the world of asset management. (3) 
The Housing Registrars were conscious of the limitations of their offices in regard to AM, and most emphasised the need for specialist skill sets and resourcing. The Housing Registrar's offices typically do not have AM expertise equivalent to that of their financial analysts. One registrar said they had very serious concerns about CHP's AM, but a combination of institutional arrangements and capacity limited regulatory options. The concern from a public policy perspective is that without quality detailed asset management plans or strategic asset management plans that can be interrogated, Housing Registrars cannot truly understand CHP liabilities - and hence their financial viability or risk.

\subsubsection{Regulation through management contracts}

In addition to formal regulation, management contracts function as another level of regulation. Further, state governments maintain some degree of control over assets provided through government capital grants or stock transfer-for example, caveats lodged on title. This introduces complexity for both Housing Registrars and CHPs.

I don't think you can look at the providers independently of the [state] housing agencies, even though they are for all intents and purposes independent legal entities (5)

The implication of differing tiers of regulation, transfers and derogations from the NRSCH are multiple AM requirements reflecting:

- who the provider is

- what state or territory they operate in

- who holds the title to the property

- how they came to hold it.

To complicate the regulatory task and CHP reporting, contracts and agreements with state agencies typically require CHPs to conform to SHA-nominated AM standards and methods-such as CA ratings. These may vary according to the transfer tranche, adding further complexity. (This is discussed further in Sections 8.2 and 8.3.) CHP AM systems must be able to generate reports reflecting this multiplicity. In one case, a CHP had an algorithm developed to translate the condition-rating system for one contract into the form required by another contract.

\subsubsection{Other regulatory requirements}

The regulatory system for CHPs is broader than the requirements of the various Housing Acts and agreements with state housing agencies. As not-for-profits, CHPs are also regulated by the ACNC, ASIC or a state government department for Incorporated Associations. This regulation has particular bearing on the governance of organisations. One participant (14) believed skill-based boards provide a 'counterpoint' to weaknesses within the formal regulatory regime.

[They provide] another level of accountability on the performance of things like asset management and another level of assurance, I suppose, to regulators as a part of that process. (14)

However, there were asset managers who pointed to their boards as being the source of problems with AM (see Section 5.6).

\subsubsection{Regulation and private financing}

A key ambition of the NRSCH regime was to create confidence in the community housing sector to facilitate private financing. Private financing imposes market disciplines. 
Financiers have extensive requirements for data and rigorous credit assessment processes. If monies are provided, they will impose loan covenants that require regular reporting against KPIs-for example, monthly reporting of cashflow and loan to value ratio. The financier has the legal right to 'step in' should a covenant be breached. This, in theory, can include directing a CHP to dispose of assets.

There are many considerations for a financier assessing a loan application. These follow the ' 5 Cs' as outlined by Bryant (2012): character, capital, capacity, conditions and collateral.

Broadly, applicants must establish a business case and their own credibility as a borrower. The organisation's policies, systems, data, skills, governance and controls all reflect upon credibility. The financiers interviewed provide both project-specific and corporate facilities. Corporate facilities - the provision of a line of credit to an organisation untied to specific projects-require an assessment of every aspect of the borrower's business. Assessment for project finance is not always as extensive.

CHP financing is different from private 'build to sell' development, as financers lend against organisational cashflow rather than project yield. Rental receipts are the main source of revenue rather than sales. Low-cost, long-tenor debt is ideal when assets are held for the long-term and cashflow is underpinned by statutory incomes. However, by definition, CHP profits are low with little margin for error. Therefore, AM as a major cost forms a key part of the lender's due diligence. Financiers are likely to want to see the asset management plans or strategic asset management plans, the inventory of assets and condition assessment-and evidence provision will be made for future liabilities. Financiers will want to understand:

- counter-party contract obligations

- the skills and qualifications of key staff members, contractors and board members

- what software systems are being used.

They will also want to test data integrity. The veracity of data provided by a CHP will be called into question if the AM systems are weak - as weak systems call into question personnel capability.

I'm reasonably certain that the financiers would be demanding the asset plans and looking at them probably with more rigour than the regulator would be. (8)

Since its establishment, NHFIC has become a key financier of community housing in Australia. However, many CHPs have been unable to secure NHFIC financing, prompting the federal government to fund a panel of expert advisers to support CHPs when they make loan applications. One participant (4) said that NHFIC loan covenants and security requirements are more onerous than those of banks. Anecdotally, the researchers were aware of CHP dissatisfaction with the information demands made by NFHIC.

While some CHPs are likely to benefit from having expert advice on how to prepare an application, it is likely a deeper problem. If a CHP developed an AMP as part of its compliance with the NRSCH standards, which it then proceeded to ignore (see Section 5.3), it suggests a lack of robust AM systems and data, and inadequate governance and management.

There's differences in scale. An organisation that has two or three hundred properties isn't going to have a full, 30-year strategic asset plan, and they won't necessarily have earmarked the properties that are underperforming - whether it's for location or value for money or the maintenance backlog. (8)

The NHFIC model, what I liked about it is you can't hide. You really have to know your numbers ... it actually effectively exposes all the risks. (2) 
NHFIC has refinanced much of the existing bank debt held by CHPs. Through the provision of long-tenor debt, NHFIC not only has a large market share but is also very exposed to maintenance liabilities. Its credit assessment process therefore necessarily focusses on AM and loan covenants relating to cashflow_for example, ensuring the CHP has sufficient funds to meet maintenance needs and other obligations.

The failure of some smaller CHPs to obtain NHFIC loans indicates a regulatory deficit. If these CHPs are unable to convince NHFIC to lend, how do they satisfy regulators that the business is financially viable and that public investment in them is protected? The answer is that owing to their size they are not required to convince the regulator.

However, one participant (24) argued that some of these CHPs are obtaining short-term bank loans for development but, as an indication of their poor AM, were then failing to make financial provision for upgrades.

The money just goes into the ether ... that's when they start selling assets. (24)

The participant viewed this as a regulatory failure, as much as a failing of the CHPs.

Thus the importance of the NHFIC is well beyond its role of financing the growth of community housing. It has a shadow regulatory role for the $\mathrm{CHPs}$ that it funds in relation to $\mathrm{AM}$, because in effect it is sharing the custodianship of these housing assets. Other lenders will not necessarily exert the same type of pressure. Indeed, other lending may exacerbate risks.

\subsection{Planning for demand}

A key element of strategic AM is planning for current and future demand. Social housing portfolios are dominated by three-bedroom and four-bedroom detached houses. However, the tenant profile is ageing, which results in under-occupancy.

SHOs are divided on whether lone tenants ought to be moved into smaller dwellings. The residualisation of social housing in Australia is also driving demand from singles, reflecting the individualisation impact of poverty (Sharam and Hulse 2014). These shifts have occurred over approximately 20 years, but the lifespan of housing assets is many times that.

Trying to reconfigure portfolios was likened by one participant (26b) to turning around an aircraft carrier, and 'takes years'. It is a process slowed down by lack of capital to deliver new stock. On top of changes to the type of household, housing is increasingly not fit for purpose. Universal accessibility is required, often necessitating extensive and expensive retrofitting (28).

CHPs' assets are generally younger and their portfolios smaller. Some CHPs provide housing to very specific population cohorts, but others are generalist services. Generalisation requires a SHO to have development, asset and tenancy management knowledge relating to many different types of assets. For example, developing and operating detached family housing is an entirely different proposition from managing a high-density rooming house for single, older men who have been street homeless for many years. Accordingly, some participants argued that specialisation of housing and tenant cohorts is more efficient than generalisation (1). If economies of scale can be reached, this is less important.

Lack of a pipeline of capital grants encourages CHP opportunism, and the result is a tendency for CHPs to widen their target cohort, asset type or locations. For example, both iParticipants $27 \mathrm{~b}$ and 31 said that they had acquired new stock in locations well out of their target areas. Geographical dispersion is sometimes managed through contracting-out maintenance (21). 
Active recycling programs create the opportunity to reconfigure portfolios to meet future demand. There was awareness among CHPs that the stock needs to cater for greater diversity. CHPs, such as participant (37), for example, planned to recycle inner-urban assets to provide one-bedroom, two-bedroom and three-bedroom apartments. The desirability of tenants being able to access employment opportunities, services and transport was a key concern $(21,32)$.

However, no coordination mechanism across public and social housing enables the right kind of housing to be delivered in the right locations. One concern was the concentration of social housing into particular localities, and some CHPs were frustrated by state agencies unwilling to support programs to dispose of property in such localities (26a).

\subsection{Policy development implications}

Planning social housing AM is complex. The future development of AMPs presents a range of issues that need to be addressed.

\subsubsection{A common Australian asset management framework}

Social housing AM practices are diverse and inconsistent. SHOs are using a diversity of frameworks, datacollection systems, software programs, assessment and appraisal systems, performance benchmarks, decisionmaking systems and other tools.

Technological differences may not be an issue in themselves. However, differences in terminology, in the data collected, in the basis on which decisions are made and in performance benchmarks make it difficult to:

- develop a skilled workforce

- systematically improve good practice

- develop best practice

- make comparisons between organisations.

Different AM approaches among SHAs were identified by Kenley, Chiazor et al. $(2009 ; 2010)$ as an obstacle to obtaining reliable data on the condition of stock, its fitness for purpose and the costs of maintaining it. The lack of a common AM framework has meant there is no rigorous method by which the effective public subsidy in different scenarios can be quantified, nor how effectively public funds are being leveraged-and hence a common framework was a key recommendation of Kenley, Chiazor et al. (2009: 3-4, 5; 2010).

The researchers believe that social housing asset management should develop processes and procedures to identify good housing asset management practices and propagate them across the social housing sector. Without these processes, the transfer of best practices is unlikely to occur, thus reducing significantly the effectiveness of efforts to improve financial and technical management of public housing.

Social housing in Australia would benefit from a new approach to social housing asset management, with consistency in approach across all jurisdictions, and with a well-defined knowledge base not dominated by one particular perspective but accommodating both.

Proctor (2014: 34) provides a good summary of some of longer-term benefits of a common AM framework:

- Better, more consistent approaches to longer-term AM strategies.

- More consistent, understandable and comparable methods of asset portfolio data management, analysis and reporting. 
- More effective and efficient procurement and management of new supply procurement and maintenance contracting.

- Improved practices in partnering with the private sector on new development.

- Improved approaches to AM workforce training, planning and management.

- More consistent approaches to disposal of assets in line with sector-wide priorities.

The large number of small CHPs and IHOs has resulted in a fragmented system of social housing provision and highlights an AM risk-but also an opportunity to assist this sector with a set of AM guidelines or practice notes, frameworks, standards and benchmarking. The need for a social housing AM framework was strongly supported by the participants, and viewed as a need that would be met collectively.

\section{... from my perspective. If the sector contributed financially to those resource requirements for a professional asset manager to develop that framework. If we all put in $\$ 2000$ or $\$ 1000$ or whatever, whatever the figure is, for somebody to come up with it instead of us, each individually trying to do it I think, because spreading it across the entire sector would be a good solution. (26b)}

The empirical research on AM among SHOs in Australia reveals that SHOs are in desperate need of a common AM framework within which they can:

- develop comprehensive AMPs

- work to common LOS and habitation standards

- work to a common AM terminology.

\subsubsection{Capacity building}

Building capacity, particularly in the community housing sector-and especially among smaller CHPs-is essential to the development of AM in the social housing sector, and for better outcomes for tenants.

One starting point is providing social housing-specific AM guidance to SHOs: guidance that takes account of the unique aspects of social housing. Increasingly SHOs are looking to ISO 55000 AM standards to drive asset planning and delivery. The IPWEA (2020a) and NAMS (2014) resources are invaluable, but have too little recognition in the sector. The ASH framework developed as part of this study (Appendix 1) responds to this gap by adding a social housing lens to the NAMS Property Manual.

Reflecting on much which is unique about social housing in Australia, AM skills and training are often obtained on the job. Professionally credentialed asset managers often cycle in and out of social housing, reflecting cultural and remuneration differences between for-profit and not-for-profit sectors. External training opportunities are few, and typically do not directly relate to social housing. As large, mature businesses, the SHAs are able to develop human resources and technology, but it is much more of a challenge for CHPs. The biggest hurdle is the need to recognise the importance of AM and the need to invest in people and systems. This is lacking among many smaller CHPs.

AM capacity building extends beyond those directly responsible for AM on a day-to-day basis to the whole organisation, but particularly to directors. Other options that would develop AM capacity are:

- a forum to showcase best practice and facilitate knowledge dissemination

- a biennial AM conference-this would raise the profile of AM and best practice, and promote knowledge sharing and transfer

- an online forum and resource repository for exchange of ideas, initiatives, issues and problems. 
Peak and industry bodies have important roles to play in facilitating the community housing sector's move towards BPAM practice. These bodies could do the following:

- Lead cooperative efforts to obtain specialist AM software and software solutions and technologies to ensure all CHPs have the most effective systems possible. This could include hosting AM software services so that less-resourced CHPs have access to affordable technology services.

- Engage with training organisations to ensure CHPs are able to obtain high quality and affordable training to support on-the-job learning (such as through unaccredited short courses) and to promote entry into AM Bachelor and Masters degree courses.

- Establish new AM communities of practice where they do not currently exist.

- Undertake regular reviews and updates of the AM guidance in the Community Housing Standards Manual.

- Initiate secondment and pro bono schemes in which AM professionals in the private and government sector can spend time in a CHP either on short-term consultancy basis or for a longer period, either on staff or with the board. An increase in the number of professionals with AM expertise on CHP boards is also needed. These need to be asset professionals rather than development professionals.

Governments could support these efforts through special-purpose grants.

\subsubsection{Indigenous housing}

Two significant developments herald change: stock transfer of properties to AHV and the establishment of NSWALC Housing Ltd. These Aboriginal-controlled organisations have high-level governance and management skills and are on growth trajectories. AHV has acquired AM capacities. NSWALC Housing Ltd will obtain demonstrable AM capacity in its drive to become a Tier 1 provider. However, most IHOs are small and require support if BPAM is to be achieved in the Indigenous sector.

Self-determination and capacity building are critical preconditions to any initiative aiming to increase supply and address the poor condition of Indigenous housing. Capacity building needs to occur to ensure IHOs can grow. Growth is required to deliver the resources required for BPAM. Capital grants are urgently required to address critical maintenance backlogs and acquisitions to alleviate overcrowding. If providers are to adopt BPAM they cannot start the journey weighed down by such legacies.

State-owned Indigenous housing AMPs could be developed as a part of a co-design process with Indigenous communities. An outcome of the co-design process could be the development of IHO AM and governance capacity. This, in turn, could put IHOs on a growth trajectory, initially through assuming management responsibility and later through stock transfer.

Capacity-building initiatives could include:

- funding Indigenous scholarships for AM training and education

- financial support for an Indigenous asset managers network

- secondment or placement within non-Indigenous housing organisations; within Māori housing organisations in New Zealand; and First Nations housing organisations in North America.

\subsubsection{Uniform standards and measures}

A process could be established to develop a set of national common AM measurement and performance standards, taking account of the specific building regulation variances between states and territories, and variables such as climatic variations or location-specific conditions. 
The development of common measurement and standards will facilitate sector benchmarking, permitting SHOs to understand their performance against peer organisations. SHAs undertake some degree of benchmarking already, but this could be regularised, and extended and incorporated into a whole-of-sector scheme.

Currently Housing Registrars' benchmarking is limited by the variances in approaches, with AM focus largely limited to Tier 1 providers. The benchmarking only applies in relation to CHPs within each jurisdiction.

\subsubsection{Habitation standard}

Although tenancy legislation around the country has improved, there remain gaps. Harmonisation reflecting the most detailed standards currently in operation would deliver benefits. In the absence of uniform national tenancy law, the community housing sector could determine a habitation standard that reflects the service the sector seeks to deliver for tenants. CHPs could adopt this habitation standard as part of a voluntary code, or approach Housing Registrars to incorporate the standard into their guidelines. Voluntary codes are common in other industries and are a means to support quality service

SHAs could also adopt the habitation standard by joining the voluntary code. Within this context, each SHO could set LOS objectives and measures for habitation standards.

\subsubsection{Regulation}

Despite having an estimated $\$ 100 \mathrm{~b}$ in assets and providing the vast majority of social housing in Australia, SHAs are not regulated-so their performance, including that of their assets, is subject only to ministerial oversight and occasional inquiries. The vastly smaller community sector is held to greater account-although this varies according to size and risk profile of the CHP and by state or territory. The workshops and interviews revealed significant support for regulation as a driver of AM performance. However, it was commonly observed that AM expertise is a skill set that Housing Registrar offices may lack, and that Registrars are under-resourced. Housing Registrars' offices require greater resourcing to ensure their capacities are at the required level.

The differential treatment of providers according to tier level clearly allows unsatisfactory practices and performance among the smaller providers. These risks in this part of the community housing sector are not being effectively addressed by regulation or policy.

Uniformity of regulation was regarded as highly desirable to reduce transaction costs and foster good practice. Another key economic efficiency measure identified was standardisation of CA rating.

\subsubsection{AM software}

Specialised social housing AM software is an invaluable tool. Some of the unique attributes of social housing in Australia create challenges_-such as the current finance system. The SHAs and many of the larger CHPs use such software, but integration with other organisational systems such as finance packages requires additional investment. Lack of standardisation of measures brings additional complexity. Each SHO has forged ahead on its own, although a coordinated approach by CHPs would entail benefits-especially for the smaller CHPs that are being left behind.

\subsubsection{Planning system-level supply}

Sector-demand forecasting, geographic demand and demand by typology and client group is resource intensive and, in a multi-provider service system, requires a coordinating mechanism. Without coordination, there is effectively no rational planning. A state-level coordination mechanism is required so that BPAM can exist on a system-level as well as at the provider level. 


\section{Social housing asset-creation practices and issues}

- Design briefs for the acquisition of assets need to incorporate considerations of accessible housing guidelines, environmental objectives and the long-term cost of maintenance and renewal.

- CHP boards need to recruit people with expertise in AM, not just development.

- CHPs often have growth objectives, but smaller CHPs often have no plan for funding renewal.

- SHOs need a consistent and predicable flow of capital funds. Scarcity of capital finance drives opportunism among CHPs, and creates a challenging environment for life-cycle asset planning and management.

- SHAs need access to borrowings for capital purposes and exemption from the global borrowing limits. They do not have the resources to grow; asset renewal is largely funded by disposal.

\subsection{Introduction}

The role of asset creation is to acquire housing stock that meets the current and future demand for social housing. It involves decisions about how (through construction of new dwelling or the purchase existing dwellings), where and when to acquire stock of specified standards, of particular types (houses, units, flats), of particular sizes, etc.

Section 5.8 outlined some of the issues with the current stock of social housing and the need to reconfigure the social housing portfolio. This includes:

- a shift from the predominance of three-bedroom and four-bedroom dwellings to one-bedroom dwellings

- accessible housing for people living with a disability, for families with children, and for people as they age

- housing that is environmentally sustainable in the materials it uses, in the processes used to construct dwellings, in its design, and in the incorporation of features such as solar panels and water tanks that reduce consumption -and reduce the tenant's financial stress. 
SHAs are predominantly focussed on the upgrading, renewal and redevelopment of current assets rather than asset creation, and many of the listed elements are included within these processes. Redevelopment relies on disposal of stock and public-private partnerships (PPPs) to fund these activities. PPPs involve partial privatisation of sites. Therefore, redevelopment of public stock does not increase the amount of public housing, and often involves a lost opportunity to grow stock in well-located areas with high land values.

CHPs, on the other hand, are often focussed on growth. CHP growth opportunities occur:

- as a result of capital finance-either government or philanthropic

- when existing sites can be intensified

- when cashflow is improved, permitting borrowing.

This occurs as a result of:

- stock or management transfers

- refinancing of existing loans

- cross-subsidisation from provision of affordable housing

- efficiency gains.

As with SHAs, CHPs sometimes have the opportunity to sell newly developed stock to cross-subsidise their developments.

The strongest views on asset creation elicited from the workshops, survey and interviews concerned:

- taking account of long-term maintenance costs

- boards' focus on development only rather than whole-of-life-cycle AM

- the preference of mainly smaller CHPs for growth over maintaining current stock

- opportunistic asset creation.

\subsection{Taking account of long-term maintenance costs}

Development and AM are typically different parts of the business. Often development appraisal and development management are undertaken by consultants, as ad hoc capital grants create a difficult environment in which to sustain a pipeline of projects to justify in-house capacity. The key challenge raised by asset managers was the inclusion of life-cycle AM considerations as part of feasibility assessment. Ideally, design criteria would include projected maintenance costs and take account of known AM issues.

One participant (13) provided the example of fire safety requirements in apartment buildings. They explained how sprinkler systems in a new building they had developed needed to be retrofitted to meet their LOS safety standards. Apartment design was identified as critical given the extent of common areas and the much higher maintenance costs associated with, for example, lifts (1). Another participant (27b) had acquired an apartment through a bequest, but the cost of holding the property was high, reflecting owners' corporation fees and increasing insurance premiums - which in turn reflects the impact of the non-conforming combustible-cladding crisis.

In a learning process, CHPs appear to be incorporating costs, with architectural designs increasingly taking account of asset manager's suggestions to reduce future maintenance liabilities (39).

From a design perspective ... Absolute costs get a lot better ... probably a 20 per cent change when we've actually been part of the design process, where l'm getting 20 per cent less [repairs and maintenance] coming through in the opex [operational expenditure]. (25b)

However, such change appears to reflect the work of asset managers internally advocating for their participation in decisions to acquire or develop stock. 


\subsection{Development versus asset management}

As noted, development and AM typically comprise different business units. This is not an issue where BPAM is adopted. The divorce between development and AM may be a reflection of board composition. Interviewee participants were asked about board composition and skills. Many participants highlighted how development experts had been recruited, as if this expertise satisfied the need for AM knowledge. None of the participants were able to identify board members who were recruited specifically to provide AM expertise. Development and AM skills are not synonymous - but there appeared to be an assumption that they were.

\subsection{Growth rather than maintaining current stock}

However, asset managers in smaller CHPs were often critical of their organisations for being too focussed on growth in the absence of real plans to adequately maintain, let alone replace, their existing stock.

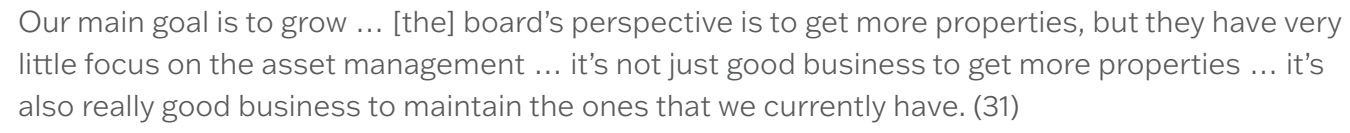

New supply is probably more glamorous than just doing the maintenance. (8)

One participant (2) argued that part of the problem is 'mission drift'. Many of the asset managers argued that their organisations were obsessed with increasing the size of their balance sheet without understanding attendant risks.

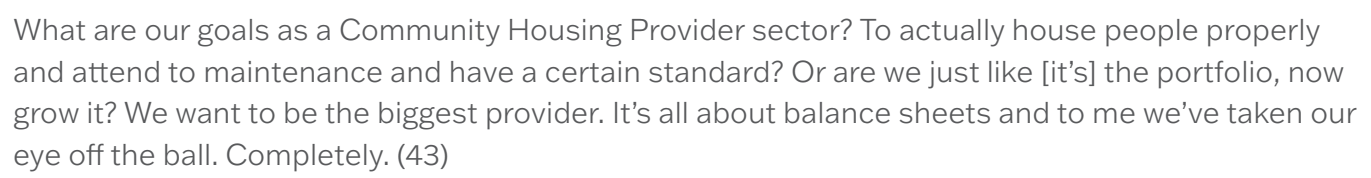

These sentiments reflect a view that perhaps CHPs are receiving government funds in the absence of demonstrable capacity to manage their existing assets. However, an alternate view was that holding out the possibility of capital grants or other funding is an important factor in driving an improvement in the AM of CHPs.

[If they want] to go up to the next tier so they can be considered for transfers and maybe gaining leases [they] need to have these five things in place: good asset data, good policies and standards, a good business process that makes it all work, resources [and] governance around assets. If you have these things and produce good reports around this, then you're in that next tier. So, I think that regulatory process is great. What l've seen is: it does drive a change in behaviour. (3)

\subsection{Opportunistic asset creation}

The irregular nature of capital grants means that CHPs are often highly opportunistic. The intention to take growth opportunities as they arise may form part of the strategic plan, but it does not mean a strategic approach is actually taken, or that the organisation is capable of managing such growth.

Ad hoc opportunities tend to arise with little notice and can involve very short timelines. One iParticipants (27b) described how their organisations are quite diverted by developing tenders and feasibilities at short notice. Substantial time and resources are consumed in competitions for-ironically-resources. However, competitive processes are to some extent driving improved AM. 
At the same time, the need to be opportunistic has problems.

Irregular capital grant programs - such the Rudd government's Social Housing Initiative, which formed part of its Nation Building Economic Stimulus Plan response to the GFC_-placed emphasis on the speed of housing delivery. Land availability in these circumstances drives development on the urban fringe. As found by Murray, Bertam et al. (2013), this results in CHPs ignoring other strategic objectives such as locating social housing close to public transport, employment opportunities and other services. One participant (31) described how a private developer made an offer, which resulted in the acquisition of housing well out of their nominated geographic target area.

The larger CHPs appear to be very nimble in responding to opportunities. Their size provides the capacity to plan ahead and have a pipeline of potential projects. Some own larger underdeveloped inner-urban sites that can be intensified. These sites offer the potential for growth to be funded via a combination of apartment sales and the provision of affordable housing. These projects can proceed without capital grants, but should grants become available they are in a prime position to secure such funds.

Some CHPs, such as that of participant 37, have increasing access to well-located land by virtue of being part of large, long-established social service or faith organisation. A key ambition of (37) is to create greater diversity of apartment sizes to cater for changes in demand. Another CHP (21) has an active recycling program firmly aimed at consolidating housing into clusters that:

- ensure maintenance efficiencies

- are located close to other services they offer, and services more generally

- ensure housing is fit for purpose and meets their LOS targets.

Opportunism and the ambition to grow can contribute to risky decision-making by CHPs. Stock transfers and management contracts are problematic because condition is typically poorly understood beforehand. This is discussed in more detail in Section 7.3 and Section 8.3.

What is relevant here is that CHP boards accepted stock without understanding the liabilities they were assuming. Unless the CHP had contingency funds available that they knew they could deploy should their assumptions prove incorrect, such a decision calls the governance and management of the organisation into question. It certainly draws attention to the difference between actual capacities and the strategic ambition to take advantage of opportunities.

\subsection{Policy development implications}

Asset creation is the beginning of the long life cycle of housing assets. It provides opportunities for putting in place assets that will meet the needs of tenants over the long-term, and for reducing the long-term costs of maintenance and renewal. Getting it right is important.

Operating on an opportunistic basis is not a rational or sensible way in which to create these long-term assets. SHOs need a consistent and predictable flow of capital funds so that they can properly plan the acquisition of dwellings. While CHPs have access to relatively low-cost private-sector capital funds through NHFIC, this access to borrowings could also be extended to SHAs by granting them exemption from state or territory global borrowing limits.

Design briefs need to incorporate considerations of accessible housing guidelines, environmental sustainability objectives, the long-term maintenance of dwelling components and the renewal prospects of dwellings.

Boards of CHPs have been recruiting people with development expertise. This needs to be extended to AM, particularly as asset management issues will becoming increasing important to the future of these CHPs. 


\section{Social housing asset management practices and issues}

- The public housing maintenance backlog is well documented.

- A community housing maintenance backlog is undocumented, but emerging.

- CHPs are facing increased maintenance costs as their portfolios age.

- The balance between reactive and planned maintenance needs to shift towards planned maintenance.

- Management transfers from SHAs to CHPs are a strategy for addressing maintenance backlogs, and CHPs are taking on liabilities for which they are unprepared.

- Management transfers raise questions as to how properties fit within the life-cycle planning of SHAs.

\subsection{Introduction}

The role of AM is to maintain dwellings at the specified LOS. On the one hand, it includes reactive and planned maintenance that restores the dwellings to current standard. On the other hand, it includes the upgrade and renewal of dwellings in order to bring them up to a current standard and extend the economic life of the dwelling. Where the dwelling cannot be upgraded, a decision must be made about when it will be demolished and redeveloped or sold. Maintenance is discussed in this chapter. Upgrades are discussed in detail in Chapter 9.

\subsection{Reactive and planned maintenance}

The purpose of maintenance is to preserve the condition of a dwelling and extend its life. Maintenance is either:

- reactive-responding to a tenant request or an emergency

- planned-conducted on a cyclical basis, reflecting the life cycle of components of the dwelling.

Planning for maintenance is captured in the AMP, which establishes the LOS the organisation aims to deliver. Shortfalls between the expected level and actual performance are detailed in the AMP, along with any risks associated with the shortfall and the work programs required for remediation (3), including budget allocation. 
Maintenance is ideally conducted as part of a planned cycle of work, with reactive works kept to a minimum. As one participant (9) argued, properties need to be inspected and their condition rated according to a scale.

In order to [understand maintenance liabilities] you've actually got to really understand your portfolio and you've got to scope it ... and you need to be using a standard that shows you what the maintenance backlog is. (9)

Maintenance is affected not just by the dwelling type and its age but also by the nature of the tenant profile. Residualisation both reduces rental receipts and increases maintenance costs.

As the houses get older, [they get] more expensive to maintain. The rental income doesn't go up because, if anything, the trend is to have more dwellings filled with singles or couples. Ever higher rates of people who are on social security benefits ... the rent is the only source of income that has to be divided up among paying rates and insurance and staff costs and other overheads. And the last thing on the list is maintenance, because you can get away with skimping maintenance. So, the big challenge is an ageing portfolio, poorer condition and finding enough money to properly maintain them. (4)

The rising complexity of tenancies_that impacts on the maintenance. (7)

SHAs have a substantial public housing maintenance backlog (AGV 2004; AONSW 2013; NSW Parliament 2014; Pawson, Martin et al. 2016; VAGO 2017), although as Pawson, Martin et al. (2016) note, there is a paucity of data. This backlog is a reflection of the age of the assets and a lack of income to support maintenance, upgrades and renewal. Aged assets inevitably involve higher maintenance costs. The asset profile of community housing is generally younger than public housing, but maintenance is now emerging as a critical issue warranting attention.

The last major period of construction for CHPs was the GFC. This housing is nearly 15 years old and maintenance needs are growing, revealing organisational gaps. Younger CHPs are facing large maintenance costs for the first time.

We found this giant hole... we don't have any asset management. (31)

Younger CHPs are not the only organisations to have issues. Longevity does not guarantee good AM practices.

They've been going for 30 years ... that whole period of time left them in a really bad state, because even though they might have a profitable income stream ... they never dealt with back then ... I mean, the issues don't go away, just kicking the can along the street as they say. (37)

A common issue for an asset manager starting a new job at a CHP is confronting the revenue-cost gap and its implications for maintenance.

When you've inspected the assets at the component level ... you begin to understand the true reflection of liability, it becomes very daunting ... it gets very scary, and so you know you find yourself quite quickly trying to find the pennies and the cents to try to make it all add up. (34)

Asset managers often struggle to get their organisations to understand what is needed.

This is one of the things I've had to explain time and time again to them: just because we haven't done something, that's not a saving, it's now a liability. You can't keep creating a greater backlog ... The auditors are actually picking this up now. (38)

They do that all the time. They have these plans and costs, and then, 'Oh, well, we can't do this yet, so we'll just push it out.' So, you [take] a really hard-nosed look at how much of a hidden liability are you actually leaving for the people who come behind you, in terms of the actual quality of the asset and its deterioration... The other big one for me is kicking the can down the road, where they delay essential maintenance. (2) 
A key requirement is the annual allocation of maintenance funds in the budget. One participant(4) described the annual discussion about putting together next year's budget:

Manager: 'Okay, well what do we need? How much do we need for maintenance this year? Oh, it doesn't matter. The finance officer's already done it. He's just pulled out the last budget and added two per cent.'

Asset Manager: 'Well it's probably not the best way to do it. Why not see what the plan says?'

Manager: 'Oh yeah, righto.'

So, we look at what the plan says and it's dangerous because the plan might say that you should be spending more money than you actually want to spend ... How does that conversation go, when you say:

Asset Manager: 'We need ten million dollars to look after our assets properly.'

Manager: 'Well, got the staff costs and we got the office rents, and we want to do this and that and we want to grow. So, we want to put some money into some new housing and there's only seven million dollars left for maintenance.'

Asset Manager: 'Well, it's not enough. Is it?'

Manager: 'Well, are you sure? Where's your evidence? Is that evidence?'

And then it gets questioned and questioned and questioned, so what any asset manager who wants to keep a job finds is that they have to work through how to have that conversation in such a way ... They don't, you know, fall on their own sword. They go, 'Okay, well, just give us whatever's left, and we'll do the best we can with it.' That's the sort of story of the asset manager's life. [Maintenance] becomes the discretional expenditure. (4)

The need to balance organisational budgets frequently results in asset-maintenance cycles being pushed out and expenditure avoided entirely.

There are absolutely competing demands and competing priorities within organisations about where to spend the money and what is seen as a priority ... there would often be ... a desire to have short-term goals ... like annual or two-year asset plans, that actually limit the scope of what you can actually include because budget cycles, being annual ... can be quite limiting. (9)

Maintenance is always seen as the evil necessity, but it's treated as [a] slush fund and that perception has to change. (38)

[If a SHO maintains an asset] past reasonable life, you end up spending maintenance money polishing turds. (7)

But when the money is not there, it's more about, 'How are we going to fix the defects? We know that the deterioration is happening. We need to start planning for having this much more money in the next five to 10 years so we can fix those things then.' So that the focus becomes driven by the amount of money available, as opposed to, if we had all the money available that we'd like, then we could just say, 'Let's plan in those big refurbishments on a seven- or 15-year basis.' (3)

Asset managers reported they could at times reasonably delay maintenance. But with tight budgets to start with, asset managers need to work hard to protect their funds.

It's insulated, I don't [let them] rob from that. (10) 
There will always be tensions within organisations regarding funding of maintenance. BPAM seeks to ensure this tension is productive and reduced by whole-of-organisation commitment to life-cycle planning. However, this can be difficult to achieve when long-lived assets require long-planning horizons and income does not reflect need.

So, it is a budget that goes up and down based on the plan. And we're trying to integrate that knowledge with the [chief financial officer] but there's always a conflict around it because it's always like, 'Can you push it to next year?' It's like, 'No, we can't, because it actually is something that needs to be done this year and we've been planning for it.' So, it is a challenge. (11)

Planning over longer time horizons is increasing common, reflecting, in good part, regulatory requirements-but there are gaps.

We have a preventative maintenance program on some of the major assets, [but] we don't have a plan as far as ... identifying that a unit may need repainting in five years' time or 10 years' time. Things like that. (41)

Accountants see it as a cost, and they'll always try and minimise costs. And it's having that discussion about long-term asset planning is about investing. Unless your strategy is to just simply turn around in 20 years, knock it down and rebuild again. And if that is your strategy and you cost it on that basis, then that can be an acceptable strategy. Very wasteful in the world without finite resources, but if that's your strategy, then that's okay. (7)

A ten-year planning cycle is becoming the norm, reflecting regulatory guidance. However, this does not reflect the life cycle of a dwelling, and so some CHPs miss opportunities when they initially develop properties to obtain data that would enable them to plan better.

It's only ever a 10-year maintenance plan that's ever requested [from the quantity surveyor] as well ... If you ask a surveyor for building condition audit for a property over a 30-year time period, the cost is negligible in terms of one from the other, but the data is infinitely more valuable on the latter than the former. (28)

It is not just budget pressures that impact maintenance. CHP cashflow is also highly constrained.

If l'm doing something big, [l'm] always checking with finance [regarding] where we're at in terms of, 'Can I pay this bill in 28 days' time or not?' And if the answer is no, then we hold off for a while. (31)

Another gap for many CHPs is the capacity to deliver the works required.

It's easy for me to sit in my asset space and say, 'We need $x$ amount of dollars here because my condition profile tells me that. The next year we need that. The next year we need that.' The problem with that, though, is that your resourcing stays the same, so there's no point having a $\$ 200,000$ program spend one year and then a \$2 million one the next year because you'll never keep up with that. (15)

BPAM seeks to strike the right balance between planned and reactive maintenance. Reactive maintenance tends to be higher cost-for example, weekend call-out fees for tradespeople. The asset managers said reactive maintenance needs to be kept to 30 or 40 per cent. A recent review of remote Indigenous housing found, for example, that reactive maintenance costs were well above this benchmark (Nous Group 2017).

Anybody that's spending 60 per cent of their budget on responsive and not planned [maintenance] is either doing one of two things; they're not having enough money to actually address it properly, or they're in reactive mode and not planned mode. (7) 
Asset managers said it required deep change within organisations to avoid a drift to reactive maintenance. AM guides such as NAMS (2014) argue that reactive maintenance levels will tend to increase unless BPAM is deeply embedded and regularly revisited.

At a certain point in the life cycle, dwellings will be unfit for purpose and would be subject to disposal or redevelopment. The public housing backlog will involve housing that could be demolished but is being kept in service. One participant (38) said their CHP had tenants living in housing that should be demolished. Repairs on such dwellings is:

... wasting maintenance money on properties that are beyond economic repair. (8)

Moreover, deferred maintenance can reduce the life of the asset, leading to earlier disposal than would otherwise be anticipated. If properties are held beyond their economic life, the poor condition of the property negatively impacts on tenant wellbeing. CHP iParticipants managing state-owned housing described situations where tenants were living in very substandard housing, but the SHA could not be convinced to demolish even when the CHP was willing to fund renewal.

Maintenance, particularly among the largest CHPs, is increasingly subject to the systems thinking that underlays BPAM. It is the smaller CHPs who face challenges, as they have lesser capacity to build systems and attract managers and board members with the AM skills and knowledge to drive organisational change. Smaller CHPs are not subject to the more stringent regulation faced by Tier 1 providers, and have less capacity to invest in people and systems. There are two key risks when maintenance regimes do not adequately protect housing assets:

1. The life of the asset may be shortened, which represents an economic loss.

2. The quality of the service provided is reduced, with attendant impacts on tenant wellbeing.

Public housing maintenance across states is extensively contracted out to private firms. One participant (1) was highly critical of this contracting-out, as it did not involve cost-benefit analysis and typically focussed on the cheapest tender-which drives poor service delivery. In the NT, maintenance is also contracted out to private maintenance firms, but is further complicated by institutional arrangements and land tenures (41, 9) (see Section 1.2 for explanation of these terms).

\subsection{Management transfer}

Where CHPs have agreed to manage SHA stock, maintenance becomes the responsibility of the CHP. Transfer of management is significant. For example, NSW has transferred management of 30 per cent of public stock to CHPs. In another significant shift around the country, lease terms are being extended from three years to 20-year or 25-year terms. From a state government perspective, management transfer is also a strategy to fund maintenance backlogs through the higher rent revenue of CHPs (Pawson, Martin et al. 2016).

The shift from short-term to long-term leases better reflects the need for planned maintenance. A long lease may also, in theory, be used as collateral by the CHP, and recent changes to accountancy standards mean that leasehold assets must now appear on the lessor's balance sheet. Therefore, management contracts are more than ever a key strategy for CHPs who own little or no stock to support growth. However, there was concern among the participants that a significant level of management transfer would require small CHPs to increase their AM capacity when these organisations lack the resources necessary to employ an actual asset manager.

The injection of the management transfer properties will probably compound some of [the] budgetary issues [facing small providers]. (8) 
The key issue in extending lease terms is to ensure CHPs are incentivised to undertake maintenance.

It's hard to have a long-term plan when you don't have a long-term guarantee around the property.

If I'd been a director and l'd been asked to take on this long-term maintenance liability with only a 3-year lease to back it up, that's a hell of a tall order. So, the conversion of the 20-year leases may give a little bit of certainty, but there's still some question marks about what [is the] degree of risk transfer from government. (8)

Management transfers may involve a competitive tendering process. As part of the bid, CHPs state the minimum they will spend on maintenance over the duration of the contract in order to keep the property at the average condition score of the portfolio at the time of transfer (4). In some instances, no condition data is provided. In other cases, condition data is provided by the SHA-but it cannot be verified by the CHP prior to transfer.

[We took] over a portfolio of $[x]$ properties that we didn't know well before we took them over ... because we weren't able to inspect. We had some information, some limited information ... we did go through a process of testing, like did a sample to test it ... In an ideal situation, we'd have a lot more information and we are still gathering some of that. (11)

There was a requirement of the providers under that program to accept [properties] sight unseen. (5)

With the management transfers, they transfer the properties as is. Certainly, there was a lot of discussion around the condition of the property as received, and to what they thought they were receiving. (8)

Earlier transfer programs involved upgrades prior to transfer, or provided funding to address any backlog. However, more recent programs have not (Pawson, Martin et al. 2016). Competitive tendering where reliable condition data is not supplied is a fraught business. The risk involved for the CHPs suggests very conservative bids, but what they can manage is constrained by the rental income.

We took over a portfolio [that] had an \$18,000 [per dwelling] ... backlog of maintenance ... they've got to be handed back at [the same] level ... if we don't spend that money in the interim ... That program is better to go back, because we just can't afford it. It is pulling the rest of our portfolio down. (38)

One participant (38) noted that properties in poor condition are harder to let, and can be difficult to undertake work quickly enough. Revenue assumptions need to take account of the likelihood for voids.

Sometimes it's just better to say we are handing back that program. (38)

Not ... all of your programs create a profit ... Are you going to prop those programs up with other programs, or are you going to pass that program back to whoever the owner might be? (32)

Older properties are more difficult to maintain and thus CHPs can find it difficult to avoid losses. Heritage properties - such as rooming houses-are especially problematic. Another participant (27b) said they would be handing back some properties because they could not afford to keep them, and the SHA would not address structural maintenance issues.

It was, 'You take them in the condition they are. We're not giving you any money to fix them. It is what it is. Here we go, all yours. We're washing our hands of it.' (27b)

[We've] given notice on a big facility ... we have a subsidy to operate it, but it runs at a loss. (10)

[We said] 'You take that portfolio away from us, and give it some other CHP'. Well, good luck to them. What we can't do is go broke, what we can do is, as you say, 'Kick the can down the road' until a crisis happens and then there's some reckoning. (4) 
Increasingly the contracts require CHPs to use the rental revenue for more than tenancy management and maintenance, which can have an adverse impact on maintenance.

The pie is - the pie is the size of the pie ... they're asking [CHPs] to ... provide wrap-around support, a lot of other things and obviously that hoovers up a lot of the income that could have either been spent on increasing supply or at least keeping the maintenance really tiptop. (8)

There's only so many dollars in the pool and that's a real stretch [for CHPs], so ... when they're called on to do a whole stack more things than what they used to do, sometimes they will ... rob Peter to pay Paul. (5)

A critical issue for the management contracts is the split in responsibility between the CHP and the SHA.

Generally it's the repairs and maintenance [that] is the responsibility of the community housing provider, and any capital activities are the responsibility of the property owner ... But that varies a little in some of the leasing arrangements. (14)

An example of the difference between capital expenditure and operating expenditure is as follows. If a hot-water service unit needs to be replaced, it is capital expenditure (reflecting the accounting definition that capital items have a lifespan greater than one year). If a valve in a hot-water service needs to be replaced it is an operating expense. NAMS (2014: VI) defines 'capital expenditure' (capex) as

Expenditure used to create new assets through addition or renewal or to increase the capacity of existing assets beyond their original design capacity or potential.

Another interpretation of this division was between 'structural' and 'non-structural' maintenance.

[The SHA is] trying to tie us up in knots about what our responsibilities are, when it's not funded. They're arguing over what is and what isn't a structural element of a house and that we should be replacing roofs that are at the end of their lives, because it's not a structural element of a house. (7)

NAMS (2014) and IPWEA (2020a) do not provide a definition.

A recent Supreme Court judgement (Kalnin Corporation Pty Ltd v AAI Ltd t/as Vero Insurance [2017] NSWSC 548 (Vero case)) concluded that 'structural' referred to those building elements that are loadbearing and hence essential to the stability of the building. One participant (7) is describing the attempt by the SHA to shift costs onto the CHP. There are two issues:

- First, standardised terminology and clear definitions are needed.

- Second, management leases pass responsibility for a significant level of maintenance to CHPs, which the CHPs then fund through rental receipts.

The purpose of increasing the lease term from 5 years to 20 or 25 years is to provide CHPs with a lease period that reflects a planned maintenance cycle. This removes a disincentive to investment and provides the basis for obtaining borrowings to fund work. On the other hand, the SHA retains ownership of the asset and is relieved of those costs, but also foregoes income to address the structural issues. Given SHAs have little revenue for renewal this creates:

- problems for the CHP, which is required to meet performance standards

- a poor basis for life-cycle planning. Many CHPs complained of stock they managed that needed to be replaced. 


\subsubsection{Condition assessment rating}

A key issue raised by CHPs was how condition assessment is measured. One CHP (34) argued that the condition assessment (CA) component level was set too high, and as a result the survey methodology used by the SHA misses 30 per cent of the liability. Following is an example of how this may occur.

Condition assessment for wall condition is graded on a scale of 1 to 7 , where $1=$ perfect and $7=$ end of life. The average condition of all walls may be $2 / 7$, but three internal walls might score only score 6/7-for example, they will need plasterboard, plaster and painting within a year. If the average is used at the higher component level, it will indicate nothing to worry about for 10 years or more, and so the SHO will not budget for the plasterboard, plaster and paint. However, this component will fail within a short period of time, requiring unplanned expenditure.

The difference creates a financial problem for the CHP as it will need to fund replacement of the components that do fail, pushing expenditure above what an average rating suggests would be required. The difficulty is that the CHP had insufficient information on which to base a tender bid. The outcome for the CHP is a significant financial loss, which was difficult for them to absorb. The relevant SHA rejected this argument. The Housing Registrar, who does not regulate the SHA, suggested an issue with SHAs exercising market power.

In another state, a CHP (38) reported the condition assessments by the SHA for a particular tranche of management transfers were based on very poor data, and the $\mathrm{CHP}$ was being generously funded for maintenance that was not necessary-and which they were not undertaking - resulting in a financial windfall.

Elsewhere a Housing Registrar (18) reported a widespread problem with CHPs not undertaking the maintenance required by their contracts, and then handing back properties to the state government in a poor state, without penalty.

One of the implications of CHPs assuming more liability than rental revenue affords is avoiding some of the liability. One participant (3) explained that it drives a focus on repairing components rather than full refurbishments. For example, cupboard doors may be replaced in lieu of the whole cupboard

SHAs dictate which condition-rating system is used for reporting purposes. The requirements vary across programs and states/territories. Large CHPs, particularly those operating in multiple states, commonly need to use multiple rating systems and marry them to fit in their own system. Management contracts, more than any other program, are the cause for lack of uniformity of standards in the community sector.

The increase in the use of management contracts raises issues about how properties fit within the life-cycle planning of SHAs. Pawson, Martin et al. (2016: 11) argue that partial responsibility for AM undercuts long-term planning considerations. CHPs held this concern. In particular, they were concerned about properties reaching the end of their life with no plans for replacement.

[CHPs are] not currently involved in any of those redevelopment decisions-all the different stages of strategic asset management, including disposal and redevelopment. (8)

When you get transfer management of properties that are really, really old, it becomes a question of how long do you keep that up before there has to be a change and by that I mean, knock-downs and rebuilds. (5)

The CHPs argued there were many missed opportunities for renewal where they could have provided funding. Sometimes they could convince the SHA, but it involves what they perceived to be an unnecessary and ridiculous struggle.

Because we were funding it ourselves ... we weren't seeking funding support, we weren't seeking land title transfer ... apart from, 'Tick, you can demolish that house which is currently vacant, and we know needs sort of two hundred thousand dollars to bring it up to an acceptable standard to ensure it can sustain the next 30 years'. It took a long time to get that approval. (10) 
Management transfers involve a somewhat uncomfortable split in AM responsibility, and militate against BPAM becoming the industry norm (12). Having only 'maintenance' responsibility does not drive AM.

Management contracts require robust data, agreed standards and measurement, and the ability for CHPs to exercise due diligence. Due diligence is difficult, however, as it is expensive and is not always possible when there are sitting tenants. Plus it would be an additional economic cost for losing tenderers. The policy objectives of contracting-out management-and hence maintenance-need to be reviewed, and if management transfers continue liability for backlogs that would attract specific funding to avoid cost-shifting. Care needs to be exercised to avoid undermining the financial viability of $\mathrm{CHPs}$.

\subsection{Policy development implications}

\subsubsection{Maintenance backlog}

Critically, across both SHAs and the community sector, there are reasons to be concerned about maintenance backlogs and provision for long-term renewal of housing stock. The public housing sector maintenance backlog is a matter of public record, and too many public tenants live in substandard housing as a result. It is also a matter of public record that many community housing tenants-especially Indigenous households living in remote regions -live in substandard housing. This is unacceptable. It also has financial implications, as deferred maintenance may result in premature disposal of the asset. This represents a financial loss and a reduction in provision at a time of growing demand.

The provision of substandard housing reflects non-compliance with regulations-or regulations that fail to provide adequate consumer protection. Residential tenancy law determines minimum mandated standards and, until recently, habitation standards were largely excluded from tenancy legislation. In some states and territories this remains the case.

SHAs have been shifting the liability for maintenance backlogs to the community housing sector via stock and management transfers. It is presumed that if CHPs set rents that capture CRA, that will provide sufficient funds to address this backlog—but this largely depends on the condition of the property. The workshops and interviews revealed liabilities are generally poorly understood prior to transfer, and CHPs often subsequently find that it is not economic for them to hold some properties. The lack of accurate data on dwelling condition is a major stumbling block to transparent and fair contracting-out arrangements.

Too many CHP asset managers reported that maintenance was being deferred when it should not be. Smaller CHPs often pursue growth without consideration of maintenance liabilities or the need to make provision for long-term renewal of housing stock. AMPs are often lodged with the Housing Registrar-and then ignored. It can be difficult for Housing Registrars to understand maintenance liabilities in the absence of more stringent reporting requirements.

\subsubsection{Shift to planned maintenance}

Some SHAs are seeking to minimise reactive maintenance and are shifting their focus to planned maintenance. This trend could be expanded with CHPs being assisted in working out how to do this.

\subsubsection{Purchasing components}

All SHOs face similar issues in working out which dwelling components and fittings to purchase-issues of quality, endurance, environmental impact, etc. An online database of dwelling components and fittings along with assessment of their relative strengths and weaknesses according to specified criteria would particularly assist smaller CHPs. 


\section{Renewal of existing housing stock}

Financial provision for the renewal of existing stock is the essential mechanism by which a SHO renews their existing stock. The current value of social housing is estimated at $\$ 100 \mathrm{~b}$. A large component of public housing portfolios were built between 1950 and 1970, and the buildings are substantially depreciated. While much of the value is in the underlying land value, the cost to replace the housing would be in the order of tens of billions of dollars. Public housing portfolios are contracting, with renewal largely premised on cannibalising existing stock, stock transfer, public-private partnerships and land sales. However, the larger CHPs are making provision for renewal-for example, through active recycling programs aimed at intensifying sites, thus allowing them to simultaneously renew and grow. Worryingly, many asset managers said that smaller CHPs often apply straight-line depreciation in their accounts, but do not allocate funds to capital works. Many smaller CHPs simply do not have a renewal plan.

Ironically, irregular government grants may encourage CHPs to take on new liabilities and ignore existing liabilities. Funding is usually simplistically aimed at delivering growth in the number of dwellings rather than also looking to the sustainability of provision. Moreover, irregular grant programs result in 'lumpy' asset profiles or renewal peaks that exacerbate the challenges for future renewal. 


\section{Social housing asset-disposal practices and issues}

- Disposal involves sale, transfer, demolition or redevelopment.

- Some CHPs are reluctant to dispose of assets even where it is warranted.

- Recycling offers the opportunity for intensification of sites and hence growth.

- SHAs have limited recycling programs financially supported through sale of other property, public-private partnerships and limited capital funding from government.

\section{- Stock transfer:}

- often provides inadequate data to assess liability for maintenance

- leaves many CHPs with backlogs that are difficult to address quickly

- often means tenants remain in housing in poor condition

- often constrains recycling.

\subsection{Introduction}

Asset disposal involves sale, transfer, demolition or redevelopment of dwellings when they reach the end of their life, or when dwellings or sites no longer meet current and future demand for social housing.

In theory, it is possible to maintain a house indefinitely through maintenance and upgrades. However, in practice, the quality of initial construction, the suitability of the design and damage impact on whether or not a house is fit for purpose and economic to preserve. Further, service capacity may be increased if a site is redeveloped-such as when a single detached house is replaced with apartments. Disposal can facilitate a reconfiguration of a portfolio to permit a better response to demand. At the point when it is no longer economic to preserve a dwelling, maintaining such properties represents poor resource management. 
It was clear that many larger CHPs are actively recycling assets. These properties may not necessarily be at the end of their life, but they may have high maintenance costs or present the opportunity for intensification. This active life-cycle management was not as evident among smaller CHPs. SHAs are undertaking limited redevelopment, financially supported through sale of other property, PPPs and limited capital funding from government.

Stock transfer is a key measure that SHAs use to dispose of stock. It requires extensive discussion, as a number of public policy objectives are at play.

\subsection{Sale of assets}

A key strategy for renewal is the recycling of assets. This involves disposal of housing with proceeds supporting replacement or redevelopment of sites. However, some CHPs are reluctant to dispose of assets.

Around recycling and introducing that concept. And it goes against the grain. I tried it a couple of times ... it goes against the grain. 'Oh, you want to sell properties. No. No.' Nobody wants to be perceived as reducing their stock levels ... we can't go backwards in our numbers. We've got to go forwards. (12)

One participant (31) said they had a property with major structural problems that should be sold to avoid costly remediation, but the board had a policy of no disposals. This CHP was less than 20 years old but had only recently developed an AMP reflecting increasing maintenance costs. The prohibition on disposals demonstrates a lack of understanding of ODM and asset recycling as part of a life-cycle strategy.

\subsection{Stock transfer}

Stock transfer involves the transfer of the property title to a CHP. Prior to the mid-2000s there was relatively little stock transfer, but after 2007 the scale and pace increased significantly. A key rationale was the 'physically run-down condition of public housing' (Pawson, Martin et al. 2016: 2).

Unlike most earlier transfers, CHPs aspiring to participate have needed to: engage in highly competitive selection processes; accept significant landlord responsibilities (e.g. the self-funded upgrading of acquired properties); and weigh up the associated risks. (Pawson, Martin et al. 2016: 10)

As a program, stock transfer meant public housing asset managers could focus their maintenance budgets on the stock they would retain.

I have seen within government, knowing that properties are going to be transferred to a community housing provider in the future, 'Oh, let's not spend any money on those because they're going across to the community housing sector.' (9)

CHPs perceive stock transfer as a major opportunity, as the titles can be used as security against borrowings. Along with the increase to their balance sheet, CHPs also accept responsibility for any maintenance backlog, future maintenance, upgrades and future redevelopment. Ostensibly, the liabilities associated with transferred stock will be funded through the CHP's higher rental revenue (as the rent-setting formula recognises CRA as income). A key issue is whether CHPs can assess the liability of properties offered. Given stock transfer is a means by which state governments can rid themselves of some of their public housing maintenance backlog, there was (and is) risk for CHPs if they get their analysis wrong.

There have been two major waves of stock transfer (Pawson et al. 2016). The maintenance liabilities associated with the second wave were much higher than indicated by transfer documentation. CHP due diligence was compromised. 
In multiple cases, CHPs reported that they could not undertake their own condition assessments prior to transfer to determine the veracity of supplied data-if any data were supplied-as properties were generally tenanted. Supplied data had gaps, or was found to be of dubious worth. The window for undertaking condition assessments post-transfer is necessarily short-the longer the period, the more difficult it is to establish whether damage, for example, existed prior to transfer. Condition assessments are costly to undertake and, to be efficient, need be undertaken in locational parcels. This is a large logistical task given tenants need to be given notice and provide access to properties.

In essence, the CHPs could not truly assess the liability, and the liabilities often proved to be higher than expected. Nevertheless Pawson, Martin et al. (2016) found CHPs chose not to hand back properties within the six months provided. There were considerable financial and performance implications as a result.

I call them poison chalices, where you might get an asset transfer ... It's transferred to you. You've taken on \$8,000,000 forward liability. (27b)

[The] transfers ... come over ... with backlog maintenance ... they came over with, literally about $\$ 80,000,000$ worth of backlog. So, this is just maintenance that was due, that's not been done, and we're slowly working our way through that. But it will take us all of 20 years, and even then, I don't think we'll fully catch up ... In the meantime, tenants just have to live with that. (38)

The problem of pricing the backlog incorrectly is delay to maintenance, which undermines tenant support for stock transfer.

Every tenant consultation ... goes to maintenance straight away... when stock transfer happened ... it was done poorly ... Maintenance is one of the reasons, one of the issues that wasn't addressed. (43)

Making CHPs compete with each for stock transfer other holds the possibility that tenderers will over-promise or, given paucity of good data, simply guess. Anecdotally, this is what the researchers had been hearing prior to the research. However, where tenders seek greater evidence of AM capacity, competition was argued as promoting better asset management $(9,3)$ as in a

competitive environment ... [there's] jostling for a better position to be seen to be better than another organisation to gain the transfers or the funding. It generates that higher level of interest and importance in producing an asset management plan to justify — to show the ability of that organisation to manage its assets in the right way. (3)

Pawson, Martin et al. (2016: 37) also found the stock transfer programs they investigated included encumbrances in the agreements intended to ring fence revenues and assets imposing 'important limitations on acquiring CHPs by eliminating the potential for cross-subsidisation and flexibility in portfolio management'. Several years down the track the experience of CHPs appears to be mixed with the largest CHPs reporting few constraints. Small CHPs, however, appear to encounter greater resistance from SHAs when they wish to reconfigure assets in line with good asset recycling strategies.

A key issue identified by one participant (4) in CHPs taking on greater liabilities than they planned for and accepting encumbrances is delays in vital recycling.

What they're actually doing is preserving an aspect of these portfolios because community housing providers don't have the funds to redevelop and sell. And they're not allowed to ... So, the strategic nature of the asset planning is really fragmented. (4) 


\subsection{Policy development implications}

Good policy encourages full life-cycle AM and active recycling programs. This ensures assets are fit for purpose and respond to need while meeting the precepts of good financial resource management. Capital grant funding accordingly needs to ensure disposals can occur when optimal and would not simply be aimed at growth.

The second major wave of stock transfers to CHPs involved cost-shifting, which placed excessive financial burdens on some CHPs and guaranteed some tenants continued to live in substandard housing. The inability of some CHPs to fund redevelopment results in some housing being uneconomic to preserve but unable to be recycled. This represents an economic loss.

Ideally, housing transferred to CHPs should:

- not have any significant backlog of maintenance or if a backlog exists funding should be provided to address it.

- be accessible prior to transfer to permit an appropriate level of due diligence.

- not be encumbered. Instead, the community housing regulatory system should be the mechanism for protecting public investment. 


\section{Financing social housing asset management}

- The current Australian social housing finance system is unviable and unsustainable, and cannot ensure the maintenance, upgrading and redevelopment of housing assets.

- The gap between rental revenue from household rent and the cost of provision is a defining characteristic of social housing in Australia. The revenue-cost gap means current liabilities are not fully funded. The gap is more severe for SHAs than for CHPs.

- This revenue-cost gap drives disposal and privatisation of public housing, along with the transfer of public stock to CHPs.

- Social housing provision exists within an unstable policy environment. CHP AM is a highwire juggling act, as there are innumerable sources of financial risk and little margin for error.

- A property rent system based on the costs of social housing provision, is required. This would ensure:

- the financial viability of SHOs

- housing affordability for tenants through the payment of rent assistance

- vertical and horizontal equity among social housing tenants by varying the level of rent assistance. 


\subsection{Introduction}

AM covers three broad areas: asset creation, AM and asset disposal. SHOs require a source of finance to undertake work in each of these areas. SHOs continually raised questions about the adequacy of capital funds and of their rental revenue stream to cover their ongoing costs (including maintenance) and, whether and how to make provision for the long-term costs of AM.

\subsection{Capital funds}

Land is a permanent asset-barring some extraordinary events such as inundation and contamination. However, dwellings are not permanent, but have a very long life (50 years plus). Asset creation, through which dwellings are acquired, thus requires a large initial capital input.

Currently in Australia, capital is provided either in the form of large grants from state, territory or Commonwealth governments, or borrowings from NHFIC. ${ }^{6}$ Through capital funds, SHOs acquire both:

- a permanent asset-land

- a non-current asset-a dwelling with a very long life, but one which is eventually 'used up' and reaches the end of its economic life.

In financing the provision of social housing, this distinction between land as a permanent asset and dwellings having a very long life is important. In financial terms, the value of the land generally increases over time, whereas the value of the dwelling decreases as it is 'used up'.

Decisions made through the asset creation process impact ongoing costs and thus the required revenue for financial viability. Where assets are created through borrowings, the cost of loan repayments substantially increases a SHO's ongoing costs and thus, their revenue requirements.

Decisions regarding a dwelling's location, size, design, layout, fittings, environmental footprint, etc. may not only increase or decrease capital requirements and impact on tenant's satisfaction but may also impact on a dwelling's maintenance requirements throughout its life and increase or decrease its long-term costs. Development feasibility studies are increasingly including projected maintenance costs, with architectural designs increasingly taking account of asset manager's suggestions to reduce future maintenance liabilities (39).

In Australia, the provision of capital funds, particularly through state, territory and Commonwealth Government grants has been reducing and is inconsistent. ${ }^{7}$ There were notable inputs in the early 1980 s and at times of economic crisis such as the GFC and the COVID-19 pandemic (Victorian Government 2020; Victorian Government 2021a) when housing construction was used as a stimulatory measure. This inconsistent pattern of capital funding has created a 'lumpy' age profile of social housing, with its attendant issues (see Section 9.3). On the other hand, capital funding for new stock will reduce the age profile of a portfolio and may smooth out its lumpiness. Thus government grants will be highly beneficial for SHOs.

Capital funding is always welcome-but it is not always unproblematic.

6 SHAs are subject to public-sector borrowing restrictions and generally do not leverage their assets. There are some exceptions; see, for example, Better Places, Stronger Communities (Pawson, Martin et al. 2016).

7 Within the current piecemeal social housing finance system, capital finance is tightly controlled, with Commonwealth and state and territory governments distributing limited funds on an annual basis. Currently, these capital grants are largely addressing past failures brought about by a failing social housing finance system. These grants are being directed into the demolition of current stock-some of which has deteriorated more quickly than it otherwise would because of inadequate funds and subsequent neglect - and redevelopment of sites, including part sale of these sites. 
Everyone loves ... cutting a ribbon and putting a plaque up, but then they move on and nobody thinks about what happens tomorrow. Even with NRAS [National Rental Affordability Scheme] properties, I don't think people have worked out what happens in year 12 when NRAS stops. (38)

It's reactionary rather than planned ... whenever state or federal government have got a stimulus package or whatever else ... [CHPs are] focussed on that. (28)

The thing that frustrates me is the lack of investment that government is showing ... We see it in spurts like now ... some crisis stimulus with the virus and they're looking to stimulate the economy and low and behold ... social housing. (37)

New housing entails liabilities associated with its renewal and maintenance. Irregular funding programs also typically seek to increase the amount of social housing. With the exception of SHAs, very few SHOs would have housing ready to be redeveloped at short notice. Irregular grants tend to focus on new sites, and so portfolios grow without ageing stock being replaced. Ageing stock may later be replaced, which is how some larger CHPs can maximise opportunities to grow while addressing renewal.

\subsection{Provision for upgrades, renewal and redevelopment}

All assets are eventually retired. In the case of social housing, the need for continuing service provision requires that dwellings be replaced at the end of their life. In the meantime, major components of dwellings-such as bathrooms and kitchens - can be replaced a number of times during the life of the dwelling. In theory, provision for upgrading, renewal and redevelopment will reflect their projected costs.

Some Tier 1 providers and housing associations are addressing the need for this future investment.

Whether it's a sinking fund or whether it's depreciation, it's accurately working out ... we don't ever lose sight of the fact that we won't risk the viability of the underlying organisation to build that growth. (7)

Other participants from smaller CHPs were concerned that provision was failing to reflect need.

Normally the depreciation is ... a theoretical depreciation rather than linked to the life-cycle maintenance plan of the asset. (28)

Some CHPs, for example (3), have very active recycling programs, involving intensification of sites. A lumpy investment profile creates challenges, both for funding of capital expenditure and marshalling organisational capacity to deliver capital works. To address such constraints, capital works will typically be smoothed across years.

We ... [have] a 'sawtooth' [profile] over 10 years. We're going to spend massive and then nothing ... I thought, 'That's not working.' (38)

So there is an element of smoothing that needs to go on around that, and knowing what your resource capacity is to deliver that. Sometimes you have to pull the odd thing forward or push the odd thing back and try, not make it a straight depreciation profile, but at least make it deliverable in terms of your resources that you have available. (15)

The largest CHPs are planning renewal, but there were concerns among small CHPs regarding lack of planning.

There just hasn't been ... enough money to get rid of the old stock and replace it with new stock. (4)

It really is that balance between incoming and repairs and maintenance, and then what's left over to do your capital works, which ... is the thing possibly that might get dropped [when] you're going towards the red. (39) 
An adequate revenue stream is a key issue, along with capacity (see Section 5.6).

The point of BPAM is to cut your cloth according to your means. It appears that many smaller CHPs may be failing to consider what will occur when their housing is no longer fit to live in. There are a number of aspects. One of these was the view that CHPs are applying depreciation for accounting purposes, but without making any provision for physical depreciation.

The depreciation coming out of the financial valuation, it's very different to the long-term renewals required from a life-cycle perspective. (3)

The key concern was an adequate revenue stream for capital expenditure.

We don't have sinking funds ... We don't put aside the depreciation element within the annual financials, which theoretically [we] should. (30)

Sinking funds are something that's not common in Community Housing. In development they understand it, but we've never used it. I know I need something like that. (38)

That 2 per cent just goes into general day-to-day cashflow and it's never captured, and it's never set aside. (28)

Here it is important that we distinguish different meanings of depreciation.

Depreciation is an accounting term that seeks to adjust the financial position of a SHO at a given time.

In a financial context, it refers to the reduction in the monetary value of an asset over time as the property condition deteriorates as the dwelling ages, and as supply and demand conditions vary for a particular type of dwelling or for dwellings in a particular area.

In this context, depreciation impacts on an organisation's balance sheet. While depreciation as an accounting mechanism bears some relationship to the physical deterioration and technological obsolescence of dwellings, it is based on the current market value of property (both land and dwelling) and thus may not reflect a dwelling's current physical and technological state or its replacement cost.

In the context of AM, depreciation reflects the asset-utilisation cost. It is an annual financial provision based on:

1. An estimate of the cost of replacing the dwelling at the end of its life.

2. The estimated life of the dwelling, or rate at which the dwelling is 'used up'.

This provision can either:

- extend the life of dwelling through upgrading

- replace the dwelling with another.

For example, the Queensland Department of Housing and Public Works Maintenance Management Framework recommends minimum funding of 1 per cent of the building asset replacement value (ARV) of the portfolio (QDHPW 2017). Traditionally, SHAs have used a benchmark of a dwelling's life being 50 years and thus, an annual provision of 2 per cent of its replacement value. 
The annual provision for depreciation or an asset-utilisation cost is required when the capital used by a SHO to acquire dwellings is free equity ${ }^{8}$ but future free equity is not envisaged. The objective of the $\mathrm{SHO}$ is an ongoing provision of housing at contemporary standards.

Where the capital used by a SHO to acquire dwellings is borrowings, that part of repayments on borrowing - that is, return of capital and interest payments - related to the dwelling (and not to the land) stand in place of the asset-utilisation cost. At the end of the life of the dwelling, the $\mathrm{SHO}$ will be in the same position as it was at the beginning, with capital finance for the replacement dwelling or for major upgrade, refurbishment or redevelopment of the dwelling once again borrowed. The cost of this capital becomes the new point of reference.

Corporate real estate commonly determines the asset cost utilisation by reference to the straight-line depreciation approach applied for accountancy purposes. That is, 2 per cent of the value of the asset is set aside for capital expenditure on assets. For-profit businesses are able to claim this spending on depreciation as a tax deduction. SHOs cannot take this approach (NAMS 2014, section 5.1). SHOs need a sinking fund that reflects the future liability for asset-utilisation costs. The extent of need will vary according to the portfolio renewal profile. Figure 11 depicts a hypothetical SHO asset profile. It compares the asset-utilisation liability on an annualised basis with annual contributions into a depreciation reserve sinking fund. It shows the emergence of a large revenue-cost gap around the year 2042 when a significant part of the portfolio needs replacing.

Any mismatch between the asset-utilisation cost and funds in the depreciation reserve can be addressed through:

- selling properties that fit within that renewal period

- redeveloping properties to change the profile

- deferring renewals

- increasing the depreciation reserve without increasing rent

- increasing rental revenues by selecting higher-income tenants.

Figure 11: Example portfolio renewal profile

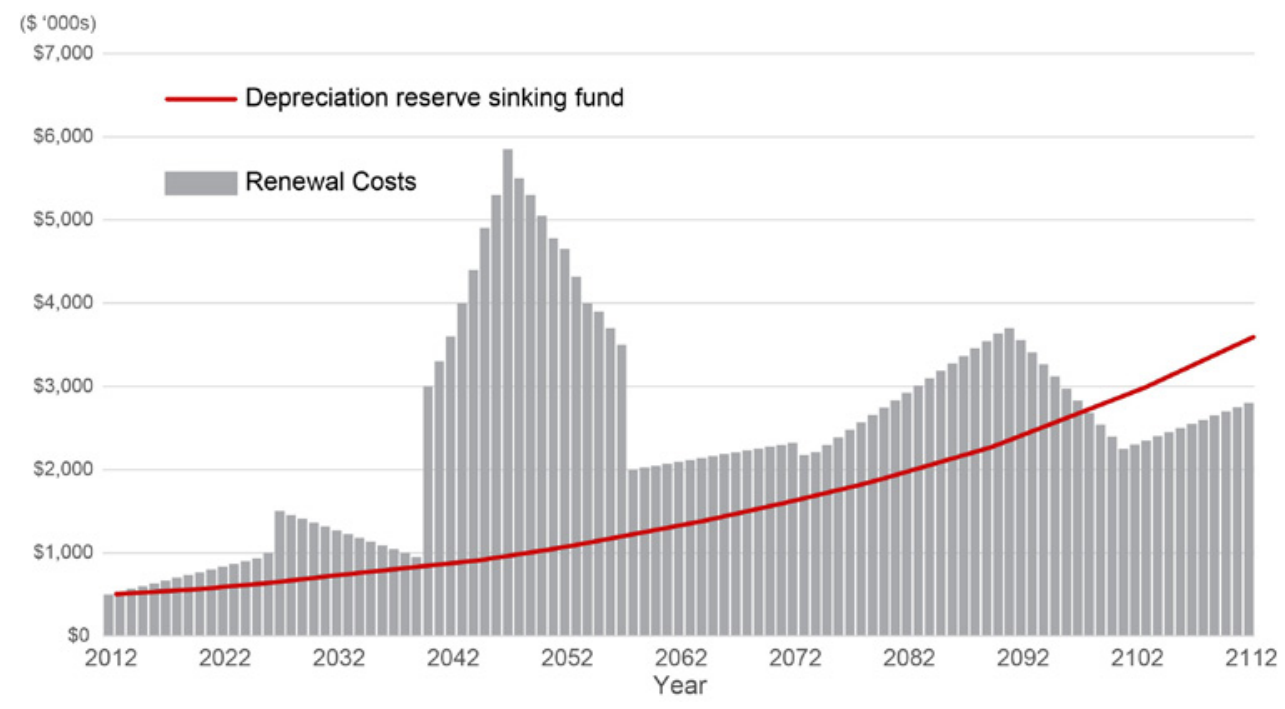

Source: Logan (2020)

8 Free equity includes those forms of equity that do not require a SHO to provide a financial return to an 'external' equity holder and so does not impact on the cost of capital. It includes grants, interest-free loans, land donations and long-term leases of land rent-free. 
Ideally, a less 'lumpy' profile is desirable, and some degree of smoothing out is possible through pulling some renewals forward, while deferring others.

Historically, SHOs have addressed the mismatch between ongoing costs, including maintenance and the asset-utilisation cost, by:

- deferring maintenance and renewal of dwellings-hence the poor condition of some social housing stock

- selling stock and reinvesting these funds into the redevelopment of other stock.

However, the favoured method for meeting the mismatch is to increase rental revenues by:

- increasing property rents to market rents

- adjusting the rent-setting formula and increasing household rents (McNelis 2006b; McNelis and Burke 2004).

The issue of an adequate revenue stream that allows SHOs to meet all their ongoing costs, including provision for the upgrade and replacement of stock, still fundamentally remains an unresolved element of the social housing finance system.

\subsection{Revenue does not cover the costs of provision}

Australia is one of a handful of nations in which housing affordability is achieved by charging households rents. It is unique, in that SHOs are not compensated in any way for housing very low-income households, nor for the gap between household rents and property rents, nor the gap between household rents and the ongoing costs of providing housing. The gap between household rents and the cost of provision is significant, particularly in the public housing sector.

The decline in public housing funding has resulted in an ageing portfolio and a maintenance backlog. Most SHA operations are internally funded, with little in the way of ongoing government budget appropriations. The ongoing residualisation of public housing means that rental revenue is declining (Pawson, Martin et al. 2016). Hence the funds for maintenance are increasingly constrained every year. Without government capital grants or access to borrowing, redevelopment is constrained by the ability of the SHA to raise funds other than through disposal of stock or PPPs.

[SHAs] have struggled with asset management over the years. There has been greater focus on the capital programs ... frankly because they're the ones governments and ministers are much more interested in, because there are more announceables. And the repairs and maintenance side of the budget, the operating expenditure side rather than the capex [capital expenditure], is the side that has faced the most difficulty. (14)

CHPs are less constrained in their revenue-raising than SHAs. CHPs do not receive any recurrent operating subsidies from governments, but as their tenants are eligible for CRA, they can adjust their rent-setting formula to capture this CRA. CHPs have access to bank finance and, as a result of the recent establishment of NHFIC, can access low-cost, long-tenor debt. Nevertheless, a revenue-cost gap remains.

Just an income-based rent doesn't support any development. No development washes its own face

... You cannot build a social house ... with the revenue stream that is coming from it. (26a)

CHPs with charitable status are able to house higher-income households provided the rent involves a discount of at least 25 per cent to market rates. This allows CHPs to charge below-market property rents. Many use their capacity to service higher-income households as a means to generate cross-subsidies. 
So, for one property l've got ... a Mum and two kids in a three-bedroom double-storey townhouse and their rent is like $\$ 180$ a week, which barely covers me managing the property ... Which is why we have got about 20 odd properties that are 75 cent [of] market rent. So, they bring in ... sometimes double or three times our lowest income-based rent ... [which] makes a huge difference for us for maintenance. (30)

CHPs therefore have greater ability than SHAs to adjust their tenant profile to ensure both cashflow and financial viability. CHPs also commonly use profit derived from other government-funded welfare programs to cross-subsidise their community housing. CHP charity status means they can receive philanthropic donations. At times governments will provide capital grants to $\mathrm{CHPs}$ - programs that are typically piecemeal and irregular.

Programs pop up here and there and we go and grab them, as a CHP, and they're great when they happen, but then there's a gap between them. (4)

Contracts to manage public housing on behalf of SHAs is another source of income for CHPs. In theory, these contracts could be profitable for CHPs. The CHP collects higher rents than SHAs in exchange for tenancy management and maintenance.

However, the revenue-cost gap can unexpectedly widen or narrow, reflecting changes in policy and creating unexpected challenges for business planning and AM. An example is when state governments started requiring CHPs to take tenants from priority waiting lists, thus constraining their ability to adjust the tenant profile to ensure profitability and cashflow. Priority tenants tend to be the lowest-yielding in terms of revenue and the highest-cost tenants (Pawson, Martin et al. 2016).

We are restricted to the ... Housing Registrar ... So you're trying to find, particularly new tenants, you do try and control the mix, [to] change the social mix. (38)

Then you're restricted in terms of where your investments are. Because you need to target those priority cases. And 70 per cent are significant. (12)

This constraint on revenue jeopardises development of social housing by $\mathrm{CHPs}$-and also places pressure on maintenance.

Governments of all persuasions for some reason expect the social housing portfolios to be self-funded off a rent-setting model that doesn't provide the income to adequately fund the maintenance. (7)

The revenue-cost gap has two major ramifications for AM.

The first is whether there are adequate funds for renewal of stock. In some industries the norm is to run to failure, with disposal of the asset at the end of its life. However, social housing need is likely to continue, hence recycling of assets is necessary to ensure ongoing provision of the service.

The second is whether there are adequate funds available to undertake maintenance to preserve and extend the life of the asset. 


\subsection{Policy development options}

AM covers three broad areas: asset creation, asset management and asset disposal. A viable strategic AMP must be underpinned by a financial management strategy that will do the following:

1. Provide a steady stream of capital for the acquisition of dwellings that meet the needs of current and future tenants; provide a defined standard of living and defined LOS; as well as incorporating elements that reduce long-term costs for both the $\mathrm{SHO}$ and tenant.

2. Cover the ongoing costs of maintaining dwellings over their economic life-which includes emergency repairs, reactive repairs and planned maintenance.

3. Cover the asset-utilisation cost of dwellings so that funds are available for the upgrade or replacement of dwellings at the end of their economic life.

4. Address the backlog of maintenance, upgrade, renewal and redevelopment of dwellings (given the past history of social housing).

This financial management strategy will allow a SHO to remain financially viable.

One clear finding from the literature, the workshops and the interviews is that the Australian social housing finance system is unviable and unsustainable and does not ensure that the four objectives outlined will be achieved. It needs a major overhaul-indeed, radical reform.

The first and fourth components of a financial management strategy would be met primarily through capital grants supplemented by borrowings. Commonwealth and state government grants provide an essential base for the expansion of social housing, and governments need to make further substantial investment.

However, the current levels of capital grants will not allow SHOs to meet the current and future demand for social housing. SHOs need access to capital funds for the acquisition of housing stock beyond this very limited source. Currently, SHAs cannot borrow funds and their borrowing restrictions should be relaxed. CHPs and IHOs can borrow funds, primarily through the recently established NHFIC but, despite high levels of equity, their borrowing capacity is severely restrained by their revenue flows.

A grossly inadequate revenue stream (from rents and subsidies) for social housing has placed the renewal of existing stock at risk. The number of social housing dwellings has been declining for many decades. But numbers will drop dramatically in the near future unless provision is made to redevelop post-WWII housing stock that is reaching the end of its life. The value of public housing stock in Australia is estimated at $\$ 100$ billion. The replacement cost of existing dwellings will therefore be significant. Inevitably, there will be disposals driven by crisis without significant capital funding.

Currently the expectation is that SHOs will cover the second and third components of a financial management strategy through rental revenue derived from household rents. The current social housing system is predominantly occupied by very low-income households on social security (Centrelink) payments, and thus the level of social housing rental revenue is largely determined by the level of these payments. (Rental revenue per dwelling tends to be higher in community housing compared to public housing because community housing tenants are eligible for CRA.)

Within the parameters of the current social housing finance system, policy options for increasing the level of rental revenue are limited. The Commonwealth Government can increase the rental revenue of SHOs by:

- increasing Centrelink payments

- increasing rental assistance, and making all tenants eligible for rental assistance. (The revenue-cost gap is particularly large for recipients of JobSeeker and Youth Allowance payments.) 
A third option, adopted in some countries, is to compensate SHOs for housing low-income and very low-income households by providing specific operating subsidies to $\mathrm{SHOs}$ based on the long-term costs of providing social housing; this would allow SHOs to meet the costs of upgrading, renewing and redeveloping their stock.

SHOs can increase their rental revenue by either of these methods:

Changing their eligibility criteria for social housing and providing housing to higher-income tenants, and strictly limiting the proportion of tenants in receipt of very low incomes - such as recipients of JobSeeker and Youth Allowance.

1. Changing their household rent formula-for example, increasing the proportion of income to 30 per cent.

2. The first option shifts the focus of social housing away from targeting those on low and very low incomes. The second option will undermine a primary objective of social housing: housing affordability.

Previous AHURI research has traced how property rents and household rents have increased over the past six decades in order to maintain the financial viability of SHOs (McNelis 2006a; McNelis and Burke 2004). This has been to the detriment of achieving housing affordability. Modelling for this research based on 2004 data-so now somewhat outdated-indicates that nearly all household types in social housing, even with CRA included, required an income higher than their Centrelink entitlements in order to have sufficient income to meet a minimum standard of living. This is particularly so for household types receiving Newstart (JobSeeker) (McNelis 2006a; McNelis 2006b).

As noted in Section 3.2, housing affordability is achieved in most other countries through housing subsidies paid directly to tenants and thus, the way in which housing affordability and financial viability are achieved are separated. However, in Australia both housing affordability for tenants and the financial viability of SHOs are achieved through household rents, which means that decisions about housing affordability or financial viability impact on one another. Thus, a key tension in the Australian social housing finance system is between a key objective of social housing, housing affordability for tenants, and a prerequisite for the achievement of that objective, financial viability for SHOs.

One way of resolving this tension is to break the nexus between housing affordability for tenants and financial viability for SHOs and develop a new social housing finance system. This can be achieved by

- abolishing household rents and moving to a single property rental system based on the costs of providing social housing

- adjusting Centrelink payments and rent assistance so that the key objective of housing affordability is achieved.

A recalibration of Commonwealth payments would ensure that the gap between rental revenue and the ongoing costs of providing social housing can be closed. In considering the adequacy of different types of Centrelink payments, we can distinguish their different contributions to SHO operating costs, particularly AM costs.

On the one hand, all Centrelink payments (pensions and allowances) could be adjusted so that recipients have sufficient income to meet the costs of reactive and planned maintenance, rates, insurance and administration. These costs are common across all tenures.

On the other hand, rent-assistance payments need to meet the depreciation or asset-utilisation cost-that is, the cost of upgrading, renewal and redevelopment of housing stock-as these costs are particular to the rental sector.

A consideration of such contributions and an adjustment of the levels of Centrelink payments to take account of this could provide the basis for a transition to a property rent system based on the costs of social housing provision, one that:

- ensures the financial viability of SHOs

- ensures housing affordability for tenants through the payment of rent assistance

- ensures vertical and horizontal equity among social housing tenants by varying the level of rent assistance. 


\section{Conclusion}

This research aimed to understand current AM practices of Australian SHOs and develop a suitable BPAM framework for social housing in Australia-an Australian social housing best practice asset management Framework. The research was informed by three research sub-questions:

- What BPAM principles and processes should guide the Framework?

- What are the specific and unique attributes of social housing provision that need to be incorporated into the Framework?

- What are the specific and unique features of social housing providers that need to be recognised in the development of the Framework?

Our research has addressed each of these questions and, in summary, the researchers have come to the following conclusions.

\subsection{An Australian social housing best practice asset management framework}

The research aimed to develop an Australian social housing best practice asset management Framework that:

- outlines AM processes and criteria for making decisions

- is suitable to the specific and unique aspects of social housing

- is flexible enough to be used by different types of social housing providers

- provides metrics to drive organisational excellence

- provides the basis for national regulation and policymaking.

The Framework developed through this research reflects the best practices provided by IPWEA and NAMS. This framework incorporates AM processes and criteria for making decisions and the type of metrics required to drive organisational excellence. It also incorporates the unique features of Australian social housing as identified through the literature and by the research participants. The Framework is flexible enough to be used by different types of social housing providers, and is provided in Appendix 1 and as a standalone document. This framework could be used by a $\mathrm{SHO}$ anywhere in the world.

The Framework incorporates both a process for developing an best practice AMP and its scope reflecting a life-cycle approach to managing assets, which puts the 'customer' (or the tenant, in the case of social housing) at the centre of provision. The scope of a social housing AMP involves asset creation, asset management and asset disposal informed by current and future demand for social housing, and by an assessment of environmental, social, economic, political and cultural costs and benefits as depicted in Figure 7. 


\subsection{Principles and processes}

ISO 55000 outlines an international standard for asset management-its principles, terminology and systems. This standard shifts:

- from tactical to strategic

- from isolated life phases and functional disciplines to a full life-cycle view

- from individual assets to asset systems and systems of systems

- from management of discrete activity types to an integrated management system.

As a result of our research, we propose the principles and processes of BPAM based on ISO 55000, as espoused by IPWEA. These principles are that:

- the AM strategy is clearly derived from a corporate strategic plan

- long-term, whole-life plans and optimisation of cost/risk/performance

- objectives and performance measures are aligned and complementary

- systems are integrated, used and understood

- competencies and training are aligned to roles, responsibilities and collaborative requirements

- strategies are risk-based, with appropriate use of predictive methods and ODM techniques to identify the optimum long-term AMP to deliver a particular level of service

- improvement is iterative and continuous.

\subsection{Unique features of Australian social housing provision}

Compared with the private rental sector, the unique features of Australian social housing provision are as follows:

- Its target group are those on very low incomes, often with complex needs, and those whom the private rental market fails or excludes.

- Rental revenue is severely constrained and barely covers operating costs, let alone the long-term costs of upgrade, renewal and redevelopment of housing stock.

- Capital funding for acquisition is dependent upon grant allocations from Commonwealth and state and territory governments, which have been 'lumpy' and largely overtaken by the demands to meet backlog maintenance, upgrade, renewal and redevelopment of current housing stock.

- Housing stock is held for very long terms, rather than turned over regularly to realise capital gains.

- The provision of social housing is increasingly cognisant of fuel poverty, the importance of energy-efficient homes and appliances, and the long-term sustainability of their housing stock.

- Eviction is an option of last resort.

- The federal political system, with its entrenched vertical fiscal imbalance, makes consistent capital funding for acquisition difficult and creates a patchwork of regulation.

\subsection{Unique features of social housing providers}

Compared with the private-sector landlords, social housing providers:

- have large, even very large, housing portfolios

- have a more complex mission, incorporating social objectives and wider social responsibilities 
- are subject to additional regulation and oversight because they provide social benefits (even though both private landlords and $\mathrm{SHO}$ are subject to residential tenancies legislation)

- often have logistical challenges for AM because of low-density populations in cities and dispersed housing across large geographical areas.

\subsection{Major barriers to implementation}

The social housing sector is seriously constrained in its ability to maintain, renew and configure stock to meet current and future demand, and faces a number of major barriers to the implementation of BPAM.

An inadequate and failing social housing finance system is at the heart of the AM challenges the sector faces. In particular, an inadequate revenue flow is the fundamental reason why SHOs are unable to maintain, upgrade and renew stock to meet current and future demand. SHO revenue flow is highly constrained by their tenant profile and target groups - that is, those households in receipt of very low incomes from Centrelink payments. This will continue unless the Commonwealth Government increases these payments or, alternatively, provides operating subsidies to $\mathrm{SHOs}$ as compensation for providing housing to very low-income tenants.

BPAM requires AM to be a whole-of-organisation commitment embedded through data collection and analysis, integration of systems and continuous improvement. Recognition that social housing is a distinct asset subclass is an important first step, as managing social housing assets has distinctly different challenges compared to other types of housing management.

Very few SHOs practice BPAM. AM practices vary greatly and urgently need improvement. A common AM framework would foster improved performance among SHOs and allow comparison between them. However, entrenched interests and considerable committed investment in differing AM systems among some SHOs will make agreement about a common AM framework difficult.

Knowledge of AM extends beyond those responsible for AM on a day-to-day basis to senior managers, governance boards, regulators and policy makers. A major challenge for government, SHOs and regulators is to commit to and develop a coordinated approach to building human and technological AM capacity_including skills development, training and education - to address current and future AM needs.

The lack of a uniform, robust habitation standard permits unacceptable living conditions for tenants. Standardisation of terminology, performance standards and measures would drive efficiencies. For more than a decade, CHPs have been subject to regulatory oversight by an external agency (NRSCH). CHP registration has proven to be an effective mechanism to support the development of the sector and ensure positive outcomes for tenants. A genuinely national uniform scheme would remove or reduce many transaction costs and support AM capacity building. While CHPs are currently regulated by external agencies, SHAs are not. The introduction of a common regulatory environment for both CHPs and SHAs would require agreement across state and territory jurisdictions. Ultimately, the goal of state and territory governments should be to require BPAM across the social housing sector. BPAM is the only way in which critical AM risks can be addressed.

\subsection{Summary}

Social housing AM is in need of thoroughgoing reform. However, the issues raised in this report are not simply confined to AM. If SHOs are to take responsibility for acquiring, maintaining, upgrading, renewing and redeveloping housing stock and establishing themselves as sound asset managers, then the social housing sector needs a new operating framework. It cannot happen through a piecemeal approach focussed exclusively on AM. It will only happen through a consolidated approach that addresses the broad range of issues identified in this report. 


\section{References}

Aboriginal Affairs New South Wales (2013) Review of the Aboriginal Land Rights Act 1983: consultation paper: land rights, housing and regulation, Aboriginal Affairs New South Wales, Sydney, accessed 25 September 2020, https:// metrolalc.org.au/wp-content/uploads/2013/04/ALRA-Review-Consultation-Final-Summary-Consultation-Paper2.pdf.

AGDSA (2017) South Australian Housing Trust, Auditor-General's Department South Australia, Adelaide, accessed 26 August 2020, https://www.audit.sa.gov.au/LinkClick.aspx?fileticket=5rD-RmNhSw4\%3D\&tabid=499\&portalid=0.

AGT (2005) Public housing: meeting the need?, Auditor-General of Tasmania, Hobart, accessed 10 September 2020, https://www.audit.tas.gov.au/wp-content/uploads/Special-Report-No-57-Public-Housing-Meeting-the-NeedAugust-20051.pdf.

AGV (2004) Maintaining public housing stock, Auditor-General Victoria, Melbourne, accessed 10 September 2020, https://www.audit.vic.gov.au/sites/default/files/20040603-Maintaining-Public-Housing-Stock.pdf.

AGWA (2003) A roof over our heads: maintenance of public housing performance examination, Auditor-General for Western Australia, Perth, accessed 10 September 2020, https://audit.wa.gov.au/wp-content/uploads/2013/05/ report2003_08.pdf.

AHO (2019) Build and grow rent policy, NSW Aboriginal Housing Office, Parramatta, accessed 25 September 2020, https://www.aho.nsw.gov.au/_data/assets/pdf_file/0003/726627/AHO-Rent-Policy-Septemebr-2019.pdf.

AlHW (2019a) National social housing survey 2018: key results, Australian Institute of Health and Welfare, Canberra, accessed 26 August 2020, https://www.aihw.gov.au/getmedia/46555204-b4ca-4429-9d1a-a1797e6a06cd/aihwhou-311.pdf.aspx?inline=true.

AlHW (2019b) National social housing survey 2018: supplementary data tables, Australian Institute of Health and Welfare, Canberra, accessed 26 August 2020, https://www.aihw.gov.au/getmedia/160eea41-417e-4efa-8b20-ce9677f8dd87/ aihw-hou-311.xlsx.aspx.

AlHW (2019c) Profile of Indigenous Australians, Australian Institute for Health and Welfare, Canberra, accessed 5 December 2020, https://www.aihw.gov.au/reports/australias-welfare/profile-of-indigenous-australians.

AlHW (2020) Housing assistance in Australia 2020, Australian Institute of Health and Welfare, Canberra, accessed 26 August 2020, https://www.aihw.gov.au/reports/housing-assistance/housing-assistance-in-australia-2020/ contents/summary.

Alexander, K. (1993) 'The emergence of facilities management in the United Kingdom National Health Service', Property Management, vol. 11, no. 1: 31-41, doi: 10.1108/EUM0000000003392.

Alexander, K., Atkin, B., Bröchner, J. and Haugen, T. (2004) Facilities Management: Innovation and Performance, CRC Press, London.

AMC (2009) Introduction to Asset Management, Asset Management Centre, Toronto.

ANAO (1996) Asset management handbook, Australian National Audit Office, Canberra, accessed 9 October 2020, https://web.archive.org.au/awa/20000706234421mp_/http:/www.anao.gov.au:80/bpg/wanao.pdf.

AONSW (2013) Making the best use of public housing, Audit Office of NSW, Sydney, accessed 26 August 2020, https:// www.audit.nsw.gov.au/sites/default/files/pdf-downloads/2013_Jul_Report_Making_the_Best_Use_of_Public_Housing.pdf. 
APCC (2001) Asset management 2001, Australian Procurement and Construction Council, Canberra.

APCC (2020) Strategic asset management framework: public sector, Australian Procurement and Construction Council, accessed 10 September 2020, https://9104f275-f216-4fd2-9506-720eb252b4fc.filesusr.com/ugd/e62cfd_a8c623390 aea458e841363415cf26007.pdf.

Australian Government (c. 2013) Community living area land reform in the Northern Territory: discussion paper, Department of Families, Housing, Community Services and Indigenous Affairs, Canberra, accessed 23 November 2020, https:// www.dss.gov.au/sites/default/files/documents/03_2013/community_living_area_land_reform_in_the_northern_territory _discussion_paper.pdf.

Bavan, M. and Shamsuddin, S. (2007) 'Policy briefs: the transition to asset management in public housing', Cityscape, vol. 9, no. 2: 185-192.

Boelhouwer, P., van der Heijden, H. and van de Ven, B. (1997) 'Management of social rented housing in Western Europe', Housing Studies, vol. 12, no. 4: 509-529, doi: 10.1080/02673039708720913.

Bowles, G., Dagpunar, J. and Gow, H. (1997) 'Financial management of planned maintenance for housing associations', Construction Management and Economics, vol. 15, no. 4: 315-326, doi: 10.1080/014461997372872.

Brackertz, N., Davison, J. and Wilkinson, A. (2017) How can Aboriginal housing in NSW and the Aboriginal Housing Office provide the best opportunity for Aboriginal people?, AHURI Research Paper, Aboriginal Housing Office NSW and Australian Housing and Urban Research Institute Limited, Melbourne, https://www.ahuri.edu.au/research/researchpapers/how-can-aboriginal-housing-in-nsw-and-the-aboriginal-housing-office-provide-the-best-opportunity-foraboriginal-people.

Braun, V. and Clarke, V. (2006) 'Using thematic analysis in psychology', Qualitative Research in Psychology, vol. 3: 77-101, doi: 10.1191/1478088706qp063oa.

Bryant, L. (2012) 'An assessment of development funding for new housing post GFC in Queensland, Australia', International Journal of Housing Markets and Analysis, vol. 5, no. 2: 118-133, doi: 10.1108/17538271211225887.

Central Land Council (n.d.) Community living areas, Central Land Council, accessed 4 September 2020, https://www.clc. org.au/index.php?/articles/cat/community-living-areas.

Chan, M., Fowler, J., Vedelago, F. and Westbrook, S. (2010) Successes and failures in Australian Indigenous housing, Bower Studio, Parkville, accessed 31 August 2020, http://citeseerx.ist.psu.edu/viewdoc/download?doi=10.1.1.458.1604\&rep= rep1\&type=pdf.

CHIA (2020) National community housing standards, Community Housing Industry Association, Sydney, accessed 10 September 2020, https://www.communityhousing.com.au/national-community-housing-standards.

CHIA NSW (2020) Asset managers network, Community Housing Industry Association NSW, Sydney, accessed 3 September 2020, https://communityhousing.org.au/services/networks/.

Chotipanich, S. (2004) ‘Positioning facility management', Facilities, vol. 22, no. 13/14: 364-372, doi: 10.1108/02632770410563086.

Commonwealth of Australia (2017) Remote housing review: a review of the National Partnership Agreement on Remote Indigenous Housing and the Remote Housing Strategy (2008-2018), Commonwealth of Australia, Department of the Prime Minister and Cabinet, Canberra, accessed 25 November 2020, https://parliament.nt.gov.au/_data/ assets/pdf_file/0003/706683/TP-5-1.pdf.

Czischke, D. (2009) 'Managing social rental housing in the EU: a comparative study', European Journal of Housing Policy, vol. 9, no. 2: 121-151, doi: 10.1080/14616710902920223.

Daly, D., Tibbs, M., Harada, T., Waitt, G. and Cooper, P. (2019) Guide to implementing low carbon retrofits for social housing, CRC for Low Carbon Living, Sydney, accessed 3 September 2020, https://apo.org.au/sites/default/files/ resource-files/2019-10/apo-nid270041.pdf.

Deakin, M. (1999) 'The development of local authority property management', in M. Deakin (ed.) Local Authority Property Management: Initiatives, Strategies, Re-Organisation and Reform, Taylor \& Francis, Milton Park.

Donald, O. (2001) National housing policy project, AHURI Research and Policy Bulletin 3, Australian Housing and Urban Research Institute Limited, Melbourne, https://www.ahuri.edu.au/research/research-and-policy-bulletins/3. 
DTF (2016) Asset management accountability framework, Victorian Department of Treasury and Finance, Melbourne, accessed 10 September 2020, https://www.dtf.vic.gov.au/infrastructure-investment/asset managementaccountability-framework.

Eringa, K., Spring, F., Anda, M., Memmott, P., Long, S. and West, M. (2008) Scoping the capacity of Indigenous Community Housing Organisations, AHURI Final Report No. 125, Australian Housing and Urban Research Institute Limited, Melbourne, https://www.ahuri.edu.au/research/final-reports/125.

FaHCSIA (2008) National Indigenous housing guide (3rd ed.), Australian Government Department of Families, Housing, Community Services and Indigenous Affairs, Canberra, accessed 31 August 2020, https://www.dss.gov.au/sites/ default/files/documents/05_2012/housing_guide_info_intro.pdf.

FFH (2021), Health and human services climate change adaptation action plan 2022-2026, Government of Victoria, Melbourne, accessed 28 July 2021, https://engage.vic.gov.au/aaps-healthandhumanservices.

Flood, J. (2004) 'Australia', in V. Gruis and N. Nieboer (eds), Asset Management in the Social Rented Sector: Policy and Practice in Europe and Australia, Kluwer Academic Publishers, Dordrecht. p.19-37.

Gruis, V. and Nieboer, N. (eds) (2004a) Asset Management in the Social Rented Sector: Policy and Practice in Europe and Australia, Kluwer Academic Publishers, Dordrecht. p.1-18.

Gruis, V. and Nieboer, N. (2004b) 'Guest editorial: market orientation in social housing management', Property Management, vol. 22, no. 3: 186-188, doi: 10.1108/02637470410544977.

Gruis, V. and Nieboer, N. (2004c) 'Strategic housing management: an asset management model for social landlords', Property Management, vol. 22, no. 3: 201-213, doi: 10.1108/02637470410544995.

Gruis, V. and Nieboer, N. (2007) 'Government regulation and market orientation in the management of social housing assets: limitations and opportunities for European and Australian landlords', European Journal of Housing Policy, vol. 7, no. 1: 45-62, doi: 10.1080/14616710601132542.

Gruis, V., Nieboer, N. and Brown, T. (2003) 'What determines asset management approaches in the social rented sector?', ENHR Conference, Tirana, 26-28 May.

Gruis, V., Nieboer, N. and Thomas, A. (2004) 'Strategic asset management in the social rented sector: approaches of Dutch and English housing associations', Urban Studies, vol. 41, no. 7: 1229-1248, doi: 10.1080/0042098042000214761.

Habibis, D., Phillips, R., Spinney, A., Phibbs, P. and Churchill, B. (2016) Reviewing changes to housing management on remote Indigenous communities, AHURI Final Report No. 271, Australian Housing and Urban Research Institute Limited, Melbourne, https://www.ahuri.edu.au/research/final-reports/271, doi: 10.18408/ahuri-4103701.

Hall, J. and Berry, M. (2004) Operating deficits and public housing: policy options for reversing the trend, AHURI Final Report No. 55, Australian Housing and Urban Research Institute Limited, Melbourne, https://www.ahuri.edu.au/ research/final-reports/55.

Hall, J. and Berry, M. (2006) Indigenous housing: assessing the long-term costs and the optimal balance between recurrent and capital expenditure, AHURI Final Report No. 93, Australian Housing and Urban Research Institute Limited, Melbourne, https://www.ahuri.edu.au/research/final-reports/93.

Hall, J. and Berry, M. (2007a) Operating deficits and public housing: policy options for reversing the trend, 2005/06 update, AHURI Final Report No. 106, Australian Housing and Urban Research Institute Limited, Melbourne, https:// www.ahuri.edu.au/research/final-reports/106.

Hall, J. and Berry, M. (2007b) Public housing: shifting client profiles and public housing revenues, AHURI Final Report No. 108, Australian Housing and Urban Research Institute Limited, Melbourne, https://www.ahuri.edu.au/research/finalreports $/ 108$.

Hall, J. and Berry, M. (2009) Operating deficits and community housing: policy options for reversing the trend, AHURI Final Report No. 126, Australian Housing and Urban Research Institute Limited, Melbourne, https://www.ahuri.edu. au/research/final-reports/126.

Hall, N. L., Memmott, P., Barnes, S., Redmond, A., Go-Sam, C., Nash, D., Frank, T. and Simpson, P. (2020) Pilyii Papulu Purrukaj-ji (Good housing to prevent sickness): a study of housing, crowding and hygiene-related infectious diseases in the Barkly Region, Northern Territory, University of Queensland, Brisbane, accessed 23 November 2020, https:// espace.library.uq.edu.au/view/UQ:aed175a. 
Hannagan, T. J. (1992) Marketing for the Nonprofit Sector, Macmillan, London.

Harloe M. (1995) The People's Home?: Social Rented Housing in Europe and America, Wiley Blackwell, Oxford.

Haynes, B., Nunnington, N. and Eccles, T. (2017) Corporate Real Estate Asset Management: Strategy and Implementation, Routledge, London.

Hennink, M. and Kaiser, B. (2019) 'Saturation in qualitative research', in P. Atkinson, S. Delamont, A. Cernat, J. Sakshaug and R. Williams, R. (eds) Sage Research Methods, p.1083-1091. doi: http://dx.doi.org/10.4135/9781526421036822322.

Housing Registrar Victoria (2016) Asset management good practice guide, Housing Registrar Victoria, Melbourne, accessed 25 September 2020, http://www.housingregistrar.vic.gov.au/files/assets/public/publications/good-practice-guides/ asset management-good-practice-guide.pdf.

Housing Registrar Victoria (2020) Who the Housing Registrar regulates, Housing Registrar Victoria, Melbourne, accessed 6 September 2021, https://www.vic.gov.au/who-the-housing-registrar-regulates.

Hulse, K., Martin, C., James, A. and Stone, W. (2018) Private rental in transition: institutional change, technology and innovation in Australia, AHURI Final Report No. 296, Australian Housing and Urban Research Institute Limited, Melbourne, https://www.ahuri.edu.au/research/final-reports/296, doi: 10.18408/ahuri-5112101.

Hulse, K., Pawson, H., Reynolds, M. and Herath, S. (2014) Disadvantaged places in urban Australia: analysing socio-economic diversity and housing market performance, AHURI Final Report No. 225, Australian Housing and Urban Research Institute Limited, Melbourne, https://www.ahuri.edu.au/research/final-reports/225.

Hulse, K., Reynolds, M., Nygaard, C., Parkinson, S. and Yates, J. (2019) The supply of affordable private rental housing in Australian cities: short-term and longer-term changes, AHURI Final Report No. 323, Australian Housing and Urban Research Institute Limited, Melbourne, http://www.ahuri.edu.au/research/final-reports/323, doi: 10.18408/ ahuri-5120101.

Hulse, K. and Sharam, A. (2013) Fighting for my family: a longitudinal study of families experiencing homelessness, Melbourne, accessed 29 January 2018, http://www.hanover.org.au/wp-content/uploads/2013/08/Hanover-Fightingfor-my-family-REPORT_ONLINE.pdf.

IAM (2015) Asset Management: An Anatomy, Institute for Asset Management, Bristol.

IFMA (2020) What is facility management?, International Facility Management Association, Texas, accessed 5 December 2020, https://www.ifma.org/about/what-is-facility-management.

Industry Commission (1993) Public housing: volume 1: report, Australian Government Publishing Service, Canberra, accessed 1 September 2020, https://www.pc.gov.au/inquiries/completed/public-housing.

International Energy Agency (2018) 2018 Global status report: towards a zero-emission, efficient and resilient buildings and construction sector, Global Alliance for Buildings and Construction (GlobalABC), accessed 3 September 2020, https://www.unenvironment.org/resources/report/global-status-report-2018.

IPA (2016) From housing assets, to housing people: fixing Australia's social housing system, Infrastructure Partnerships Australia, Sydney, accessed 6 March 2021, https://infrastructure.org.au/wp-content/uploads/2016/12/IPA2734Social housing-Paper-FA2-online-1.pdf.

IPWEA (2006) International Infrastructure Management Manual, Wellington, New Zealand.

IPWEA (2015) International Infrastructure Management Manual (5th ed.), Institute of Public Works Engineering Australia, Sydney.

IPWEA (2020a) International Infrastructure Management Manual (6th ed.), Institute of Public Works Engineering Australia, Sydney.

IPWEA (2020b) Optimised Decision Making Guidelines, IPWEA, Wellington, accessed 26 August 2020, https://www.ipwea. org/newzealand/bookshop/nzpubs/nzbookshop/odmg-nz.

IPWEA (2020c) IPWEA Bookshop, Wellington, accessed 10 August 2020, https://www.ipwea.org/publications/bookshop.

Irwin, R. and Medley, R. (2015) 'Asset planning', Inside Housing, accessed 26 August 2020, https://www.insidehousing. co.uk/sponsored/sponsored/asset-planning.

ISO (2014a) Asset management-management systems-requirements, International Organization for Standardization, accessed 26 August 2020, https://www.iso.org/obp/ui/\#iso:std:iso:55001:ed-1:v1:en. 
ISO (2014b) ISO 55000:2014 (en), Asset management-overview, principles and terminology, International Organization for Standardization, accessed 26 August 2020, https://www.iso.org/obp/uil\#iso:std:iso:55000:ed-1:v2:en.

ISO (2018) ISO 55002:2018 (en): Asset management-management systems-guidelines for the application of ISO 55001, accessed 26 August 2020, International Organization for Standardization, https://www.iso.org/obp/ui\#iso:std:iso: 55002:ed-2:v1:en.

JLL Advisory (1995) Asset Management, Leading Edge Research, Building Owners and Managers Association, Sydney.

Johnston, D., McFallan, S. and Tilley, P. (2002) 'Implementation of a property standard index', Facilities, vol. 20, no. 3: 136-144, doi: 10.1108/02632770210697431.

JPX Consulting Pty Ltd (2010) National community housing standards manual, Housing NSW, Sydney, accessed 10 September 2020, https://www.facs.nsw.gov.au/_data/assets/pdf_file/0004/333337/AccreditationStandards Manual.pdf.

Kasperskaya, Y. (2018) 'Asset management', in A. Farazmand (ed.) Global Encyclopedia of Public Administration, Public Policy, and Governance, SpringerLink, Switzerland.

Kenley, R., Chiazor, M., Hall, J. and Heywood, C. (2010) Good practices for managing Australia's public and community housing assets, AHURI Final Report No. 148, Australian Housing and Urban Research Institute, Melbourne, https:// www.ahuri.edu.au/research/final-reports/148.

Kenley, R., Chiazor, M., Heywood, C. and McNelis, S. (2009) Towards best practice for public housing asset management, AHURI Positioning Paper No. 118, Australian Housing and Urban Research Institute Limited, Melbourne, https:// www.ahuri.edu.au/research/position-papers/118.

Kleit, R. and Page, S. (2015) 'The changing role of public housing authorities in the affordable housing delivery system', Housing Studies, vol. 30, no. 4: 621-644, doi: 10.1080/02673037.2014.953919.

Koskelo, T. (2005) A method for strategic technical life cycle management of real estates, Dissertation, Doctor of Science in Technology, Helsinki University of Technology, Espoo, accessed 5 December 2020, http://lib.tkk.fi/Diss/2005/ isbn9512275066/isbn9512275066.pdf.

Larkin, A. (2000) Asset Management Strategies: A Review of Asset Management Strategies of Housing Associations in England and Social Housing Providers in Australia, Metropolitan Housing Trust/The Housing Corporation, London.

Law Society of New South Wales (2019) Draft strategic framework for Aboriginal social housing in NSW, Law Society of New South Wales, Sydney, accessed 25 September 2020, https://www.lawsociety.com.au/sites/default/ files/2019-08/Letter\%20to\%20Aboriginal\%20Housing\%200ffice\%20-\%20Draft\%20Strategic\%20Framework\%20 for\%20Aboriginal\%20Social\%20Housing\%20in\%20 NSW\%20-\%2031\%20 January\%202019.pdf.

Leong, K. (2004) The Essence of Asset Management: A Guide, United Nations Development Programme, Kuala Lumpur.

Liu, E. and Daly, D. (2019) 'Energy efficiency in the Australian social housing sector: barriers along avenues of assistance', 9th State of Australian Cities National Conference, Perth, accessed 3 September 2020, https://apo.org.au/sites/ default/files/resource-files/2019-12/apo-nid303583.pdf.

Long, S., Memmott, P. and Seelig, T. (2007) An audit and review of Australian Indigenous housing research, AHURI Final Report No. 102, Australian Housing and Urban Research Institute Limited, Melbourne, https://www.ahuri.edu.au/ research/final-reports/102.

Martin, C. (2016) Tenants' Rights Manual-NSW, The Federation Press, Sydney.

McNelis, S. (2006a) 'Rental policy: financial viability or affordability in Australian public housing', in S. Darby, P. Flatau and I. Hafekost (eds), Building for Diversity: National Housing Conference 2005, Australian Housing and Urban Research Institute and Department of Housing and Works, Government of Western Australia, Perth, Western Australia: 83-108, accessed 27 July 2021, http://artfulhousing.com.au/wp-content/uploads/2021/07/McNelis-2005Rent-policy.pdf.

McNelis, S. (2006b) Rental systems in Australia and overseas, AHURI Final Report No. 95, Australian Housing and Urban Research Institute Limited, Melbourne, https://www.ahuri.edu.au/research/final-reports/95.

McNelis, S. (2007) 'Social housing and its objective: towards a theory of social housing', 2nd Australian Housing Researchers Conference, Brisbane, 20-22 June, accessed 23 March 2021, http://artfulhousing.com.au/wp-content/ uploads/2021/03/McNelis-2007-social housing-and-its-objective.pdf. 
McNelis, S. and Burke, T. (2004) Rental systems in Australia and overseas, AHURI Positioning Paper No. 74, Australian Housing and Urban Research Institute Limited, Melbourne, https://www.ahuri.edu.au/research/position-papers/74.

Memmott, P. (2007) Gunyah, Goondie + Wurley: the Aboriginal architecture of Australia, University of Queensland Press, St Lucia.

Memmott, P. and Chambers, C. (eds) (2003) TAKE 2: Housing Design in Indigenous Australia, Royal Australian Institute of Architects, Red Hill.

Memmott, P., Birdsall-Jones, C. and Greenop, K. (2012) Australian Indigenous house crowding, AHURI Final Report No. 194, Australian Housing and Urban Research Institute Limited, Melbourne, https://www.ahuri.edu.au/research/finalreports/194.

Miles, M., Haney, R. and Berens, G. (1996) Real Estate Development: Principles and Process, Urban Land Institute, Washington DC.

Milligan, V., Hulse, K., Pawson, H., Flatau, P. and Liu, E. (2015) Strategies of Australia's leading not-for-profit housing providers a national study and international comparison, AHURI Final Report No. 237, Australian Housing and Urban Research Institute Limited, Melbourne, https://www.ahuri.edu.au/research/final-reports/237.

Morrison, N. (2013) 'Meeting the Decent Homes Standard: London Housing Associations' asset management strategies', Urban Studies, vol. 50, no. 12: 2569-2587, doi: 10.1177/0042098012474512.

Murie, A. (1999) 'The acquisition and sale of properties by social landlords: justifications and consequences', Netherlands Journal of Housing and the Built Environment, vol. 14, no. 3: 293-307, doi: 10.1007/BF02496683.

Murray, S., Bertam, N., Khor, L., Rowe, D., Meyer, B., Newton, P., Glackin, S., Alves, T. and McGauren, R. (2013) Design innovations delivered under the Nation Building Economic Stimulus Plan-Social Housing Initiative, AHURI Positioning Paper No. 155, Australian Housing and Urban Research Institute Limited, Melbourne, https://www.ahuri.edu.au/ research/position-papers/155.

NAMS (2014) NAMS Property Manual, IPWEA, Wellington, accessed 5 December 2020, http://www.nams.org.nz/manuals guidelines.

New Zealand Tenancy Services (2021) About the Healthy Homes Standards, accessed 6 March 2021, https://www.tenancy. govt.nz/healthy-homes/about-the-healthy-homes-standards/.

NHFIC (2020) Affordable Housing Bond Aggregator (AHBA) loans [Online], National Housing Finance and Investment Corporation, accessed 7 March 2021, https://www.nhfic.gov.au/what-we-do/affordable-housing-bond-aggregator/\#.

Nieboer, N. (2007) 'How does portfolio management structure investments of social landlords in reality?', European Network for Housing Research Conference, Rotterdam, 25-28 June.

Northern Territory Government (2004) National Issues in Indigenous Housing 2004/2005 and Beyond: Position Paper, Northern Territory Government Department of Community Development, Sport and Cultural Affairs, Darwin.

Northern Territory Government (2016) Report on Repairs and Maintenance of Housing on Town Camps, Legislative Assembly of the Northern Territory, Public Accounts Committee, Darwin, accessed 10 September 2020, https:// parliament.nt.gov.au/committees/previous/public-accounts-committee-12th-assembly/inquiry-into-housingrepairs-and-maintenance-on-town-camps.

Nous Group (2017) Efficient system costs of remote Indigenous housing, Nous Group, Melbourne, accessed 23 November 2020, https://www.niaa.gov.au/sites/default/files/publications/Nous-Group-Final-Report-Efficient-system-costs-ofremote-Indigenous-housing.pdf.

NRSCH (2014) Evidence guidelines, National Regulatory System for Community Housing, accessed 7 December 2020, https://www.nrsch.gov.au/_data/assets/pdf_file/0012/798357/Evidence-Guidelines-Updated-15122020.PDF.

NRSCH (n.d.) Tier guidelines, National Regulatory System for Community Housing, Sydney, accessed 16 February 2020, https://www.nrsch.gov.au/_data/assets/file/0005/288230/D_Tier_Guidelines.pdf.

NSW Aboriginal Land Council (2019) The NSW Aboriginal Land Council's submission on the right to adequate housing for Indigenous peoples, New South Wales Aboriginal Land Council, Parramatta, accessed 23 November 2020, https:// www.ohchr.org/Documents/Issues/Housing/IndigenousPeoples/CSO/NewSouthWalesAboriginalLandCouncil.pdf. 
NSW Government and AHO (c. 2018) Strong families, strong communities, NSW Government and the Aboriginal Housing Office, Sydney, accessed 25 September 2020, https://www.aho.nsw.gov.au/download?file=628182.

NSW Parliament (2014) Social, public and affordable housing, Legislative Council, Select Committee on Social, Public and Affordable Housing, Sydney, accessed 10 September 2020, https://www.parliament.nsw.gov.au/committees/ Pages/committeeprofile/social-public-and-affordable-housing.aspx.

NSW Treasury (2019) Asset management policy for the NSW public sector: policy and guidelines paper, TPP 19-07, NSW Treasury, Sydney, accessed 10 September 2020, https://www.treasury.nsw.gov.au/documents/tpp-19-07-nsw-asset management-policy.

Owen, D., Winter, I. and Van Rooyen, D. (2002) A new framework for the Commonwealth-State Housing Agreement, National Consultation Summary Report, AHURI Research and Policy Bulletin No. 15, Australian Housing and Urban Research Institute Limited, Melbourne, https://www.ahuri.edu.au/research/research-and-policy-bulletins/15.

Parkinson, S., Ong, R., Cigdem, M. and Taylor, E. (2014) Wellbeing outcomes of lower income renters: a multilevel analysis of area effects, AHURI Final Report No. 226, Australian Housing and Urban Research Institute Limited, Melbourne, https://www.ahuri.edu.au/research/final-reports/226.

Parnell, M. and Seemann, K. (2005) 'Developing life cycle models for sustainable investment in desert communities', Proceedings of the Building for Diversity National Housing Conference, Perth, 26-28 October.

Pawson, H. (2006) 'Restructuring England's social housing sector since 1989: undermining or underpinning the fundamentals of public housing?', Housing Studies, vol. 21, no. 5: 767-783, doi: 10.1080/02673030600807720.

Pawson, H. and Herath, S. (2015) Disadvantaged places in urban Australia: residential mobility, place attachment and social exclusion, AHURI Final Report No. 243, Australian Housing and Urban Research Institute Limited, Melbourne, https://www.ahuri.edu.au/research/final-reports/243.

Pawson, H., Martin, C., Flanagan, K. and Phillips, R. (2016) Recent housing transfer experience in Australia: implications for affordable housing industry development, AHURI Final Report No. 273, Australian Housing and Urban Research Institute Limited, Melbourne, https://www.aahuri.edu.au/research/final-reports/273, doi: 10.18408/ahuri-7108101.

PCA (2019) Glossary of Terms, Property Council of Australia, Sydney, accessed 10 August 2020, https://www. propertycouncil.com.au/Web/Events_Services/Research_Services/Glossary_of_Terms.aspx.

PHADA (2002) PHADA grades Harvard's study, Public Housing Authorities Directors Association, Washington, accessed 9 October 2020, https://www. phada.org/Portals/21/pdf/1813hcs.pdf?ver=2018-08-16-160548-753.

PHADA (2006) Asset management, yes-micromanagement, no: PHADA's solutions for getting HUD's asset management guidance on the right track, Public Housing Authorities Directors Association, Washington, accessed 9 October 2020, https://www.phada.org/Portals/21/pdf/PHADA_Asset_Management_Guidance.pdf?ver=2018-08-20-090332-683.

Pholeros, P. and Phibbs, P. (2012) Constructing and maintaining houses, Resource sheet 13, Closing the Gap Clearinghouse, AlHW, Canberra, accessed 7 December 2020, https://www.aihw.gov.au/reports/indigenous-australians/constructing -and-maintaining-houses/contents/table-of-contents.

Prentice, D. and Scutella, R. (2020) 'What are the impacts of living in social housing? New evidence from Australia', Housing Studies, vol. 35, no. 4: 612-647, doi: 10.1080/02673037.2019.1621995.

Priemus, H., Dieleman, F. and Clapham, D. (1999) 'Current developments in social housing management', Netherlands Journal of Housing and the Built Environment, vol. 14, no. 3: 211-223 doi: 10.1007/BF02496678.

Proctor, D. (2014) Communities of practice: getting to the heart of workplace learning, sharing and innovation, Henry Halloran Trust, accessed 3 September 2020, http://usyd.nikashsingh.com/hht/PROCTOR_CommunitiesOfPractice.pdf.

Productivity Commission (2019) Vulnerable private renters: evidence and options, Productivity Commission, Canberra, accessed 19 November 2020, https://www.pc.gov.au/research/completed/renters/private-renters.pdf.

QDHPW (2017) Strategic asset management framework, Queensland Department of Housing and Public Works, Brisbane, accessed 10 September 2020, https://www.forgov.qld.gov.au/strategic-asset management-framework.

Reserve Bank of Australia (2017) Financial stability review October 2017, Reserve Bank of Australia, Sydney, accessed 7 March 2021, https://www.rba.gov.au/publications/fsr/2017/oct/.

Rondeau, E. P., Brown, R. K. and Lapides, P. D. (2012) Facility Management, Wiley, Hoboken. 
Saridayi, H. (2019) Asset management in the social rented sector: how to measure the financial efficiency and social return of housing associations' assets?, Masters thesis, Eindhoven University of Technology, accessed 3 October 2020, https://research.tue.nl/files/136265377/Saridayi_1025187.pdf.

Scottish Housing Regulator (2012) Strategic asset management: recommended practice, Scottish Housing Regulator, Glasgow, accessed 2 December 2020, https://www.west-dunbarton.gov.uk/media/4306009/housing_strategy_ briefing_note_12-12_-_scottish_housing_regulator_recommended_practice_on_business_planning_and_asset_ management_12_12.pdf.

Scottish Housing Regulator (2020) Asset management guidance-survey briefing paper 6 March 2020, Scottish Housing Regulator, Glasgow, accessed 7 October 2020, https://www.housingregulator.gov.scot/media/1357/asset-managementbriefing.pdf.

SCRGSP (2021) Report on government services 2020, part G: housing and homelessness, section 18 housing, Steering Committee for the Review of Government Service Provision, Productivity Commission, Canberra, accessed 5 December 2020, https://www.pc.gov.au/research/ongoing/report-on-government-services/2021/housing-andhomelessness/housing.

Seemann, K., Parnell, M., McFallan, S. and Tucker, S. (2008) Housing for livelihoods: the life cycle of housing and infrastructure through a whole-of-system approach in remote Aboriginal settlements, Desert Knowledge Co-operative Research Centre, Alice Springs, accessed 17 February 2021, http://hdl.handle.net/1959.3/233290.

Shah, A., Tan, T. and Kumar, A. (2004) 'Building infrastructure asset management: Australian practices', 2004 CIB World Building Congress, Session CIB T2S5, Toronto, 2-7 May, accessed 4 September 2020, https://eprints.qut.edu.au/ 27215/1/27215.pdf.

Sharam, A. (2007) 'What the gas and electricity arrears of private low-income tenants can tell us about financial stress', Journal of Economic and Social Policy, vol. 11, no. 2: 23-38.

Sharam, A. and Hulse, K. (2014) 'Understanding the nexus between poverty and homelessness: relational poverty analysis of families experiencing homelessness in Australia', Housing, Theory and Society, vol. 31, no. 3: 15.

Sharam, A., Byford, M., Karabay, B., McNelis, S. and Burke, T. (2018) Matching markets in housing and housing assistance, AHURI Final Report No. 307, Australian Housing and Urban Research Institute Limited, Melbourne, https://www.ahuri. edu.au/research/final-reports/307, doi: 10.18408/ahuri-5315301.

Sharam, A., Moran, M., Mason, C. and Stone, W. (2018) Understanding opportunities for social impact investment in the development of affordable housing, AHURI Final Report No. 294, Australian Housing and Urban Research Institute Limited, Melbourne, https://www.ahuri.edu.au/research/final-reports/294, doi: 10.18408/ahuri-5310202.

Social Housing Regulation Review (2021a) Background and scoping paper, Government of Victoria, Melbourne, accessed 28 July 2021, https://engage.vic.gov.au/social housing-regulation-review.

Social Housing Regulation Review (2021b) Service delivery and the tenant experience, Government of Victoria, Melbourne, accessed 28 July 2021, https://engage.vic.gov.au/social housing-regulation-review.

Styles, P. (Felix Schrodinger) (2013) An asset management system for social housing, accessed 26 August 2020, https:// felixschrodinger.files.wordpress.com/2013/11/ams-for-social housing.pdf.

Supreme Court of Victoria (1999) The Uniting Church in Australia Property Trust v Royal Victorian Institute for the Blind [1999] VSC 485 (2 December 1999), accessed 5 December 2020, http://www8.austlii.edu.au/cgi-bin/viewdoc/au/ cases/vic/VSC/1999/485.html?context=1;query=6731; mask_path=au/cases/vic/VSC.

Tasmanian Audit Office (2016) Provision of social housing, Report of the Auditor-General No. 8 of 2015-16, Tasmanian Audit Office, Hobart, accessed 10 September 2020, https://www.audit.tas.gov.au/wp-content/uploads/Report-ofthe-Auditor-General-No.-8-of-2015-16-Provision-of-social housing.pdf.

Troy P. (2012) Accommodating Australians: Commonwealth Government Involvement in Housing, The Federation Press, Sydney

Tucker, S. N. and Rahilly, M. (1990) 'Life cycle costing of housing assets', Building maintenance and modernisation worldwide: proceedings of the International Symposium on Property Maintenance Management and Modernisation, Singapore.

Tucker, S. N. and Rahilly, M. (1991) 'Identification of funds for managing public housing maintenance', European Symposium on Management Quality and Economics in Housing and Other Building Sectors, Lisbon. 
Tucker, S. N., Bromilow, F. and Rahilly, M. (c. 1989) Life cycle costs of housing: final report on the Government Employee Housing Authority Life Cycle Costing Pilot Program, Government Employee Housing Authority, Melbourne.

Tucker, S. N., McFallan, S., Boxhall, P. and Kivlighon, L. (1996) Housing Stock Condition Index: AHRF Project, CSIRO Division of Building, Construction and Engineering, Melbourne.

UK DCLG (2006) A decent home: definition and guidance for implementation, June 2006-Update, Department for Communities and Local Government, London, accessed 6 March 2021, https://assets.publishing.service.gov.uk/ government/uploads/system/uploads/attachment_data/file/7812/138355.pdf.

UK DETR (2000) Quality and choice: a decent home for all: The Housing Green Paper, Department of Environment Transport and Regions, London, accessed 7 October 2020, https://web.archive.org/web/20001019033113/http:// www.housing.detr.gov.uk/information/consult/homes/pdf/hous_gpr.pdf.

UK House of Commons (2010) Beyond decent homes, UK House of Commons, Communities and Local Government Committee, London, accessed 7 October 2020, http://www.publications.parliament.uk/pa/cm200910/cmselect/ cmcomloc/60/60i.pdf.

US Government (1998) Quality Housing and Work Responsibility Act, US Government, Washington, accessed 9 October 2020, https://www.hud.gov/sites/documents/DOC_8905.pdf.

US HUD (1996) Stock and asset management in public housing: background readings from HUD reports, Office of Policy Development and Research, Department of Housing and Urban Development, accessed 8 October 2020, https:// www.huduser.gov/Publications/pdf/stock.pdf.

VAGO (2017) Managing Victoria's public housing, Victorian Auditor-General's Office, Melbourne, accessed 20 December 2017, https://www.audit.vic.gov.au/sites/default/files/20170621-Public-Housing.pdf.

van Overmeeren, A. and Gruis, V. (2011) 'Asset management of social landlords based on value creation at neighbourhood level', Property Management, vol. 29, no. 2: 181-194 doi: 10.1108/02637471111122462.

Varcoe, B. (2000) 'Implications for facility management of the changing business climate', Facilities, vol. 18, no. 10/11/12: 383-391, doi: 10.1108/02632770010349619.

Victorian Government (2020) Almost $\$ 500$ million social housing boost to strengthen our economy and provide stability for Victorians, Department of Health and Human Services, Melbourne, accessed 25 September 2020, https://www. dhhs.vic.gov.au/news/social housing-boost-to-strengthen-our-economy.

Victorian Government (2021a) Our plan to create more social and community housing, accessed 6 March 2021, https:// www.vic.gov.au/our-plan-create-more-social-and-community-housing.

Victorian Government (2021b) Review of Social Housing Regulation, accessed 6 March 2021, https://www.vic.gov.au/ review-social housing-regulation.

Victorian Government (2021c), Victoria's Big Housing Build, accessed 28 July 2021, https://www.premier.vic.gov.au/ victorias-big-housing-build.

Victorian Government (2021d), Homes Victoria, accessed 28 July 2021, https://www.vic.gov.au/homes-victoria.

WA Treasury (2020) Strategic asset management framework, WA Treasury, Perth, accessed 4 September 2020, https:// www.wa.gov.au/government/document-collections/strategic-asset management-framework.

WALA.SCULIA (1997) Ministerial Councils, Western Australia Legislative Assembly Standing Committee on Uniform Legislation and Intergovernmental Agreements, Perth, accessed 26 November 2020, https://www.parliament. wa.gov.au/Parliament/commit.nsf/(Report+Lookup+by+Com+ID)/C9E67B51A451631948257831003E953E/\$file/ No19-ul.pdf.

Wiewiora, A., Brown, K., Dhakl, S. and Mahmood, M. (2012) 'Managing knowledge for asset management: shifting from process to relational frames', WCEAM Proceedings from the 7th World Congress on Engineering Asset Management. 


\section{Appendix 1: The Australian social housing best practice asset management Framework}

\section{Purpose of this guide}

This guide provides a simplified generic asset management framework (AMF) intended for use by social housing organisations (SHOs) seeking to bring their asset management into line with best practice. It will provide a starting point for SHOs that have not yet developed an AMF or asset management plan (AMP). Other SHOs wishing to review, update and validate their current $A M F$ and $A M P$ may also find it useful.

This guide is intended to be used in conjunction with both:

- the International Infrastructure Management Manual produced by IPWEA, ${ }^{9}$ which is a comprehensive but general guide to asset management (AM); and

- the associated NAMS Property Manual, ${ }^{10}$ a more-specific guide to property AM.

Readers are encouraged to use the NAMS Property Manual in conjunction with this guide.

\section{Why asset management?}

SHOs across Australia hold billions of dollars in housing assets. Asset management is about stewardship. Stewardship is concerned with extending the life of assets to maximise the financial investment; it is concerned with ensuring assets are fit for purpose both in the present and the future; and are able to deliver a broad range of beneficial outcomes to tenants and society. Stewardship requires planning.

Failure to undertake appropriate AM exposes an organisation to significant financial and legal risks.

Lack of appropriate planning may be the consequence of a poor AM vision, often exacerbated by decision-making based on poor data. An example would be growing the portfolio at huge expense when, in five years' time, there is no funding to meet the bare minimum legal maintenance standards.

The systemisation of AM practice is a relatively recent practice. For example, the International Organization for Standards' (ISO) ISO 55000 was released only in 2014. Currently there is no publicly available guide to AM developed specifically for social housing providers. The NAMS Property Manual includes some good examples from social housing, but the highly specific nature of the social housing sector warrants special attention.

9 Available from https://www.ipwea.org/publications/ipweabookshop/iimm.

10 Available from https://www.ipwea.org/newzealand/bookshop/nzpubs/nzbookshop/pmia-nz. 
Social housing has evolved into a complex set of delivery modes in Australia, ranging from some very large providers to many more small providers. Smaller SHOs often lack the resources to fund asset management adequately or lack well-trained asset staff. This makes them vulnerable to the unknown liabilities that lay ahead. One of the more complex arrangements are stock and management transfers governed by state agreements. For example, with management leases, the responsibility for maintenance and some renewal work rests with the CHP, yet structural works rest with the state. The SHAs' Director's Interest in the case of title transfers may inhibit portfolio reconfiguration, and adds another layer of regulation beyond existing community housing regulation.

Two examples highlight the special nature of social housing. In the private rental sector, value is expressed in terms of monetary value, determined by the net rent model. Other values, such as a dwelling being a 'home' and not simply a utilitarian service, are rarely considered. By contrast, a social landlord's business is tenant outcomes, and thus their asset management needs to take account of a broader range of metrics - for example, the impact of concentration of social housing. Social landlords are required to be strategic and consider not just how a neighbourhood might impact on their investment but how their investment will contribute to place.

Social housing provision involves a fragmented and complex set of delivery modes where some organisations own and manage their assets, some organisations lease and manage the assets, some are bound by management contracts with SHAs, some are registered providers, and some are not. Some providers are standalone organisations, while others are part of large human service or faith organisations. Regardless of who owns the assets, information about the assets and the appropriate use of that information to ensure the prudent management of those assets is critical to the success of social housing provision in perpetuity.

\section{What is asset management?}

Best practice social housing asset management considers all the social, economic, cultural and environmental benefits of social housing provision, introducing complexity. These broader elements, which are often ignored, are part of the sustainability set often referred to as 'all of government' or 'societal' costs and should be assessed. Housing has an ability to add significant social benefit not just by way of lower rent, but also in health benefits, education benefits, cultural and environmental benefits. For example, a solar generation retrofit program can lower energy costs for the tenant and have a positive impact on the environment.

An AMP should be a very transparent and defensible document that shows the alignment of strategy, tactics and operational planning. At the highest level, asset strategies and their KPIs will directly contribute to the housing organisation's goals and objectives. They should be devoid of political influence (both internal and external), and will represent the optimal programs of work, whether they be maintenance programs, capital renewal programs, redevelopment and new supply programs, or retrofit capital programs.

In its simplest form, an AMF consists of policy, strategy and a plan-or 'why', 'how' and 'what'. Policy is a broad term, encompassing organisational policy and external policy such as statutes and regulations. Strategy shows how the asset management of a portfolio of assets will add to policy outcomes, and the plan is the operational program guide. The AMF is the document that shows clear and transparent alignment of policy, strategy and programs of work. Policy, strategy and the plan are organic, and change as the environment, political landscape, economy and legal, social and technology settings change within and around the business of social housing.

Equally, an AMF is not just an annual process of documenting policy, strategy and work programs. It includes asset targets and an improvement plan, and should be seen as a living document that is constantly revisited and refined. Each organisation is different and will its own asset management needs, with individualised policy, strategy and plans. 


\section{The Framework}

The Australian social housing best practice asset management Framework consists of two components:

- the material or content of the framework

- the processes and elements required to complete an best practice asset management plan (BPAMP).

These components are illustrated in Figure A1 and Figure A2, which detail the process.

\section{Content of an best practice asset management plan}

The content of an best practice AMP includes data on assets, housing demand, vacancies, turnover and housing supply within the various housing sub-markets within which the organisation operates. This data informs asset planning, which covers dwellings at different stages of the life cycle:

- asset creation - the acquisition of stock through building, purchasing and head leasing

- asset management - the maintenance, allocation and upgrade of current stock

- asset disposal-demolition and redevelopment on sites that meet current or future demand, and the sale or transfer of land or dwellings that no longer meet current or future demand.

Figure A1 outlines the relationship between the different types of content within an best practice AMP.

Figure A1: Sustainable asset management over the life cycle of social housing

Data collection: asset condition, housing supply, housing demand, vacancies, turnover

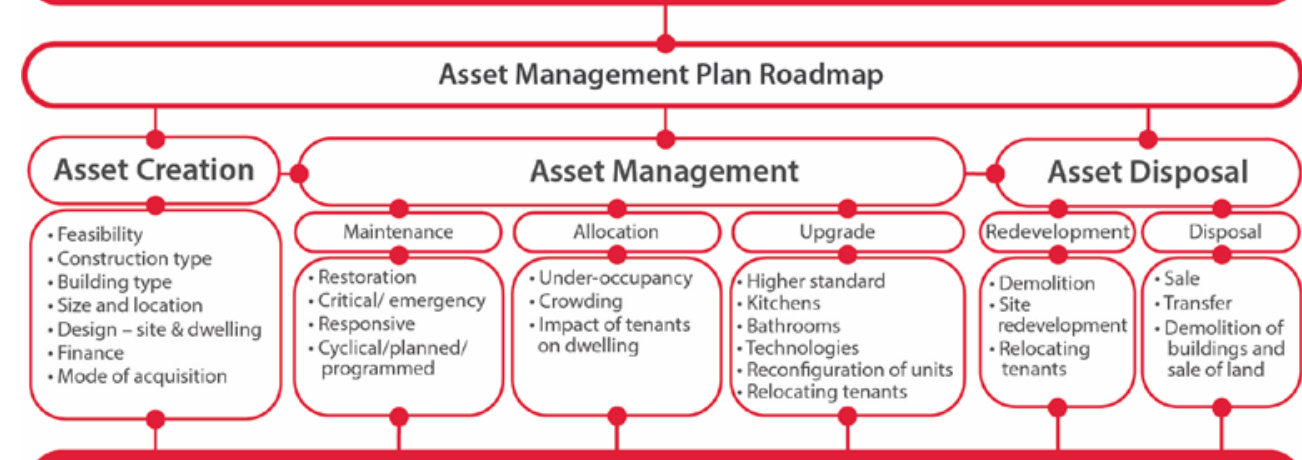

Decisions based on an assessment of: (i) the housing needs of current and future tenants,

(ii) defined service standards, (iii) the mission and objectives of the SHO, and

(iv) the environmental, economic, social, political and cultural costs and benefits.

Source: McNelis 2020.

An asset management plan will cover all stages in the life cycle of housing assets: asset creation, asset management and asset disposal.

\section{Process to develop an AMP}

Figure A2 depicts the asset management plan (AMP) roadmap, detailing the process and elements needed to complete an AMP. It starts with understanding the organisational mission and objectives, and development of complementary asset strategies. During the scenario modelling and optimised decision-making (ODM) process, levels of service (LOS) evolve. 
ODM is defined as the best asset strategy or project to minimise long-term costs and maximise outcomes for the organisations and its customers. LOS are the standards the SHO aims to deliver. These are powerful components within the planning process, and should be used to help inform and refine organisational objectives and policy as much as organisational objectives and policy inform the AMP.

It starts with understanding the organisational mission and objectives, and the development of complementary asset strategies. The asset management framework (AMF) for social housing considers vertical and horizontal integration of an iterative annual asset management planning process, with life-cycle management that accounts for all aspects of sustainability required for ODM. That means that all points of an asset's life cycle, data, systems and tools allow for ODM.

The AMF must provide data and systems for this type of decision-making to ensure the sustainability of portfolios under management over time.

Figure A2: Asset management plan roadmap

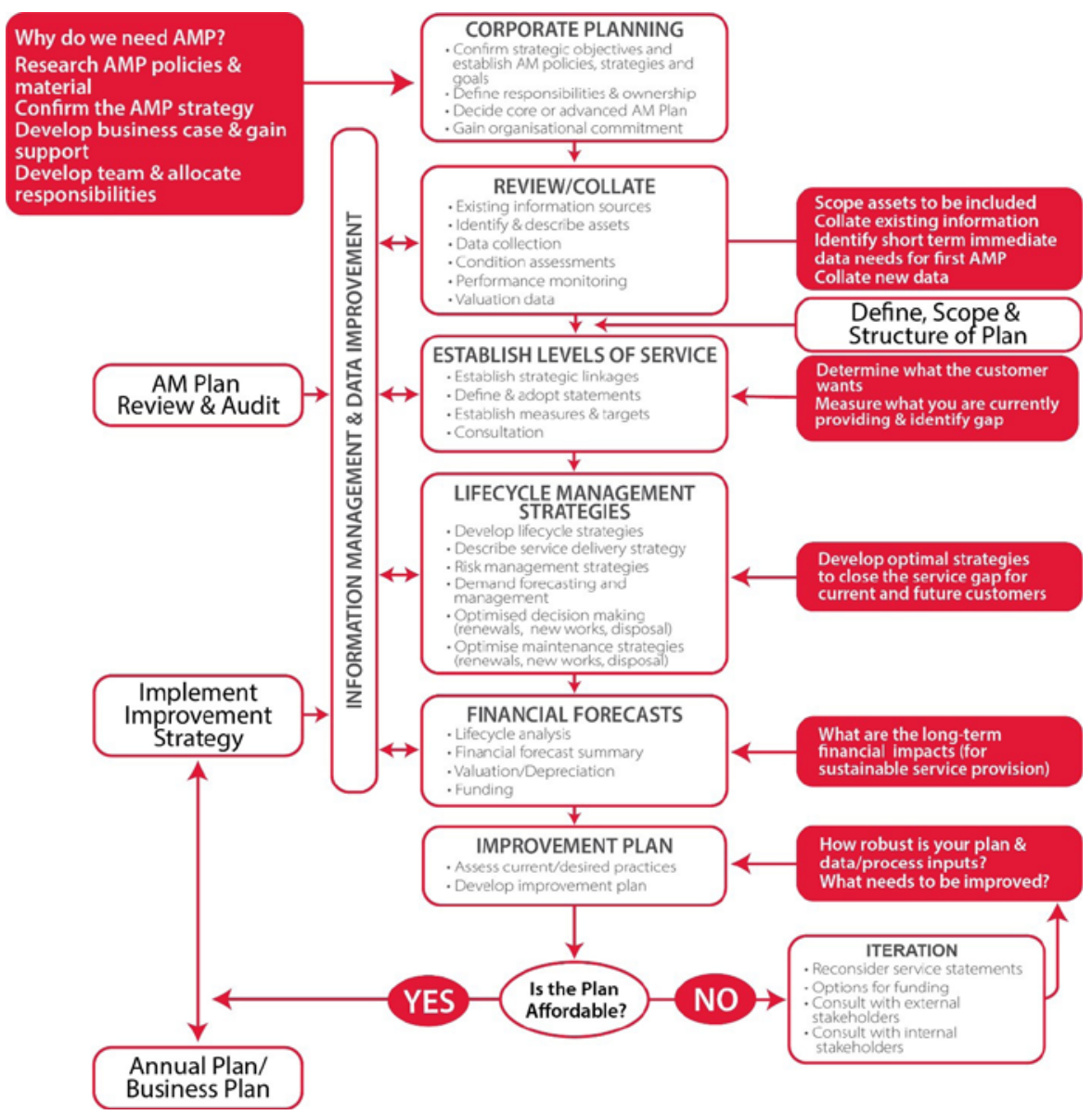

Source: Adapted from IIMM 2015. 


\section{Developing an asset management plan}

\section{Preliminaries}

For asset management to be effective, the asset team must be allowed time to plan rather than be consumed by reactive needs and wants. This often represents a leap of faith by organisations, which is normally followed by an investment in asset staff, training, software and data collection. Good asset data, tools and systems are critical to make the task of asset management and planning manageable. Training, allocation of responsibilities and reporting lines are critical, as well as documented processes and deliverables, and creation of team key performance indicators (KPIs). Good asset planning requires resources. Smaller organisations may choose to contract-out the asset management planning component or work cooperatively with other like-minded organisations.

The content of an AMP is defined by the AMP roadmap (Figure A2). A good reference for chapter and subheadings for an AMP is contained in the NAMS Property Manual (NAMS, 2014: 7.15-7.18). The NAMS Property Manual is also a good source to asset management practitioners because of its many practical property-asset management examples, including social housing.

\section{Corporate planning}

The role of the asset manager is to link strategic, tactical and operational asset planning with the organisation's mission, objectives, goals and priorities. This requires sitting down with the chief executive officer and others who helped develop the organisation's business plan to gain a thorough understanding of it, in order create an AMP that actually adds value to the business.

Asset data, analysis and forecasting is key to understanding how the asset portfolio can evolve and what the limitations are.

Equally important is the involvement of senior asset team members in the development of the business plan, as this may result in changes to an organisation's mission statement to something more attainable. This is particularly important for organisations that are new to asset planning. This process should be viewed as a top-down and bottom-up approach to objective setting.

Strategic, tactical and operational planning must show clear linkage to the business plan and added value outcomes:

- Strategic planning: the connection with organisational objectives.

- Tactical planning: the asset actions or options taken to solve problems.

- Operational planning: the individual programs or interventions and resources used by the assets.

Ultimately, the strategy, statements and actions should be highly visible within an AMP and reflect all of the work undertaken to collect asset data, the analysis of that data, forecasting of operational and capital expenditure, sensitivity testing, risk management, and options analysis to determine the optimal set of actions.

An example of an organisational mission statement may be: 'ABC Organisation will provide affordable, secure and suitable housing.'

In this example, there are AM strategy linkages around a definition of suitable housing that will consider condition standards, tenant matching to typology, amenities and location. The word 'secure' housing refers to security of tenure, but could also refer to security for tenants and their possessions, which leads to all kind of considerations around design to minimise the potential for criminal activity and security features such as door locks, alarm systems and security lighting. An organisational goal could also reference growing the portfolio to meet emerging demand. Where the organisational resources dictate alternate solutions are needed, a tactical asset solution may be to consider leasing additional dwellings or exploring a partnership arrangement with private developers, or other alternatives such as building on leasehold land. Where none of these options are possible the organisations business plan needs to reflect this constraint. 


\section{Review and collate: data collection}

\section{Current and future demand}

As part of the process of developing an AMP, the organisation should undertake an analysis of current and future demand for social housing-especially demand that will impact their organisation and the future demand they will need to satisfy.

Establishing future demand for social housing is a complex task, given the number of variables that may influence demand. It is not simply the number of people seeking social housing, nor the number of people who are eligible. Demand also includes the type of housing that will be needed. So, an estimate of future demand requires an analysis by household type.

Econometric modelling can be used to forecast demand using relevant economic and demographic variables derived from different sources such as the Reserve Bank of Australia or ABS. Future demand should be analysed across dwelling typologies, household type and locations in order to plan to fund and develop complementary asset solutions. Wiewiora, Brown et al. (2012) emphasise the need for customer-centric planning to obtain greater alignment of assets to user requirements. Demand forecasting and management must involve current and prospective tenant consultation to ascertain location, dwelling type and dwelling amenity expectations. These models are highly sensitive to changes in tenant allocation settings, and will complicate the future demand forecasting process.

New supply to meet demand represents new capital - apart from leased dwellings —and must be considered alongside other competing capital projects in long-term forecasting and cashflow analysis.

\section{Asset register}

An organisation will also need to develop and maintain an inventory or asset register. This will include:

- whether dwellings are owned or managed and, if managed, the term of the headlease and its conditions

- property descriptions

- critical components

- condition of buildings

- functionality of buildings

- utilisation of buildings

- strategic land holdings.

Land and dwelling data

Ideally an AMP includes sufficient dwelling data to produce individual asset long-term (life-cycle) forecasts of rent and expenses-including rates, insurance, management costs and owner corporation fees-along with maintenance backlog and projections, and capital renewal work. Capital renewal would be informed by understanding the condition-based life-cycle forecasting, but could be overridden by redevelopment options and modelling of cashflow in order to determine cost-benefit.

This allows for strategic decision-making at the individual asset level. Based on the outcomes from the analysis, each asset can ultimately be assigned a code: Long-Term hold, Redevelop or Sell. Information systems should be able to aggregate this data for any number of assets and allow subset analysis by:

- number of bedrooms

- type-for example, public housing estate, standalone dwellings, units, townhouses, apartments

- location

- total portfolio

- tenure 
- portfolio under management by individual asset managers

- dwellings that have redevelopment potential

- property amenity offered-for example, disability amenities

- local amenity offered-for example, properties within $10 \mathrm{~km}$ of a medical service

- overcrowding

- underutilisation

- vacancy.

In addition, there is a requirement to be able to identify individual properties that fall short of LOS targets, so that programs of work can be identified, packaged and undertaken on assets. These shortfalls could arise from a failure against a standard for an existing asset component, or address a component that is missing. Assets coded 'redevelopment' or 'sell' may only need to meet minimum legal regulatory compliance until disposed of. An exception to this is when a higher sale price could be achieved that more than offsets the cost of renovation.

Individual asset-maintenance projections and capital renewal projections determined by an averaging approach -based, for example, on the decade built-is insufficient for BPAM. This averaging process represents a planning risk, as it will make some assets appear to be better than they are and others worse than they are, leading to suboptimal asset decisions. This type of data cost-saving measure should be avoided.

It is critical to ensure asset data integrity, reliability and currency. Before conducting condition assessments, it is important to develop a data management strategy that will include a process for updating renewed component data and condition grades. This will also determine the resources needed.

Another important issue is to determine the ideal level of componentisation to collect data. For example, do you record the condition of paint on walls in one room or all four walls? Thousands of components exist for one dwelling, but the cost of collecting that level of data and maintaining it may involve high costs. This may not represent value for money. There will be a point between the cost of collection and value gained from having the data that will determine component level. A practical consideration when determining component level is the base lives of components, since components that depreciate at different rates should be separated in order to forecast their renewal.

A final important consideration that will determine component level is how your organisation can package planned maintenance work or renewals in a way that achieves economies of scale during any tendering process. For example, packaging multiple room redecoration work for tender rather than calling on contractors to paint one or two walls in each dwelling in an unplanned and unpackaged manner. From a contractor's perspective, their tender price will reflect their own cost-saving strategies, such as minimising travel costs or bulk purchase of paint and other materials.

Periodic inspection and measurement against LOS standards will determine the level of failure of each component and trigger how remediation will be prioritised. For example, a health and safety issue will require immediate repair or replacement. Non-critical work forms a backlog maintenance that should be addressed though forward-planned maintenance and forward-planned capital to address the amenity gap.

Ideally, planned maintenance should reduce reactive maintenance costs. For example, when the cost of contracting bulk purchase and replacement of hot-water services is less on a per unit basis than getting a plumber in for emergency replacement on a weekend. Where possible, reactive maintenance should be avoided because of the costs involved in individual jobs (including internal administrative costs). No more than 20 per cent of the maintenance budget should be allocated to reactive maintenance under an BPAM regime. Setting such a benchmark as a KPI will drive the systems change needed to deliver the desired efficiencies. Reactive maintenance levels and costs should reduce with better condition assessment processes and better planning. Packaging planned works, tendering and contract management will become easier. This will lead to economies of scale and reduced internal administration. 
As the condition assessment requires the identification of component condition grades-which is a scaled assessment of component life cycle - then qualified builders or building surveyors would normally be tasked with conducting the condition assessment (CA). Training is vital for this role, so that all involved have a collective understanding of component condition ratings using practical examples and photos of different levels of degradation with matching condition grade. For example, picture cards may be provided to assessors to be used on site to show different condition states, such as peeling paint, worn carpet or water damage with matching condition grades. Auditing of condition grade assessment should also form part of the process to improve accuracy. Auditing, training and aids such as condition-grade pictures should aim to remove variation between assessors and improve accuracy.

The current condition, base life estimates and criticality of components-combined with their associated replacement or repair cost schedule-is part of the data-collection process. This data, combined with predictive forecast tools, determines the timing of component failure and life-cycle projections of planned maintenance and capital renewal. The 'nice to have' programs such as new capital initiatives will be feed into the ODM model as optional extras to be assessed using net present value (NPV) analysis.

In addition to condition and amenity data, Geographical Information System (GIS) data should be used to help determine:

- viability for development sites by overlaying land-use planning and comparison to current built form

- calculating distances to local amenities, such as hospitals, schools, public transport

- submarket analysis studies of local population trends, other social housing provider locations, concentration levels, etc.

GIS-based measures can be used to create yet another set of standards-for example, a standard that all dwellings shall be within $5 \mathrm{~km}$ of a medical clinic.

Data collection, data storage and analysis, interpretation and reporting are key to achieving best practice AM practice. This can be categorised into five data groups, as outlined in Table A1.

Table A1: Categorisation of data

\begin{tabular}{ll}
\hline Data category & Data required \\
\hline Physical property attributes & - Condition of components including all site improvements \\
- Site slope & - Number of bedrooms \\
- Lot/section size \\
- Number of bathrooms \\
- Car parks \\
- Accessibility (disability features) \\
- Floor area \\
- Single/multi-level \\
- Body corporate details (Strata) \\
- Level of flexibility \\
- Functionality \\
- NaTHErs rating \\
- Energy-efficient elements such as solar panels \\
- Cultural design elements \\
- Existing building standards, e.g. insulation? \\
- Means of heating \\
- Stove-efficiency rating? \\
- Lighting type-LED/incandescent \\
\hline
\end{tabular}




\begin{tabular}{|c|c|}
\hline Data category & Data required \\
\hline $\begin{array}{l}\text { Neighbourhood or } \\
\text { spatial attributes }\end{array}$ & $\begin{array}{l}\text { - Distance to healthcare } \\
\text { - Distance to main employment centres } \\
\text { - Distance to mental health services } \\
\text { - Distance to public transport } \\
\text { - Local crime levels } \\
\text { - Distance to training or further education institutions } \\
\text { - Local broadband accessibility and reliability } \\
\text { - Distance to recreational areas and parks } \\
\text { - Distance to places of worship } \\
\text { - Planning overlays } \\
\text { - Other overlays that could inhibit development potential } \\
\text { - Existing concentration rate }\end{array}$ \\
\hline Household attributes & $\begin{array}{l}\text { - Number in household } \\
\text { - Ages } \\
\text { - Type and level of disability } \\
\text { - Ethnicity } \\
\text { - Overcrowding } \\
\text { - Underutilisation }\end{array}$ \\
\hline Financial & $\begin{array}{l}\text { - Rent } \\
\text { - Vacancy rate } \\
\text { - Rates } \\
\text { - Insurance } \\
\text { - Debt repayment amounts } \\
\text { - Management overheads } \\
\text { - Backlog maintenance } \\
\text { - Routine maintenance } \\
\text { - Reactive maintenance estimate } \\
\text { - Renewal or redecoration requirements } \\
\text { - Depreciation reserve } \\
\text { - Grants and other alternate revenue } \\
\text { - Cost and benefits of non-economic and indirect outcomes (social/environmental/cultural) } \\
\text { - Cost of any new capital programs e.g. Healthy Homes } \\
\text { - Valuation data }\end{array}$ \\
\hline Demand & $\begin{array}{l}\text { - Future household demand } \\
\text { - Spatial or location demand } \\
\text { - Asset configuration demand }\end{array}$ \\
\hline
\end{tabular}

Source: Authors. 
Information technology systems

Information technology (IT) systems are important for the delivery of an best practice AMP (BPAMP). It is possible to analyse data for a small portfolio using Excel spreadsheets without using specialised asset management software. However, once component-level data is introduced, this would be tedious and time-consuming to maintain beyond 30-50 properties, depending on the number of components.

Component-level data is required to generate maintenance programs, capital renewal programs and new capital investment programs. Ideally, to collect dynamic data that allows for BPAMP, the following systems and tools are needed:

- Field data collection device (e.g. a tablet with SIM card), component-level condition assessment (CA) and asset amenity.

- A system that records component-level CA data and utilises predictive modelling for maintenance and renewal work specific to each asset.

- GIS systems that enable collection and monitoring of spatial data for each asset, such as distance to health services, public transport, etc. - - these can also aid spatial demand modelling and overlaying zoning maps to determine highest and best use. ${ }^{11}$

- A system that captures current rental income and expenses, including maintenance and renewal work, and forecasts this over a long life span (90 years) for future profile analysis.

- Consideration of non-economic costs and benefits of the social and environmental aspects of social housing provision in cashflow analysis.

- A system that captures attribute data, such as bedroom numbers and accessibility for tenant matching, overcrowding and underutilisation metrics.

- A system that is capable of connecting all data mentioned in the previous six points for the purposes of creating an ODM tool that can be used at any point of the asset's life cycle from acquisition to disposal.

- A system capable of aggregating data to portfolio level and filtering at all levels down to an individual asset.

- A system capable of reporting performance against target benchmarks.

- Data that is continually updated and as live as possible for asset specificity, not averaged across the portfolio.

- Project management and contract management software.

- A shared system that provides an interface between asset teams and tenancy teams, and that details asset programs, asset rate of return, asset amenity, asset condition, suitability for disability, maintenance, distance to healthcare, schools, future use determinations, demand for location, and so on. This could be provided by way of dashboard data, as illustrated in Figure A3.

11 The concept of 'highest and best use' is a valuation principle that considers the maximum utility of a site, assuming planning and related consents can be obtained, and looks past the present use or utility. 
Appendix 1: The Australian social

housing best practice asset

management Framework

Figure A3: Sustainability dashboard wheel

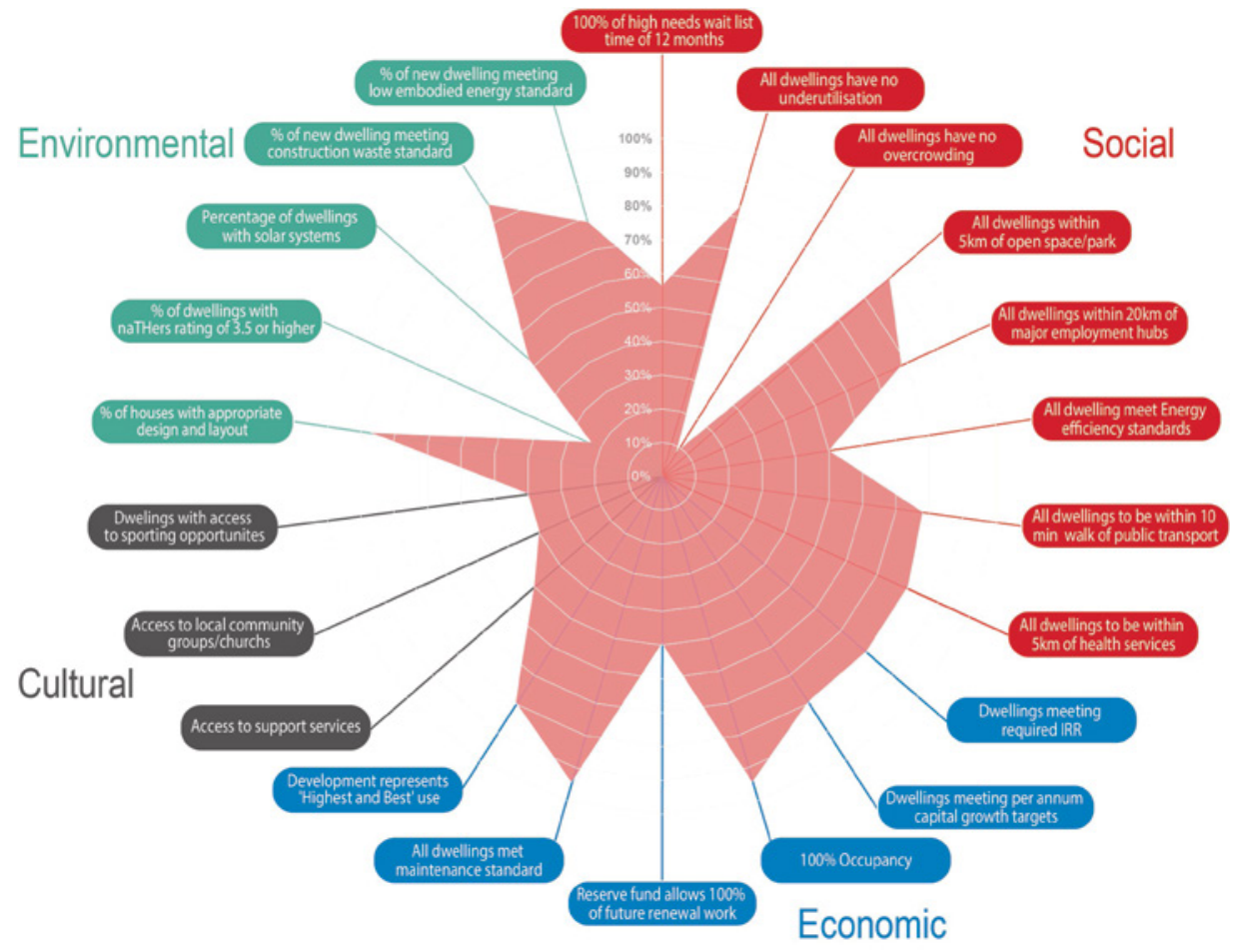

Source: Logan 2020.

Figure A4 outlines the mapping of tools that operate individually but are connected. Part or fully optioned systems - should they exist - will consolidate parts of this diagram.

Figure A4: Connectivity mapping

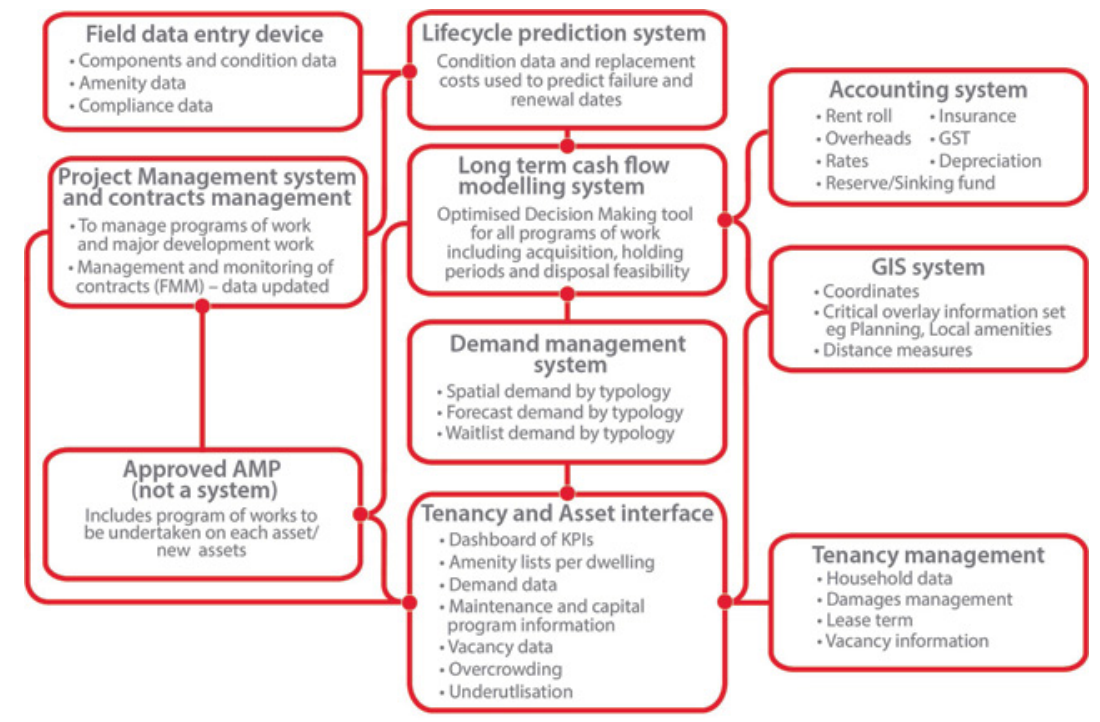

Source: Authors. 


\section{Levels of service}

Levels of service (LOS) are statements and measures that link an organisation's objectives and policies with asset outcomes, including associated asset programs of work and budgets. They represent a set of service levels provided to the customer. Internal and external stakeholder engagement is critical to their development. They also represent a set of KPIs. They consist of:

- objectives

- statements

- measures

- targets

- current performance.

LOS statements must include strategic, tactical, operational and implementation measures. Current performance data will change as programs of work are rolled out, and the monitoring of this data is important for reporting achievements towards LOS targets. These will ultimately illustrate the contribution of asset programs to the organisation's objectives. Ideally, a system is needed that allows reporting of achievements at any point in time using actual data returned by contractors and audit inspections.

LOS should reflect the requirements of Residential Tenancies Acts (RTAs), OHS laws and regulations, the Building Code of Australia and other relevant statutes or regulations where relevant. Community housing needs to comply with the asset-performance requirements of the National Regulatory System for Community Housing (NRSCH), and any state-based variations. These performance standards inform LOS, but do not in themselves constitute the breadth and depth of LOS required for BPAM. The National Community Housing Standards Manual provides more detailed guidance.

Setting standards is easiest when reflecting regulations, although regulations may not include sufficient details - for example, the various RTAs. SHOs need to address such gaps. Further, beyond mandated standards, SHOs should consider additional or higher standards - for example, universal accessibility or eight-star energy ratings. The establishment of standards beyond mandated minimums will depend on the organisational mission and affordability. Affordability is determined through cost-benefit analysis and scenario modelling.

Setting standards beyond compliance is complex; it is an iterative process based on assessment of affordability. Adjustments to LOS statements, timeframes and program budgets is one way that programs can fit within budget constraints over time.

LOS become key discussion points with internal and external stakeholders in the planning process. The financial assessment of LOS needs to be accurate, transparent and able to show clear outcomes and contribution to the organisation's objectives.

Once the AMP is approved, the LOS statements and measures become the KPIs against which performance is measured. These should be periodically reviewed throughout the year and reported annually.

A critical component of this process is the continual and live updating of data as programs of work are completed during the financial year. This includes updates to the maintenance condition as work is completed, and updates to amenity data as amenity shortfalls are addressed and 'nice to have' programs are carried out. For larger organisations, this work is often packaged and contracted out via a Facilities Maintenance contract. Where this is the case, an audit of works should be carried out. 
LOS statements may relate to many things. For example:

- new build standards

- overcrowding standards

- concentration standards

- underutilisation standards

- condition standards

- maintenance standards

- demand management standards

- vacancy turnover standards

- management contract standards (for CHPs).

Table A2 shows an example of a corporate objective and related asset strategy, LOS statements, target and budget allocation. This plan will be reviewed periodically to determine if targets have been met. Over-spend or under-provision need to be addressed in the next iteration of the AMP.

Table A2: Example of level of service alignment to corporate plan

\begin{tabular}{|c|c|c|c|c|c|c|c|}
\hline $\begin{array}{l}\text { Corporate } \\
\text { business plan } \\
\text { objectives }\end{array}$ & $\begin{array}{l}\text { Asset } \\
\text { management } \\
\text { strategy } \\
\text { statement }\end{array}$ & $\begin{array}{l}\text { Tactical } \\
\text { statement }\end{array}$ & $\begin{array}{l}\text { Operational } \\
\text { statement }\end{array}$ & $\begin{array}{l}\text { Implementation } \\
\text { statement }\end{array}$ & Measures & Target & $\begin{array}{l}\text { Current } \\
\text { performance }\end{array}$ \\
\hline \multirow[t]{5}{*}{$\begin{array}{l}\text { Objective 1: ABC } \\
\text { Corporation } \\
\text { will provide } \\
\text { appropriate } \\
\text { housing for those } \\
\text { in greatest need }\end{array}$} & \multirow[t]{3}{*}{$\begin{array}{l}\text { All tenants will } \\
\text { have access to } \\
\text { healthy, energy- } \\
\text { efficient homes }\end{array}$} & $\begin{array}{l}\text { All dwellings } \\
\text { must be } \\
\text { insulated } \\
\text { within } 2 \text { years }\end{array}$ & $\begin{array}{l}\text { For older dwellings, } \\
\text { retrofitting ceiling } \\
\text { and wall insulation } \\
\text { only. All new } \\
\text { dwellings insulated } \\
\text { to new build } \\
\text { standards }\end{array}$ & $\begin{array}{l}\text { Tenants will be } \\
\text { inconvenienced } \\
\text { during installation. } \\
\text { Minimum 2-week } \\
\text { notice and reminder } \\
\text { 24-hour notice to } \\
\text { be provided }\end{array}$ & $\begin{array}{l}\text { All ceilings in cool- } \\
\text { climate zones are } \\
\text { insulated to R5.0. } \\
\text { Warmer climates } \\
\text { to R2.5. Walls to } \\
\text { R2.5 and floors to } \\
\text { R2 unless on slab }\end{array}$ & $\begin{array}{l}100 \% \text { of houses } \\
\text { to comply } \\
\text { within } 2 \text { years } \\
(2023)\end{array}$ & $50 \%$ \\
\hline & & \multirow[t]{2}{*}{$\begin{array}{l}\text { Maximise } \\
\text { renewable } \\
\text { energy } \\
\text { opportunities }\end{array}$} & \multirow[t]{2}{*}{$\begin{array}{l}\text { All homes with roof } \\
\text { aspects suitable } \\
\text { for solar should } \\
\text { have solar energy } \\
\text { systems }\end{array}$} & \multirow{2}{*}{$\begin{array}{l}\text { Tenants will be } \\
\text { inconvenienced } \\
\text { during installation. } \\
\text { Minimum 2-week } \\
\text { notice and reminder } \\
\text { 24-hour notice to } \\
\text { be provided }\end{array}$} & \multirow{2}{*}{$\begin{array}{l}\text { All solar systems } \\
\text { sized to meet } \\
100 \% \text { of household } \\
\text { demand }\end{array}$} & $\begin{array}{l}80 \% \text { of current } \\
\text { portfolio to } \\
\text { have solar } \\
\text { systems in } 5 \\
\text { years }\end{array}$ & $25 \%$ \\
\hline & & & & & & $\begin{array}{l}100 \% \text { of new } \\
\text { homes }\end{array}$ & $10 \%$ \\
\hline & \multirow[t]{2}{*}{$\begin{array}{l}\text { All high-needs } \\
\text { waitlist clients } \\
\text { to have access } \\
\text { to an affordable } \\
\text { dwelling }\end{array}$} & \multirow{2}{*}{$\begin{array}{l}\text { Use new } \\
\text { supply } \\
\text { to target } \\
\text { smaller } \\
\text { homes to } \\
\text { better match } \\
\text { waitlist } \\
\text { demand } \\
\text { profile }\end{array}$} & \multirow[t]{2}{*}{$\begin{array}{l}\text { Growing demand } \\
\text { for housing to be } \\
\text { satisfied though } \\
\text { new housing } \\
\text { provision }\end{array}$} & $\begin{array}{l}\text { Work with } \\
\text { developers to } \\
\text { acquire new stock. } \\
\text { Redevelop Shady } \\
\text { Acres site }\end{array}$ & $\begin{array}{l}\text { Acquire } 10 \times 2 \text {-bed } \\
\text { units each year for } \\
\text { the next five years }\end{array}$ & \multirow{2}{*}{$\begin{array}{l}\text { Maintain } \\
\text { waitlist demand } \\
\text { at no more than } \\
500 \text { high-needs } \\
\text { households, } \\
\text { and a wait time } \\
\text { of less than } 6 \\
\text { months }\end{array}$} & \multirow[t]{2}{*}{$\begin{array}{l}600 \text { on } \\
\text { waitlist with } \\
\text { a 12-month } \\
\text { wait time }\end{array}$} \\
\hline & & & & $\begin{array}{l}\text { Work with investor } \\
\text { groups to develop } \\
\text { ongoing lease } \\
\text { contracts }\end{array}$ & $\begin{array}{l}\text { Lease } 30 \times 1 \text {-bed } \\
\text { apartments each } \\
\text { year for the next } \\
5 \text { years }\end{array}$ & & \\
\hline
\end{tabular}

Source: Authors.

\section{Life-cycle management strategies}

BPAM involves the ability to make the best asset-related decisions from an individual component level-for example, repair or replace - through to the highest portfolio level. This capacity to make decisions based on immediate and long-term objectives is known as optimised decision-making (ODM). IPWEA describe ODM as the best asset strategy or project to minimise long-term costs and maximise outcomes for the organisation and its customers (IPWEA 2020a). 
In practice, ODM is a tool that considers net present value (NPV) and risk assessment of operations and maintenance, renewals and capital projects for growth. It is based on the premise that social, cultural, environmental and financial benefits are included in cost-benefit analysis and multi-criteria analysis, and that ODM is used throughout an asset's life cycle. Specialised asset management software provides the tools for ODM. Aggregation of these ODM metrics is also critical to examine groups of assets for strategy, tactical and operational planning and reporting.

Life-cycle management require requires forecasting of capital needs and financial provision. Figure A5 provides a hypothetical capital renewal profile for a portfolio of housing assets forecast over a 100-year period compared to the depreciation reserve. A critical issue for $\mathrm{SHOs}$ - unlike corporate real estate-is that the accounting method called 'straight-line depreciation' is a not an appropriate basis for determining the quantum of funds that should be set aside for capital works. A depreciation reserve should be established, but this too should not simply be an annualised amount. Financial provision for future capital expenditure should reflect actual future need. A depreciation reserve is like a sinking fund, where a certain amount of capital funding is set aside annually for future capital renewals, but allocation into the fund must ensure capital is available when required.

Figure A5: Example of portfolio renewal profile

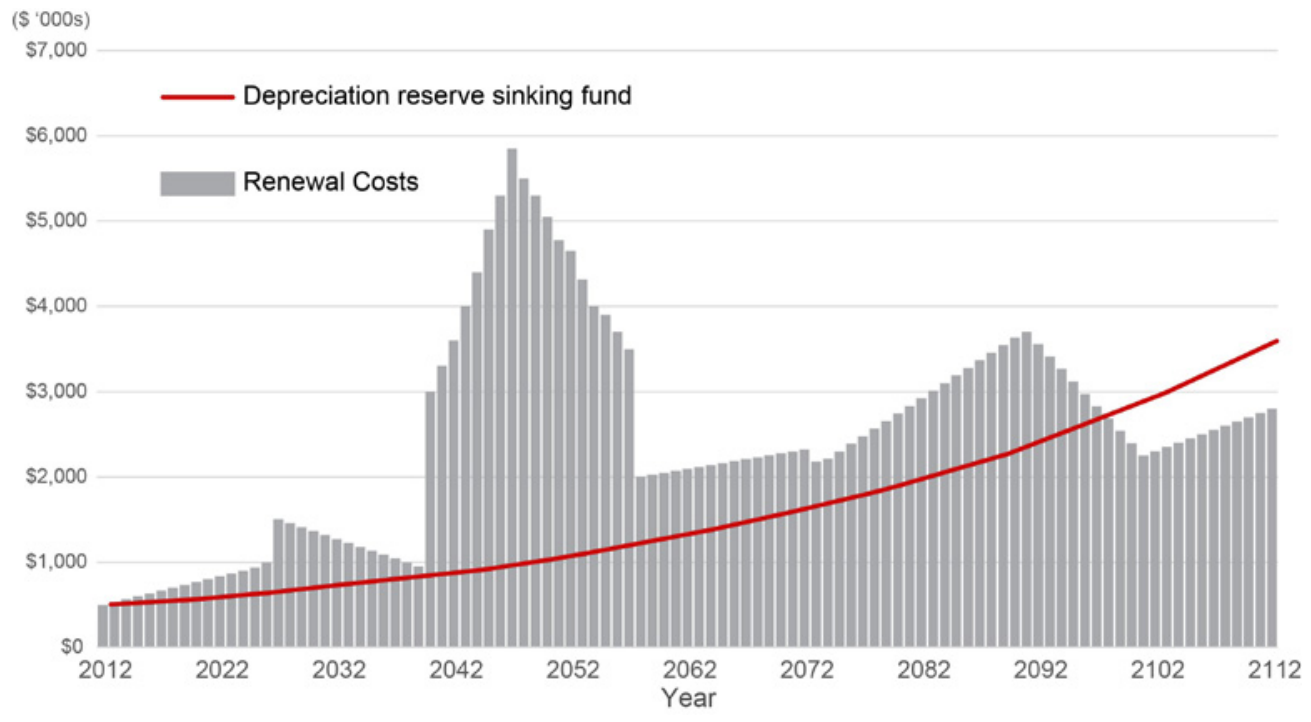

Source: Logan (2021).

Figure A5 shows the period 2042-2057 as one where renewal costs are significantly greater than available funds. There are several choices, including the following:

1. Increasing rent and increasing the depreciation reserve.

2. Selling properties that fit within that renewal period.

3. Redeveloping properties to change the profile.

4. Deferring renewals and hoping for the best.

5. Increasing the depreciation reserve without increasing rent.

A consequence of deferring expenditure is intergenerational inequity, as tenants in the future suffer the increased burden of costs attributable to provision for tenants in the past. Or alternatively, future tenants miss out on housing altogether. 
Intergenerational equity is a key element of sustainability of services. Organisational revenues today must reflect the true cost of running the service. The cost today can be represented as the NPV of future revenue less forecast expenditure over a period of time, as in Figure A5. The period needs to reflect the life of the assets. If rent levels are lower than the NPV rent required, then the portfolio must evolve to reduce costs, rents must increase, or both.

Another option would be to refinance or seek alternate funding support-for example, capital grants for renewal. This is an example of ODM at the portfolio level. The same analysis at individual asset level allows the SHO to know which assets are performing well and which ones are not-that is, which assets may be slated for upgrade, redevelopment or disposal. A simple NPV cashflow example of an individual asset is provided in Table A3.

Table A3 shows the cashflow forecast for the first nine years of a 100-year forecast. An amount of \$12,000 is forecast to be spent on capital renewal (for a new kitchen) in Year 6. Renewal of the kitchen will occur several times over the remaining 91-year life of the dwelling. The NPV of that renewal kitchen work is $\$ 16,320$, assuming an appropriate discount rate. This compares to the current depreciation reserve of just $\$ 10,000$ for the property. A shortfall of $\$ 6,320$ has to be financed partly through allocating the properties net cashflow to the reserve fund and partly through charging more rent (another $\$ 45$ per week).

Of course, there are other alternatives - and rent increases are typically not an option in the Australian social housing context. Other options include:

- adjustments to a lower maintenance standard

- reducing management overheads

- refinancing or getting grants

- changing the frequency that kitchens and other capital items are replaced.

In this example, the true cost in rent per week of the dwelling is \$245 per week compared to \$200 per week being charged (including rent assistance). At \$245, the management of the asset would be sustainable. At the current rent, future generations will need to pick up the tab for the shortfall in the reserve fund.

Other important considerations to note are that NPV figures in cashflow analysis tend to smooth cashflow, and variances occur beyond 10-15 years. Therefore, it is recommended that annual NPVs are calculated for each year and reviewed regularly as part of the AMP process. There are two key components from this simple cashflow that fulfil two elements of the AMP roadmap. The first is ODM, and the second is LOS. The cashflow is an example of ODM, as the asset manager can adjust elements of the assumptions to determine the best course of action for the asset. In addition, alternate configurations - or redevelopment scenarios - can also be assessed. LOS can be adjusted to suit at asset and portfolio level. Clearly the analysis of the asset in Table A3 does not allow for a LOS that aims to grow the portfolio when the analysis indicates a risk of not being able to maintain it.

Behind each cashflow line item, except rates and other fixed costs, sits a LOS statement that will include target maintenance standards and component-level renewal cycles-for example, how often to renew a kitchen. Each of these is adjustable - subject to constraints such as upper and lower base life. Costs are estimated and have measurable outcomes-good and bad. There may also be capital programs to address amenity shortfalls such as heating, and insulation upgrades aligned to a Healthy Homes objective. Each of these is a LOS that forms part of a basket of LOS, which can be traded for one another, given affordability constraints. These LOS, working in conjunction with a sustainable rent model, provide the transparency needed for robust asset management planning and budgeting. 
Table A3: Example of simple cashflow of an individual housing asset

\begin{tabular}{|c|c|c|c|c|c|c|c|c|c|}
\hline Year & 1 & 2 & 3 & 4 & 5 & 6 & 7 & 8 & 9 \\
\hline Rent & $\$ 15,000$ & $\$ 15,300$ & $\$ 15,606$ & $\$ 15,918$ & $\$ 16,236$ & $\$ 16,561$ & $\$ 16,892$ & $\$ 17,230$ & $\$ 17,575$ \\
\hline \multicolumn{10}{|l|}{ Expenses } \\
\hline Vacancy & $\$ 300$ & $\$ 306$ & $\$ 312$ & $\$ 318$ & $\$ 325$ & $\$ 331$ & $\$ 338$ & $\$ 345$ & $\$ 351$ \\
\hline Maintenance backlog & $\$ 1,200$ & $\$ 1,224$ & $\$ 1,248$ & $\$ 1,273$ & $\$ 1,299$ & $\$ 1,325$ & $\$ 1,351$ & $\$ 1,378$ & $\$ 1,406$ \\
\hline Scheduled maintenance & $\$ 800$ & $\$ 816$ & $\$ 832$ & $\$ 849$ & $\$ 866$ & $\$ 883$ & $\$ 901$ & $\$ 919$ & $\$ 937$ \\
\hline Reactive maintenance & $\$ 500$ & $\$ 510$ & $\$ 520$ & $\$ 531$ & $\$ 541$ & $\$ 552$ & $\$ 563$ & $\$ 574$ & $\$ 586$ \\
\hline Management overheads & $\$ 728$ & $\$ 743$ & $\$ 757$ & $\$ 773$ & $\$ 788$ & $\$ 804$ & $\$ 820$ & $\$ 836$ & $\$ 853$ \\
\hline \multicolumn{10}{|l|}{ Debt-servicing costs } \\
\hline Rates & $\$ 1,500$ & $\$ 1,530$ & $\$ 1,561$ & $\$ 1,592$ & $\$ 1,624$ & $\$ 1,656$ & $\$ 1,689$ & $\$ 1,723$ & $\$ 1,757$ \\
\hline Insurance & $\$ 1,200$ & $\$ 1,224$ & $\$ 1,248$ & $\$ 1,273$ & $\$ 1,299$ & $\$ 1,325$ & $\$ 1,351$ & $\$ 1,378$ & $\$ 1,406$ \\
\hline Other & $\$ 300$ & $\$ 306$ & $\$ 312$ & $\$ 318$ & $\$ 325$ & $\$ 331$ & $\$ 338$ & $\$ 345$ & $\$ 351$ \\
\hline Expenses subtotal & $\$ 6,528$ & $\$ 6,659$ & $\$ 6,792$ & $\$ 6,928$ & $\$ 7,066$ & $\$ 7,207$ & $\$ 7,352$ & $\$ 7,499$ & $\$ 7,649$ \\
\hline Net cashflow before any capital renewals or new capital investment & $\$ 8,472$ & $\$ 8,641$ & $\$ 8,814$ & $\$ 8,991$ & $\$ 9,170$ & $\$ 9,354$ & $\$ 9,541$ & $\$ 9,732$ & $\$ 9,926$ \\
\hline Capital renewal requirements & $\$-$ & $\$-$ & $\$-$ & $\$-$ & $\$-$ & $\$ 12,000$ & $\$-$ & $\$-$ & $\$-$ \\
\hline Capital renewal NPV & $\$ 14,940$ & & & & & & & & \\
\hline Current depreciation reserve/sinking fund & $\$ 5,000$ & & & & & & & & \\
\hline Depreciation reserve shortfall & $\$ 9,940$ & & & & & & & & \\
\hline Shortfall to be funded from net cashflow & $\$ 8,472$ & & & & & & & & \\
\hline Additional rent required to break even & $\$ 1,468$ & $\$ 28$ & perweek & & & & & & \\
\hline
\end{tabular}

Source: Logan 2020. 
The same cashflow model can be used with the addition of other capital programs, such as energy efficiency retrofits, as well as additional line items for other social, cultural or environmental benefits and costs. For example, if allocating housing to a tenant reduces the tenant's housing costs and delivers health benefits amounting to 'savings' of \$5,000 per annum, then the feasibility suddenly looks a lot more viable. However, as these are social returns on investment and do not accrue to the housing organisation itself, they should be reported separately.

\section{Financial forecasts}

Financial forecasting and the development of a funding strategy are critical components of asset management. It shows how the plan is affordable (or not) and that the long-term sustainability of the service is in good hands. As a general rule, borrowing to fund future programs should only be undertaken when there is sufficient equity, and when interest costs on borrowings are lower than the portfolio net return. Where this is the case, leveraging makes sense-but it is not without risk. Any debt introduces risk, and loan covenants may constrain the SHO's ability to reconfigure its portfolio. Other funding options such as grants are preferable.

Modelling is used to determine feasibility of plans to address demand. Each LOS is subject to a cost-benefit analysis of options to achieve the standards - for example, the best intervention to achieve healthy, energy-efficient homes. Behind each LOS, a long-term forecast of funding requirements forms a line item in the cashflow. The LOS standards, targets and annual budget can be adjusted to ensure the long-term viability of provision by the SHO. Cost-benefit analysis can also be used as a means of prioritising one program of work against all others, provided the costs and benefits are measured correctly.

Financial forecasting, setting LOS and life-cycle management all work together to create the most efficient, best cost-benefit programs of work. Typically, the 'ideal standard' for assets is not obtainable within budget limitations, so adjustments must be made to the LOS and programs to generate an affordable plan. If the minimum mandated standards cannot be achieved, there will be a severe funding issue, which will result in unacceptable management risk and deterioration of portfolio value over time unless alternate funding can be obtained or rental revenue can be increased-for example, through selecting households with higher incomes.

\section{Improvement plan}

The improvement plan starts with self-auditing to determine the confidence you have in your AMP and a plan to address the shortfalls. Consider whether there are data shortfalls in crucial areas that mean having to make decisions based on limited data. The improvement plan represents an opportunity to record improvement items (with targeted timeframes) to address shortfalls in training, resources, data, analysis or process issues.

An example of a process issue that often needs improving for new AMPs is keeping the condition data live after the initial CA or, in some cases, making broad assumptions at portfolio level to conduct analysis in the absence of individual dwelling amenity and condition data.

Other examples may relate to improving the confidence in demand models or new software to fulfil a critical gap in data storage and analysis capacity. These improvement items should be monitored and form part of the work plan for asset team members. Improvement plans need to be funded and realistic. 


\section{Appendix 2: Ethics approval}

\section{Notice of Approval}

Date: $\quad 9$ July 2020

Project number: 23193

Project title: Developing an Australian Social housing Advanced Asset management (ASHAAM) framework

Risk classification: More than low risk

Chief investigator: Dr Andrea Sharam

Approval period: From: 9 July 2020

To: 9 July 2023

The above application has been approved by the RMIT University HREC as it meets the requirements of the National statement on ethical conduct in human research (NH\&MRC, 2007).

Terms of approval:

\section{Responsibilities of chief investigator}

It is the responsibility of the above chief investigator to ensure that all other investigators and staff on a project are aware of the terms of approval and to ensure that the project is conducted as approved by HREC. Approval is valid only whilst the chief investigator holds a position at RMIT University.

\section{Amendments}

Approval must be sought from HREC to amend any aspect of a project. To apply for an amendment, use the request for amendment form, which is available on the HREC website and submitted to the HREC secretary. Amendments must not be implemented without first gaining approval from HREC.

\section{Adverse events}

You should notify the HREC immediately (within 24 hours) of any serious or unanticipated adverse effects of the research on participants, and unforeseen events that might affect the ethical acceptability of the project. 


\section{Annual reports}

Continued approval of this project is dependent on the submission of an annual report. Annual reports must be submitted by the anniversary of approval (20 March 2019) of the project for each full year of the project. If the project is of less than 12 months duration, then a final report only is required.

\section{Final report}

A final report must be provided within six months of the end of the project. HREC must be notified if the project is discontinued before the expected date of completion.

\section{Monitoring}

Projects may be subject to an audit or any other form of monitoring by the HREC at any time.

\section{Retention and storage of data}

The investigator is responsible for the storage and retention of original data according to the requirements of the Australian code for the responsible conduct of research (section 2) and relevant RMIT policies.

\section{Special conditions of approval}

Nil.

In any future correspondence please quote the project number and project title above.

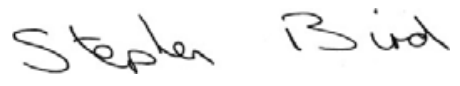

Prof Stephen Bird

Chairperson RMIT HREC

CC:

Dr Peter Burke, HREC secretary

Dr Sean McNelis, Co-investigator, Swinburne University Dr Joe Cho, Co-investigator, University of South Australia Mr Peter Rossini, Co-investigator, University of South Australia Prof Terry Burke, Co-investigator, Swinburne University Dr Lyndall Bryant, Co-investigator. 


\section{Appendix 3: Survey instrument}

Welcome to the research study on Developing an Australian social housing advanced asset management (ASHAAM) framework!

\section{Introduction}

\section{Chief Investigator}

- Dr Andrea Sharam, RMIT School of Property, Construction and Project Management

\section{Associate Investigators}

- Callum Logan, RMIT School of Property, Construction and Project Management

- Dr Hyunbum Cho, Business School, University of South Australia

- Peter Rossini, Business School, University of South Australia

- Dr Sean McNelis, Centre for Urban Transitions, Swinburne University of Technology

- Prof Terry Burke, Centre for Urban Transitions, Swinburne University of Technology

- Dr Lyndall Bryant, independent consultant

\section{What is the purpose of this research?}

The aim of the research is to develop a social housing advanced asset management (SHAAM) framework. This survey is intended to collect information on the current practices across social housing asset management in Australia. It focusses on data collection, tools, systems and processes, resources, reporting and communication used across organisations in order to achieve optimal social housing outcomes. The questions begin with some organisational and individual profile questions, followed by questions about your organisation's approach to housing asset management during the acquisition, management, reconfiguration and disposal phases of your assets.

This research has been initiated by the researchers, Andrea Sharam and Callum Logan from the RMIT School of Property, Construction and Project Management; Hyunbum Cho and Peter Rossini from the University of South Australia; Sean McNelis and Terry Burke from Swinburne University; and Lyndall Bryant (independent consultant).

The research is funded by the Australian Housing and Urban Research Institute Ltd (AHURI). 


\section{What does participation in this research involve?}

This is the second stage of the research and involves the completion of an online survey. It is estimated that the survey will take approximately 30 minutes to complete. At the completion of the survey you can indicate if you are willing to participate in a face-to-face or Skype interview in three months' to six months' time. There are no costs associated with participating in this research project, nor will you be paid. Your responses to this survey will be confidentialised, meaning that your name or your organisation's name will be not be used in any publications or presentations.

\section{Do I have to take part in this research project?}

Participation in any research project is voluntary. If you do not wish to take part, you do not have to. Your decision whether to take part or not to take part, or to take part and then withdraw, will not affect your relationship with the researchers, with RMIT University, University of SA, or Swinburne University.

Submitting your completed survey is an indication of your consent to participate in the study. You can withdraw your responses any time.

\section{What are the possible benefits of taking part?}

The benefits of participating in this research include:

- reducing the costs and risks of providing social housing

- improving community and Indigenous housing access to private financing

- addressing barriers to public housing stock transfer

- providing community housing regulators with improved capacity to meet their statutory duties

- reducing the cost of regulation.

\section{What are the risks and disadvantages of taking part?}

This project will use an external site to create, collect and analyse data collected in a survey format. The site we are using is Qualtrics. If you agree to participate in this survey, the responses you provide will be stored on their host server. Once we have completed our data collection and analysis, we will store the data on a RMIT external drive which will be stored securely for five years. Data may be used by the researchers listed above for future reference and comparison.

\section{What happens when the research project ends?}

The outcomes of the research will be shared with participants in 2021. The findings will be made available via a report published by AHURI on their website (www.ahuri.edu.au) and at AHURI seminars and conferences. Journal articles for peer-reviewed journals will be submitted for publication. In any publication or presentation, participants and their organisations will not be identified.

\section{Who has reviewed the research project?}

All research in Australia involving humans is reviewed by an independent group of people called a Human Research Ethics Committee (HREC). This research project has been approved by the RMIT University HREC. This project will be carried out according to the National Statement on Ethical Conduct in Human Research (2007). This statement has been developed to protect the interests of people who agree to participate in human research studies. 


\title{
Further information and who to contact
}

\author{
If you want any further information concerning this project \\ Name: $\quad$ Dr Andrea Sharam \\ Position: Chief investigator \\ Telephone: $\quad 0399251439$ \\ (RMIT uses Business Skype so staff are available while working from home during the \\ COVID-19 crisis) \\ Email: $\quad$ andrea.sharam@rmit.edu.au
}

Should you have any concerns or questions about this research project, which you do not wish to discuss with the researchers listed in this document, then you may contact:

RMIT University HREC Secretary Peter Burke

Telephone: $\quad 0399252251$

Email: $\quad$ human.ethics@rmit.edu.au

Mailing address: Research Ethics Co-ordinator

Research Integrity Governance and Systems

RMIT University

GPO Box 2476, MELBOURNE, VIC 3001

At the conclusion of the survey, there is the option to make additional comments. If you think of any topics you would like to comment on in the process of completing the survey, please make a note of these for yourself along the way and include them at the end.

The study should take you around 30 minutes to complete.

\section{About you}

Please provide the name of your organisation.

How long have you been in your current role or a similar role within the social housing sector?

$\square$ Less than 12 months

$\square 1$ to 2 years

$\square \quad 3$ to 10 years

$\square 11$ to 20 years

$\square$ More than 20 years 
What is your role within your organisation?

$\square$ Asset Manager

$\square$ Head of Property

$\square$ Head of Tenancy Services

$\square$ Housing Manager

$\square$ Other, please state

If you selected 'Asset Manager' as your role, would you also describe your role as covering some other non-asset management duties? Please describe some non-asset management responsibilities below.

Is your organisation a State Housing Authority (SHA), Community Housing Provider (CHP), State-Owned \& Managed Indigenous Housing (SOMIH) or Indigenous Housing Organisation)?

$\square$ State Housing

$\square$ Community Housing Provider

$\square$ State-Owned and Managed Indigenous Housing

$\square$ Indigenous Housing Organisation

$\square$ Other. Please specify

How long has your organisation managed social housing?

$\square$ Less than 12 months

$\square 1$ to 2 years

$\square \quad 3$ to 10 years

$\square 11$ to 20 years

$\square$ More than 20 years

\section{About your assets}

How many dwellings are owned by your organisation, leased from government, or under a management contract with a private landlord?

Owned by your organisation

Leased from government

$\square$ Management contract with private

Other

$\square$ Total dwellings

If your organisation is a SHA and you also have a SOMIH portfolio, please differentiate the stock split below.

Number of SHA dwellings

$\square$ Number of SOMIH dwellings 
What percentage of your dwellings are within a reasonable distance from an office with asset staff, or are they geographically spread?

$\square$ Relatively centralised, e.g., within city limits

$\square$ Spread out, but within 2-hour drive

$\square$ Very spread out and beyond 2 hours away

What percentage of your portfolio would you describe as up to 10 years old, 11 to 20 years old, 21 to 30 years old, 31 to 40 years old and over 41 years old?

$\square$ Up to 10 years

$\square 11$ to 20 years

$\square 21$ to 30 years

$\square 31$ to 40 years

$\square$ Over 41 years

What percentage of your portfolio would you describe as good, average and poor maintenance condition?

$\square$ Good condition

$\square$ Average condition

$\square$ Poor condition

How does your organisation assess the market value of the assets for internal purposes?

If you have applied for lending from a private institution, what does the lender require as part of a market-value assessment for security purposes?

\section{About your housing asset documentation and communication}

Do you currently have a document, or a set of documents, covering your asset strategy, asset planning and asset operations?

$\square$ Yes

$\square$ Maybe

$\square$ No

Do you have a documented asset management framework?

$\square$ Yes

$\square$ No

$\square$ Probably not documented, but I could describe it

Do you have an internal (own staff) asset management model or are the asset management services undertaken by an external asset management agency?

\section{External agency}

Internal

$\square$ We outsource some components of asset management 
Which of the following standards inform your housing asset management strategy, planning and operations? You can select more than one option.

$\square$ National Asset Management Standards and the Institute of Public Works Engineering Australasia (NAMS/ IPWEA) standards

$\square$ International Standard ISO 55001

$\square$ We don't use any standards

$\square$ We use other manuals/standards. Please detail these and explain why you use them.

Do you measure dwelling compliance with statutory or regulatory requirements such as $\mathrm{OH} \& \mathrm{~S}$, National Construction Code, Housing Registrars' housing and tenancy standards?

$\square$ Yes

$\square$ No

$\square$ Don't know

Do you collect information on assets that have contamination issues at acquisition or during the holding period, e.g., a survey of compliance with EPA standards?

$\square$ Yes

$\square$ No

$\square$ Only if a particular issue arises

Do you register any of the following housing characteristics?

\begin{tabular}{lc}
\hline & Yes \\
\hline Disability accessibility features & $\square$ \\
\hline Sustainability features (PVs, water tanks) & $\square$ \\
\hline Easements & $\square$ \\
\hline Bushfire-prone zones information & $\square$ \\
\hline Heritage protection & $\square$ \\
\hline
\end{tabular}

Are the asset strategy, planning and operations documents communicated effectively across the organisation at appropriate levels?

$\square$ Definitely yes

$\square$ Not sure

Definitely not

Do your organisation's strategy and goals adequately reflect the need to maintain and replace assets?

$\square$ Yes

$\square$ Maybe

$\square$ No

Are your current and long-term asset management needs fully funded?

$\square$ Yes

$\square$ No. Please estimate the percentage that your depreciation reserve is underfunded. 
Do you currently have IT systems and tools that allow you to report housing asset information quickly within your organisation?
$\square$ Yes
$\square$ No
$\square$ No, but reports can generated in a few minutes
$\square$ Don't know

\section{About acquisitions}

During dwelling acquisitions, do you use financial models that include estimates for rent and costs to determine if the acquisition is feasible?

$\square$ Yes

$\square$ No, we use other models/methods. What are they? Please state below.

$\square$ Don't know

Do you include other financial allowances (other than rent and expenses) for social benefits and costs in your financial model when acquiring housing?

$\square$ Yes

$\square$ No

$\square$ Don't know

Are the costs and benefits of different levels of sustainability features included in the financial modelling when acquiring housing? e.g., renewable energy features.

$\square$ Yes

$\square$ No

$\square$ Don't know

Please use the slider to indicate how important the following dwelling-acquisition considerations are to your organisation.

\begin{tabular}{|c|c|}
\hline & $0=$ Not important, $100=$ Very important \\
\hline Financial feasibility (rent-less-expenses type model) & $=$ \\
\hline Dwelling profile, e.g., type of stock or number of bedrooms & \\
\hline Location & \\
\hline $\begin{array}{l}\text { Reducing concentration (number of social housing dwellings in neighbourhoods } \\
\text { compared to all dwellings) }\end{array}$ & \\
\hline Meeting annual targets & \\
\hline Reducing age profile of portfolio & 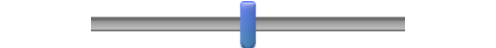 \\
\hline Sustainability features & - \\
\hline Cultural considerations & \\
\hline Modern building standards & 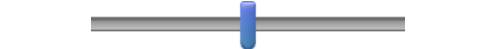 \\
\hline Meeting requirements for building standards, accessibility, etc. & - \\
\hline
\end{tabular}


Do you conduct an audit of the due diligence process after the acquisitions and then make any required adjustments to your process?

$\square$ Yes

$\square$ No

$\square$ We do, but we don't update our processes

$\square$ Don't know

Please allocate a percentage, representing your usage, of the following funding mechanisms for acquisitions. If you don't do any acquisitions, insert $100 \%$ against that option.

$\square$ We don't do any acquisitions

$\square$ We only lease

$\square$ Equity from retained earnings

Equity from government grants

$\square$ Equity from philanthropical grants

Part equity from retained earnings and part borrowings

Part equity from government grants and part borrowings

$\square$ Part equity from philanthropical grants and part borrowings

Other. Please state:

What type of hurdle rate do you use in your financial model for acquisitions?

$\square$ An organisation-set financial hurdle rate such as Weighted Average Cost of Capital (WACC) or Net Present Value (NPV). Please state the hurdle rate percentage below.

$\square$ A market-based hurdle rate for similar private rental investment properties in similar locations

$\square$ Don't use one

$\square$ Don't know

Do you have the financial resources to meet waiting list demand?

$\square$ Definitely yes

$\square$ Probably yes

$\square$ Might or might not

$\square$ Probably not

$\square$ Definitely not

$\square$ Don't know

Are your waiting lists shared between other social housing providers?

$\square$ No, as it's a privacy issue

$\square$ Only where tenants consent to it

$\square$ Yes

$\square$ Don't know 


\section{About maintenance}

Do you have a documented maintenance condition standard that you aim to meet?

$\square$ Yes

$\square$ No

$\square$ Don't know

How is that maintenance standard set?

Do you currently measure the condition of your portfolio at component level using condition ratings to assess backlog maintenance, short-term (next 1 to 3 years) and longer-term future maintenance, and renewal work using life-cycle models?

$\square$ Yes

$\square$ No

$\square$ We use historic repair and renewal data to determine future renewals and maintenance requirements

$\square$ We use another method. Please advise what it is:

$\square$ Don't know

Is the condition standard you set something that you know other providers also use, or is it your own?

$\square$ Yes, other providers use the same standard

$\square$ No, it's our own

$\square$ We don't have a set standard

$\square$ Don't know

How often do you set suboptimal (less than best practice) condition standards due to financial constraints?

Note: $0=$ Not at all, $10=$ a lot

How do you set a standard for amenity and functionality levels offered by your dwellings?

Is there a large or small gap in the amenity and function levels offered compared to the standard you set? These could include kitchen facilities or number of dwellings offering disability features as examples.

$\square$ Large gap, large cost

$\square$ Average gap, average cost

$\square$ Small gap, small cost

$\square$ We don't have a standard

$\square$ Don't know

When do you do redecoration work?

$\square$ Only when an asset becomes vacant

$\square$ At regular planned cycles during a tenancy

$\square$ When urgently required during a tenancy

$\square$ Don't know 
How would you rank the following issues in terms of their growing impact on management of your dwellings?

\begin{tabular}{ll}
\hline Drug use & $0=$ little impact, $100=$ significant impact \\
\hline Drug development contaminating/damaging houses & \\
\hline Mental health & \\
\hline Antisocial behaviour & \\
\hline Other. Please state
\end{tabular}

\section{About dwelling asset disposal}

During the holding period of a housing asset, do you regularly review its financial performance and review its potential future use?

$\square$ Yes

$\square$ No. Please state why:

$\square$ Don't know

Do you have systems and tools in place that identify assets for potential disposal, redevelopment or reconfiguration?

$\square$ Yes, the systems are largely automated so that we can quickly generate a list of candidates quickly

$\square$ No, it's on a case-by-case basis

Don't know

Do you have an active disposal plan driven by the need to redevelop, renew, reconfigure or sell?

$\square$ Yes

$\square$ No

$\square$ Don't know

\section{About your asset management staff}

Does the most senior person from asset management team report directly to the CEO? i.e. do they have a second-tier position in the organisation?

$\square$ Yes

$\square$ No

$\square$ Don't know

Does the most senior asset management employee provide input into your organisation's business plan, strategy, goals and objectives?

$\square$ Yes

$\square$ No

$\square$ Don't know 
How many asset staff do you have in total in your organisation?

Do you have the asset management human-resource capacity to manage the assets effectively?

$\square$ Yes

$\square$ No

$\square$ Don't know

If you currently lack enough human resources:

How many more FTEs are required?

What constrains the team from growing?

Is there overall capability within the asset management team to achieve asset management practice standards you set?

$\square$ Yes

$\square$ No. Please state what constrains the achievement of capability:

$\square$ Don't know

How do asset staff access continued professional development? Use the slider to indicate how staff access training opportunities.

\begin{tabular}{ll}
\hline On the job & $0=$ option not accessed at all, $100=$ accessed most often \\
\hline External providers & \\
\hline Formal in-house training & \\
\hline National asset management conferences & \\
\hline Self learning
\end{tabular}

Does the asset team have enough investment in IT systems to allow for collection and analysis of asset data for the purpose of achieving an optimal asset management strategy/plan?

$\square$ Yes

$\square$ No

$\square$ Don't know

If you would like to be involved further in this research and are happy to be interviewed, please fill in your contact email address, name and best contact phone number.

Email address

Name

Contact phone number

Would you like a copy of your survey answers sent to you? Please select 'Yes' below and provide your email address.

$\square$ Yes. Please state email address below

$\square$ No 


\section{Appendix 4: Interview guide

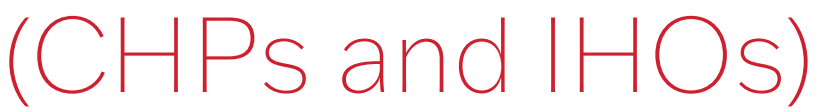

\section{Preamble}

Thank you for providing your time today. We appreciate your commitment.

In this interview, we want you to reflect on asset management as it is now practised across social housing in Australia and how it could be improved.

We would like this to be an opportunity for you to offer what you regard as the important issues for social housing asset management in Australia. We will go through seven main elements of asset management, which are:

- the philosophy and approaches to asset management

- the scope of asset management

- the process of developing an asset management plan

- the tools used in the process

- the content of an asset management plan

- performance indicators and measures

- decision-making processes.

Q1. To start, can you tell me a little about your background and experience in social housing provision?

Q2. As I mentioned, l'll go through some specific issues-but to start, what do you think are the key issues for social housing asset management planning in Australia?

\section{Philosophy/approaches to asset management}

Firstly, I am going to ask you about approaches to AM.

Q3. In your view, what is the purpose of asset management in the social housing context?

\section{PROMPTS}

Fulfil mission to provide housing

To extend the useful life of the housing asset

Return on investment 
Q4. What do you see as the purpose of an asset management plan in achieving the objectives of social housing providers?

\section{PROMPT}

Ensure systems

Skills

Renewal

Q5. How do external factors (such as public policy) impact on approaches to social housing asset management in Australia?

Q6. To what extent does continuous improvement, as an approach, inform asset management in social housing?

\section{Scope of an asset management plan}

I want to turn now to the scope of AM.

Asset management usually focusses on individual dwellings but can extend beyond this.

Q7. What do you think is the scope of an asset management plan?

\section{PROMPT}

Does it also include planning for estates/multi-unit sites?

Does it include local neighbourhoods?

Does it include portfolio management?

\section{Process of developing asset management plans}

Let's turn to the process of developing an asset management plan.

Q8. How would you describe the processes social housing providers are using in developing their asset management plans?

PROMPTS:

Elements of the process: links with organisation's mission and objectives; analysis (e.g. SWOT); goals, strategies, implementation, evaluation and feedback A process from a practice manual, e.g. ISO 55000 or IPWEA Your own

\section{Tools used in developing an asset management plan}

Now we will turn to the tools used in developing an asset management plan.

Tools are necessary to collect and analyse data, and provide assessment of performance against predetermined objectives. Tools therefore may be techniques (for measurement against standards, for example), technology or frameworks to name a few.

Q9. What do you see as the main challenges for providers regarding collection and analysis of data?

\section{PROMPTS:}

quality of data, multiple software, interoperability (integration of systems), skills variation in methodologies 
Q10. What do you see as the main challenges regarding integration of data to inform optimised decision-making?

PROMPTS:

funds to deliver the systems, regulation e.g. accounting standards, lack of whole-of-organisation commitment

\section{Content of the asset management plan}

Now we will turn to asset plan.

Q11. Life-cycle planning covers asset creation, asset management and asset disposal. Do you think there a lack of life-cycle planning in social housing, and what do you think drives this?

\section{PROMPTS:}

Poor governance

Lack of skills

Lack of funding of depreciation

Q12. What do you think drives deviation from or failure to implement asset management plans?

\section{PROMPTS:}

Growth agenda (irregular public capital funding)

Crisis-building failure

\section{Performance indicators and measures}

The next few questions relate to performance indicators and measures.

Q13. What standards are social housing providers in Australia using as they develop their asset management frameworks and plans?

PROMPTS:

ISO 55000?

State government, treasury or finance standards?

National Regulatory System for Community Housing?

National Community Housing Standards?

Local regulatory standards?

Q14. What are the challenges in determining dwelling standards and turning these into measures to drive performance?

Q15. What financial indicators and measures are used, and how adequate do you think they are?

\section{PROMPT:}

Internal performance measures?

Regulator performance measures?

Ability to compare or benchmark against peers?

Valuation methodologies?

Depreciation? 
Q16. How do accounting standards impact upon asset management plans?

\section{PROMPTS:}

Asset performance on financial statements

Book value v. asset value

Q17. Is there a sufficient focus on depreciation?

Q18. What impact are poorly defined performance indicators and measures, or lack thereof, having on social housing asset management?

Q19. Do you see a common, sector-wide set of asset management standards and measures as being important?

\section{Decision-making processes}

Now I want to turn to decision-making processes (how decisions about asset management are made).

Q20. Who are the key stakeholders that need to be part of a provider's asset management planning, and what does their participation involve/look like?

\section{PROMPTS:}

Staff

Tenants

Funders

Community

Q21. How can conflict between competing objectives be resolved? In particular, how can the conflict between funding of future needs (such as growth or renewal) and current demands for financial resources be addressed?

Q22. How do you think boards/board makeup is affecting the capacity of CHPs/lHOs to develop and implement AM that can address the complex needs of social housing?

\section{PROMPTS:}

Lack of asset management knowledge

Remuneration

Strategic understanding of social housing provision and housing need

Poor organisation systems/lack of reporting

Competition for limited funds

\section{Finally reflecting more generally}

Q23. In your view what are the main constraints and opportunities for improving asset management for social housing in Australia? 


\section{Appendix 5: Workshop guide}

\begin{tabular}{|c|c|c|c|}
\hline Start time & Duration & Finish time & Activity \\
\hline \multirow{9}{*}{$\begin{array}{l}11 \text { AM } \\
(\text { AEST) }\end{array}$} & \multirow[t]{9}{*}{ Oh 30m } & \multirow[t]{9}{*}{$11: 30$} & Technology issues (if online) \\
\hline & & & Welcome and introduction. \\
\hline & & & The sessions are being recorded \\
\hline & & & Acknowledgement of country \\
\hline & & & Purpose and the agenda outlined \\
\hline & & & Please sign the consent form (in the files) \\
\hline & & & Use of chat function \\
\hline & & & Participants should have watched the pre-recorded video/Power Point as preparation \\
\hline & & & Introduction of the concept of an ideal advanced AM framework. \\
\hline \multirow[t]{6}{*}{$11: 30$} & \multirow[t]{6}{*}{$30 m$} & \multirow[t]{6}{*}{12.20} & Introduction of participants \\
\hline & & & Introduce yourselves \\
\hline & & & - Your name \\
\hline & & & - Your organisation \\
\hline & & & - Your role \\
\hline & & & $\begin{array}{l}\text { What are the unique aspects of providing social housing in Australia? (you can add } \\
\text { comments into chat in addition to when you speak) }\end{array}$ \\
\hline \multirow[t]{2}{*}{12.00} & \multirow[t]{2}{*}{$10 \mathrm{~m}$} & \multirow[t]{2}{*}{12.30} & Brief intro to factors influencing advanced AM frameworks. \\
\hline & & & The factors identified to inform the breakout sessions. \\
\hline \multirow[t]{8}{*}{$1 \mathrm{pm}$} & \multirow[t]{8}{*}{ 1h $30 \mathrm{~m}$} & \multirow[t]{8}{*}{ 2:30pm } & Breakout groups \\
\hline & & & Getting to advanced AM \\
\hline & & & (WORKSHEET DOCUMENT ‘FACTORS’) \\
\hline & & & Each breakout group to consider the factors defined in the morning session. \\
\hline & & & - What are the current practices in relation to the identified factors? \\
\hline & & & - What barriers/constraints impact your organisation improving AM? \\
\hline & & & - How would you rank these factors in terms of their importance? \\
\hline & & & $\begin{array}{l}\text { Note: Issues/challenges will be different across the different types of providers and } \\
\text { we'd like to capture these. }\end{array}$ \\
\hline
\end{tabular}




\section{Appendix 6: Community housing performance requirements}

Table A4: Housing assets performance requirements under the National Regulatory System for Community Housing

Performance outcome: The community housing provider manages its community housing assets in a manner that ensures suitable properties are available now, and in the future.

\begin{tabular}{ll}
\hline Performance requirement & Performance indicator \\
\hline $\begin{array}{l}\text { Determining changing housing needs and planning } \\
\text { asset acquisitions, disposals and reconfiguration to } \\
\text { respond (strategic asset management). }\end{array}$ & $\begin{array}{l}\text { The provider plans for how it will manage its housing assets to optimise } \\
\text { outcomes on financial investment, service delivery and meeting } \\
\text { housing needs. }\end{array}$ \\
$\begin{array}{ll}\text { Setting and meeting relevant property condition } \\
\text { standards. }\end{array}$ & $\begin{array}{l}\text { The provider manages community housing assets in accordance with } \\
\text { the specific legal and policy property condition requirements relevant } \\
\text { to its jurisdiction. }\end{array}$ \\
\hline
\end{tabular}

Planning and undertaking responsive, cyclical and life- The provider ensures (commensurate with its responsibilities): cycle maintenance to maintain property conditions (asset maintenance).

- properties are well maintained

- maintenance is undertaken in a timely manner

- maintenance work is undertaken by suitably qualified staff / contractors / consultants.

Tenants are provided with easy-to-use information on repairs and maintenance.

The provider maintains a satisfactory level of tenant and resident satisfaction with maintenance and housing amenity.

Planning and delivering its housing development The provider plans, monitors and reviews its development program to program (asset development). ensure effective and efficient delivery of new housing.

Source: NRSCH (2014: 18-23) 
Table A5: Asset management standards in the National Community Housing Standards

\begin{tabular}{|c|c|}
\hline Standard & Good practice \\
\hline \multirow{2}{*}{$\begin{array}{l}\text { Standard 2.1: Asset management } \\
\text { strategy }\end{array}$} & 2.1.1 Purpose of an asset management strategy \\
\hline & The organisation has a documented and up-to-date Asset Management Strategy \\
\hline \multirow{3}{*}{$\begin{array}{l}\text { The organisation plans for the } \\
\text { management of its housing assets to } \\
\text { ensure they deliver optimal return in } \\
\text { terms of financial investment, service } \\
\text { delivery and meeting housing need. }\end{array}$} & $\begin{array}{l}\text { that ensures the housing stock it manages is of appropriate size, condition and } \\
\text { specification and is financially sustainable. }\end{array}$ \\
\hline & 2.1.2 Objectives \\
\hline & $\begin{array}{l}\text { The objectives of the Asset Management Strategy are clearly defined and } \\
\text { complexity of the organisation's activities. }\end{array}$ \\
\hline
\end{tabular}

2.1.3 Annual review

The Asset Management Strategy and its component elements are reviewed and updated at least annually.

\subsubsection{Databases}

The databases and analyses supporting the Asset Management Strategy are maintained accurately and kept up to date. Any cost implications are evaluated and integrated into the financial planning process.

\subsubsection{Monitoring}

The organisation monitors progress against the objectives of the Asset Management Strategy.

\section{Standard 2.2: Responsive} maintenance and repairs

The organisation's systems enable the effective delivery of repairs and maintenance so that housing is well maintained, and the assets managed by the organisation are protected.
2.2.1 General guidelines for maintenance and repairs

The organisation has a documented system for responsive maintenance and repairs that:

- ensures transparency of decisions

- provides good service in a timely manner

- is equitable between tenants and across properties.

\subsubsection{Budgeting}

The organisation has budgeted an appropriate amount for responsive maintenance and repairs.

2.2.3 A variety of mechanisms for tenant access and feedback

The organisation provides tenants with easy-to-use information on repairs and maintenance including:

- how to request repairs

- timeframes for different categories of repairs

- ways to comment on the repairs.

2.2.4 Preventative strategies

The organisation works with tenants to reduce the need for maintenance call-outs.

\subsubsection{Property inspections}

The organisation has a program for regularly inspecting properties.

\subsubsection{Selection of contractors}

The organisation selects and works with contractors to ensure that the interests of the organisation are protected and, in particular, that the contractors:

- respect the tenants and their home and property

- deliver good quality work in a timely fashion

- are competitively priced and represent value for money.

\subsubsection{Setting performance targets}

The organisation measures its performance in the area of repairs and maintenance, using indicators such as tenant satisfaction, timeliness, quality and price. 


\begin{tabular}{ll}
\hline Standard & Good practice \\
\hline Standard 2.3: Planned maintenance & $\begin{array}{l}\text { 2.3.1 Planned maintenance and upgrades } \\
\text { The organisation has a documented system for planned maintenance and upgrading } \\
\text { The organisation plans for the }\end{array}$ \\
$\begin{array}{l}\text { of properties that includes a plan for each property it controls, which is linked to } \\
\text { financial planning and budgets. }\end{array}$ \\
\cline { 2 - 2 } $\begin{array}{l}\text { its housing assets to ensure } \\
\text { accommodation quality and overall } \\
\text { value is sustained. }\end{array}$ & $\begin{array}{l}\text { 2.3.2 Balancing the needs of the tenant and the organisation } \\
\text { Planned maintenance and upgrade is coordinated to balance the needs of current and } \\
\text { future tenants with achieving value for money. }\end{array}$
\end{tabular}

2.3.3 Protecting the organisation's interests

The organisation ensures that its own interests are protected when major upgrades are contracted.

\subsubsection{Monitoring progress}

The organisation monitors the progress made against its maintenance plans.

\section{Standard 2.4: Stock acquisition and} development

The organisation acquires and develops new and existing housing stock in accordance with strategic growth objectives and to meet identified need.

\subsubsection{Integrated strategy}

Where funding arrangements allow such activity, the organisation has a documented strategy for stock acquisition, disposal and development that is consistent with its organisational mission and corporate plan.

\subsubsection{Project briefs for acquisitions}

The organisation prepares specific individual project briefs that describe the stock to be acquired.

\subsubsection{Feasibility study}

Before deciding on the best method to acquire new stock, the organisation researches the feasibility of the various options.

\subsubsection{Tenant input}

Where possible, the organisation involves tenants / members in the design process of developing new housing stock.

2.4.5 Selection of contractors

When employing an architect, project manager or builder, the selection and appointment process ensures transparency, quality service, value and minimal risk to the organisation.

\subsubsection{Clear contracts that are actively managed}

Whenever it signs agreements for another party to develop a property, the organisation ensures that the agreement delineates rights and responsibilities of all parties, agreed monitoring and conflict-resolution arrangements and is considered a partnership arrangement.

\subsubsection{Gathering the documentation}

When taking possession of a property (leased or acquired), all relevant documentation is received.

2.4.8 Defect identification and rectification

The organisation monitors any defects and ensures they are rectified.

2.4.9 Monitoring

The organisation monitors and reviews its acquisition and development processes to ensure they are efficient and effective. 


Standard
Standard 2.5: Partnerships and new
business

The organisation's growth strategy is based on sound financial planning.

\section{Good practice}

2.5.1 General guidelines / Ethics statement

The organisation has written documents to guide its development of property partnerships, which includes a statement of ethics.

\subsubsection{Assessing viability of possible partnerships}

The organisation assesses the viability of potential partnership arrangements.

2.5.3 Identifying and using planning incentives

The organisation explores and utilises the full range of planning incentives set by state and local government to maximise its potential in developing financial partnerships.

\subsubsection{Contractual agreements}

When entering into partnerships with other organisations to develop stock, formal contractual agreements are signed, which include sound risk-management strategies.

2.5.5 Contributing to community capacity building

Development strategies seek to build community capacity.

\subsubsection{Promotion as partner}

The organisation promotes and markets its potential as a partner for property development.

\subsubsection{Access to appropriate expertise}

The organisation ensures that it has access to appropriate and high-level expertise in business planning, project management and property development.

\subsubsection{Cost-benefit analysis}

The organisation monitors and reviews its efforts to develop new income streams.

Source: National Community Housing Standards Manual (JPX Consulting Pty Ltd 2010: 45-73). 


\section{Appendix 7: Prescribed minimum housing standards for residential tenancies ${ }^{12}$}

\begin{tabular}{|c|c|}
\hline $\begin{array}{l}\text { State or } \\
\text { Country }\end{array}$ & Standard \\
\hline Victoria & 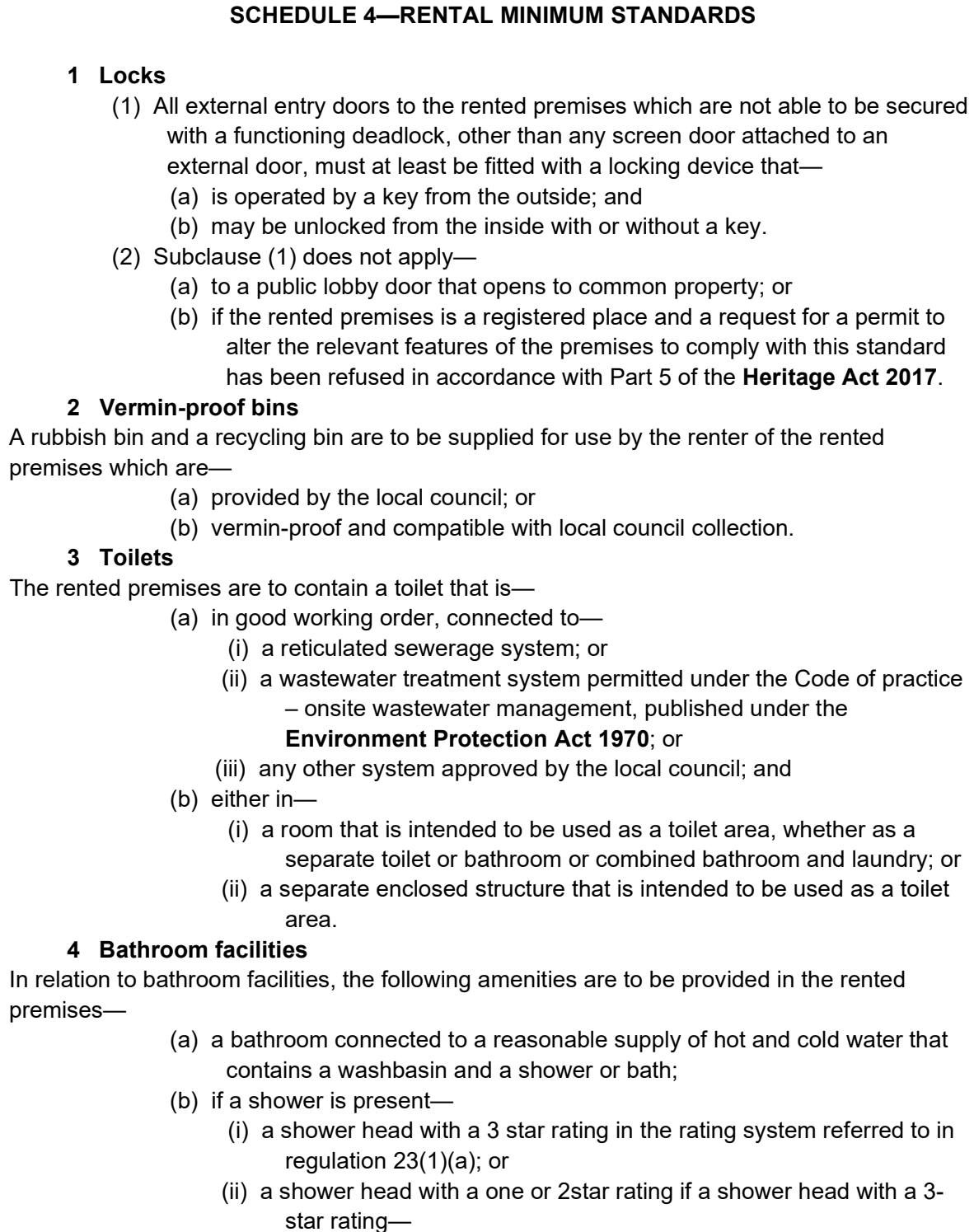 \\
\hline
\end{tabular}




\begin{tabular}{|c|}
\hline 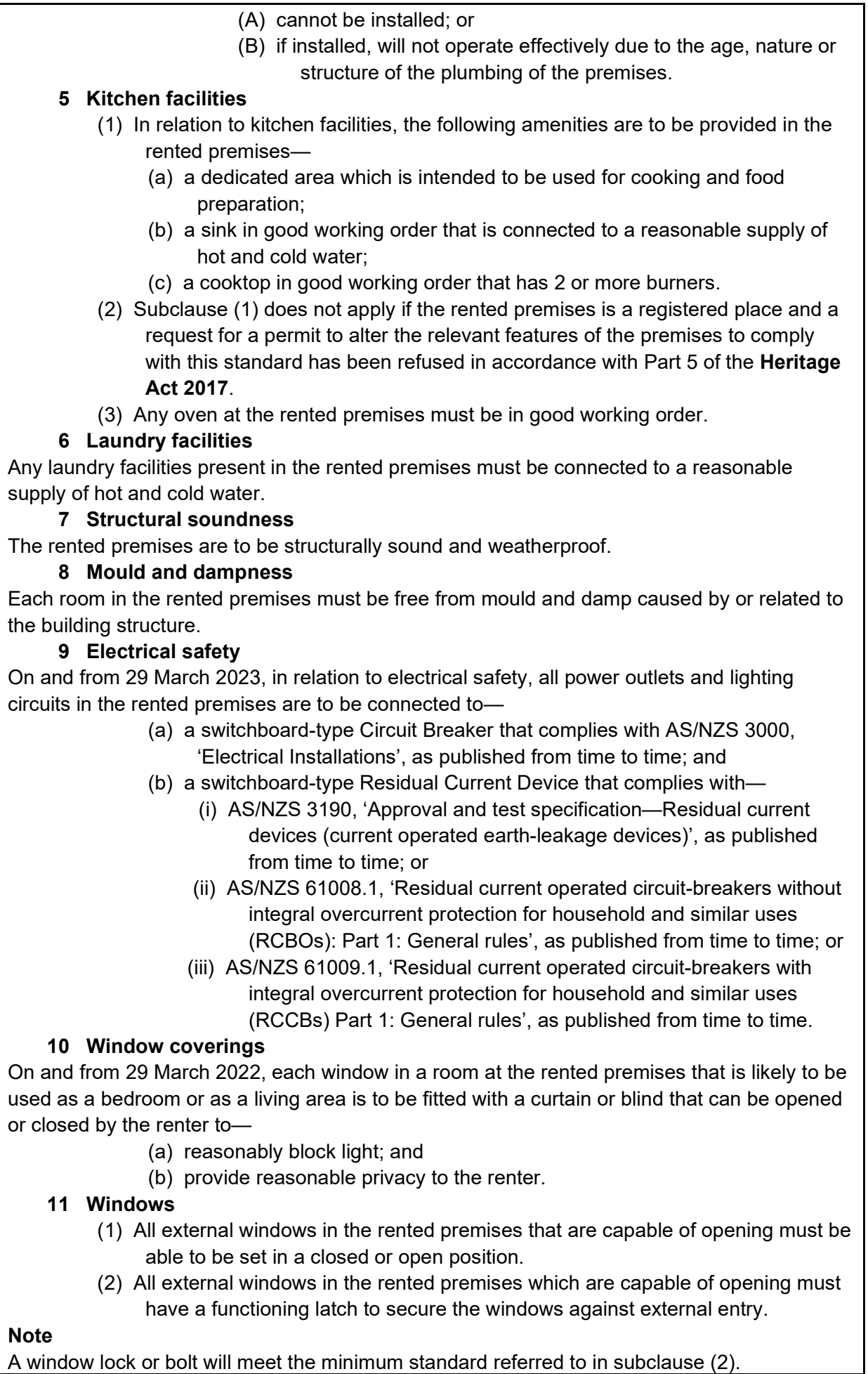 \\
\hline
\end{tabular}




\section{Lighting}

(1) The interior rooms, corridors and hallways of the rented premises are to have access to light, whether natural or artificial, which provides a level of illuminance appropriate to the function or use of those rooms.

(2) Each habitable room of the rented premises is to have access to-

(a) natural light, including borrowed light from an adjoining room, during daylight hours, which provides a level of illuminance appropriate to the function or use of the room; and

(b) artificial light during non-daylight hours which provides a level of illuminance appropriate to the function or use of the room.

(3) Subclauses (1) and (2) do not apply if the rented premises is a registered place and a request for a permit to alter the relevant features of the premises to comply with the standard has been refused in accordance with Part 5 of the Heritage Act 2017.

\section{Ventilation}

(1) If the rented premises is a Class 1 building, each habitable room, bathroom, shower room, toilet and laundry must have ventilation satisfying Performance Requirement P2.4.5 of the BCA Volume Two, or the Acceptable Construction Practice in Part 3.8.5 of the BCA Volume Two.

(2) If the rented premises is within a Class 2 building, each habitable room, bathroom, shower room, toilet and laundry must have ventilation satisfying Performance Requirements FP4.3, FP4.4 and FP4.5 of the BCA Volume One, or the Deemed to-Satisfy Provisions requirements in F4.5, F4.6 and F4.7 of the BCA Volume One.

\section{Heating}

(1) On and from 29 March 2021 until 28 March 2023, in relation to heating in a Class 1 building-

(a) a fixed heater in good working order is to be in the main living area of the rented premises; or

(b) if a fixed heater has not been installed in the main living area of the rented premises on or by 29 March 2021, an energy-efficient fixed heater in good working order is to be installed in the main living area of the rented premises.

(2) On and from 29 March 2021 until 28 March 2023, in relation to heating in a Class 2 building-

(a) a fixed heater in good working order is to be in the main living area of the rented premises; or

(b) if a fixed heater has not been installed in the main living area of the rented premises on or by 29 March 2021, an energy-efficient fixed heater in good working order is to be installed in the main living area of the rented premises unless it would be unreasonable to install an energy-efficient fixed heater.

(3) On and from 29 March 2023, in relation to heating in a Class 1 building, an energy-efficient fixed heater in good working order is to be installed in the main living area of the rented premises.

(4) On and from 29 March 2023, in relation to heating in a Class 2 building-

(a) an energy-efficient fixed heater in good working order is to be installed in the main living area of the rented premises unless it is unreasonable to install an energy-efficient fixed heater; or

(b) if it is unreasonable to install an energy-efficient fixed heater in the main living area of the rented premises, a fixed heater in good working order is to be installed in the main living area of the rented premises. 


\begin{tabular}{|c|c|}
\hline & $\begin{array}{l}\text { (5) For the purposes of subregulations (2)(b) and (4) it would be unreasonable to } \\
\text { install an energy-efficient fixed heater if- } \\
\text { (a) the cost of installation would be significantly higher than the average price of installation in } \\
\text { a Class } 2 \text { building; or } \\
\text { (b) owners corporation rules prohibit installation of the appliance; or } \\
\text { (c) compliance with any other Act or local law makes the cost of installation prohibitive. } \\
\text { (6) In this clause- } \\
\text { energy-efficient fixed heater means- } \\
\text { (a) a non-ducted air conditioner or heat pump with a 2-star or above } \\
\text { heating rating in the prescribed energy rating system for non- } \\
\text { ducted air conditioners or heat pumps; or } \\
\text { (b) a gas space heater with a 2-star or above heating rating in the } \\
\text { prescribed energy rating system for gas space heaters; or } \\
\text { (c) a ducted heating or hydronic heating system which has an outlet in } \\
\text { the main living area of the rented premises; or } \\
\text { (d) a domestic solid fuel burning appliance; } \\
\text { fixed heater means a heater that is not designed or manufactured to be portable. }\end{array}$ \\
\hline NSW & $\begin{array}{l}\text { LANDLORD'S GENERAL OBLIGATIONS FOR RESIDENTIAL PREMISES } \\
\text { 19. The landlord agrees: } \\
19.1 \text { to make sure that the residential premises are reasonably clean and fit to live in, and } \\
\text { Note } 1 \text {. Section } 52 \text { of the Residential Tenancies Act } 2010 \text { specifies the minimum requirements } \\
\text { that must be met for residential premises to be fit to live in. These include that the residential } \\
\text { premises: } \\
\text { (a) are structurally sound, and } \\
\text { (b) have adequate natural light or artificial lighting in each room of the premises other than a } \\
\text { room that is intended to be used only for the purposes of storage or a garage, and } \\
\text { (c) have adequate ventilation, and } \\
\text { (d) are supplied with electricity or gas and have an adequate number of electricity outlet } \\
\text { sockets or gas outlet sockets for the supply of lighting and heating to, and use of appliances } \\
\text { in, the premises, and } \\
\text { (e) have adequate plumbing and drainage, and } \\
\text { (f) are connected to a water supply service or infrastructure that supplies water (including, but } \\
\text { not limited to, a water bore or water tank) that is able to supply to the premises hot and cold } \\
\text { water for drinking and ablution and cleaning activities, and } \\
\text { (g) contain bathroom facilities, including toilet and washing facilities, that allow privacy for the } \\
\text { user. } \\
\text { Note } 2 \text {. Premises are structurally sound only if the floors, ceilings, walls, supporting structures } \\
\text { (including foundations), doors, windows, roof, stairs, balconies, balustrades and railings: } \\
\text { (a) are in a reasonable state of repair, and } \\
\text { (b) with respect to the floors, ceilings, walls and supporting structures-are not subject to } \\
\text { significant dampness, and } \\
\text { (c) with respect to the roof, ceilings and windows-do not allow water penetration into the } \\
\text { premises, and } \\
\text { (d) are not liable to collapse because they are rotted or otherwise defective. } \\
\text { Source: https://www.legislation.nsw.gov.au/view/pdf/asmade/sl-2019-629 }\end{array}$ \\
\hline
\end{tabular}




\begin{tabular}{|c|c|}
\hline QLD & $\begin{array}{l}\text { Consultation is yet to commence in relation to the prescribed minimum housing standards for } \\
\text { rental accommodation, although the Residential Tenancy Act has been amended to facilitate } \\
\text { inclusion of new standards. } \\
\text { https://www.chde.qld.gov.au/news-publications/legislation/residential-rooming }\end{array}$ \\
\hline Tasmania & 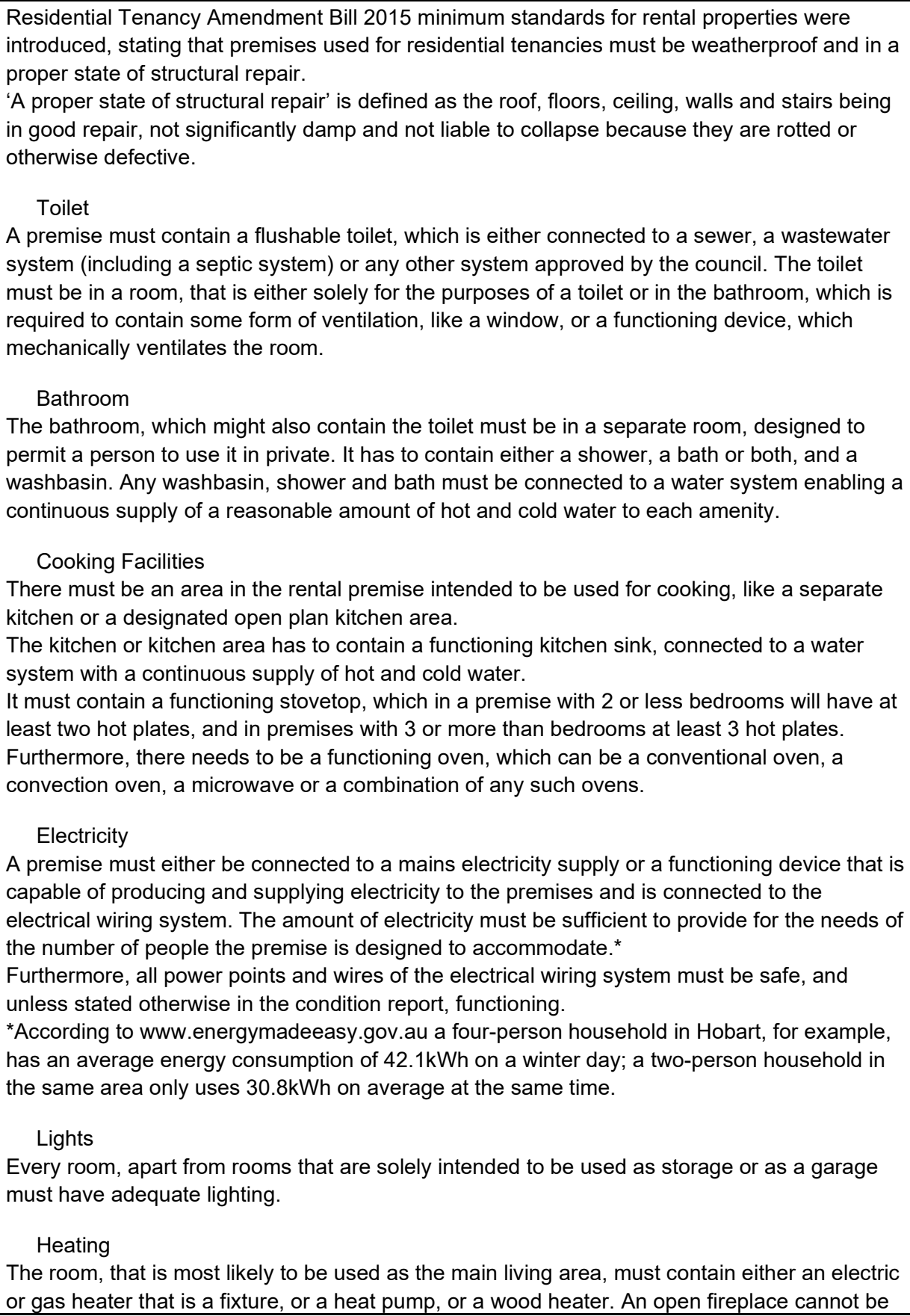 \\
\hline
\end{tabular}




\begin{tabular}{|c|c|}
\hline & $\begin{array}{l}\text { the main heating source unless approved by the Residential Tenancy Commissioner. The } \\
\text { commissioner may add conditions to the approval. } \\
\text { Window Coverings } \\
\text { Each window in a room, that is likely to be used as a bedroom or living area has to be covered } \\
\text { by curtains or blinds for the purpose of protecting tenants' privacy. } \\
\text { Note: Housing Tasmania and Community Housing properties are exempt from this provision. } \\
\text { Ventilation } \\
\text { Adequate ventilation has to be provided to each room. A room is considered adequately } \\
\text { ventilated when it has a window to an outside area. The window should not be smaller than } 5 \\
\text { per cent of the floor area of the room. } \\
\text { If there is no window to an outside area, the room can alternatively be connected to another } \\
\text { room, which has a window or a door and does not contain a toilet. Both the connecting } \\
\text { opening between the two rooms and the other door or window in the second room must each } \\
\text { be larger than } 5 \text { per cent of the floor area of the second room. } \\
\text { For the sake of combining security and adequate ventilation, windows must be lockable into a } \\
\text { position that creates a gap between the window and the window frame. The gap should be not } \\
\text { less than } 15 \text { cm wide and should not enable a person to enter the room in which the window is } \\
\text { situated. } \\
\text { Rooms including toilets, bathrooms and laundries may also be ventilated by an exhaust fan or } \\
\text { a similar device, that takes air either from the room to the outside or an adequately ventilated } \\
\text { roof space. } \\
\text { Source: http://tutas.org.au/factsheet/minimum-standards-for-premises/ }\end{array}$ \\
\hline SA & $\begin{array}{l}\text { Part 3-Prescribed minimum housing standards } \\
\text { 8-Purpose of Part } \\
\text { This Part establishes the prescribed minimum housing standards for the purposes of section } 5 \\
\text { of the Act (being standards that must be met for residential premises to be considered safe } \\
\text { and suitable for human habitation). } \\
\text { 9-General standards } \\
\text { The following general standards apply to residential premises: } \\
\text { (a) the residential premises and any fixtures, fittings or other facilities provided with the } \\
\text { residential premises must not present a health or safety hazard; } \\
\text { (b) the fixtures, fittings and facilities prescribed as minimum housing standards under this } \\
\text { Part must be- } \\
\text { (i) properly installed; and } \\
\text { (ii) fit for the purpose for which those fixtures, fittings or facilities are intended or ordinarily } \\
\text { used; and } \\
\text { (iii) in good working order. } \\
\text { 10-Toilet, bathroom, kitchen and laundry areas } \\
\text { The following standards relating to toilet, bathroom, kitchen and laundry areas apply to } \\
\text { residential premises: } \\
\text { (a) the residential premises must be provided with the following items as reasonably } \\
\text { required for domestic purposes: } \\
\text { (i) a toilet, bath or shower, hand basin, kitchen sink and laundry washtrough or basin; } \\
\text { (ii) space, and designated water supply outlets within immediate proximity of that space, } \\
\text { for a washing machine; } \\
\text { (iii) a wastewater discharge pipe for a washing machine; } \\
\text { (iv) an oven and cooktop; } \\
\text { (v) adequate kitchen bench space for food preparation; } \\
\text { (vi) a food storage cupboard or pantry in or within reasonable proximity of the kitchen; }\end{array}$ \\
\hline
\end{tabular}




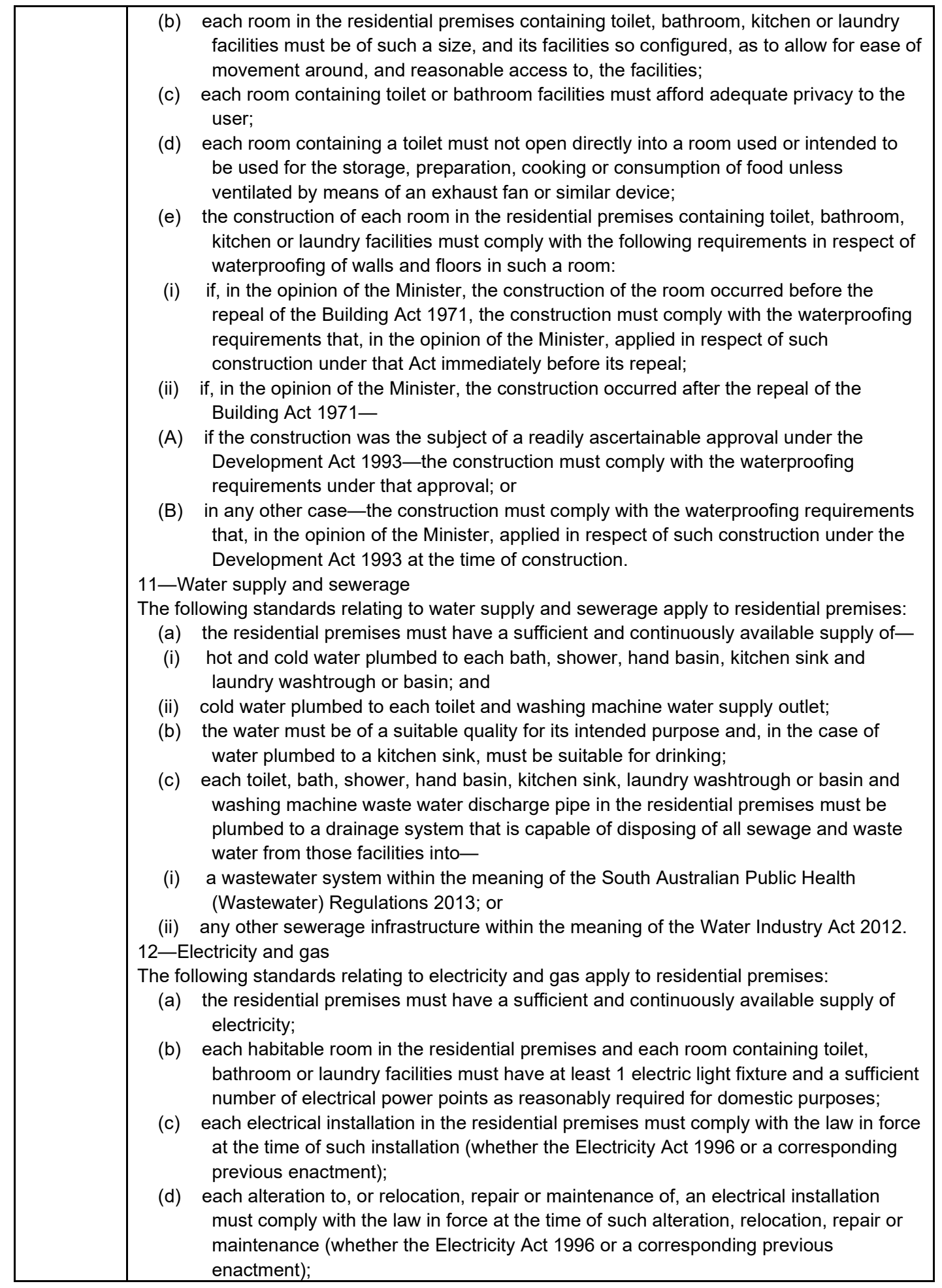




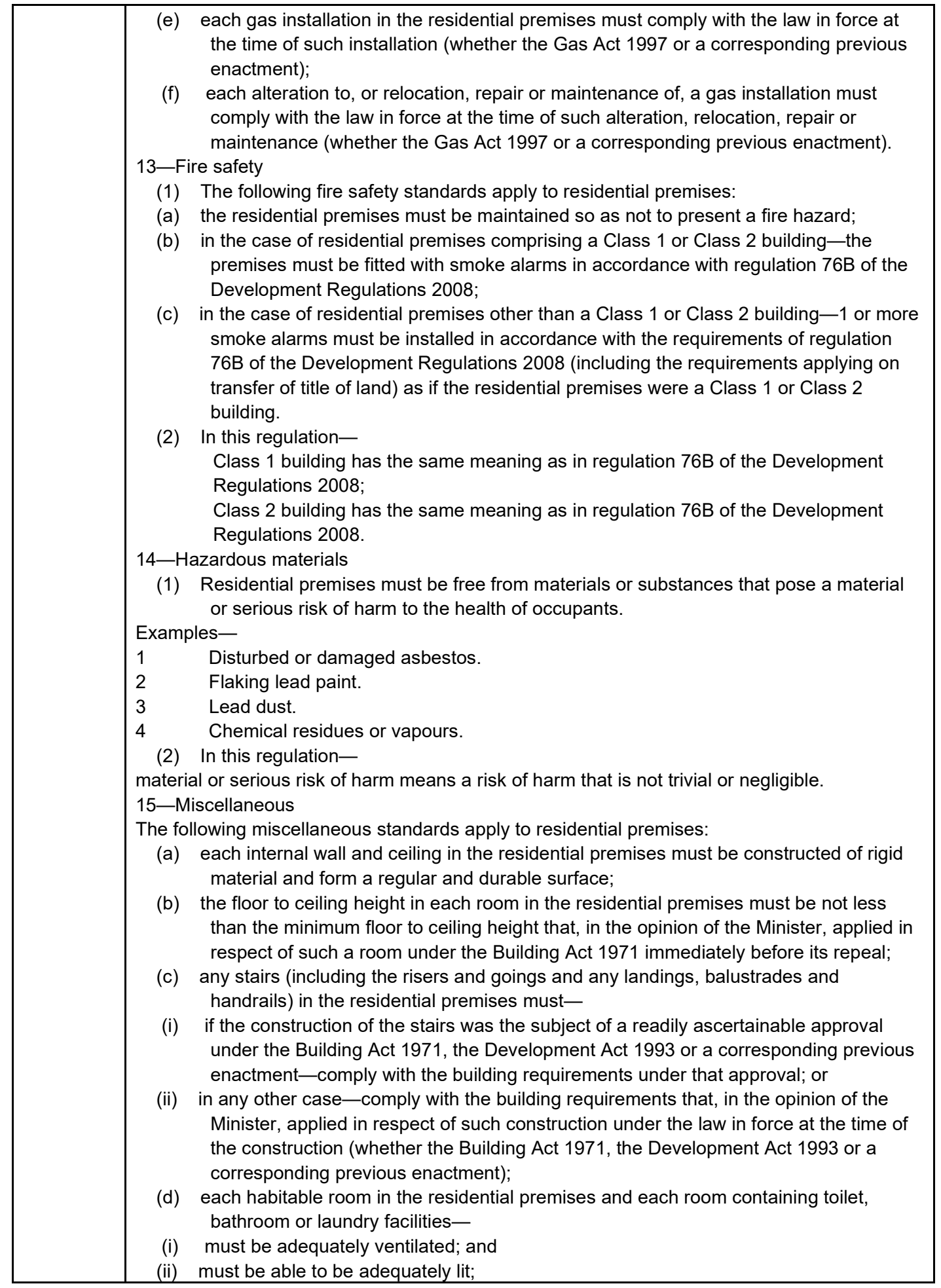




\begin{tabular}{|c|c|}
\hline & $\begin{array}{l}\text { (e) each external door in the residential premises must be fitted with a lock that is able to } \\
\text { be operated from the outside with a key and unlocked from the inside without a key; } \\
\text { each external window in the residential premises that is able to be opened must be } \\
\text { fitted with a latch; } \\
\text { (g) in order for occupants of the residential premises to safely screen visitors, the } \\
\text { residential premises must be provided with the following items at the main point of } \\
\text { entry to the residential premises: } \\
\text { (i) a suitably placed window, lockable screen door, peep-hole, security chain or intercom } \\
\text { system; } \\
\text { (ii) an external light fitting; } \\
\text { (h) the footings must provide effective structural support to the residential premises; } \\
\text { (i) the residential premises must be reasonably draughtproof and weatherproof; } \\
\text { (j) the residential premises must be reasonably free from mould or other irritants, } \\
\text { structural disrepair or other adverse effects caused, or contributed to, by moisture or } \\
\text { damp; } \\
\text { (k) the grounds of the residential premises must be effectively drained; } \\
\text { (I) the residential premises must provide reasonably free and unimpeded access to and } \\
\text { from the premises so that, in the event of an emergency- } \\
\text { (i) occupants are able to escape from the premises; and } \\
\text { (ii) persons are able to enter the premises to provide medical or other emergency } \\
\text { (m) the residential premises and its grounds must be maintained to prevent- } \\
\text { (i) the accumulation of rubbish; and } \\
\text { (ii) infestation by vermin; } \\
\text { (n) any swimming pool on the grounds of the residential premises must comply with the } \\
\text { requirements relating to swimming pool safety features under section } 71 \mathrm{AA} \text { of the } \\
\text { Development Act } 1993 \text {. } \\
\text { Source: } \\
\text { https://www.legislation.sa.gov.au/LZ/C/R/Housing\%20lmprovement\%20Regulations\%202017. } \\
\text { aspx }\end{array}$ \\
\hline ACT & $\mathrm{NIL}$ \\
\hline WA & $\begin{array}{l}\text { The habitation standards of RTA are currently under review. } \\
\text { Residential Tenancies Act } 1987 \text { s42 } \\
\text { (2) It is a term of every residential tenancy agreement that the lessor - } \\
\text { (a) must deliver up to the tenant vacant possession of the premises in a reasonable state of } \\
\text { cleanliness and a reasonable state of repair having regard to its age and character; and } \\
\text { (b) must maintain the premises in a reasonable state of repair having regard to its age and } \\
\text { character and must conduct any repairs within a reasonable period after the need for the } \\
\text { repair arises; and } \\
\text { (c) must comply with all requirements in respect of buildings, health and safety under any } \\
\text { other written law insofar as they apply to the premises. } \\
\text { Source: } \\
\text { https://www.legislation.wa.gov.au/legislation/prod/filestore.nsf/FileURL/mrdoc 43961.pdf/\$FIL } \\
\text { E/Residential\%20Tenancies\%20Act\%201987\%20-\%20\%5B06-m0-00\%5D.pdf?OpenElement }\end{array}$ \\
\hline NT & $\begin{array}{l}\text { Residential Tenancies Act } 1999 \\
\text { Part } 7 \\
\text { Dvision } 1 \\
48 \text { Premises to be clean and suitable for habitation } \\
\text { (1) It is a term of a tenancy agreement that the landlord must ensure that the premises and } \\
\text { ancillary property to which the agreement relates: } \\
\text { (a) are habitable; }\end{array}$ \\
\hline
\end{tabular}




\begin{tabular}{|l|l|}
\hline & (b) meet all health and safety requirements specified under an Act that apply to residential \\
premises or the ancillary property; and \\
(c) are reasonably clean when the tenant enters into occupation of the premises. \\
(2) It is not a breach of the term specified in subsection (1) if the failure to comply with the \\
term is caused by: \\
(a) an act or omission of the tenant; or \\
(b) the tenant's failure to notify the landlord of repairs required to the premises. \\
Source: https://legislation.nt.gov.au/en/Legislation/RESIDENTIAL-TENANCIES-ACT-1999 \\
\hline New & $\begin{array}{l}\text { Heating } \\
\text { Tealand }\end{array}$ \\
& $\begin{array}{l}\text { There must be fixed heating devices, capable of achieving a minimum temperature of at least } \\
\text { and will not meet the requirements under the heating standard. } \\
\text { Insulation } \\
\text { The minimum level of ceiling and underfloor insulation must either meet the 2008 Building } \\
\text { Code, or (for existing ceiling insulation) have a minimum thickness of 120 mm. } \\
\text { Ventilation } \\
\text { Ventilation must include openable windows in the living room, dining room, kitchen and } \\
\text { bedrooms. Also an appropriately sized extractor fan(s) in rooms with a bath or shower or } \\
\text { indoor cooktop. } \\
\text { Moisture ingress and drainage } \\
\text { Landlords must ensure efficient drainage and guttering, downpipes and drains. If a rental } \\
\text { property has an enclosed subfloor, it must have a ground moisture barrier if it's possible to } \\
\text { install one. } \\
\text { Draught stopping } \\
\text { Landlords must stop any unnecessary gaps or holes in walls, ceilings, windows, floors and } \\
\text { doors that cause noticeable draughts. All unused chimneys and fireplaces must be blocked. } \\
\text { Source: https://www.tenancy.govt.nz/healthy-homes/about-the-healthy-homes-standards/ }\end{array}$ \\
\hline
\end{tabular}




\section{AHURi}

Australian Housing and Urban Research Institute Level 12, 460 Bourke Street

Melbourne VIC 3000

\section{Australia}

+61396602300

information@ahuri.edu.au

ahuri.edu.au

(2) twitter.com/AHURI_Research

f facebook.com/AHURI.AUS

in Australian Housing and Urban Research Institute 